Florida International University FIU Digital Commons

\title{
Sonochemical Synthesis of Zinc Oxide Nanostructures for Sensing and Energy Harvesting
}

Phani Kiran Vabbina

Department of Electrical and Computer Engineering, Florida International University, pvabb001@fiu.edu

DOI: $10.25148 /$ etd.FIDC000787

Follow this and additional works at: https://digitalcommons.fiu.edu/etd

Part of the Biomedical Commons, Electrical and Electronics Commons, Electromagnetics and Photonics Commons, Electronic Devices and Semiconductor Manufacturing Commons, and the Nanotechnology Fabrication Commons

\section{Recommended Citation}

Vabbina, Phani Kiran, "Sonochemical Synthesis of Zinc Oxide Nanostructures for Sensing and Energy Harvesting" (2016). FIU Electronic Theses and Dissertations. 2534.

https://digitalcommons.fiu.edu/etd/2534 


\title{
FLORIDA INTERNATIONAL UNIVERSITY
}

\author{
Miami, Florida
}

\section{SONOCHEMICAL SYNTHESIS OF ZINC OXIDE NANOSTRUCTURES FOR SENSING AND ENERGY HARVESTING}

A dissertation submitted in partial fulfillment of

the requirements for the degree of

DOCTOR OF PHILOSOPHY

in

\section{ELECTRICAL ENGINEERING}

by

Phani Kiran Vabbina 


\section{To: Interim Dean Ranu Jung}

\section{College of Engineering and Computing}

This dissertation, written by Phani Kiran Vabbina, and entitled Sonochemical Synthesis of Zinc Oxide Nanostructures for Sensing and Energy Harvesting, having been approved in respect to style and intellectual content, is referred to you for judgment.

We have read this dissertation and recommend that it be approved.

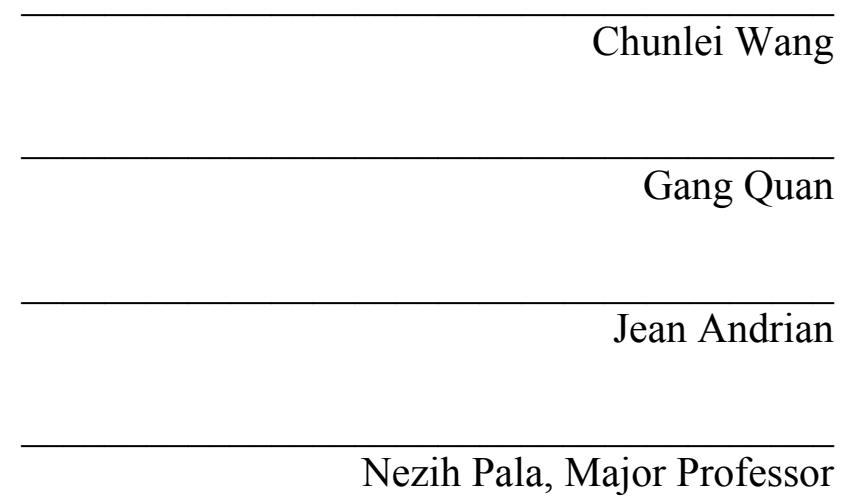

Date of Defense: July 6, 2016

The dissertation of Phani Kiran Vabbina is approved.

Interim Dean Ranu Jung College of Engineering and Computing

Andrés G. Gil Vice President for Research and Economic Development and Dean of the University Graduate School

Florida International University, 2016 
C Copyright 2016 by Phani Kiran Vabbina

All rights reserved. 


\section{ACKNOWLEDGMENTS}

First and foremost, I would like to express gratitude to my advisor and mentor, Dr. Nezih Pala, for giving me the opportunity to work on an exciting project for my doctoral dissertation. I am also thankful for his encouragement and support in developing my research skills and personality through the many opportunities provided during my time at Florida International University.

I would like to thank the members of my dissertation committee Dr. Jean Andrian, Dr. Gang Quan, and Dr. Chunlei Wang, for agreeing to be my dissertation committee, and for their valuable inputs towards my dissertation research. I would also like to thank Dr. Ajeet Kaushik for his support and constant thought provoking discussions.

I thank the Department of Electrical and Computer Engineering, for the logistical support. I would like to thank the Graduate \& Professional Student Committee (GPSC) for the support received through conference travel grants to present my research at many national and international conferences.

I take this opportunity to also thank all the members of the INSYST Lab and other graduate students that worked along with me at Electrical and Computer Engineering and Advanced Materials Engineering Research Lab. Many thanks to my dearest friends who have supported me and stood by me through the hardest times of this journey, Raju Sinha, Kishore Dhavala, and Vivek Chaturvedi. Special thanks to Yesenia Escobar for tremendous patience and encouragement.

I would like to acknowledge the funding sources that made this work possible:

Graduate teaching assistantship from the Department of Electrical and Computer Engineering at Florida International University. 
Finally, I could not have come this far without the unconditional love, support, patience and blessings from my family. Many thanks to my father, Rama Rao Vabbina, mother, Ramana Kumari Vabbina and sister, Sireesha Kandiraju for their support and unconditional love. 


\title{
ABSTRACT OF THE DISSERTATION \\ SONOCHEMICAL SYNTHESIS OF ZINC OXIDE NANOSTRUCTURES FOR SENSING AND ENERGY HARVESTING
}

\author{
by \\ Phani Kiran Vabbina \\ Florida International University, 2016 \\ Miami, Florida \\ Professor Nezih Pala, Major Professor
}

Semiconductor nanostructures have attracted considerable research interest due to their unique physical and chemical properties at nanoscale which open new frontiers for applications in electronics and sensing. Zinc oxide nanostructures with a wide range of applications, especially in optoelectronic devices and bio sensing, have been the focus of research over the past few decades. However $\mathrm{ZnO}$ nanostructures have failed to penetrate the market as they were expected to, a few years ago. The two main reasons widely recognized as bottleneck for $\mathrm{ZnO}$ nanostructures are (1) Synthesis technique which is fast, economical, and environmentally benign which would allow the growth on arbitrary substrates and (2) Difficulty in producing stable p-type doping. The main objective of this research work is to address these two bottlenecks and find a solution that is inexpensive, environmentally benign and CMOS compatible. To achieve this, we developed a Sonochemical method to synthesize 1D ZnO Nanorods, core-shell nanorods, 2D nanowalls and nanoflakes on arbitrary substrates which is a rapid, inexpensive, CMOS compatible and environmentally benign method and allows us to grow $\mathrm{ZnO}$ nanostructures on any 
arbitrary substrate at ambient conditions while most other popular methods used are either very slow or involve extreme conditions such as high temperatures and low pressure.

A stable, reproducible p-type doping in $\mathrm{ZnO}$ is one of the most sought out application in the field of optoelectronics. Here in this project, we doped $\mathrm{ZnO}$ nanostructures using sonochemical method to achieve a stable and reproducible doping in $\mathrm{ZnO}$. We have fabricated a homogeneous $\mathrm{ZnO}$ radial $\mathrm{p}$-n junction by growing a $\mathrm{p}$-type shell around an n-type core in a controlled way using the sonochemical synthesis method to realize $\mathrm{ZnO}$ homogeneous core-shell radial p-n junction for $\mathrm{UV}$ detection.

$\mathrm{ZnO}$ has a wide range of applications from sensing to energy harvesting. In this work, we demonstrate the successful fabrication of an electrochemical immunosensor using $\mathrm{ZnO}$ nanoflakes to detect Cortisol and compare their performance with that of $\mathrm{ZnO}$ nanorods. We have explored the use of $\mathrm{ZnO}$ nanorods in energy harvesting in the form of Dye Sensitized Solar Cells (DSSC) and Perovskite Solar Cells. 


\section{TABLE OF CONTENTS}

CHAPTER

PAGE

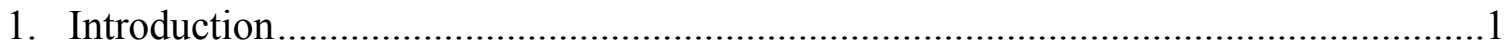

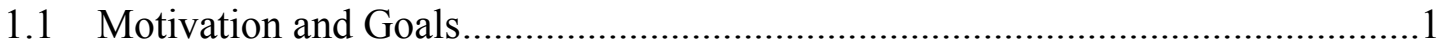

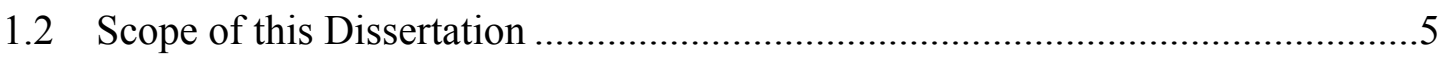

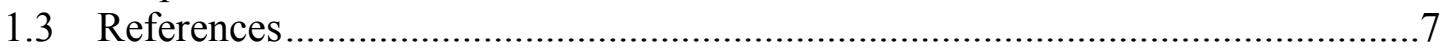

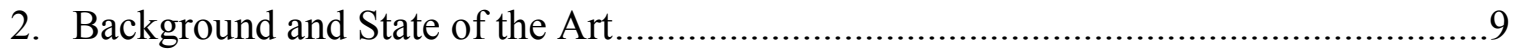

2.1 Properties of Zinc Oxide ........................................................................

2.1.1 Crystal Structure, Lattice Parameters \& Mechanical Properties ...................10

2.1.2 Electrical and Optical Properties ............................................................. 11

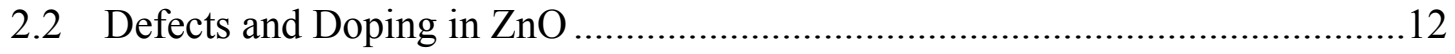

2.3 ZnO Nanostructures and Synthesis Techniques .............................................13

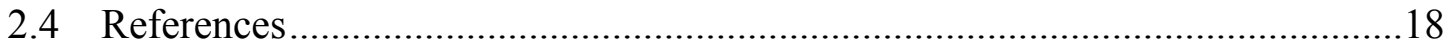

3. Sonochemical Synthesis of Zinc Oxide Nanostructures .......................................21

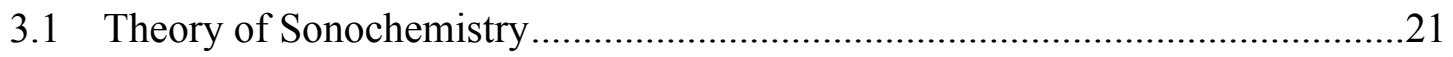

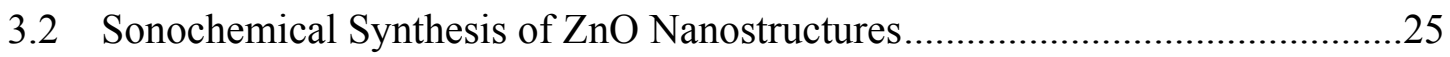

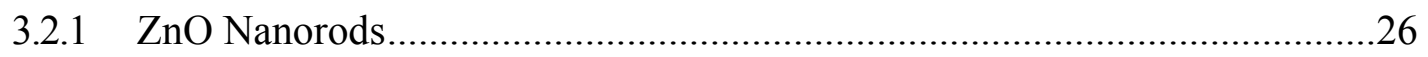

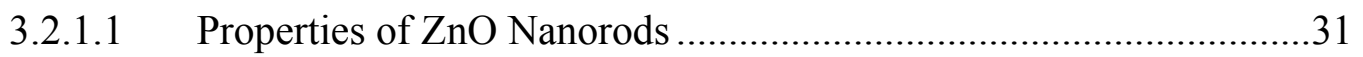

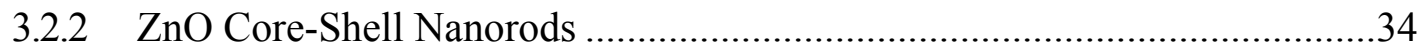

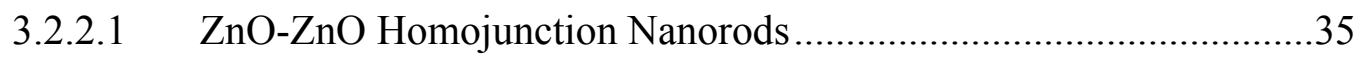

3.2.2.2 ZnO- ZnS Heterojunction Nanorods.............................................37

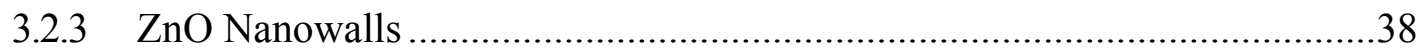

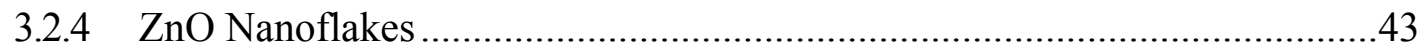

3.2.4.1 Properties of $\mathrm{ZnO}$ Nanoflakes .................................................4 47

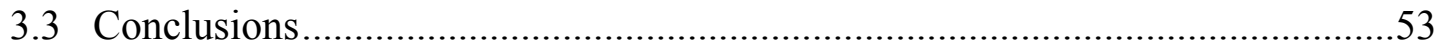

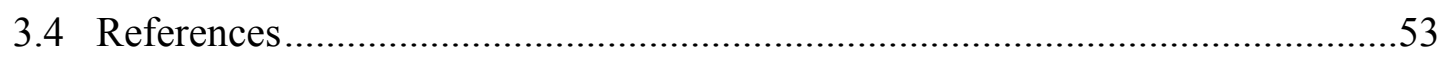

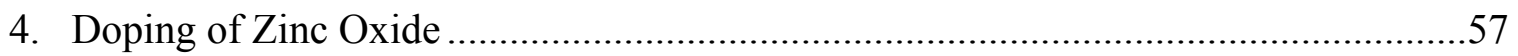

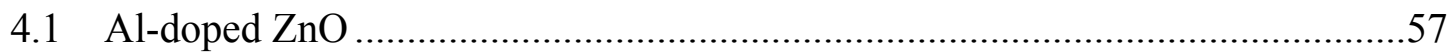

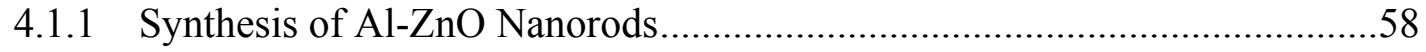

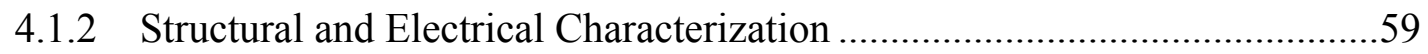

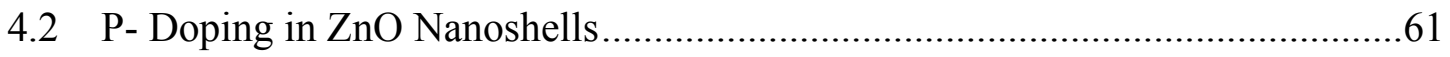

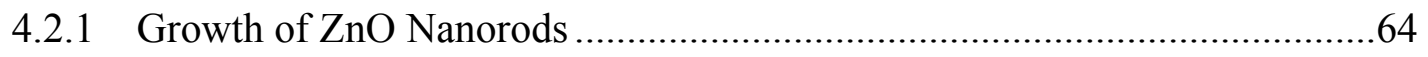

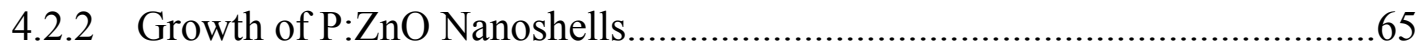

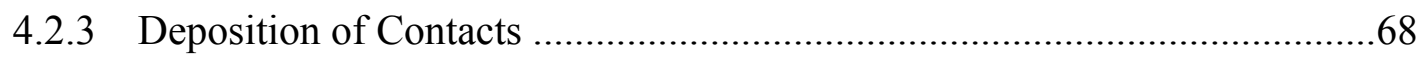

4.2.4 Structural and Electrical Characterization ...............................................68 
4.3 Conclusions

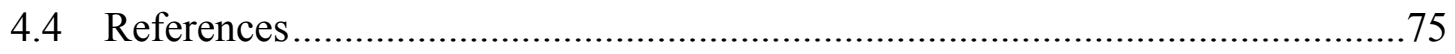

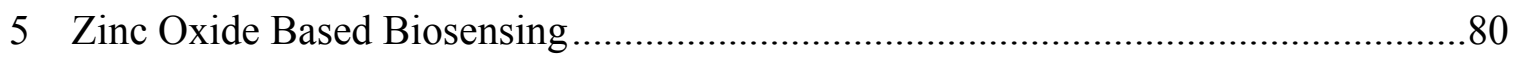

5.1 Electrochemical Cortisol Immunosensor Based on Sonochemically Synthesized 1D ZnO Nanorods and 2D ZnO Nanoflakes ...................................80

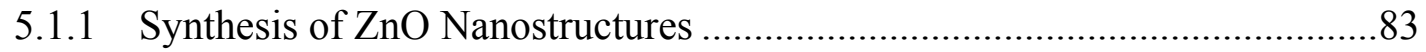

5.1.2 Fabrication of ZnO-NSs Based Immunosensors............................................8

5.1.3 Structural and Morphological Characterization..............................................

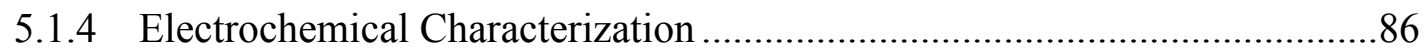

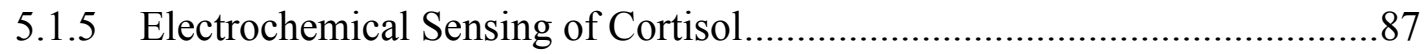

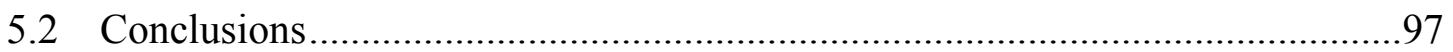

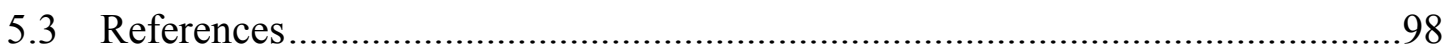

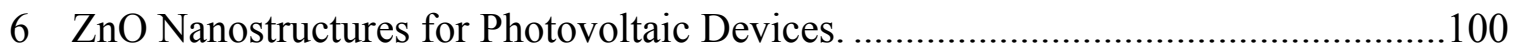

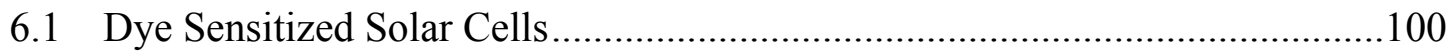

6.1.1 Fabrication of Dye Sensitized Solar Cells ................................................104

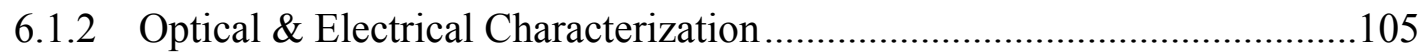

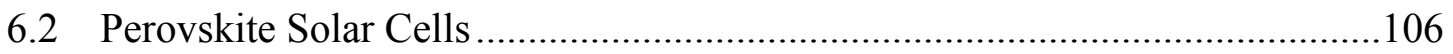

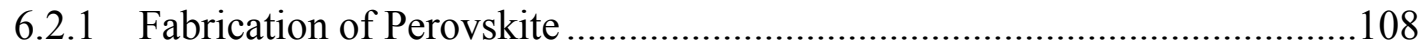

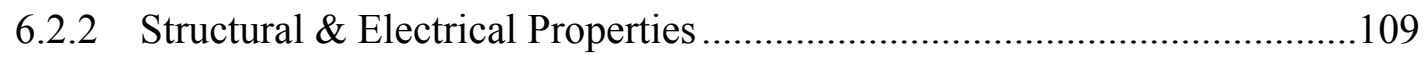

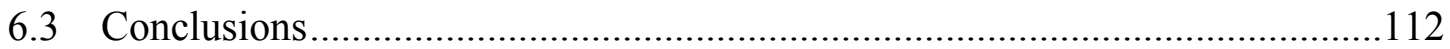

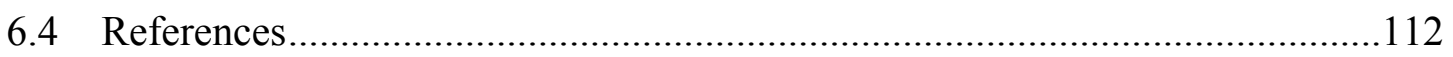

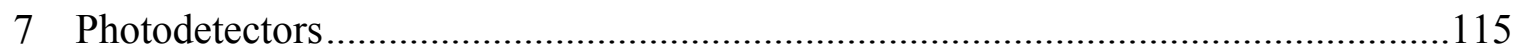

7.1 P:ZnO-ZnO Core-Shell Photodetectors ...........................................................115

7.2 Highly Sensitive Wide Bandwidth Photodetector Based on Internal Photoemission in CVD Grown P-Type $\mathrm{MoS}_{2} /$ Graphene

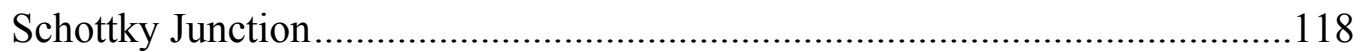

7.2.1 Fabrication of $\mathrm{MoS}_{2} /$ Graphene Photodetector ...........................................120

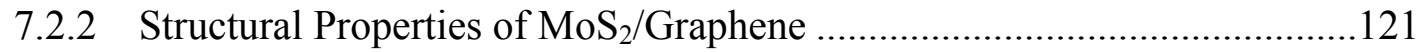

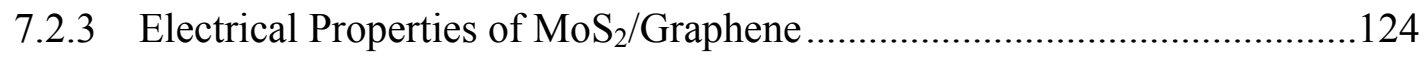

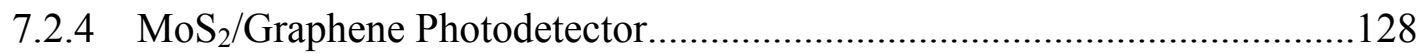

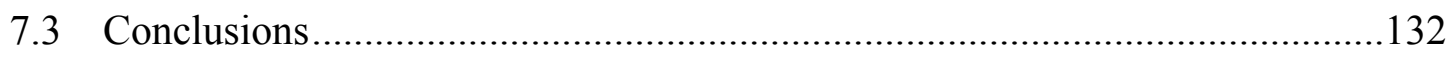

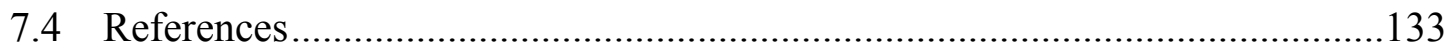

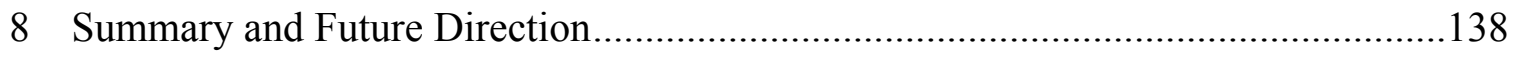

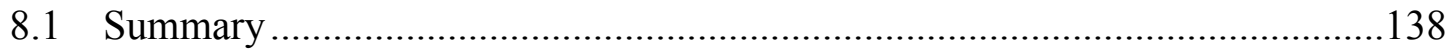

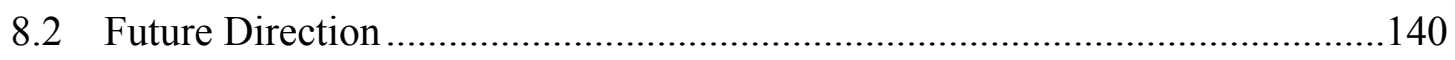


8.2.1 Flexible and Transparent P:ZnO Nanoshell/n-ZnO Nanorod

Core- Shell LED ................................................................................141

8.2.2 Flexible Perovskite Solar Cells..............................................................142

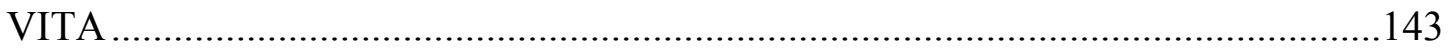




\section{LIST OF TABLES}

TABLE

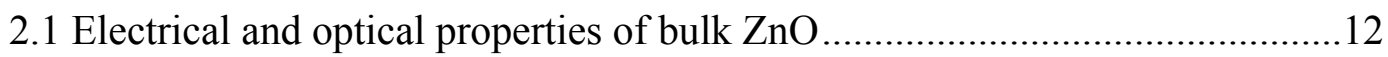

5.1 Summary of the impedimetric parameters obtained in stepwise fabrication of immunosensor.

5.2 Comparison of saliva cortisol estimated using ELISA and ZnO-NSs based cortisol immunosensor ................................................................. 97

6.1 Summary of DSSCs base don ZnO nanostructures .................................103

7.1 Performance comparison of the fabricated UV photo detector with the recently reported ones. 


\section{LIST OF FIGURES}

FIGURE

2.1 (a) Hexagonal wurtzite structure of $\mathrm{ZnO}$ crystal (b) Lattice structure with planes in wurtzite structure ................................................................ 10

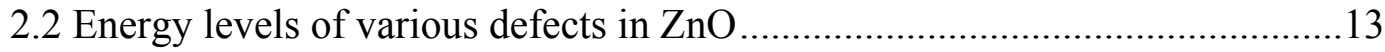

2.3 (a) Growth process in VLS method (b) In house 3 zone CVD furnace (c) $\mathrm{ZnO}$ nanorods grown via CVD method on Si substrate. ............................16

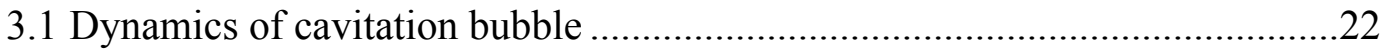

3.2 Sonochemical set-up from Sonics and Systems .....................................26

3.3 Cross-sectional view of $\mathrm{ZnO}$ seed layer on Si substrate...............................27

3.4 The role of HMT in directional growth of $\mathrm{ZnO}$ nanostructures .....................29

3.5 Shows the SEM images of Sonochemically grown $\mathrm{ZnO}$ nanorods on (a) Silicon (b) SiO2/ Si (c) Ni/Fe alloy (d) Teflon (f) Copper (g) Iron (h) ITO (i) Sapphire (j) Kaplan tape (k) cotton fiber (L) PET .

3.6 $\mathrm{ZnO}$ nanorods after 15 minutes of growth (b) $\mathrm{ZnO}$ nanorods after 30 minutes of growth 30

3.7 Change of dimensions with growth cycles in $\mathrm{ZnO}$ nanorods

3.8 $\mathrm{ZnO}$ nanorods on ITO (b) $\mathrm{PL}$ of $\mathrm{ZnO}$ nanorods showing a significant peak at $380 \mathrm{~nm}$.

3.9 (a) SAED pattern of $\mathrm{ZnO}$ nanorod (b) HRTEM image of $\mathrm{ZnO}$ nanorod, both confirming the single crystal nature of the nanorod.....

3.10 (a) XRD on $\mathrm{ZnO}$ nanorods showing a relatively high intensity (002) peak

(b) Raman spectra of $\mathrm{ZnO}$ nanorods with $\mathrm{E}_{2}$ peak at $436 \mathrm{~cm}^{-1}$

3.11 (a) Optical transmittance of $\mathrm{ZnO}$ nanorods, with the dip at $368 \mathrm{~nm}$, corresponding to the bandgap of $\mathrm{ZnO}$ nanorods (b) Current- Voltage measurements in dark and under UV light, $\mathrm{ZnO}$ nanorods show a 3 order magnitude gain in presence of UV light.

3.12 (a) $\mathrm{ZnO}$ nanorods grown by sonochemical method with an average diameter of $55 \mathrm{~nm}$ (b) $\mathrm{ZnO}-\mathrm{ZnO}$ core- shell nanorods grown by varying the ratio of 
ZNH and HMT with an average $60 \mathrm{~nm}$ shell thickness (c) Shell structure grown around $\mathrm{ZnO}$ rod by assistance of sodium citrate as surfactant

3.13 (a) $\mathrm{ZnO}$ nanorods grown by sonochemical method with an average diameter of $55 \mathrm{~nm}$ (b) $\mathrm{ZnO}-\mathrm{ZnO}$ core- shell nanorods grown by varying the ratio of ZNH and HMT (c) TEM image of ZnO- ZnO core shell nanorod, clearly showing a shell encapsulating $60 \mathrm{~nm}$ thick nanorod

3.14 (a) $\mathrm{ZnO}-\mathrm{ZnS}$ core- shell nanorods, shell grown for 10 minutes resulting in a thin shell (b) With longer process time the shell thickness increases depleting the $\mathrm{ZnO}$ core (c) $\mathrm{XRD}$ data on a $\mathrm{ZnO}-\mathrm{ZnS}$ nanorods, a clear peak at $28^{0}$ indicating the successful formation of $\mathrm{ZnS}$...........................................38

3.15 SEM image of ZnO Nanowalls grown over $6 \mathrm{~nm}$ thick Aluminum coated $\mathrm{Si}$ substrate

3.16 Growth kinetics of formation of $\mathrm{ZnO}$ Nanowalls at (a) 3 minutes (b) 6 minutes (c) 9 minutes (d) 12 minutes (e ) 15 minutes and (f) 60 minutes

3.17 (a) The PL peak at $378 \mathrm{~nm}$ are a good indication of $\mathrm{ZnO}$ material. The visible peak is indicative of the defect levels commonly observed in $\mathrm{ZnO}$. (b) Raman peak intensity for 3 minute intervals and at 60 minutes. We observe a faint peak at $419 \mathrm{~cm}^{-1}$ at 15 minutes and a more distinct peak at $660 \mathrm{~cm}^{-1}$ is observed for $\mathrm{ZnAl}_{2} \mathrm{O}_{4}$. The $520 \mathrm{~cm}^{-1}$ peak is attributed to $\mathrm{Si}$, the $937 \mathrm{~cm}^{-1}$ is distinctive of $\mathrm{Zn}_{2} \mathrm{SiO}_{4}$. The incrementally increasing peak at $1053 \mathrm{~cm}^{-1}$ is attributed to dioxygen. The $438 \mathrm{~cm}^{-1}$ peak is attributed to $\mathrm{ZnO} \ldots . .40$

3.18 (a) SEM picture of the FIB prepared lamella of the $\mathrm{ZnO}$ Nanowalls on $\mathrm{Al}$ coated Si substrate (b) TEM image of Nanowalls (c) SAED pattern of ZnO NWs confirming the single crystalline nature of $\mathrm{ZnO} N W s$

3.19 Current voltage characteristics of $\mathrm{ZnO}$ nanowalls measured at dark and under UV illumination.

3.20 (a) $\mathrm{ZnO}$ nanoflakes grown over $\mathrm{Si}$ for 30 seconds (b) $\mathrm{ZnO}$ nanoflakes grown over Si for 60 seconds (c) $\mathrm{ZnO}$ nanoflakes grown over Si for 3 minutes (d) $\mathrm{ZnO}$ nanoflakes grown over Si for 15 minutes (e ) $\mathrm{ZnO}$ nanoflakes grown over Si for 30 minutes

3.21 (a) SAED pattern showing a single crystalline wurtzite structure oriented in $<0001>$ direction and lateral growth direction perpendicular to (0110) (b) HRTEM at the edge of a flake with fringes almost parallel to the edge with a spacing of $2.74{ }^{0} \mathrm{~A}$, which is close to $2.82 \AA$ of (1010) plane. 
3.22 Schematic of the growth mechanism of $\mathrm{ZnO}$ nanoflakes showing the growth from hexagonal structure to parallelogram structure and further increase in thickness as new layers are formed

3.23 Evolution of length and thickness of the flakes by time showing that the lateral dimensions of the flakes increases rapidly to around $10 \mu \mathrm{m}$ at around $15 \mathrm{~min}$ and then stabilizes. The thickness of the single flakes remains constant around $20 \mathrm{~nm}$

3.24 (a) Raman spectrum of $\mathrm{ZnO}$ on $\mathrm{Si}$, a strong second order longitudinal phonon vibration peak characteristic of confinement in ' $c$ ' direction is observed at $1050 \mathrm{~cm}^{-1}$ (b) PL spectrum of the $\mathrm{ZnO}$ nanoflakes on graphene shows a peak at $376 \mathrm{~nm}$, which is in agreement with the bandgap of $\mathrm{ZnO}$. The peak intensity is not strong since the flakes are extremely thin

3.25 (a) Current-voltage $(I-V)$ for samples of growth time 3, 5, 15 min show that the conductance of the flakes increases with the time of synthesis as the thickness increases and new layers are added with time (b) $I-V$ for continuous fi $\mathrm{lm}$ of $\mathrm{ZnO}$ nanoflakes with growth time $15 \mathrm{~min}$ and three cycles show a 10 -fold increase in conductivity in the presence of UV light...50

3.26 (a) $\mathrm{ZnO}$ nanoflakes on $\mathrm{SiO}_{2}$ Substrate (b) graphene showing aggressive growth on graphene making the growth process highly selective

3.27 (a) $\mathrm{ZnO}$ nanoflakes/ graphene on a TEM grid (b) TEM image of Individual flakes on graphene (c) SAED image of $\mathrm{ZnO} \mathrm{NF} /$ graphene showing single crystal nature of $\mathrm{ZnO} \mathrm{NF}$ (d) HRTEM image at the ZnO $\mathrm{NF}$ and graphene interface, $\mathrm{ZnO}$ nanoflake shows a single crystalline nature but at the interface where amorphous like behavior is observed.

3.28 (a) Electrical conductivity comparison in the presence of graphene and without graphene shows that the conductivity increases for the hybrid structure $\mathrm{ZnO}$-graphene by more than 10 times when compared with just $\mathrm{ZnO}$ (b) Comparison of transmission for graphene and $\mathrm{ZnO}$-graphene hybrid structure

4.1 (a) SEM picture of undoped $\mathrm{ZnO}$ (S10) (b) $\mathrm{ZnO}$ nanorods doped with 0.5 mM AlN (S11) (c) ZnO nanorods doped with $1 \mathrm{mM}$ AlN (S12) (d) EDS showing $0.42 \%$ weight percent of Al in S11 (e ) EDS showing 1.23\% weight percent of $\mathrm{Al}$ in $\mathrm{S} 12$

4.2 XRD analysis of S10, S11 and S12 samples showing a double gahnite peak and a peak shift in Al doped samples (b) Transmission spectra of undoped and $\mathrm{Al}$ doped $\mathrm{ZnO}$ (c) Current- voltage characteristics of S10, S11 and S12 after 
annealing at $300 \mathrm{C}$ (d) Current- voltage characteristics of S10, S11 and S12 after annealing at $500{ }^{\circ} \mathrm{C}$ after dopants are activated

4.3 Synthesis of p-doped $\mathrm{ZnO}$ nanoshells around $\mathrm{ZnO}$ nanorods: (a) Vertically oriented $\mathrm{ZnO}$ nanorods grown on $\mathrm{n}-\mathrm{Si}$; (b) A thin layer of PMMA spin coated to cover the $\mathrm{ZnO}$ nanorods; (c) Partially etched $\mathrm{ZnO}$ nanorods; (d) Growth of $\mathrm{p}-\mathrm{ZnO}$ around partially exposed $\mathrm{ZnO}$ nanorods.

4.4 Structural characterization of $\mathrm{ZnO}$ core-shell by SEM: (a) $\mathrm{ZnO}$ nanorods with mean diameter of $50 \mathrm{~nm}$; (b) $\mathrm{ZnO}$ core-shell structure with mean diameter $100 \mathrm{~nm}$; (c) Cross-sectional view of P:ZnO nanoshell/n- ZnO NR filled with PMMA; (d) partially etched PMMA and exposed tips of P:ZnO nanoshell for contact deposition.

4.5 Growth orientation determination and chemical composition analysis by TEM, SAED, EDS, XRD and Raman: (a) TEM image of $\mathrm{ZnO}$ core-shell nanorod scratched from the substrate, shows a clear interface between nanoshell and core; (b) SAED pattern showing the nanorods are oriented along (002) plane; (c) EDS showing the presence of $\mathrm{ZnO}$ and P; (d) XRD of $\mathrm{ZnO}$ nanorods showing the growth dominated along (002) plane; (e) Raman spectrum of undoped and $\mathrm{p}$-doped $\mathrm{ZnO}$ on ITO substrate where $\mathrm{E}_{2}{ }^{\text {high }}$ peak is shifted by $1.8 \mathrm{~cm}^{-1}$ towards the lower frequency.

4.6 Verification of $p-n$ junction by I-V measurements: (a) Schematic of $\mathrm{P}: \mathrm{ZnO}$ nanoshell/ $\mathrm{n}-\mathrm{ZnO}$ NR p-n junction; (b) I-V curve for $1 \mathrm{mM}$ ADP doped $\mathrm{ZnO}$ nanoshell; (c) I-V curve for $1.2 \mathrm{mM}$ ADP doped $\mathrm{ZnO}$ nanoshell; (d) I-V curve for $1.4 \mathrm{mM}$ ADP doped $\mathrm{ZnO}$ nanoshell; ( e) I-V curve for 1.6 $\mathrm{mM}$ ADP doped $\mathrm{ZnO}$ nanoshell at room temperature; (f) I-V curve for 1.6 $\mathrm{mM}$ ADP doped $\mathrm{ZnO}$ nanoshell at $300^{\circ} \mathrm{C}$; (g) I-V curve for $1.6 \mathrm{mM}$ ADP doped $\mathrm{ZnO}$ nanoshell at $400{ }^{\circ} \mathrm{C}$; (h) I-V curve for $1.6 \mathrm{mM}$ ADP doped $\mathrm{ZnO}$ nanoshell at $500{ }^{\circ} \mathrm{C}$.

4.7 Study of doping concentration by C-V measurements: (a) Capacitance vs Voltage measurements at frequencies between $5 \mathrm{k} \mathrm{Hz}$ to $10 \mathrm{k} \mathrm{Hz}$; (b) 1/ $(\mathrm{C} / \mathrm{A})^{2}$ vs Reverse Voltage at $10 \mathrm{~K} \mathrm{~Hz}$ frequency.

5.1 Figure 1 (a) $\mathrm{ZnO}$ nanorods on $\mathrm{Au} / \mathrm{Si}$ substrate (b) $\mathrm{ZnO}$ nanoflakes grown in $\mathrm{Au} / \mathrm{Si}$ substrate.

5.2 (a) Illustration of $\mathrm{ZnO}-\mathrm{NRs}$ and $\mathrm{ZnO}-\mathrm{NFs}$, prepared using sonochemical method along with immobilization of monoclonal anti-cortisol antibody onto $\mathrm{ZnO}-\mathrm{NSs}$ to fabricate electrochemical cortisol immunosensor. (b) Electrochemical response at the fabricated electrodes. 
5.3 (a) FSEM image of Anti-Cab/ZnO-NRs/Au immunoelectrode, (b) FSEM image of Anti-C/ZnO-NFs/Au immunoelectrode showing change in morphology after antibody introduced, (c) AFM image of Anti- $\mathrm{C}_{\mathrm{ab}} / \mathrm{ZnO}$ $\mathrm{NRs} / \mathrm{Au}$ with a measured roughness of $124 \mathrm{~nm}$, (d) AFM image of Anti- $\mathrm{C}_{\mathrm{ab}}$ /ZnO-NFs/Au immunoelectrode with a measured roughness of $158 \mathrm{~nm}$, (e) Raman shift of Anti-C $\mathrm{C}_{\mathrm{ab}} / \mathrm{ZnO}-\mathrm{NRs} / \mathrm{Au}$ immunoelectrode and (f) Raman shift for Anti-C $\mathrm{ab} / \mathrm{ZnO}-\mathrm{NFs} / \mathrm{Au}$ immunoelectrode.

5.4 Stepwise characterization related to the fabrication of $\mathrm{ZnO}-\mathrm{NSs}$ based electrochemical immunosensor using electrochemical impedance spectroscopy and cyclic voltammetry (A and B). (a) An increase in $R_{c t}$ from bare $\mathrm{Au}$ electrode to BSA/Anti- $\mathrm{C}_{\mathrm{ab}} / \mathrm{ZnO}-\mathrm{NRs} / \mathrm{Au}$. (b) Rise of $\mathrm{R}_{\mathrm{ct}}$ from bare $\mathrm{Au}$ electrode to $\mathrm{BSA} / \mathrm{Anti}-\mathrm{C}_{\mathrm{ab}} / \mathrm{ZnO}-\mathrm{NFs} / \mathrm{Au}$ immunoelectrode. (c) Fall in the magnitude of oxidation response current from $\mathrm{Au}$ electrode to BSA/Anti-C $\mathrm{ab}_{\mathrm{a}} / \mathrm{ZnO}-\mathrm{NRs} / \mathrm{Au}$ immunoelectrode. (d) Fall in the magnitude of oxidation response current from Au electrode to BSA/Anti- $\mathrm{C}_{\mathrm{ab}} / \mathrm{ZnO}-$ $\mathrm{NFs} / \mathrm{Au}$ immunoelectrode. (e) An increment in the magnitude of oxidation response current of Anti- $\mathrm{C}_{\mathrm{ab}} / \mathrm{ZnO}-\mathrm{NRs} / \mathrm{Au}$ immunoelectrode with increase in scan rate from $10 \mathrm{mV} / \mathrm{s}$ to $100 \mathrm{mV} / \mathrm{s}$. (f) An increment in the magnitude of oxidation response current of Anti- $\mathrm{C}_{\mathrm{ab}} / \mathrm{ZnO}-\mathrm{NFs} / \mathrm{Au}$ with increase in scan rate from $10 \mathrm{mV} / \mathrm{s}$ to $100 \mathrm{mV} / \mathrm{s}$.

5.5 (a) CV studies of immunosensors as function of cortisol concentration varying from $100 \mathrm{pM}$ to $100 \mathrm{nM}$ for $\mathrm{BSA} / \mathrm{Anti}-\mathrm{C}_{\mathrm{ab}} / \mathrm{ZnO}-\mathrm{NFs} / \mathrm{Au}$ electrode, inset: a calibration plotted between the obtained change in response current with respect to cortisol concentration (b) CV curves with cortisol concentration varying from $100 \mathrm{pM}$ to $100 \mathrm{nM}$ for BSA/Anti$\mathrm{C}_{\mathrm{ab}} / \mathrm{ZnO}-\mathrm{NRs} / \mathrm{Au}$ immunoelectrode, inset: a calibration plotted between the obtained change in response current with respect to cortisol concentration (c) Change in EIS of BSA/Anti- $\mathrm{C}_{\mathrm{ab}} / \mathrm{ZnO}-\mathrm{NFs} / \mathrm{Au}$ immunoelectrode with respect to cortisol concentrations (d) Change in EIS of BSA/Anti- $\mathrm{C}_{\mathrm{ab}} / \mathrm{ZnO}$ $\mathrm{NRs} / \mathrm{Au}$ immunoelectrode with respect to cortisol concentrations.

6.1 The rise of solar cell technologies over past 40 years 100

6.2 (a) ZnO nanorod based DSSC (b) Working mechanism of DSSC 102

6.3 (a) $\mathrm{ZnO}$ nanorods grown over FTO (b) Photovoltaic behavior 104

6.4 (a) Sol 2A Solar simulator set up from ORIEL (b) Solar cell spectral response measurement system from PV measurements system 105

6.5 Mbarun's glove box for perovskite fabrication 
6.6 (a) Schematic of fabricated Perovskite solar cell (b) Top view of $\mathrm{ZnO}$ nanorods on FTO (c) Cross-sectional view of ZnO nanorods on FTO (d) Perovskite filling on $\mathrm{ZnO}$ nanorods/FTO (e) Cross-sectional view of perovskite/ZnO nanorods/FTO (f) Perovskite filling on $\mathrm{ZnO}$ nanorods/FTO at low spin speed

6.7 (a) XRD showing the change in peaks as $\mathrm{PbI}_{2}$ is changed to perovskite after introduction of $\mathrm{CH}_{3} \mathrm{NH}_{3} \mathrm{I}$ and heating. (b) Perovskite formed in cubic lattice at $\quad 3000 \mathrm{rpm}$ spin speed (c) perovskite formation in cubic lattice at $1000 \mathrm{rpm}$ spin speed and showing less peaks of $\mathrm{ZnO}$ due to higher coverage.

6.8 (a) $\mathrm{ZnO}$ nanorods grown over $\mathrm{ZnO}$ nanoflakes/graphene/PET as electron transport layer (b) Partially grown $\mathrm{ZnO}$ nanorods on $\mathrm{ZnO}$ nanoflakes/PET showing both $\mathrm{ZnO}$ nanorods and graphene (c) $\mathrm{ZnO}$ Nanowalls grown over $\mathrm{Al} / \mathrm{PET}$ as scaffolding layer planar perovskite solar cell.

7.1 Characterization of the fabricated UV radial p-n junction photo detector: (a) Schematic of $\mathrm{p}-\mathrm{ZnO} / \mathrm{n}-\mathrm{ZnO}$ core-shell homojunction; (b)

Photoresponse in presence of UV light.

7.2 (a) Schematic of p-type $\mathrm{MoS}_{2} /$ graphene junction device (b) Optical image of $\mathrm{MoS}_{2} /$ graphene junction with individual areas clearly visible (c) AFM height profile showing height of $\mathrm{MoS}_{2}$ (d) AFM image of $\mathrm{MoS}_{2}-\mathrm{SiO}_{2}$ interface (e) Thickness of graphene at $\mathrm{MoS}_{2} /$ graphene junction (f) AFM image of $\mathrm{MoS}_{2} /$ graphene junction

7.3 (a) Raman spectrum of $\mathrm{MoS}_{2}$ and Graphene on $\mathrm{SiO}_{2}$ and junction (b) Photoluminescence of $\mathrm{MoS}_{2}$ on $\mathrm{SiO}_{2}$ showing sharp peaks at 1.7, 1.75 and $1.85 \mathrm{eV}$ and smaller ones at 1.4 and $1.55 \mathrm{eV}$

7.4 (a) Energy level alignment for $\mathrm{MoS}_{2} /$ graphene structure, band diagram at junction in equilibrium, forward bias and reverse bias with carrier flow ....125

7.5 (a) J-V curve showing rectification under reverse bias and exponentially increasing current in forward bias (inset: Absolute value of $\mathrm{J}-\mathrm{V}$ plotted in logarithmic scale) (b) Reverse current from experimental and analytical model (c) J-V at different temperatures showing an increase in $\mathrm{J}$ with increase in temperature (d) $1 / \mathrm{C}^{2}$ plotted against voltage 126

7.6 (a) MGPD under illumination (b) Illustration of photocurrent generation in a Schottky diode under illumination (c) J-V at dark and under 100 $\mathrm{mW} / \mathrm{cm}^{2}$ illumination (d) Photo responsivity of MGPD at different wavelengths (Spectral Response) (e) Photoconductivity of graphene. 
8.1 P:ZnO nanoshell/n- $\mathrm{ZnO}$ nanorod core- shell structure grown on $\mathrm{Au} /$ graphene.

8.2 Perovskite solar cells based on $\mathrm{ZnO}-\mathrm{ZnS}$ core-shell nanorods synthesized on $\mathrm{ZnO}$ nanoflakes/graphene/ PET as electron transport layer 142 


\section{LIST OF ACRONYMS \& ABBREVATIONS}

\begin{tabular}{|c|c|}
\hline MEMS & Microelectromechanical Systems \\
\hline IEP & Isoelectric point \\
\hline LED & Light emitting diode \\
\hline CVD & Chemical Vapor deposition \\
\hline $1 \mathrm{D}$ & one dimensional \\
\hline $2 \mathrm{D}$ & Two dimensional \\
\hline NWs & Nanowalls \\
\hline NFs & Nanoflakes \\
\hline NRs & Nanorods \\
\hline CMOS & $\begin{array}{l}\text { Complementary metal-oxide } \\
\text { semiconductor }\end{array}$ \\
\hline ITO & Indium Tin oxide \\
\hline FTO & Fluorine doped Tin oxide \\
\hline DSSCs & Dye sensitized solar cells \\
\hline PSCs & Perovskite solar cells \\
\hline FESEM & $\begin{array}{l}\text { Field emission scanning electron } \\
\text { microscope }\end{array}$ \\
\hline TEM & Transmission electron microscope \\
\hline AFM & Atomic force microscope \\
\hline HRTEM & High resolution transmission electron microscope \\
\hline PL & Photo luminescence \\
\hline XRD & $\mathrm{X}$ - ray diffraction \\
\hline $\mathrm{CV}$ & Cyclic Voltammetry \\
\hline EIS & electrochemical impedance spectroscopy \\
\hline ELISA & enzyme-linked immunosorbent assay \\
\hline
\end{tabular}




\begin{tabular}{|c|c|}
\hline UV & Ultra violet \\
\hline PVD & Physical vapor deposition \\
\hline MOCVD & Metal organic chemical vapor deposition \\
\hline MBE & Molecular beam epitaxy \\
\hline PLD & Pulsed laser deposition \\
\hline SCCM & Standard Cubic Centimeters per Minute \\
\hline $\mathrm{ZNH}$ & Zinc Nitrate Hexahydrate \\
\hline $\mathrm{ZAD}$ & Zinc Acetate dehydrate \\
\hline TMD & Transition metal dichalcogenides \\
\hline EDS & Energy dispersive X- ray spectroscopy \\
\hline SAED & Selective area electron diffraction \\
\hline HMT & Hexamethylene tetramine \\
\hline DI & Deionized \\
\hline PET & Polyethylene terephthalate \\
\hline LO & longitudinal \\
\hline IPCE & Incident photon to charge carrier efficiency \\
\hline FIB & Focused ion beam \\
\hline SCLC & Space- charge limited current \\
\hline AlN & Aluminum Nitrate \\
\hline $\mathrm{Al}: \mathrm{ZnO}$ & Aluminum doped $\mathrm{ZnO}$ \\
\hline $\mathrm{TCO}$ & Transparent conductive oxide \\
\hline LD & Laser diode \\
\hline $\mathrm{PD}$ & Photodetector \\
\hline $\mathrm{P}: \mathrm{ZnO}$ nanoshell & Phosphorous doped $\mathrm{ZnO}$ nanoshell \\
\hline $\mathrm{ADP}$ & Ammonium dihydrogen phosphate \\
\hline $\mathrm{n}-\mathrm{ZnO}$ & $\mathrm{n}$ type $\mathrm{ZnO}$ \\
\hline
\end{tabular}




$\begin{array}{ll}\text { PMMA } & \text { Poly (methyl methacrylate) } \\ \text { RIE } & \text { Reactive ion etching } \\ \text { BSA } & \text { Bovine saline albumin } \\ \text { NEP } & \text { Noise equivalent power } \\ \text { MGJ } & \text { MoS }_{2} / \text { graphene junction } \\ \text { FET } & \text { Field effect transistor } \\ \text { SBJ } & \text { Schottky barrier junction } \\ \text { SBH } & \text { Schottky barrier height } \\ \text { MGPD } & \text { MoS }_{2} / \text { graphene photodetector }\end{array}$




\section{CHAPTER 1}

\section{Introduction}

\subsection{Motivation and Goals}

Semiconductor nanostructures have attracted considerable research interest due to their unique physical and chemical properties at the nanoscale, which opens new frontiers for applications in electronics and sensing. $\mathrm{ZnO}$ is one of the most important semiconducting material in (II-VI) group. $\mathrm{ZnO}$ possess a wide bandgap of $3.37 \mathrm{eV}$ and a high exciton energy of $60 \mathrm{meV}$, which attracted the attention of scientific community dating back to 1935 especially in the short wavelength optoelectronics. [1] The lack of center of symmetry and strong electromechanical coupling makes $\mathrm{ZnO}$ piezoelectric and pyroelectric which was made use in MEMS as transducers. Apart from the above applications, $\mathrm{ZnO}$ is also an important material in bioelectronics owing to its high biocompatibility, less toxicity and high IEP value. [2, 3]

Zinc Oxide nanostructures with wide range of applications especially in optoelectronic devices and bio sensing have been the focus of research over the past few decades. There were numerous reports that illustrated the use of $\mathrm{ZnO}$ nanostructures in various applications such as pressure sensors, [4] biosensors, [5] gas sensors, [6] light emitting diodes (LEDs), [7] displays, [8] transparent electrodes, [9] and solar cells [10] to name a few. Another important feature of $\mathrm{ZnO}$ that has fuelled the interest in $\mathrm{ZnO}$ is the availability of diverse family of $\mathrm{ZnO}$ nanostructures [11, 12, 13] such as nanorods, [14] nanobelts, [15] nanoflowers, [16] nanocombs, [17] and nanotetrapods [18] to name a few. 
Despite the immense potential and the many advantages they bring, devices based on $\mathrm{ZnO}$ nanostructures have failed to attain the success similar to other materials such as Titanium dioxide $\left(\mathrm{TiO}_{2}\right)$ or Gallium nitride $(\mathrm{GaN})$ as was expected to, a few years ago. The two main reasons widely recognized as bottleneck for the development of devices based on $\mathrm{ZnO}$ nanostructures are (1) Synthesis technique which is fast, economical and environmentally benign which would allow the growth on arbitrary substrates (2) Difficulty in producing stable p-type doping. The main objective of this research work is to address these bottlenecks and achieve improved performance in $\mathrm{ZnO}$ devices.

Research spanning several decades has yielded several synthesis techniques to grow $\mathrm{ZnO}$ nanostructures with precise control over morphology and aspect ratios. Among all, the most widely used techniques are based on vapor transport process in which Zinc (Zn) and Oxygen vapor are transported and then allowed to react at the desired site for the formation of Zinc Oxide ( $\mathrm{ZnO})$ nanostructures. Formation of ' $\mathrm{Zn}$ ' in vapor form requires high temperature, precise pressure control and ratio of ' $\mathrm{Zn}$ ' to oxygen vapor which has a significant effect on the morphology of the nanostructures. Chemical vapor deposition (CVD) technique, which is a widely used vapor transport method uses $\mathrm{ZnO}$ and graphite powders to generate ' $\mathrm{Zn}$ ' and oxygen vapors at temperatures from $800{ }^{\circ} \mathrm{C}$ to $1000{ }^{\circ} \mathrm{C}$ to grow highly crystalline nanostructures. However, the need for extreme growth conditions makes it an impractical solution for growth on flexible, plastic substrates. Chemical synthesis methods such as solvothermal methods, sol-gel method, electrodeposition technique and microwave assisted growth to name a few have been hugely popular methods as they can be performed at ambient conditions without use of many specialized equipment, 
at the same time having control over the size and morphology of the nanostructures by varying the parameters such as $\mathrm{pH}$, growth time and temperature. However while the CVD technique is limited by the extreme growth conditions which increase the cost of synthesis and places a serious limitation on the choice of substrate, chemical methods are largely limited by their long synthesis times and high level of hydrogen $(\mathrm{H})$ and Oxygen $(\mathrm{O})$ impurities in the as grown nanostructures. This calls for development of a comprehensive synthesis technique to synthesize $\mathrm{ZnO}$ nanostructures at ambient conditions on arbitrary substrates which can facilitate the use of flexible substrates for wearable electronics and minimize the defects. In this dissertation we developed a Sonochemical method to synthesize 1D ZnO Nanorods (NRs), ZnO homojunction and heterojunction core-shell nanostructures, 2D Nanowalls (NWs) and Nanoflakes (NFs) on arbitrary substrates. Sonochemical method is rapid, inexpensive, CMOS compatible and environmentally benign method which allows us to grow $\mathrm{ZnO}$ nanostructures on any arbitrary substrate at ambient conditions while most other popular methods used are either very slow or involve extreme conditions such as high temperatures and low pressure. $\mathrm{ZnO}$ with its direct band gap of $3.37 \mathrm{eV}$ and high exciton energy $(60 \mathrm{meV})$ is an important material in optoelectronic applications, however a low intrinsic electron concentration which results in low conductivity meant that its application in microelectronics industry is limited. Assembling or direct growth of $\mathrm{ZnO}$ on other materials with high conductivity is one way of improving the properties of the material yet retaining most of the optical and material properties of $\mathrm{ZnO}$. Using Sonochemical method we were able to grow $\mathrm{ZnO}$ nanorods on various substrates including Gold, Aluminum, Iron and Graphene. Another popular method to increase the carrier concentration in semiconductors is doping. Group (iii) metals such as 
Boron (B), Aluminum (Al), Gallium (Ga) and Indium (In) can be used to successfully dope $\mathrm{ZnO}$ to increase the electron concentration. We present for the first time n-type doping of $\mathrm{ZnO}$ nanorods with 'Al' using Sonochemical technique.

Despite its many advantages over other direct bandgap semiconductors, the applications of $\mathrm{ZnO}$ in optoelectronics is hampered by the lack of stable p-type doping due to self-compensation by donor like native defects. This is especially prominent in a low temperature, solution method growth process. A stable, reproducible p-type doping in $\mathrm{ZnO}$ is one of the most sought out application in the field of optoelectronics. The sonochemical synthesis method offers a major advantage over other solution methods as the amount of self-compensating defects introduced in the sonochemical process is very small compared to other solution methods which should significantly improve the chances of achieving a stable p-type doping in $\mathrm{ZnO}$ which has for so long eluded researchers. Here, in this dissertation we focus on fabricating a homogeneous $\mathrm{ZnO}$ radial $\mathrm{p}-\mathrm{n}$ junction by growing a p-type shell around an n-type core in a controlled way using sonochemical synthesis. Coreshell hybrid nanostructures have inspired various applications as they help improve the performance of the native nanostructure. Core-shell structures were used to increase the functionality, improve the thermal and chemical stability, increase storage capacity and improve the efficiency and responsivity of optoelectronic devices by minimizing the recombination losses and improved optical properties. In this research we used the sonochemical technique to synthesize $\mathrm{ZnO}-\mathrm{ZnO}$ homojunction core-shell nanorods and $\mathrm{ZnO}-\mathrm{ZnS}$ heterojunction Core-shell nanorods. 
We have explored the as synthesized nanostructures in various applications such biosensors for point of care Cortisol detection, UV photodetectors and energy harvesting devices such as Dye Sensitized Solar Cells (DSSCs) and Perovskite Solar Cells (PSCs). Apart from $\mathrm{ZnO}$ we have also explored other $2 \mathrm{D}$ materials such as graphene and $\mathrm{MoS}_{2}$ which have attracted the interest of research and industry lately owing to their extraordinary electronic properties such as ballistic transport over $0.4 \mu \mathrm{m}$ and extremely high carrier mobility at room temperature in graphene, and high luminescence from monolayer $\mathrm{MoS}_{2}$. In this study we have fabricated and characterized a $\mathrm{MoS}_{2} /$ graphene Schottky junction photodetector with wide spectral response.

\subsection{Scope of this Dissertation}

This dissertation describes sonochemical synthesis, characterization and applications of $\mathrm{ZnO}$ nanostructures. Chapter 2 to 5 discuss the synthesis and characterization of $\mathrm{ZnO}$ nanostructures in various morphologies while chapter 5 to chapter 7 describes in detail the applications and advantages of $\mathrm{ZnO}$ nanostructures. Chapter 8 provides a summary of the dissertation and proposed future work.

Chapter 2, gives the background of $\mathrm{ZnO}$ and describes its properties in detail. $\mathrm{ZnO}$ crystal structure and resulting mechanical, electrical and optical properties were listed. Various $\mathrm{ZnO}$ morphologies and synthesis techniques with their merits and de-merits were explained. This chapter also describes the origin of $\mathrm{n}$-type doping in $\mathrm{ZnO}$ and the hardship in achieving p-type doping. The various attempts at achieving p-type doping in $\mathrm{ZnO}$ nanostructures were reviewed. 
In chapter 3, the theory of sonochemistry and the method of applying sonochemistry to synthesize $\mathrm{ZnO}$ nanorods, $\mathrm{ZnO}-\mathrm{ZnS}$ core-shell nanorods, $\mathrm{ZnO}$ Nanowalls and ZnO Nanoflakes at INSYST lab were discussed in detail. The morphological and crystallographic characterization of the nanostructures using, Field emission scanning electron microscope (FESEM), Transmission electron microscope (TEM), Atomic force microscopy (AFM), High resolution transmission electron microscopy (HRTEM), Photo luminescence (PL), X- ray diffraction (XRD) and Raman spectrum were presented. Electrical characterization using, four point probe station, Hall measurements were presented. The optical characteristics of the nanostructures studied by measuring the transmittance, quantum efficiency and photo gain was presented in detail.

Chapter 4 discusses the theory of doping in $\mathrm{ZnO}$. The role of defects in natural ntype doping is presented. The defects also play a major role in limiting the $\mathrm{p}$ - type doping in $\mathrm{ZnO}$. This chapters presents the various attempts at achieving p-type doping in $\mathrm{ZnO}$ using IA group and VA group elements. In this chapter, we also present the sonochemical approach employed for the first time to dope $\mathrm{ZnO}$ with Aluminum (Al) and Phosphorous (P) to achieve n-type doping and p-type doping respectively. The fabrication of a homogeneous $\mathrm{p}-\mathrm{n}$ junction and its characterization was presented in detail.

Chapter 5 discusses the role of $\mathrm{ZnO}$ in biosensing. We have used $\mathrm{ZnO}$ NRs and $\mathrm{ZnO} \mathrm{NFs}$ as immobilizing agents to detect cortisol. The as synthesized anodes for immunosensing were characterized using cyclic voltammetry (CV) and electrochemical impedance spectroscopy (EIS). The results were compared with standard ELISA results and found that the as synthesized cortisol sensor is 100 times sensitive than standard methods. It was also observed that the electron transfer rates on $\mathrm{ZnO}$ NFs is much higher 
than $\mathrm{ZnO}$ NRs. Further in chapter 6, we present the successful attempt to fabricate Dye Sensitized Solar Cells (DSSC) with high open circuit voltage and discuss the difficulties in attaining high short circuit current in perovskite solar cells. We propose and provide initial results for fabrication of $\mathrm{ZnO}$ nanorods by using $\mathrm{ZnO}$ nanoflakes as seed layer in order to reduce the recombination losses. In chapter 7 we present the use of doped $\mathrm{ZnO}$ nanorods in $\mathrm{P}: \mathrm{ZnO}$ nanoshell/ $\mathrm{n}-\mathrm{ZnO} \mathrm{NR}$ radial $\mathrm{p}-\mathrm{n}$ junction configuration to detect $\mathrm{UV}$ radiation. We also explore next generation materials such as $2 \mathrm{D} \mathrm{MoS}_{2}$ and graphene. We present the first $\mathrm{p}-\mathrm{MoS}_{2} /$ graphene Schottky junction photo detector, which exhibits a wide spectrum due to the use of both band to band edge detection and internal photo emission over the Schottky junction. In chapter 8 , we summarize the contribution of this dissertation and propose two new devices, (1) Flexible and transparent LEDs and (2) Flexible perovskite solar cells.

\subsection{References}

1 Özgür, Ü. et al (2005). A comprehensive review of $\mathrm{ZnO}$ materials and devices. Journal of Applied Physics, 98 (4):041301.

2. Janotti, A., \& Van de Walle, C. G. (2009). Fundamentals of zinc oxide as a semiconductor. Reports on Progress in Physics, 72 (12):126501.

3. Arya, S. K., Saha, S., Ramirez-Vick, J. E., Gupta, V., Bhansali, S., \& Singh, S. P. (2012). Recent advances in $\mathrm{ZnO}$ nanostructures and thin films for biosensor applications: review. Analytica chimica acta, 737: 1-21.

4. Wang, X., Zhou, J., Song, J., Liu, J., Xu, N., \& Wang, Z. L. (2006). Piezoelectric field effect transistor and nanoforce sensor based on a single $\mathrm{ZnO}$ nanowire. Nano letters, 6 (12):2768-2772.

5. Ümit, Ö., Hofstetter, D., \& Morkoc, H. (2010). ZnO devices and applications: a review of current status and future prospects. Proceedings of the IEEE, 98 (7):1255-1268. 
6. Suchea, M., Christoulakis, S., Moschovis, K., Katsarakis, N., \& Kiriakidis, G. (2006). $\mathrm{ZnO}$ transparent thin films for gas sensor applications. Thin Solid Films, 515 (2):551554.

7. Fang, X., et al (2009). Phosphorus-doped p-type $\mathrm{ZnO}$ nanorods and $\mathrm{ZnO}$ nanorod $\mathrm{p}-\mathrm{n}$ homojunction LED fabricated by hydrothermal method. The Journal of Physical Chemistry C, 113 (50):21208-21212.

8. Nakanishi, Y., et al (1999). Preparation of $\mathrm{ZnO}$ thin films for high-resolution field emission display by electron beam evaporation. Applied Surface Science, 142 (1):233236.

9. Minami, T. (2005). Transparent conducting oxide semiconductors for transparent electrodes. Semiconductor Science and Technology, 20 (4):S35.

10. Zhang, Q., et al (2009). ZnO Nanostructures for Dye-Sensitized Solar Cells. Advanced Materials, 21 (41):4087-4108.

11. Wang, Z. L. (2004). Zinc oxide nanostructures: growth, properties and applications. Journal of Physics: Condensed Matter, 16 (25):R829.

12. Xu, S., and Zhong L. W. (2011). One-dimensional $\mathrm{ZnO}$ nanostructures: solution growth and functional properties. Nano Research, 4 (11):1013-1098.

13. Shiosaki, T., et al (1978). As-grown CVD ZnO optical waveguides on sapphire. Applied Physics Letters, 33 (5):406-407.

14. Vayssieres, L. (2003). Growth of arrayed nanorods and nanowires of $\mathrm{ZnO}$ from aqueous solutions. Advanced Materials, 15 (5):464-466.

15. Pan, Z. W., Dai, Z. R., \& Wang, Z. L. (2001). Nanobelts of semiconducting oxides. Science, 291 (5510):1947-1949.

16. Wang, Y., et al (2008). Controllable synthesis of $\mathrm{ZnO}$ nanoflowers and their morphology-dependent photocatalytic activities. Separation and Purification Technology, 62 (3):727-732.

17. Liu, F., et al (2004). Controlled self-assembled nanoaeroplanes, nanocombs, and tetrapod-like networks of zinc oxide. Nanotechnology, 15 (8):949.

18. Xiangfeng, C., et al (2005). Gas-sensing properties of thick film based on $\mathrm{ZnO}$ nanotetrapods. Chemical Physics Letters, 401 (4):426-429. 


\section{CHAPTER 2}

\section{Background and State of the Art}

\subsection{Properties of Zinc Oxide}

Zinc Oxide $(\mathrm{ZnO})$ is one of the most important common and widely studied semiconducting material in (II-VI) group. $\mathrm{ZnO}$ possess a wide bandgap of $3.37 \mathrm{eV}$ and a high exciton energy of $60 \mathrm{meV}$ which attracted the attention of scientific community dating back to 1935 especially in the short wavelength optoelectronics. [1] Zinc oxide thin films have traditionally been used as transparent electrodes and UV photodetectors. [2] The lack of center of symmetry and strong electromechanical coupling makes $\mathrm{ZnO}$ piezoelectric and pyroelectric which was made use in MEMS as transducers. Apart from the above applications, $\mathrm{ZnO}$ is also an important material in bioelectronics owing to its high biocompatibility, less toxicity and high isoelectric point (IEP) value. [3, 4]

The last few decades saw an unprecedented advancement in nanotechnology where, the electronic and mechanical properties depend greatly on morphology and the dimensions of the material. This made $\mathrm{ZnO}$ one of the most studied material owing to the ease with which $\mathrm{ZnO}$ nanostructures can be synthesized in diverse morphologies and controlled dimensions. In the past, researchers were successful in developing techniques to synthesize $\mathrm{ZnO}$ nanostructures in 1D nanorods, nanowires, nanotubes, 2D nanobelts, nanocombs and many other morphologies which showed remarkable features in fields of sensing and field emission. [5] 


\subsubsection{Crystal Structure, Lattice Parameters \& Mechanical Properties}

(a)

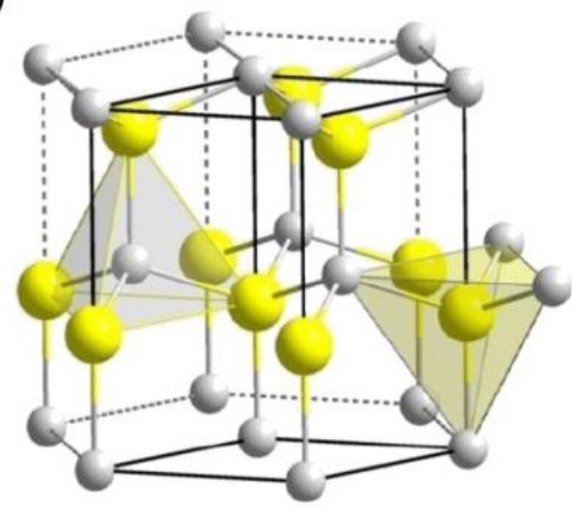

(b)

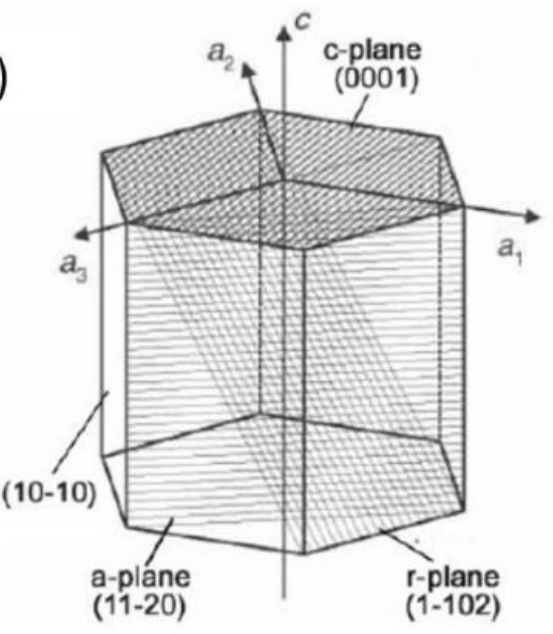

Figure 2.1 (a, b) Hexagonal wurtzite structure of $\mathrm{ZnO}$ crystal [6]

Even though $\mathrm{ZnO}$ like other II-VI semiconductors occurs in three crystal structures namely zinc blend, rock salt and wurtzite, naturally occurring $\mathrm{ZnO}$ is found to be thermodynamically stable in wurtzite hexagonal structure with a space group of $\mathrm{P} 6_{3} \mathrm{mc}$. The lattice constants of $\mathrm{ZnO}$ measured by X-ray diffraction are $\mathrm{a}=3.2426(+/-) 0.0001 \AA$, $\mathrm{b}=3.2426(+/-) 0.0003 \AA, 3.2426$ (+/-) $0.0001 \AA$. [7] Wurtzite $\mathrm{ZnO}$ structure can be described as alternating planes composed of a zinc ion surrounded tetrahedrally by four oxygen ions and vice versa. These planes are stacked upon each other in c-direction. This tetrahedral coordination of $\mathrm{Zn}^{2+}$ ions and $\mathrm{O}^{2-}$ ions results in non-central symmetric structure which makes $\mathrm{ZnO}$ piezoelectric and pyroelectric. [8] Also the oppositely charged ions along the basal plane results in normal dipole moment and spontaneous polarization along 
the c-axis results in a lack of symmetry in the wurtzite structure which enhances the piezoelectric nature of $\mathrm{ZnO}$. [9] The typical values of piezoelectric and pyroelectric coefficients of $\mathrm{ZnO}$ thin film are $11.0 \mathrm{pC} / \mathrm{N}$ and $-9.4 \times 10^{-6} \mathrm{C} / \mathrm{m}^{2} \mathrm{~K}$ respectively. This property has been widely used in making $\mathrm{ZnO}$ cantilevers and pressure sensors. [10, 11]

\subsubsection{Electrical and Optical Properties}

Zinc Oxide is a direct bandgap semiconductor material with a bandgap of $3.37 \mathrm{eV}$. This large bandgap which is near ultraviolent light (UV) range means $\mathrm{ZnO}$ devices have higher breakdown voltage, can sustain large electric fields and produce lower electrical noise. The large band gap also means $\mathrm{ZnO}$ is transparent to visible light. This property of $\mathrm{ZnO}$ has made it one of the most researched material for transparent electrodes as a replacement for the widely used indium tin oxide (ITO) and titanium dioxide $\left(\mathrm{TiO}_{2}\right) . \mathrm{ZnO}$ possesses a high exciton binding energy of $60 \mathrm{meV}$ which is 2.4 times that of thermal energy at room temperature. This paves way for intense near-band-edge excitonic emission at room temperatures which was suggested to be the mechanism behind $\mathrm{ZnO}$ lasing. [12] Another important feature of $\mathrm{ZnO}$ is its surface sensitivity. The conductivity of $\mathrm{ZnO}$ is very sensitive to surface adsorbents, this coupled with its high iso-electric point (IEP) of 9.5 [4] and biocompatibility has made $\mathrm{ZnO}$ a highly desirable and exploited material in electrochemical biosensing and gas sensing. Other $\mathrm{ZnO}$ parameters and properties such as dielectric constant, carrier concentration etc. are listed in table 1. 
Table 2.1. Electrical and optical properties of bulk $\mathrm{ZnO}$ [13]

\begin{tabular}{|c|c|}
\hline Static dielectric constant & 8.656 \\
\hline Refractive Index & $2.008,2.029$ \\
\hline Energy Gap & $3.4 \mathrm{eV}$ \\
\hline Intrinsic carrier concentration & $\begin{array}{c}<10^{6} \mathrm{~cm}^{-3} \text { (max n-type doping }>10^{20} \mathrm{~cm}^{-3} \\
\text { Electrons; max p-type doping }>10^{17} \mathrm{~cm}^{-3} \\
\text { holes })\end{array}$ \\
\hline Exciton binding energy & $60 \mathrm{meV}$ \\
\hline Electron effective mass & 0.24 \\
\hline $\begin{array}{c}\text { Electron Hall mobility at 300 K for } \\
\text { low n-type conductivity }\end{array}$ & $200 \mathrm{~cm}^{2} / \mathrm{Vs}$ \\
\hline Hole effective mass & 0.59 \\
\hline $\begin{array}{c}\text { Hole Hall mobility at 300 K for low } \\
\text { p-type conductivity }\end{array}$ & $5-50 \mathrm{~cm}^{2} / \mathrm{Vs}$ \\
\hline
\end{tabular}

\subsection{Defects and Doping in $\mathrm{ZnO}$}

$\mathrm{ZnO}$ is naturally n-type, the reason being still debated. However the most widely accepted reason is the presence of unintentional intrinsic defects such as oxygen $\left(\mathrm{O}_{\mathrm{v}}\right)$ and $\mathrm{Zn}\left(\mathrm{Zn}_{\mathrm{v}}\right)$ vacancies or Oxygen $\left(\mathrm{O}_{\mathrm{i}}\right)$ and Zinc interstitials $\left(\mathrm{Zn}_{\mathrm{i}}\right)$ or antisites such as Oxygen $\left(\mathrm{Zn}_{\mathrm{o}}\right)$ and Zinc $\left(\mathrm{O}_{\mathrm{zn}}\right)$ antisites [14]. Beside Oxygen and Zinc defects, doping of hydrogen donor which can be easily incorporated during the growth process can be a major reason for the unintentional n-type doing observed in $\mathrm{ZnO}$. The average electron concentration in $\mathrm{ZnO}$ films is approximately $10^{21} \mathrm{~cm}^{-3}$. [13] Figure 2.2 shows energy levels of various defects present in the $\mathrm{ZnO}$ band gap. 


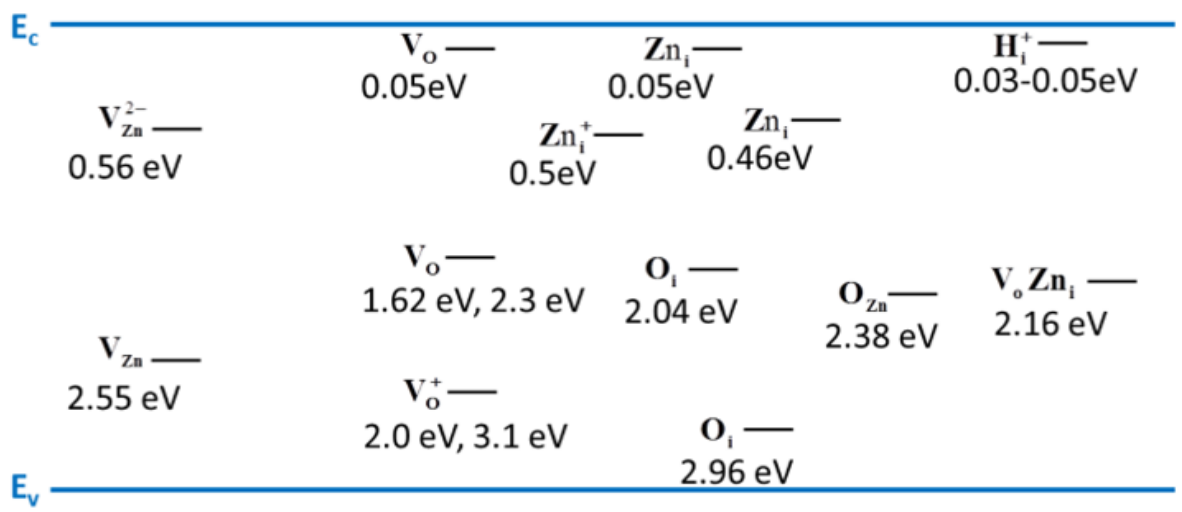

Figure 2.2. Energy levels of various defects in $\mathrm{ZnO}$ [15]

This unintentional naturally occurring n-type conductivity in $\mathrm{ZnO}$ is advantageous in various applications such as transparent electrodes, but also forms a bottle neck in achieving p-type doping in $\mathrm{ZnO}$ as they self-compensate the p-type dopants. Several groups have reported partial success in doping $\mathrm{ZnO}$ with group-I and group- $\mathrm{V}$ elements as dopants. $[16,17,18]$ However a successful and reliable method is yet to be realized. Here in this research work, we have successfully doped $\mathrm{ZnO}$ nonoshells with phosphorous using sonochemical synthesis.

\subsection{ZnO Nanostructures and Synthesis Techniques}

During the past 15 years, nanotechnology has progressed at an unprecedented phase. By virtue of their unique properties that differ significantly from their bulk counterparts, nanomaterials offer novel applications to the field of science and technology. As the size 
of a material reduces to nanoscale, the movement and degree of freedom of electrons (and photons) is confined to a limited space. This quantum confinement alters the physical and chemical properties of the material compared to its bulk counterpart. At this scale, the morphology of the material plays a vital role in defining the properties of the material. The asymmetrical structure of the $\mathrm{ZnO}$ can induce growth in different growth directions depending on the growth conditions. This has encouraged researchers around the world to develop diverse morphologies of $\mathrm{ZnO}$ nanostructures by controlling the growth kinetics. Nanostructures such as nanorods, [19] nanowires, [20] nanowhiskers, [21] nanowalls, [22] nanobelts, [23] nanotetropods, [24] nanocombs [25] are few of the many morphologies of $\mathrm{ZnO}$ nanostructures that have been reported over the past decade using various synthesis techniques such as chemical vapor deposition (CVD), [26] physical vapor deposition (PVD), [20] metal organic chemical vapor deposition (MOCVD), [27] molecular beam epitaxy (MBE), [28] pulsed laser deposition (PLD) [29] and wet chemical process such as hydrothermal method, [30] electrodeposition method, [31] microwave irradiation assisted growth [32] and sol-gel method [33] to name a few. Among these techniques, CVD method and hydrothermal methods which attracted the interest of researchers have been widely reported over years. These techniques were studied in detail come with their own drawbacks.

CVD technique is performed by allowing $\mathrm{ZnO}$ powder to react with carbon (C) powder at high temperatures $\left(800{ }^{\circ} \mathrm{C}\right.$ to $\left.900{ }^{\circ} \mathrm{C}\right)$ in a furnace. The transformation of $\mathrm{ZnO}$ powder and carbon at the elevated temperature in to $\mathrm{Zinc}(\mathrm{Zn})$ and Carbon dioxide $\left(\mathrm{CO}_{2}\right)$ gas forms the basis of CVD technique. These gases are carried by a carrier gas (Argon) to 
a substrate coated with a catalyst $(\mathrm{Au})$, and placed at a lower temperature in the same furnace. At lower temperature ' $\mathrm{Zn}$ ' gas oxidizes back in to $\mathrm{ZnO}$. The nucleation of the $\mathrm{ZnO}$ nanocrystal happens at the tip of the catalyst and develops in to nanostructures. The morphology of the nanostructures depends on various factors such as gas flow rate, temperature and pressure. Figure 2.3 (a) shows the mechanism of growth via CVD technique and figure 2.3 (b) shows the CVD set up at INSYST lab. Figure 2.3 (c) shows the $\mathrm{ZnO}$ nanorods grown on $\mathrm{Si}$ substrate using CVD technique where substrate is placed at $500{ }^{\circ} \mathrm{C}$. In this process a catalyst (commonly Gold $(\mathrm{Au})$ ) is deposited on Si substrate. This catalyst at high temperature forms an alloy with the source material. When the concentration of the semiconductor reaches the upper solubility limit, nanowire nucleation commences. $\mathrm{ZnO}$ nanowires were synthesized in low pressure chemical vapor deposition system. In this method, equal amounts of Carbon (C) and $\mathrm{ZnO}$ powder are well mixed and used as the source material. The substrate is gold sputtered followed by annealing at 400 ${ }^{\circ} \mathrm{C}$. The whole process is performed in a 3 zone furnace as shown in figure 2.3 (a). The source is maintained at $800{ }^{\circ} \mathrm{C}-900{ }^{\circ} \mathrm{C}$ while the substrate is placed around $500{ }^{\circ} \mathrm{C}$. The whole furnace is maintained at 63 Torr pressure. A constant Argon gas flow of 100 SCCM is maintained. The process takes 60 mins. 
(a)

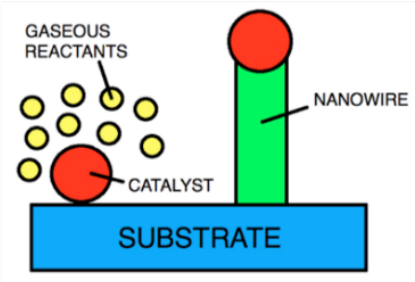

(b)

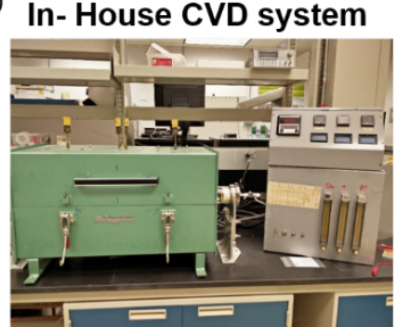

(c)

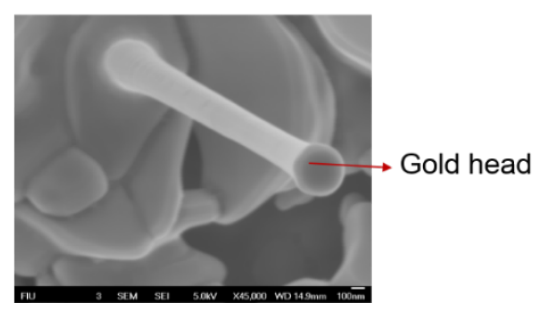

Figure 2.3 (a) Growth process in VLS method (b) In house 3 zone CVD furnace (c) $\mathrm{ZnO}$ nanorods grown via CVD method on Si substrate.

Various morphologies such as rods, whiskers, tripods and 2D nanobelts synthesized using this process have been reported. CVD process gives a very high quality single crystalline $\mathrm{ZnO}$ nanostructures but requires high temperatures $\left(800{ }^{\circ} \mathrm{C}-900{ }^{\circ} \mathrm{C}\right)$ which limits the choice of substrates that can be used. Also the need for catalyst can induce impurities in to $\mathrm{ZnO}$ nanostructures. Therefore this method cannot be used to grow $\mathrm{ZnO}$ nanostructures on flexible organic substrates for future flexible and wearable electronics.

Hydrothermal process is a chemical process, in which Zinc ions $\left(\mathrm{Zn}^{2+}\right)$ derived from precursors such as Zinc Nitrate Hexahydrate $(\mathrm{ZNH})$ and Zinc Acetate Dehydrate react with $\mathrm{OH}^{-}$ions from water $\left(\mathrm{H}_{2} \mathrm{O}\right)$ and other alkaline solutions to form $\mathrm{ZnO}$ nanostructures. Hydrothermal method requires low temperatures from $100{ }^{\circ} \mathrm{C}$ to $180{ }^{\circ} \mathrm{C}$ and no additional catalysts making it a suitable method for organic and flexible substrates and requires simple setup making it an inexpensive process. However this method takes longer times up to 1224 hours for the process to complete. The low temperature involved in the process have been known to result in higher defects, especially hydrogen defects when compared with high temperature CVD process. To be able to be a part of practical low cost electronic applications, these techniques are either not cost effective or require conditions too harsh 
to give any flexibility for the growth on desired substrates. In this dissertation, sonochemical methods which involves the use of high intensity ultrasonic irradiation of an aqueous solution was developed as an alternative method for the synthesis of $\mathrm{ZnO}$ nanowires.

Recently, there has been a lot of interest in the synthesis and study of 2D inorganic structures after the discovery of graphene. 2D Graphene has revolutionized nanoelectronics like no other material in the new century owing to its remarkable mechanical, electrical and optical properties. Graphene exhibits remarkably high mobility with a maximum reported mobility of $\sim 200,000 \mathrm{~cm}^{2} \mathrm{~V}^{-1} \mathrm{~s}^{-1}$. [34] This has the potential to take the field of electronics and communications in to unchartered territories. However the lack of band gap has been the major obstacle in achieving the desired goals. Integrating other 2D semiconductor materials with graphene can bring best of both the worlds. Researchers around the world have dedicated their efforts in realizing 2D counterparts of many bulk semiconducting materials and integrate them with graphene. Recently, 2D atomic layers of semiconductor transition metal dichalcogenides (sTMDs) such as $\mathrm{MoS}_{2}, \mathrm{WSe}_{2}$ were successfully realized and explored for various optoelectronic applications. [35,36] These structures have also been assembled with graphene to form 2D hybrid materials which improve the functioning of both graphene and other 2D materials. [3,38] In this study, we present the fabrication and junction properties of $\mathrm{MoS}_{2} /$ Graphene Schottky junction photodetector. 


\section{$2.4 \quad$ References}

1. Özgür, Ü. et al (2005). A comprehensive review of $\mathrm{ZnO}$ materials and devices. Journal of applied physics, 98 (4):041301.

2. Liang, S., et al (2001). ZnO Schottky ultraviolet photodetectors. Journal of Crystal Growth, 225 (2):110-113.

3. Arya, S. K., et al (2012). Recent advances in $\mathrm{ZnO}$ nanostructures and thin films for biosensor applications: review. Analytica chimica acta, 737:1-21.

4. Franklin, N. M., et al (2007). Comparative toxicity of nanoparticulate $\mathrm{ZnO}$, bulk $\mathrm{ZnO}$, and $\mathrm{ZnCl} 2$ to a freshwater microalga (Pseudokirchneriella subcapitata): the importance of particle solubility. Environmental Science \& Technology, 41:8484-8490.

5. Lee, C. J., et al (2002). Field emission from well-aligned zinc oxide nanowires grown at low temperature. Applied Physics Letters, 81 (19):3648-3650.

6. Wikipedia The Free Encyclopedia. http://en.wikipedia.org/wiki/Zinc_oxide (accessed June 13, 2016)

7. C.W.Bunn, Proceedings of the Physical Society 1935, 47, 835.

8. Tjhen, W., Tamagawa, T., Ye, C. P., Hsueh, C. C., Schiller, P., \& Polla, D. L. (February, 1991). Properties of piezoelectric thin films for micromechanical devices and systems. Paper presented at the meeting of Micro Electro Mechanical Systems, Nara.

9. Wang, Z. L., \& Song, J. (2006). Piezoelectric nanogenerators based on zinc oxide nanowire arrays. Science, 312 (5771):242-246.

10. Rogers, B., Manning, L., Sulchek, T., \& Adams, J. D. (2004). Improving tapping mode atomic force microscopy with piezoelectric cantilevers. Ultramicroscopy, 100 (3):267276.

11. Chang, S. J., Hsueh, T. J., Hsu, C. L., Lin, Y. R., Chen, I. C., \& Huang, B. R. (2008). A $\mathrm{ZnO}$ nanowire vacuum pressure sensor. Nanotechnology, 19 (9):095505.

12. Bagnall, D. M., Chen, Y. F., Zhu, Z., Yao, T., Koyama, S., Shen, M. Y., \& Goto, T. (1997). Optically pumped lasing of $\mathrm{ZnO}$ at room temperature. Applied Physics Letters, 70 (17):2230-2232.

13. Pearton, S. J., Norton, D. P., Ip, K., Heo, Y. W., \& Steiner, T. (2005). Recent progress in processing and properties of $\mathrm{ZnO}$. Progress in materials science, 50 (3):293-340. 
14. Zhang, S. B., Wei, S. H., \& Zunger, A. (2001). Intrinsic n-type versus p-type doping asymmetry and the defect physics of ZnO. Physical Review B, 63 (7):075205.

15. Willander, M., et al (2010). Luminescence from zinc oxide nanostructures and polymers and their hybrid devices. Materials 3 (4):2643-2667.

16. Thomas, M. A., \& Cui, J. B. (2010). Electrochemical route to p-type doping of $\mathrm{ZnO}$ nanowires. The Journal of Physical Chemistry Letters, 1 (7):1090-1094.

17. Tay, C. B., Chua, S. J., \& Loh, K. P. (2010). Stable p-type doping of ZnO film in aqueous solution at low temperatures. The Journal of Physical Chemistry C, 114 (21):9981-9987.

18. Lee, W. J., Kang, J., \& Chang, K. J. (2008). p-type doping and compensation in ZnO.

19. Wang, X., Summers, C. J., \& Wang, Z. L. (2004). Large-scale hexagonal-patterned growth of aligned $\mathrm{ZnO}$ nanorods for nano-optoelectronics and nanosensor arrays. Nano Letters, 4 (3):423-426.

20. Yang, P., Yan, H., Mao, S., Russo, R., Johnson, J., Saykally, R., \& Choi, H. J. (2002). Controlled growth of $\mathrm{ZnO}$ nanowires and their optical properties. Advanced Functional Materials, 12 (5):323.

21. Li, P., Liu, H., Lu, B., \& Wei, Y. (2010). Formation mechanism of $1 \mathrm{D} \mathrm{ZnO}$ nanowhiskers in aqueous solution. The Journal of Physical Chemistry C, 114 (49):21132-21137.

22. Li, P., Liu, H., Lu, B., \& Wei, Y. (2010). Formation mechanism of 1D ZnO nanowhiskers in aqueous solution. The Journal of Physical Chemistry C, 114 (49):21132-21137.

23. Pan, Z. W., Dai, Z. R., \& Wang, Z. L. (2001). Nanobelts of semiconducting oxides. Science, 291 (5510): 1947-1949.

24. Chen, Zheng, et al. Zinc oxide nanotetrapods. (2004) Nanotechnology, 15.3: 365.

25. Xu, C. X., Sun, X. W., Dong, Z. L., \& Yu, M. B. (2004). Self-organized nanocomb of $\mathrm{ZnO}$ fabricated by Au-catalyzed vapor-phase transport. Journal of crystal growth, 270 (3):498-504.

26. Kim, S. W., Fujita, S., Park, H. K., Yang, B., Kim, H. K., \& Yoon, D. H. (2006). Growth of $\mathrm{ZnO}$ nanostructures in a chemical vapor deposition process. Journal of crystal growth, $292(2): 306-310$. 
27. Muthukumar, S., Sheng, H., Zhong, J., Zhang, Z., Emanetoglu, N. W., \& Lu, Y. (2003). Selective MOCVD growth of $\mathrm{ZnO}$ nanotips. Nanotechnology, IEEE Transactions on, 2 (1):50-54.

28. Isakov, I., Panfilova, M., Sourribes, M. J., \& Warburton, P. A. (2013). Growth of ZnO and $\mathrm{ZnMgO}$ nanowires by $\mathrm{Au}$-catalysed molecular-beam epitaxy.physica status solidi (c), 10 (10):1308-1313.

29. Sun, Y., Fuge, G. M., \& Ashfold, M. N. (2006). Growth mechanisms for ZnO nanorods formed by pulsed laser deposition. Superlattices and Microstructures, 39 (1):33-40.

30. Tong, Y., Liu, Y., Dong, L., Zhao, D., Zhang, J., Lu, Y., \& Fan, X. (2006). Growth of $\mathrm{ZnO}$ nanostructures with different morphologies by using hydrothermal technique. The Journal of Physical Chemistry B, 110 (41):20263-20267.

31. Pradhan, D., \& Leung, K. T. (2008). Controlled growth of two-dimensional and onedimensional $\mathrm{ZnO}$ nanostructures on indium tin oxide coated glass by direct electrodeposition. Langmuir, 24 (17):9707-9716.

32. Cho, S., Jung, S. H., \& Lee, K. H. (2008). Morphology-controlled growth of ZnO nanostructures using microwave irradiation: from basic to complex structures. The Journal of Physical Chemistry C, 112 (33):12769-12776.

33. Ahn, S. E., Ji, H. J., Kim, K., Kim, G. T., Bae, C. H., Park, S. M., ... \& Ha, J. S. (2007). Origin of the slow photoresponse in an individual sol-gel synthesized $\mathrm{ZnO}$ nanowire. Applied physics letters, 90 (15):153106.

34. Bolotin, K. I., Sikes, K. J., Jiang, Z., Klima, M., Fudenberg, G., Hone, J., \& Stormer, H. L. (2008). Ultrahigh electron mobility in suspended graphene. Solid State Communications, $146(9): 351-355$.

35. Lopez-Sanchez, O., Lembke, D., Kayci, M., Radenovic, A., \& Kis, A. (2013). Ultrasensitive photodetectors based on monolayer MoS2. Nature nanotechnology, 8 (7):497-501.

36. Ross, J. S., Klement, P., Jones, A. M., Ghimire, N. J., Yan, J., Mandrus, D. G., \& Cobden, D. H. (2014). Electrically tunable excitonic light-emitting diodes based on monolayer WSe2 pn junctions. Nature nanotechnology, 9 (4):268-272.

37. Bertolazzi, S., Krasnozhon, D., \& Kis, A. (2013). Nonvolatile memory cells based on MoS2/graphene heterostructures. Acs Nano, 7 (4):3246-3252.

38. Xiang, Q., Yu, J., \& Jaroniec, M. (2012). Synergetic effect of MoS2 and graphene as cocatalysts for enhanced photocatalytic $\mathrm{H} 2$ production activity of $\mathrm{TiO} 2$ nanoparticles. Journal of the American Chemical Society, 134 (15):6575-6578. 


\section{CHAPTER 3}

\section{SONOCHEMICAL SYNTHESIS OF ZINC OXIDE NANOSTRUCTURES}

\subsection{Theory of Sonochemistry}

Sonochemistry is a study of chemical reactions and crystallization induced in a solution after application of ultra sound. Introduction of ultrasound in to solution creates regions inside the solution with high and low pressure regions due to periodic compression and expansion. [1] This change in pressure initiates a process called acoustic cavitation, in which air bubbles are formed in the solution and proceeds to grow in size before they collapse releasing a large amount of energy in to its immediate surroundings. Air molecules dissolved in the solution diffuse to form bubbles at the low pressure cycle. During the next cycle, the bubble is subjected to immense amount of external pressure which compresses the bubble. This process of bubble growth and compression continues until it reaches a point where the external pressure is larger than the surface energy of the bubble at which point the bubble collapses releasing a large amount of energy and pressure in to its immediate vicinity. It was measured that temperatures as high as $5000 \mathrm{~K}$ and a pressure of 1000 atm can be reached during this process. The core of the bubble known as hot spot, features high energy collisions which generates an energy as high as $13 \mathrm{eV}$. [1,2] This property of acoustic cavitation and its effects has been the center of research for many years starting from Lord Rayleigh in year 1983 when he was assigned to determine the cause of the damages done to the propeller of HMS Daring, which shed light on both the constructive and destructive behavior of acoustic cavitation. He deduced that acoustic cavitation was the reason behind the damage caused to the propeller. He developed a 
mathematical model for the formation of cavities in liquid and predicted the existence of hotspot inside the bubble. The sequential process of acoustic cavitation is shown in figure 3.1

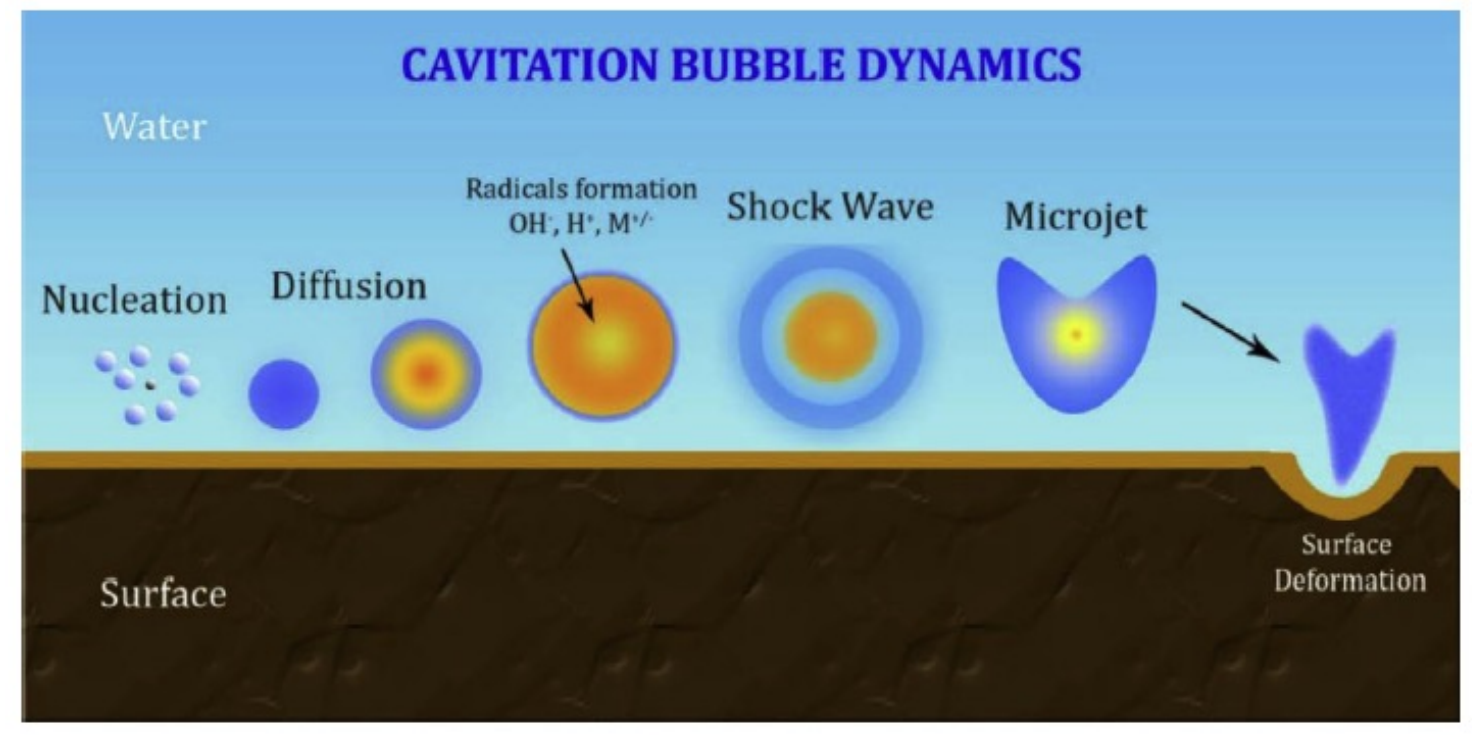

Figure 3.1. Dynamics of cavitation bubble [2]

Rayleigh equation shown below gives relation between the size of the bubble, density of solution and pressure difference between compression and rarefaction cycle. The size and growth of the bubble reciprocates the change in pressure. [3]

$R \ddot{R}+\frac{3}{2}(\dot{R})^{2}=\frac{\left(p-p_{0}\right)}{\rho}$

Rayleigh however, in his model did not take the viscosity and surface tension of the solvent in to account. Plesset in 1949 proposed a modified Rayleigh's equation to include the effect of viscosity and surface tension given by Raleigh-Plesset equation (2). [4] 
$R \ddot{R}+\frac{3}{2}(\dot{R})^{2}+\frac{4 \sigma \dot{R}}{R}+\frac{2 S}{\rho R}=\frac{\left(p-p_{0}\right)}{\rho}$

Where ' $R$ ' is the radius of the bubble and a function of time. $\rho$ is density, $\sigma$ is viscosity and $S$ is the surface tension of the liquid. ( $\left.p-p_{0}\right)$ is the pressure difference between compression and rarefaction cycle. This pressure difference can be calculated using simple wave equation given in equation (3).

$P(x, t)=A \cos (\omega t-\beta x+\varphi)$

where, ' $A$ ' is the amplitude, $\omega$ is $2 \pi$ times the frequency of the sound wave, $\beta$ is given by $2 \pi$ divided by the wavelength and $\varphi$ is the reference phase of the sound wave respectively. The amplitude and frequency determines the magnitude and rate of oscillation of the pressure field which is critical to the formation and sustaining of acoustic bubbles. The pressure decreases at rarefaction, such that the local temperature becomes sufficient for dissolved air bubbles and edge cavities to diffuse, a process known as rectified diffusion. During rectified diffusion, air cavities nucleate around a particle or conglomerate to form bigger cavity - a sub process known as nucleation. The diffusion process completes within a rarefaction cycle and leads to the oscillating growth of the bubble. After rarefaction, the new born bubble is squeezed and shrunk by the external pressure that tries to implode it. The bubble overcomes this high pressure cycle by adapting a suitable size. Depending on the applied amplitude and frequency, the size increases from few micrometers to hundreds of micrometer between the inception and final phase within few milliseconds. As the bubble reaches the compression at its peak, the external pressure dominates and the bubble implodes. The dying bubble is reduced instantaneously to $\sim 10$ th of its size before 
implosion; while the matter inside turns to plasma due to the violent compression. Filled with high energy ions diffused by the decomposing chemical solution, the energy inside the bubble can rise to as high as $13 \mathrm{eV}$ from inter-ion collisions. This hotspot energy is then conferred to the ambient liquid along with the ions and chemicals upon bubble implosion which is used by sonochemists to facilitate chemical reactions and nanostructure growth, which is not achieved in normal solution process methods. Another attractive aspect of using sonochemistry in nanomaterial synthesis is the faster kinetics of chemical reactions, which reduces the time of reaction considerably.

Several factors affect the growth of nanomaterials using Sonochemistry. As lord Rayleigh found out, sonochemistry can be devastating if not controlled in an effective manner. In order to control the cavitation and chemical reactions in a solution, it is important for the solution to be a homogeneous mixture. In case of heterogeneous solution, the physical effects of cavitation becomes dominant. Small particles driven by shock wave undergo drastic structural transformation upon collision while, bigger particles participate in shock wave induced collisions which give rise to micro jets at the boundaries. These physical effects not only cause a severe damage to the equipment and particles used, but can also drive the process out of control. Therefore it is important to have a very homogeneous solution for the process. Apart from the homogeneity of the solution, other factors such as vapor pressure of the solvent and concentration of the precursors play a vital role in shaping the chemical reaction and determining the morphology of the nanoparticles that result from the cavitation process. [5] It was found that the viscosity and the surface tension of the solvent are other two factor which play a significant role in determining the size and density of the bubble which in turn, determines the intensity of 
the cavitation. The concentration of the solute also plays a major role in determining the morphology of the nanoparticles. [6] Another important player in the sonochemical process is frequency. The effect of change in frequency reflects on the pressure cycle which is crucial to the cavitation process. As the frequency increases the size of the bubbles become smaller and results in a uniform distribution. However, the energy buildup inside the bubble does not follow the increase in frequency. [7] It is crucial to find the optimum frequency range for enhanced cavitation process for a particular solution in order to achieve the desired chemical reaction. Other factors that affect the final outcome are sonication time, power and the substrate used. [8]

\subsection{Sonochemical Synthesis of $\mathrm{ZnO}$ Nanostructures}

At INSYST lab we make use of a simple, commercially available high intensity ultrasound set up which boasts a $750 \mathrm{~W}$ ultrasonic processor from Sonics and Systems as shown in figure 3.2. This system allows us to vary the amplitude of sonication and time of each cycle to a desired value, thereby giving a great control over the process. Using sonication method, we have successfully synthesized 1D ZnO NRs, 2D ZnO NWs, 2D ZnO NFs, ZnO-ZnO

core-shell nanorods, $\mathrm{ZnO}-\mathrm{ZnS}$ core-shell nanorods on arbitrary substrates. Extensive material characterization using, XRD, EDS, SAED and HRTEM has revealed that the nanostructures grown are single crystalline in nature and are oriented in (0002) direction. 


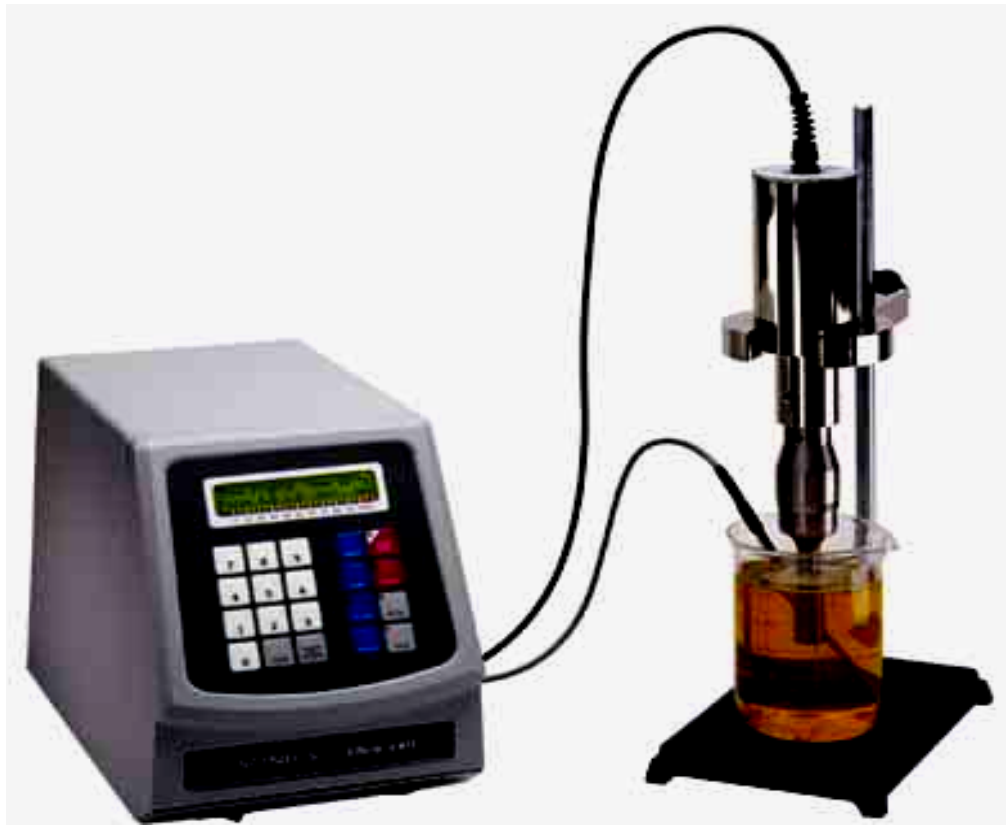

Figure 3.2 Sonochemical Setup from Sonics and Systems

\subsubsection{ZnO Nanorods}

We used a two-step process for synthesis of $\mathrm{ZnO}$ nanorods on different substrates. In the first step, a uniform layer of $\mathrm{ZnO}$ seed was deposited on an arbitrary substrate by sonochemical method using $0.5 \mathrm{mM}$ Zinc Acetate Dehydrate (ZAD) in $100 \mathrm{ml}$ of isopropanol (IPA) as precursors. ZAD has been extensively studied for its ability to form seeds suitable for subsequent nanowire/nanorod growth on both polar and nonpolar substrates capable of tolerating $200{ }^{\circ} \mathrm{C}$ [9]. We modified this approach and utilized the effects of sonication to produce solution phase seeding and growth of nanorods in a solution at ambient conditions. Initially a $0.5 \mathrm{mM}$ concentration of ZAD in isopropyl alcohol solution was prepared at room temperature by stirring with a magnetic stir bar at 
$350 \mathrm{rpm}$ for 5 minutes. The substrates were cleaned with methanol, acetone and isopropanol before immersing in to the solution. The solution with immersed substrate was then irradiated using commercially available high intensity ultrasound setup in 15 minute cycles at $75 \%$ of the maximum amplitude $\left(\sim 30 \mathrm{~W} \mathrm{~cm}^{-2}\right)$ and $20 \mathrm{kHz}$ frequency. The solution was refreshed after each cycle, the substrate is rinsed with DI water, dried with nitrogen and the process was then repeated as necessary to obtain a desired distribution and uniformity. During the whole process, the global temperature of the aqueous solution never exceeds $\sim 70{ }^{\circ} \mathrm{C}$ which makes it suitable flexible plastic substrates. Figure 3.3 shows the SEM picture of $\mathrm{ZnO}$ seed layer on Si grown over 4 cycles of sonication with each cycle running for 15 minutes. The thickness and uniformity of the seed layer increases with the number of cycles while the diameter of seed increases with duration of each cycle.

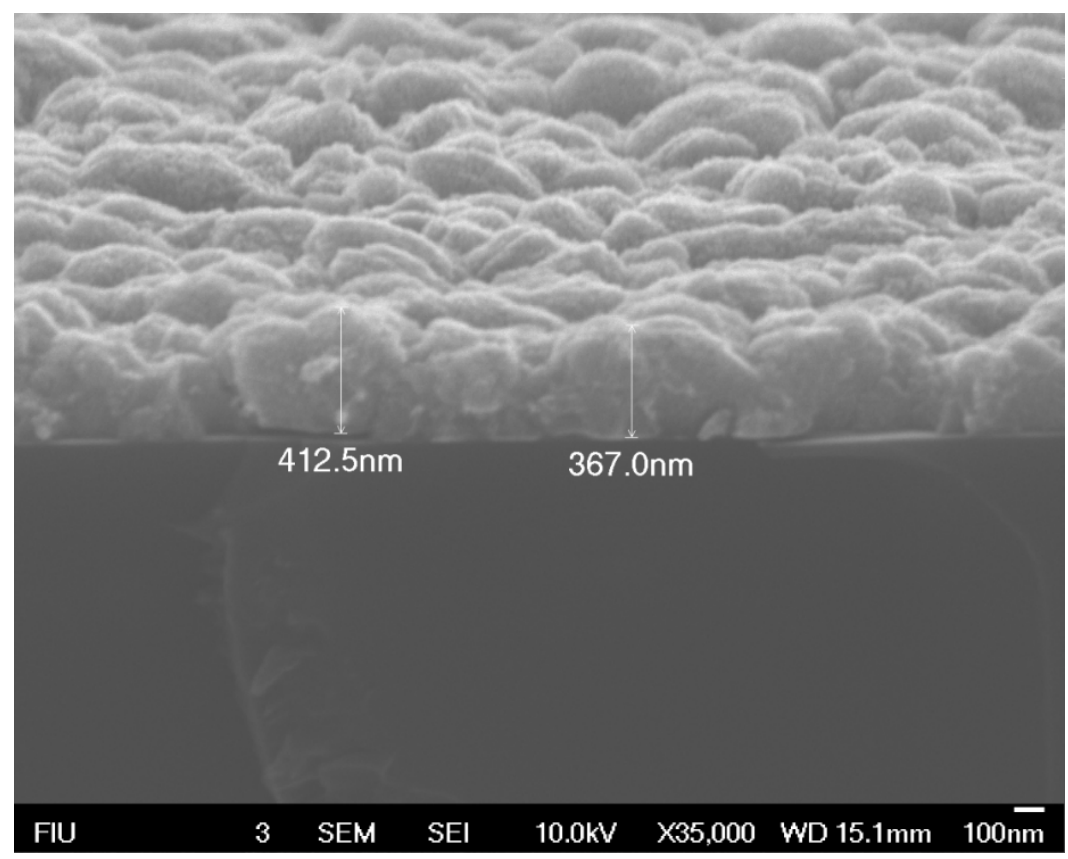

Figure 3.3. Cross- sectional view of $\mathrm{ZnO}$ seed layer on Si substrate. 
Following the seeding process, $\mathrm{ZnO}$ nanorods were synthesized by sonicating a mixture of $0.020 \mathrm{M}$ Zinc Nitrate Hexahydrate $(\mathrm{ZNH})$ and $0.020 \mathrm{M}$ Hexamethylene tetramine (HMT) solution in $100 \mathrm{ml}$ of deionized water (DI) at $50 \%$ amplitude $\left(\sim 20 \mathrm{~W} \mathrm{~cm}^{-}\right.$ ${ }^{2}$ ). The samples were rinsed with DI water and then dried in air after each cycle. When the solution containing $\mathrm{ZNH}$ and $\mathrm{HMT}$ in DI water is sonicated, $\mathrm{OH}, \mathrm{O}_{2}, \mathrm{HO}_{2}$ and $\mathrm{H}$ radicals are produced. The $\mathrm{OH}^{-}$ions are released by both water and HMT. The released $\mathrm{OH}^{-}$ions promote the precipitation of $\mathrm{ZnO}$ from $\mathrm{Zn}(\mathrm{OH})_{2}$. The detailed chemical reaction is shown below. [10]

$\left(\mathrm{CH}_{2}\right) \cdot 6 \mathrm{~N}_{4}+6 \mathrm{H}_{2} \mathrm{O} \rightarrow 4 \mathrm{NH}_{3}+6 \mathrm{HCHO}$

$\mathrm{NH}_{3}+\mathrm{H}_{2} \mathrm{O} \rightarrow \mathrm{NH}_{4}+\mathrm{OH}^{-}$

$\mathrm{Zn}\left(\mathrm{NO}_{3}\right) \cdot 6 \mathrm{H}_{2} \mathrm{O} \rightarrow \mathrm{Zn}^{2+}+2 \mathrm{NO}^{3-}$

$\mathrm{Zn}^{2+}+2 \mathrm{OH}^{-} \rightarrow \mathrm{Zn}(\mathrm{OH})_{2}$

$\mathrm{Zn}(\mathrm{OH})_{2} \rightarrow \mathrm{ZnO}+\mathrm{H}_{2} \mathrm{O}$

These reactions take place extremely slow under normal room temperature. A typical process takes 24 hours even at concentration of precursors above $10 \mathrm{~m} \mathrm{~mol}$. However under sonication, these reactions take place extremely fast which gives a growth rate as high as $10 \mathrm{~nm} / \mathrm{min}$. Apart from providing $\mathrm{OH}^{-}$ions, $\mathrm{HMT}$ also plays a vital role in directional growth of $\mathrm{ZnO}$ nanorods. HMT a long chain polymer and a nonpolar chelating attach to the nonpolar facets of Zinc Oxide there by cutting the supply of further $\mathrm{Zn}^{2+}$ ions as shown in figure 3.4. This leaves only the polar (0001) face for epitaxial growth. [11, 12] The topography and morphology of the nanorods was studied using Scanning electron microscopy (SEM) and Atomic force microscopy (AFM), shows that $\mathrm{ZnO}$ nanorods grow in vertical direction. 


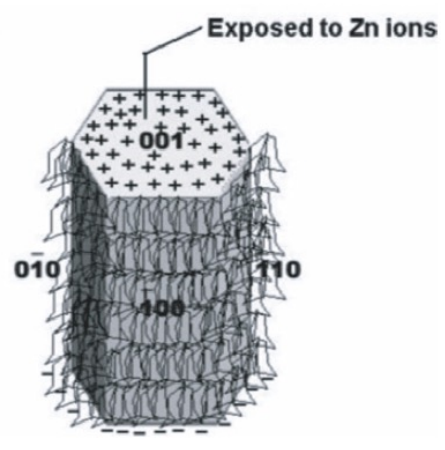

Figure 3.4. HMT attached to non- polar facets of $\mathrm{ZnO}$ resulting in a directional growth of $\mathrm{ZnO}$ nanorod
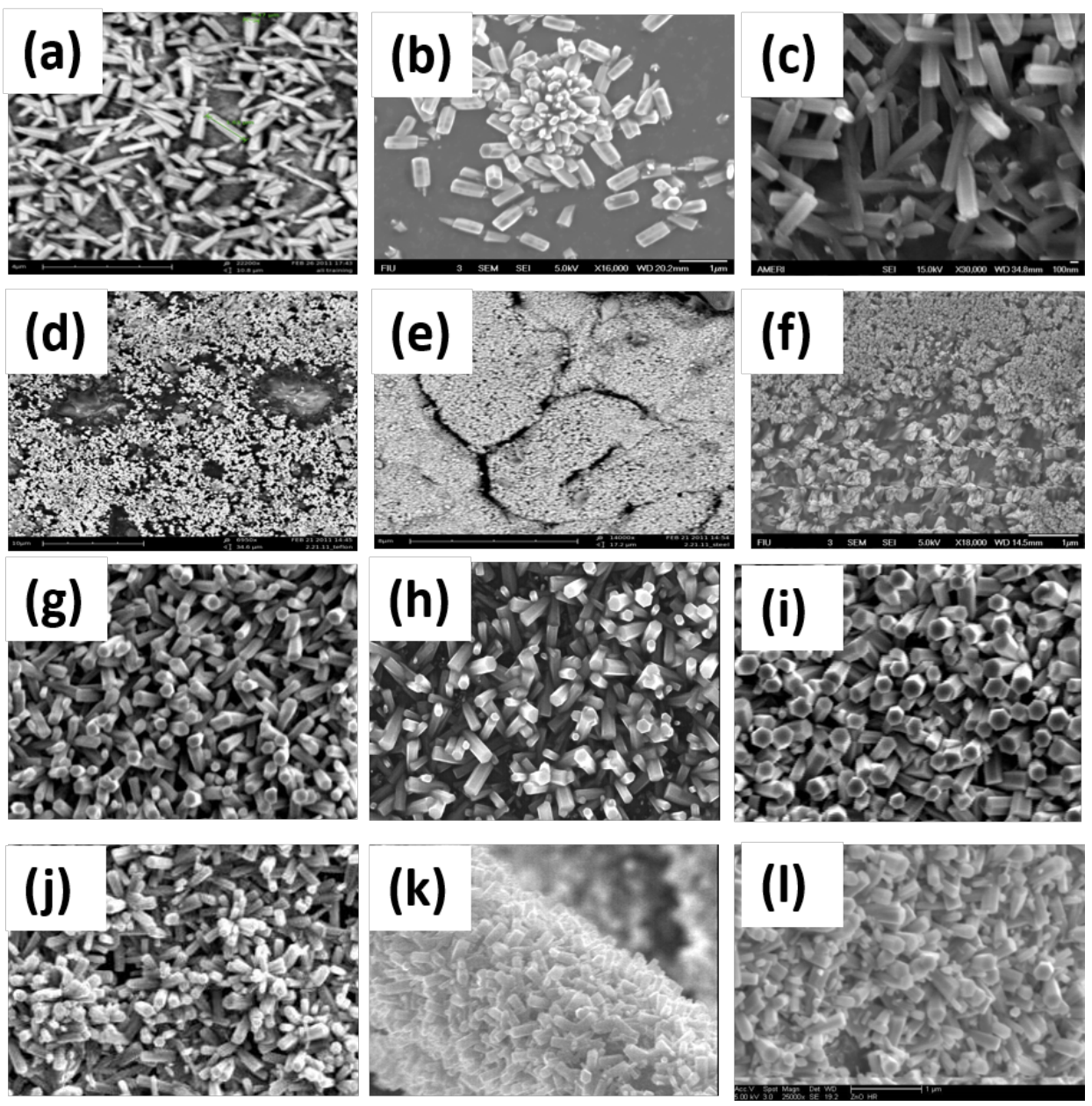

Figure 3.5 shows the SEM images of Sonochemically grown $\mathrm{ZnO}$ nanorods on (a) Silicon (b) $\mathrm{SiO}_{2} /$ $\mathrm{Si}$ (c) Ni/Fe alloy (d) Teflon (f) Copper (g) Iron (h) ITO (i) Sapphire (j) Kaplan tape (k) cotton fiber (1) PET 
To understand the effect of number of cycles and the duration of each cycle, $\mathrm{ZnO}$ NRs were grown by sonicating the solution with constant concentration over varying times and cycles. It was observed from the SEM pictures that the length of nanorods increases with the duration of each cycle as the rod length increases from $500 \mathrm{~nm}$ after 15 minutes of growth to $750 \mathrm{~nm}$ after 30 minutes of growth.
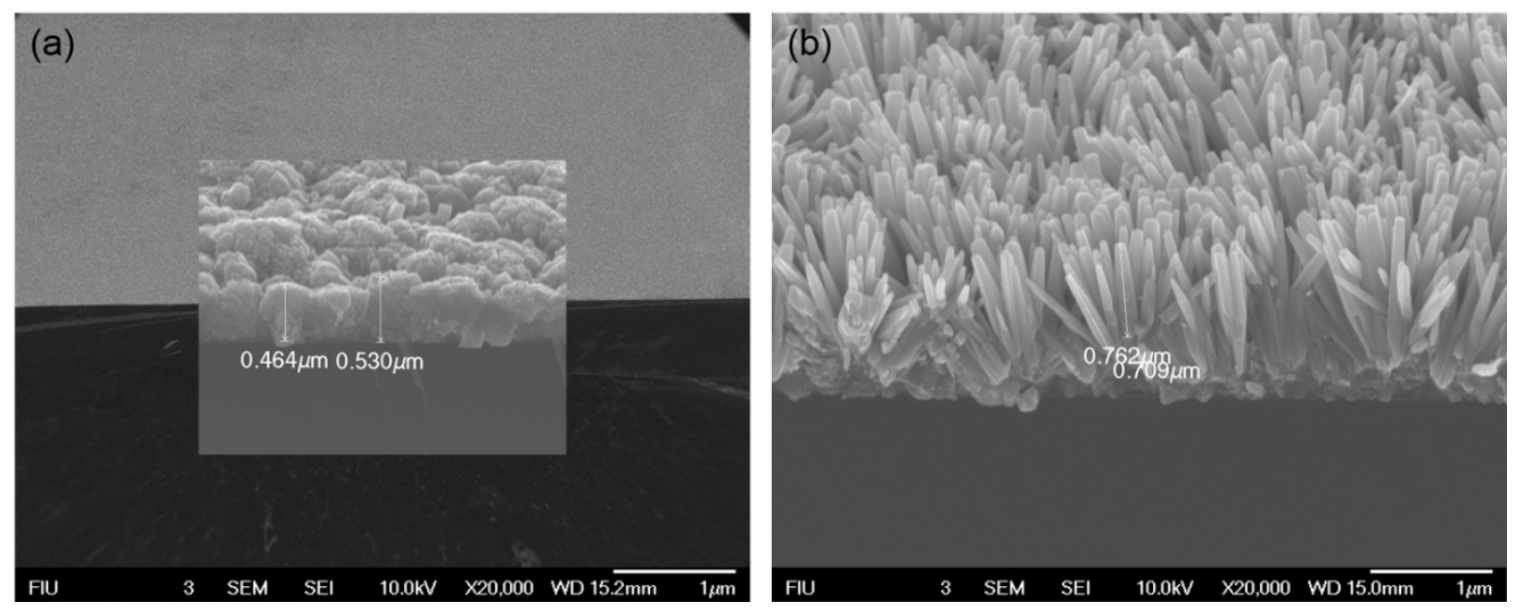

Figure 3.6 (a) $\mathrm{ZnO}$ nanorods after 15 minutes of growth (b) $\mathrm{ZnO}$ nanorods after 30 minutes of growth

The length also increases with increase in cycles as it increases from $0.36 \mu \mathrm{m}$ for 5 cycles to $2 \mu \mathrm{m}$ for 26 cycles. The increase in diameter with number of cycles is more conservative however, as it was observed that the diameter plateaus around $50 \mathrm{~nm}$. The results of this study are plotted in figure 3.7

In summary, we have achieved control over the growth of $\mathrm{ZnO}$ nanorods as the density of growth can be increased with increase in number of cycles, while the duration of each cycle determines the length of the $\mathrm{ZnO}$ nanorods. $\mathrm{ZnO}$ nanorods as long as $3 \mu \mathrm{m}$ 
can be achieved while keeping the diameter constant at $50 \mu \mathrm{m}$ which gives high surface to volume ratio.

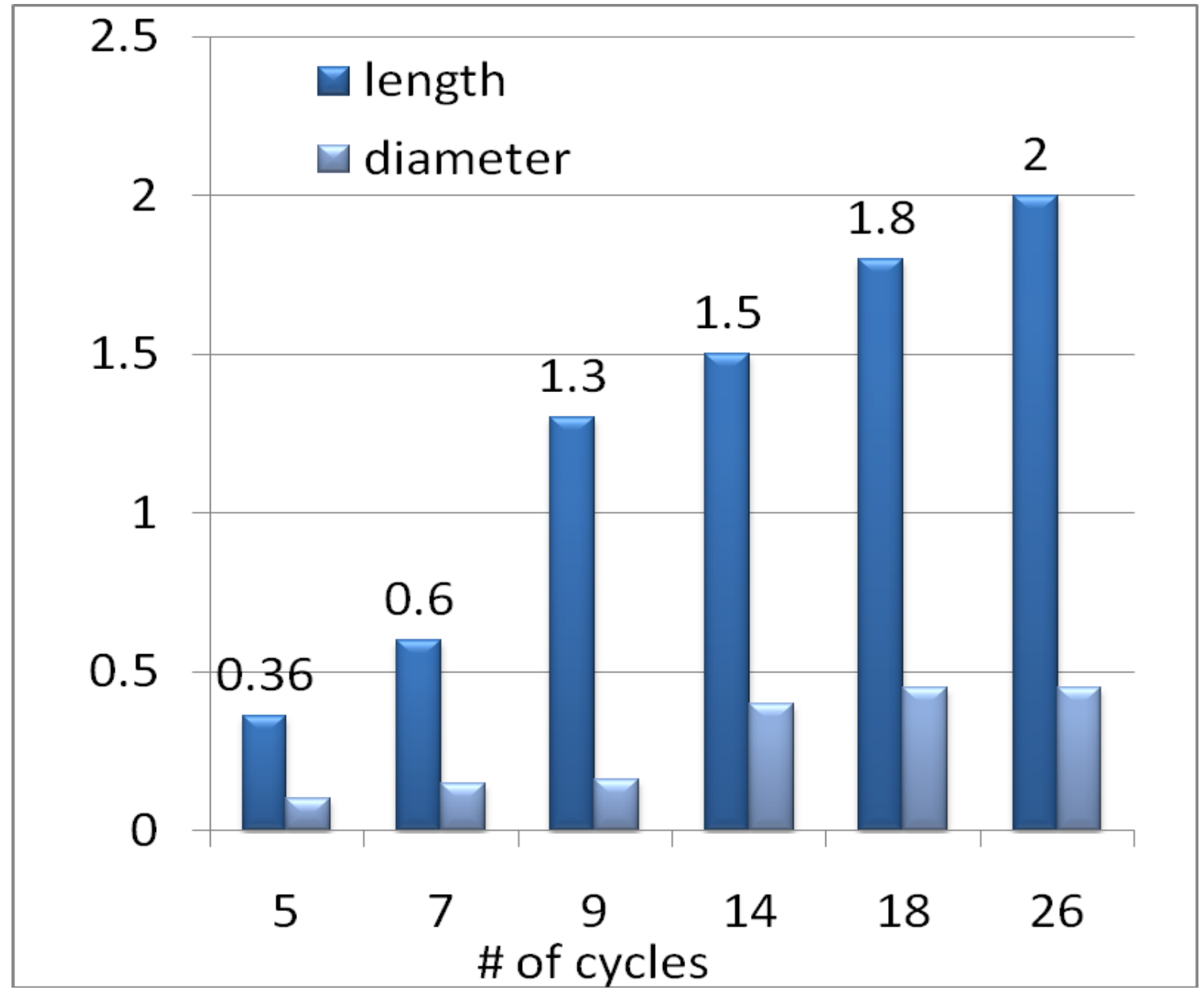

Figure 3.7. Change of dimensions with growth cycles in $\mathrm{ZnO}$ nanorods

\subsubsection{Properties of ZnO Nanorods}

Photo Luminescence (PL), X-ray diffraction (XRD) and Transmission electron microscopy were used to study the morphology and crystallographic properties of $\mathrm{ZnO}$ nanorods. Figure $3.8 \mathrm{~b}$ shows the $\mathrm{PL}$ of $\mathrm{ZnO}$ nanorods grown on ITO. It can be noted that the spectrum 
is comparable to the catalyzed growth on 'Ag' and ' $\mathrm{Zn}$ ' coated substrates which have shown to result in high quality $\mathrm{ZnO}$ nanostructures. The intensity of $380 \mathrm{~nm}$ peak observed is significantly higher than the defect peak at $550 \mathrm{~nm}$.[13] This suggests that sonochemical synthesis results in high quality, low defect nanorods unlike other solution methods.
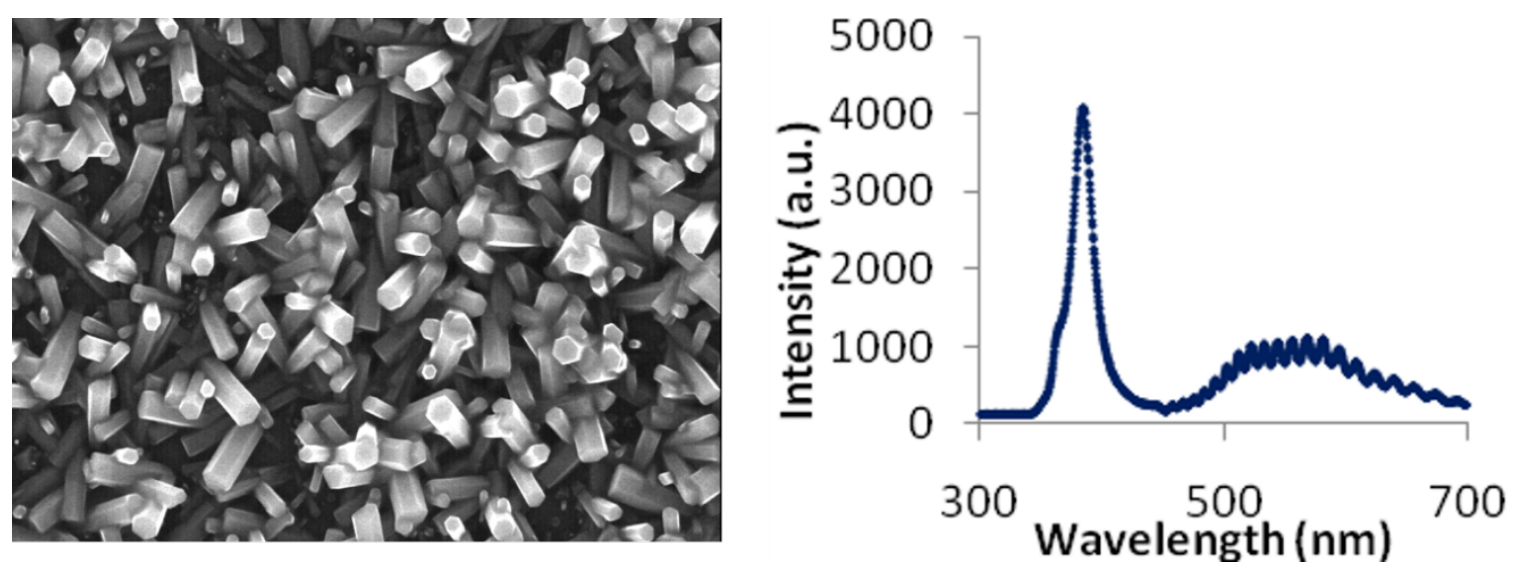

Figure 3.8. (a) $\mathrm{ZnO}$ nanorods on ITO (b) $\mathrm{PL}$ of $\mathrm{ZnO}$ nanorods showing a significant peak at $380 \mathrm{~nm}$.

Further structural analysis was performed by transmission electron microscopy (TEM). Figure 3.9 (a) shows the selected area diffraction pattern (SAED) which confirms the single crystalline wurtzite structure of the $\mathrm{ZnO}$ nanorods with a dominant growth direction along (0002) plane. The same can be confirmed from the HRTEM image shown in figure 3.9 (b). The HRTEM images show that the synthesized nanorods are structurally uniform and contain no defects such as dislocations and stacking with a measured lattice spacing of $\sim 0.5$ $\mathrm{nm}$ which corresponds to the d-spacing of (0002) crystal planes.

Figure 3.10 (a) shows the X-Ray diffraction pattern, which is a typical XRD pattern for hexagonal wurtzite $\mathrm{ZnO}$ nanorods. [14] Figure 3.10 (b) shows the Raman spectra 
obtained from $\mathrm{ZnO}$ nanorods grown over a Si substrate using a $532 \mathrm{~nm}$ laser. We observed a dominant $E_{2}$ (high) phonon peak at $436 \mathrm{~cm}^{-1}$ which is blue shifted by $3 \mathrm{~cm}^{-1}$ when compared to the bulk $\mathrm{ZnO}$. [15]

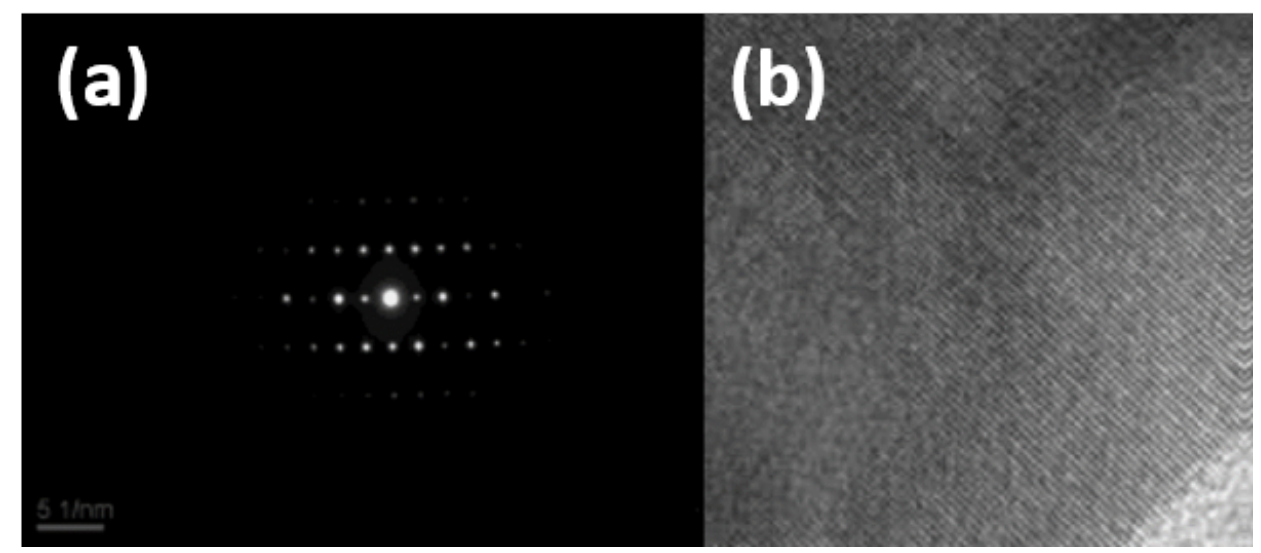

Figure 3.9 (a) SAED pattern of $\mathrm{ZnO}$ nanorod $\quad$ (b) HRTEM image of $\mathrm{ZnO}$ nanorod, both confirming the single crystal nature of the nanorod

The 'LO' phonon peaks observed in bulk material at $574 \mathrm{~cm}^{-1}$ which corresponds to longitudinal phonon vibrations were not observed in $1 \mathrm{D} \mathrm{ZnO}$ nanorods, as the incident light is perpendicular to the c-axis of wurtzite $\mathrm{ZnO}$.
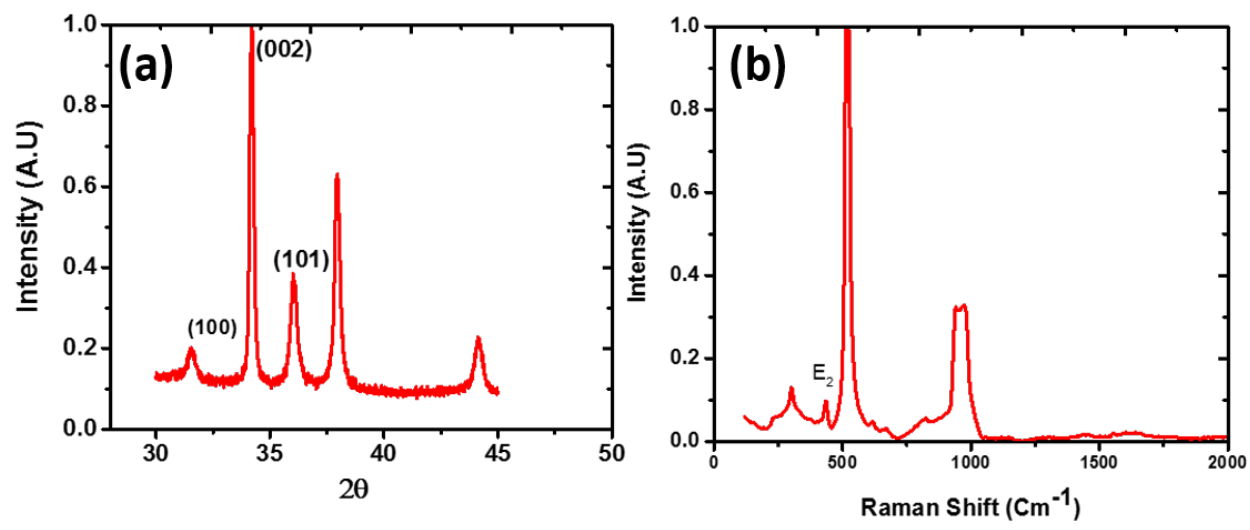

Figure 3.10 (a) XRD on $\mathrm{ZnO}$ nanorods showing a relatively high intensity (002) peak (b) Raman spectra of $\mathrm{ZnO}$ nanorods with $\mathrm{E}_{2}$ peak at $436 \mathrm{~cm}^{-1}$. 
The optical transmission spectra was measured using IPCE measurement system from PV measurements and is shown in figure 3.11 (a). To measure the transmission spectra and the dependence of transmission on the density and thickness of $\mathrm{ZnO}$ nanorods grown, we prepared two samples with $\mathrm{ZnO}$ nanorods grown in one and two cycles respectively over a glass substrate. A sharp valley denoting absorption is observed on the curve at $368 \mathrm{~nm}$ corresponding to the $3.37 \mathrm{eV}$ which agrees with the bandgap in $\mathrm{ZnO}$ nanorods reported in literature. [16] Figure 3.11 (b) shows the electrical response of $\mathrm{ZnO}$ nanorods in dark and under UV illumination.
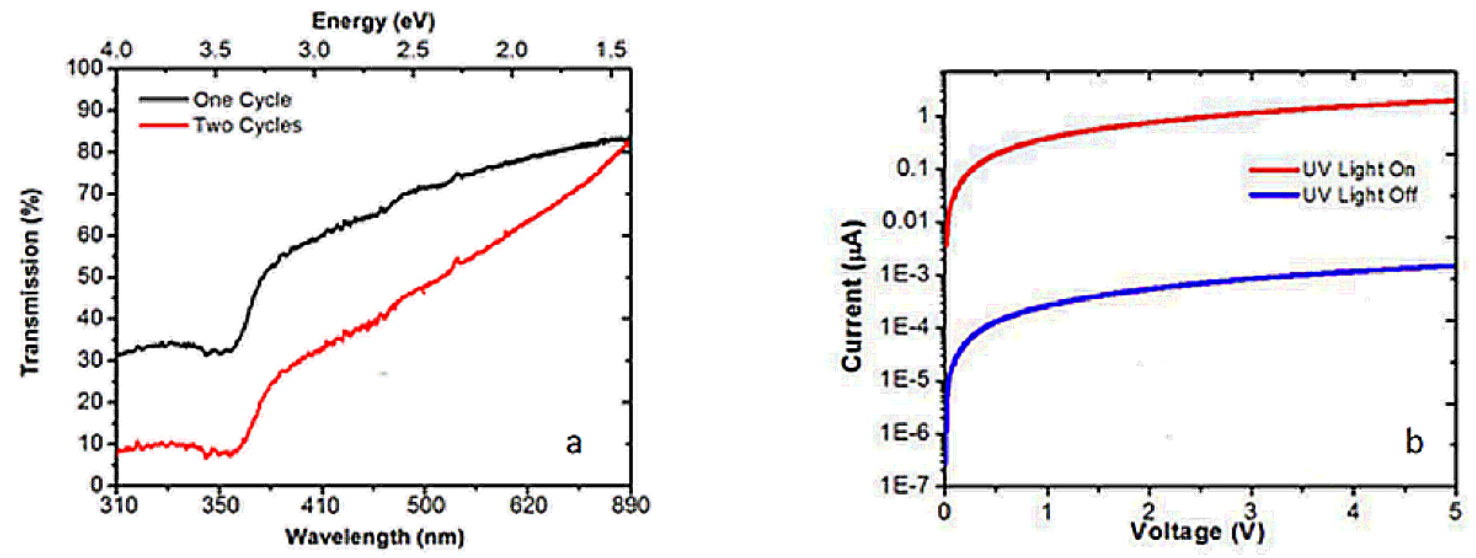

Figure 3.11 (a) Optical transmittance of $\mathrm{ZnO}$ nanorods, with the dip at $368 \mathrm{~nm}$, corresponding to the bandgap of $\mathrm{ZnO}$ nanorods (b) Current- Voltage measurements in dark and under UV light, $\mathrm{ZnO}$ nanorods show a 3 order magnitude gain in presence of UV light.

We observed a three order magnitude gain in current in the presence of UV light. This photo response is due to the fast carrier thermal excitation and trapping at the surface of $\mathrm{ZnO}$ nanorods. During the growth of $\mathrm{ZnO}$ nanorods, there is usually a high density of defects at the surface which traps holes and increases photocurrent response. When UV 
light is present, the photon energy is larger than the band gap of $\mathrm{ZnO}$ which generates electron hole pairs. While the high density surface trapping states are leaving the material, the photo-generated holes are trapped along the surface. The photo generated electrons are left unpaired and therefore contribute to the rapid increase in photocurrent. This property of $\mathrm{ZnO}$ has been used in many applications such as UV photodetectors, UV light emitting diodes and UV lasers.

\subsubsection{ZnO Core-Shell Nanorods}

Since the start of the century, researchers saw an increased interest in core-shell nanostructures such as core-shell microspheres, [17] nanotubes, [18] nanobelts, [19] nanorods [20] etc. Core-shell structures have shown to enhance the properties of semiconductor materials such as increased functionality, improved thermal and chemical stability, modulated band gap, improved efficiency in solar cells, increased storage capacity, and controlled drug delivery. [21-23] In this dissertation, we have used sonochemical method to develop $\mathrm{ZnO}-\mathrm{ZnO}$ homojunction nanorods and $\mathrm{ZnO}-\mathrm{ZnS}$ heterojunction nanorods.

\subsubsection{ZnO-ZnO Homojunction Nanorod}

Long has researchers controlled the growth direction of $\mathrm{ZnO}$ nanocrystals and growth kinetics of $\mathrm{ZnO}$ facets to synthesize diverse morphologies. Surfactants such as citrate ions were used to cap the basal plane of $\mathrm{ZnO}$ and thereby control the growth in ' $\mathrm{c}$ ' direction. However this method introduces unnecessary impurities in to the $\mathrm{ZnO}$ crystal, moreover it 
also introduces surface defects which increase the surface recombination when used in opto-electronic devices. In this dissertation, we have developed a sonochemical method to synthesize core-shell nanorods by varying the concentration of HMT (a surfactant in itself) to enhance the growth in planes other than c-direction. Core-shell nanorods were also synthesized by using citrate ions as surfactants for comparison purpose. Figure 3.12 (a-c) shows the SEM images of $\mathrm{ZnO}$ nanorods before and after the growth of $\mathrm{ZnO}$ shell using both citrate ions and HMT. Figure 3.13 (c) shows the TEM picture of $\mathrm{ZnO}-\mathrm{ZnO}$ coresshell nanorod grown by varying HMT concentration.
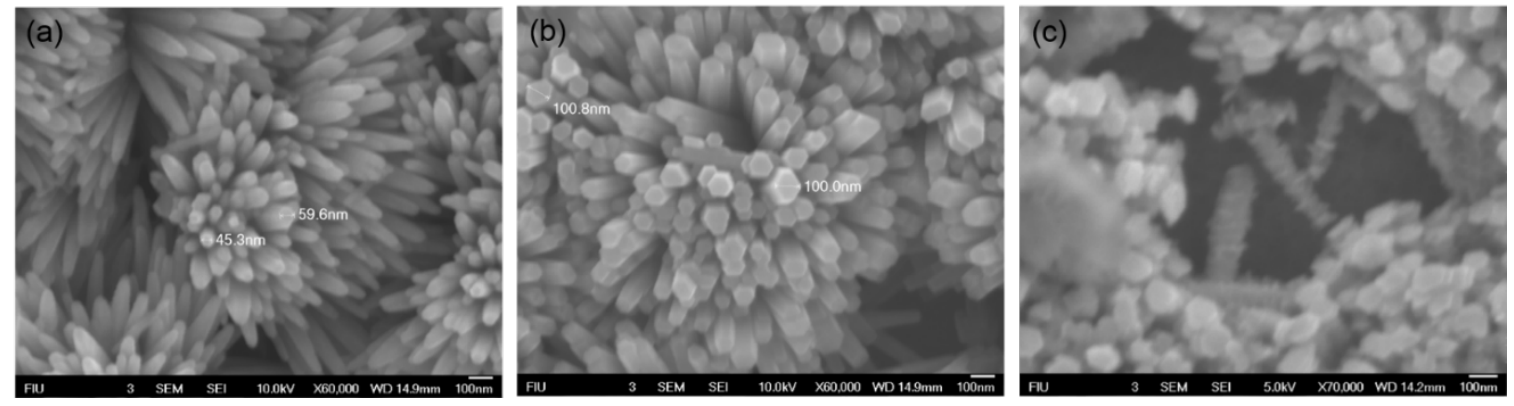

Figure 3.12 (a) $\mathrm{ZnO}$ nanorods grown by sonochemical method with an average diameter of $55 \mathrm{~nm}$ (b) $\mathrm{ZnO}-\mathrm{ZnO}$ core- shell nanorods grown by varying the ratio of ZNH and HMT with an average $60 \mathrm{~nm}$ shell thickness (c) Shell structure grown around $\mathrm{ZnO}$ rod by assistance of sodium citrate as surfactant
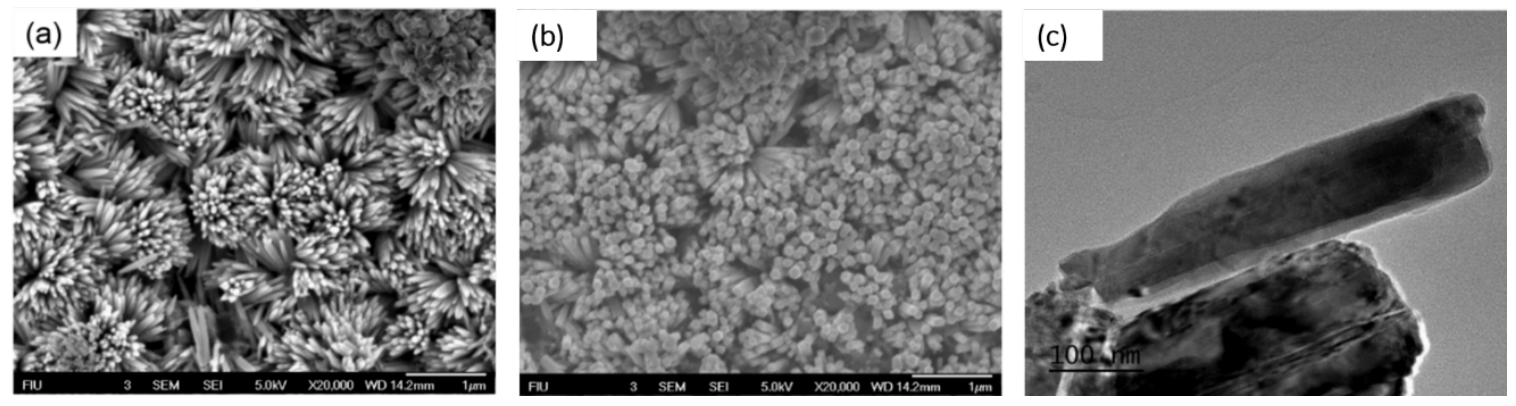

Figure 3.13 (a) $\mathrm{ZnO}$ nanorods grown by sonochemical method with an average diameter of $55 \mathrm{~nm}$ (b) $\mathrm{ZnO}-\mathrm{ZnO}$ core- shell nanorods grown by varying the ratio of ZNH and HMT (c) TEM image of $\mathrm{ZnO}-\mathrm{ZnO}$ core shell nanorod, clearly showing a shell encapsulating 60 nm thick nanorod 
From both SEM and TEM pictures we observe that the diameter of the $\mathrm{ZnO}$ core is $50 \mathrm{~nm}$ $60 \mathrm{~nm}$ and the thickness of shell to be $30 \mathrm{~nm}$. It can be observed that the latter case forms a much smoother and continuous interface between the core and shell. This structure will be used in formation of $\mathrm{p}-\mathrm{n}$ homojunction discussed in the proceeding chapters.

\subsubsection{ZnO-ZnS Heterojunction Nanorod}

$\mathrm{ZnS}$ a wide band gap semiconductor with a band gap of $3.7 \mathrm{eV}$ is a widely used luminescence material with applications in sensors and lasers. [24] Modifying the surface of $\mathrm{ZnO}$ by growing a $\mathrm{ZnS}$ shell around $\mathrm{ZnO}$ core is a well-recognized method to improve the functionality, chemical stability and optical response of the nanostructures, especially $\mathrm{ZnO}-\mathrm{ZnS}$ core shell structures were used to improve the performance of solar cells where $\mathrm{ZnS}$ acts as a barrier between electrons and holes and thereby reducing the recombination loses. [25, 26] Many researchers have reported the synthesis of $\mathrm{ZnO}-\mathrm{ZnS}$ core shell structures by sulfuration of $\mathrm{ZnO}$ core. However, there was no report known to have reported the growth of $\mathrm{ZnO}-\mathrm{ZnS}$ core-shell nanorods using sonochemistry. We have for the first time synthesized $\mathrm{ZnO}-\mathrm{ZnS}$ core- shell nanorods using sonochemistry.

The $\mathrm{ZnO}$ core material was synthesized as described in the earlier section. To develop $\mathrm{ZnS}$ shell, a solution of $0.6 \mathrm{M}$ sodium sulfide $\left(\mathrm{Na}_{2} \mathrm{~S}\right)$ solution was first prepared and then added drop wise to a solution of $0.02 \mathrm{M} \mathrm{ZnH}$ and $0.02 \mathrm{M}$ HMT until a $\mathrm{pH}$ value of $6.0-6.15$ is achieved. Already prepared substrate with $\mathrm{ZnO}$ nanorods is immersed in to 
this solution and sonicated for 15 minutes. During this process the Sulfur replaces 'O' from the outer surface of $\mathrm{ZnO}$ forming $\mathrm{ZnS}$ shell. The chemical reactions taking place are:

$$
\begin{aligned}
& \mathrm{Na}_{2} \mathrm{~S}+\mathrm{H}_{2} \mathrm{O} \rightarrow \mathrm{NaHS}+\mathrm{NaOH} \\
& \mathrm{NaHS}+\mathrm{H}_{2} \mathrm{O} \rightarrow \mathrm{H}_{2} \mathrm{~S}+\mathrm{NaOH} \\
& \mathrm{H}_{2} \mathrm{~S}+\mathrm{ZnO} \rightarrow \mathrm{ZnS}+\mathrm{H}_{2} \mathrm{O} \\
& \mathrm{NaHS}+\mathrm{ZnO} \rightarrow \mathrm{ZnS}+\mathrm{NaOH}
\end{aligned}
$$

Figure 3.14 (a-b) shows the SEM picture of $\mathrm{ZnO}-\mathrm{ZnS}$ nanorods grown by sonicating for different times and figure 3.14 (c) shows the XRD data from $\mathrm{ZnO}-\mathrm{ZnS}$ core shell nanorods. The peak at $2 \Theta=28^{\circ}$ indicates the formation of (111) plane of $\mathrm{ZnS}$.

(a)

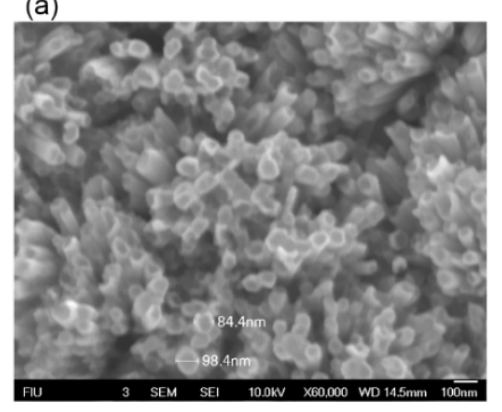

(b)

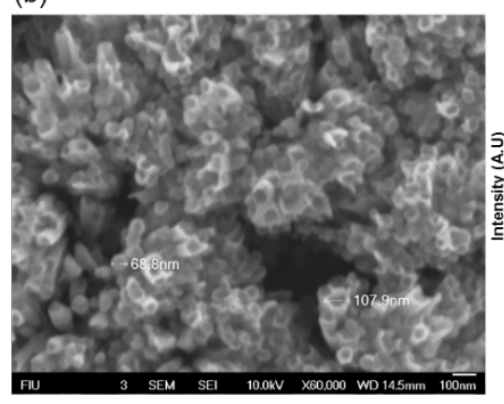

(c)

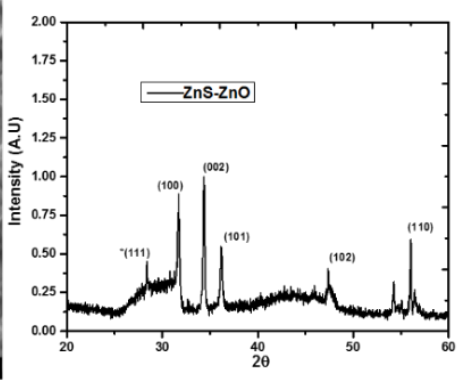

Figure 3.14 (a) $\mathrm{ZnO}-\mathrm{ZnS}$ core-shell nanorods, shell grown for 10 minutes resulting in a thin shell (b) With longer process time the shell thickness increases depleting the $\mathrm{ZnO}$ core (c) XRD data on a $\mathrm{ZnO}-\mathrm{ZnS}$ nanorods, a clear peak at $28^{\circ}$ indicating the successful formation of $\mathrm{ZnS}$

\subsubsection{ZnO Nanowalls:}

The same experimental procedure as above when performed over alumina $\left(\mathrm{Al}_{2} \mathrm{O}_{3}\right)$ and aluminum (Al) coated substrates resulted in growth of $\mathrm{ZnO}$ Nanowalls instead. We later observed that there is no need for seed layer deposition as well. Figure 3.15 shows $\mathrm{ZnO}$ 
Nanowalls grown over $6 \mathrm{~nm}$ thick 'Al' over silicon substrate. The growth is largely substrate dependent as such growth was not observed on any other substrate.

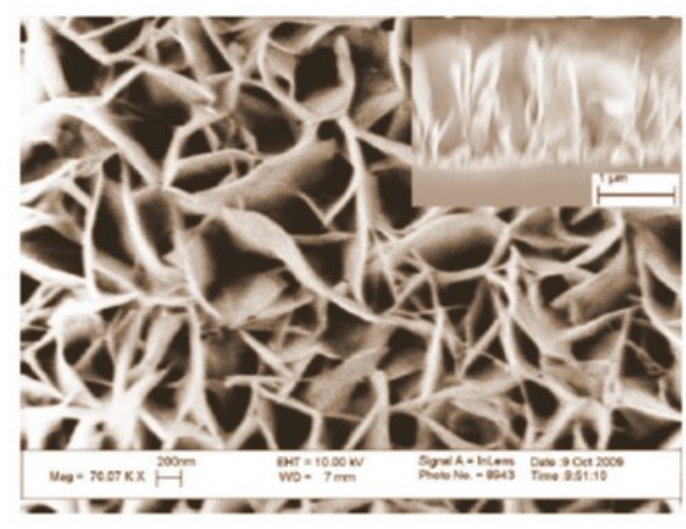

Figure 3.15. ZnO Nanowalls grown over 6nm thick Aluminum coated Si substrate

To further understand the growth mechanism and kinetics of this process we conducted time dependent study. ZnO NWs were grown over Al coated Si substrate for 3 minutes, 6 minutes, 9 minutes, 12 minutes, 15 minutes, and 60 minutes. The growth kinetics and morphological changes were studied under FESEM. As shown here in figure 3.16 (a-f) $\mathrm{ZnO}$ NWs forms within first 9 minutes and by 15 minutes a complete $\mathrm{ZnO} \mathrm{NW}$ network is formed. Further PL and Raman studies were used to study the growth mechanism. Figure 3.17 (a-b) shows the Photoluminescence (PL) and Raman spectroscopy of ZnO Nanowalls. The absorbance peak at $368 \mathrm{~nm}$ is observed as an indication of the inherent property of ZnO. The $378 \mathrm{~nm}$ PL peak is attributed to the free-exciton annihilation in $\mathrm{ZnO}$. [27] Vaneusden et al. show that the large green emission is related to a deep-level or trap-state emission. They suggest that the green PL in $\mathrm{ZnO}$ is due to the recombination of electrons in singly occupied oxygen vacancies with photo-excited holes in the valence band. [28, 29] 
Raman spectroscopy shows an emergence of a faint peak at $419 \mathrm{~cm}^{-1}$ at 15 minutes which indicates the presence of $\mathrm{ZnAl}_{2} \mathrm{O}_{4}$.
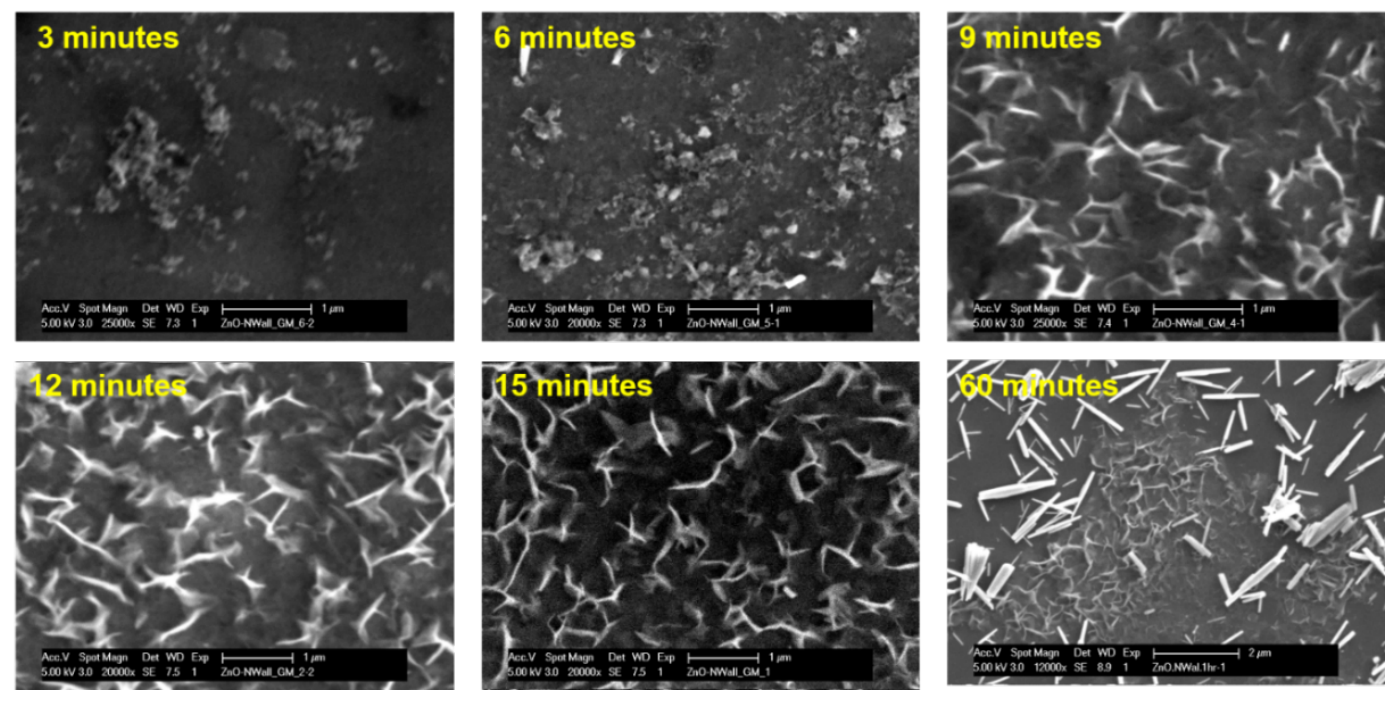

Figure 3.16. Growth kinetics of formation of $\mathrm{ZnO}$ Nanowalls at (a) 3 minutes (b) 6 minutes (c) 9 minutes (d) 12 minutes (e ) 15 minutes and (f) 60 minutes

(a)

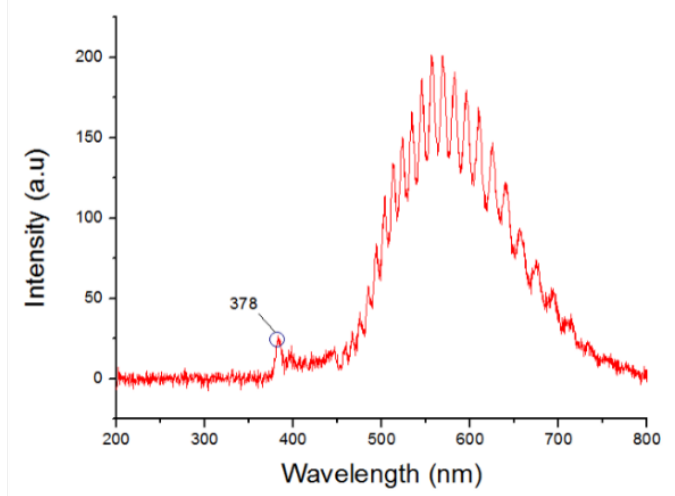

(b)

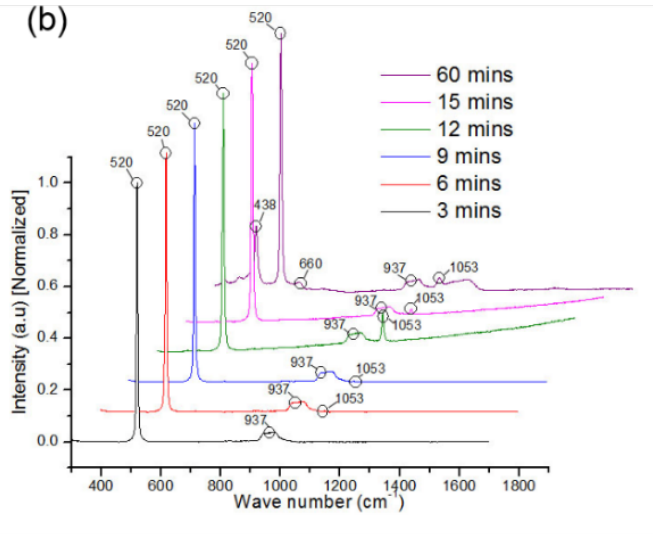

Figure 3.17 (a) the PL peak at $378 \mathrm{~nm}$ are a good indication of $\mathrm{ZnO}$ material. The visible peak is indicative of the defect levels commonly observed in $\mathrm{ZnO}$. (b) Raman peak intensity for 3 minute intervals and at 60 minutes. We observe a faint peak at $419 \mathrm{~cm}^{-1}$ at 15 minutes and a more distinct peak at $660 \mathrm{~cm}^{-1}$ is observed for $\mathrm{ZnAl}_{2} \mathrm{O}_{4}$. The $520 \mathrm{~cm}^{-1}$ peak is attributed to $\mathrm{Si}$, the $937 \mathrm{~cm}^{-1}$ is distinctive of $\mathrm{Zn}_{2} \mathrm{SiO}_{4}$. The incrementally increasing peak at $1053 \mathrm{~cm}^{-1}$ is attributed to dioxygen. The $438 \mathrm{~cm}^{-1}$ peak is attributed to $\mathrm{ZnO}$ 
From the PL and Raman measurements a possible growth mechanism was proposed as shown below.

$$
\begin{aligned}
& \left(\mathrm{CH}_{2}\right) 6 \mathrm{~N}_{4}+6 \mathrm{H}_{2} \mathrm{O} \rightarrow 4 \mathrm{NH}_{3}+6 \mathrm{HCHO} \\
& \mathrm{NH}_{3+} \mathrm{H}_{2} \mathrm{O} \rightarrow \mathrm{NH}^{++}+\mathrm{OH}^{-} \\
& \left.\mathrm{Zn}^{2} \mathrm{NO}_{3}\right) 6 \mathrm{H}_{2} \mathrm{O} \rightarrow \mathrm{Zn}^{2+}+2 \mathrm{NO}^{3-} \\
& \mathrm{Zn}^{2+}+2 \mathrm{OH} \rightarrow \mathrm{Zn}(\mathrm{OH})_{2} \\
& \mathrm{Zn}(\mathrm{OH})_{2} \rightarrow \mathrm{ZnO}+\mathrm{H}_{2} \mathrm{O}_{2} \\
& \mathrm{Al}+2 \mathrm{H}_{2} \mathrm{O} \rightarrow 1.5 \mathrm{H}_{2}+(\mathrm{AlO}) \mathrm{OH} \\
& \mathrm{Zn}(\mathrm{OH})_{2}+2 \mathrm{AlO}(\mathrm{OH}) \rightarrow \mathrm{ZnAl}_{2} \mathrm{O}_{4}+2 \mathrm{H}_{2} \mathrm{O}
\end{aligned}
$$

The induced high pressure and temperature from the cavitation bubble imploding produces $\mathrm{AlOOH}$ during cavitation. The zinc/aluminum interface allows for zinc aluminate $\left(\mathrm{ZnAl}_{2} \mathrm{O}_{4}\right)$ or "spinel" to form. [30] The reaction between $\mathrm{Zn}(\mathrm{OH})_{2}$ and $\mathrm{AlOOH}$ allows for the formation of $\mathrm{ZnAl}_{2} \mathrm{O}_{4}$, this zinc aluminate has been synthesized in a hydrothermal solution at high temperatures. [31] HMTA and $\mathrm{ZnAl}_{2} \mathrm{O}_{4}$ would then support the vertical growth $\{0001\}$ of $\mathrm{ZnO}$ Nanowalls. We find that the $\mathrm{ZnO}$ Nanowalls grow perpendicular to the alumina/spinel interface.

The crystal quality and orientation of the $\mathrm{ZnO}$ Nanowalls were studied by using selective area electron diffraction (SAED) using a $300 \mathrm{KV}$ transmission electron microscope (TEM). Figure 3.18 (a-c) shows the lamella extracted using focused ion beam (FIB) tool along with TEM image and SAED pattern. To ensure a single layer of nanowalls was characterized, we extracted a thin lamella using focused ion beam (FIB) tool and measured SAED at the very edge of the sample. SAED patterns show that the nanowalls are single crystalline throughout the sample. 


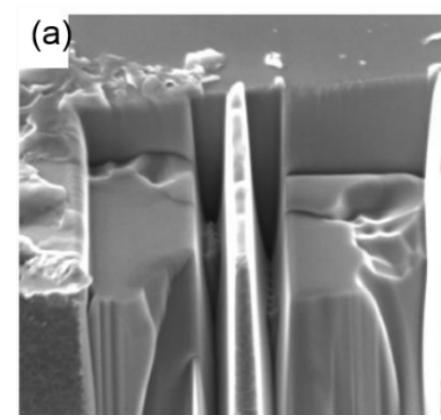

(b)

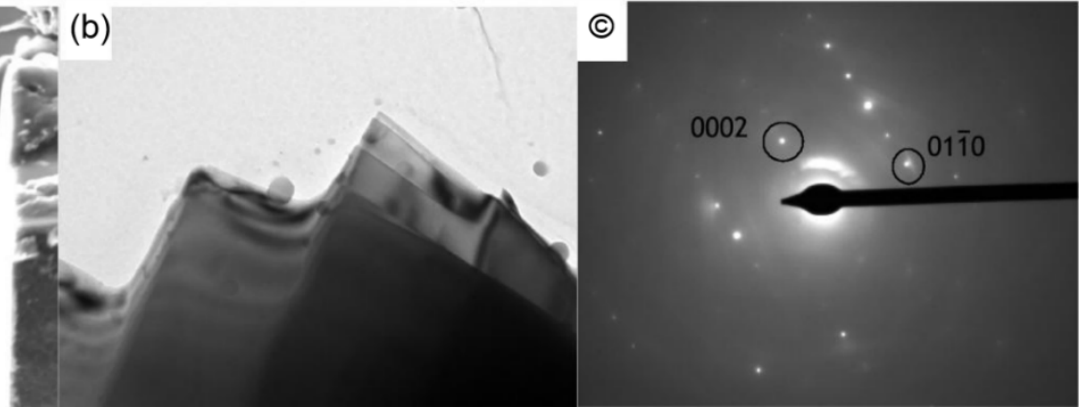

Figure 3.18 (a) SEM picture of the FIB prepared lamella of the $\mathrm{ZnO}$ Nanowalls on $\mathrm{Al}$ coated Si substrate (b) TEM image of Nanowalls (c) SAED pattern of ZnO NWs confirming the single crystalline nature of $\mathrm{ZnO}$ NWs

Current-voltage characteristics of $\mathrm{ZnO}$ nanowalls measured at dark and under UV illumination are shown in Figure 3.19.

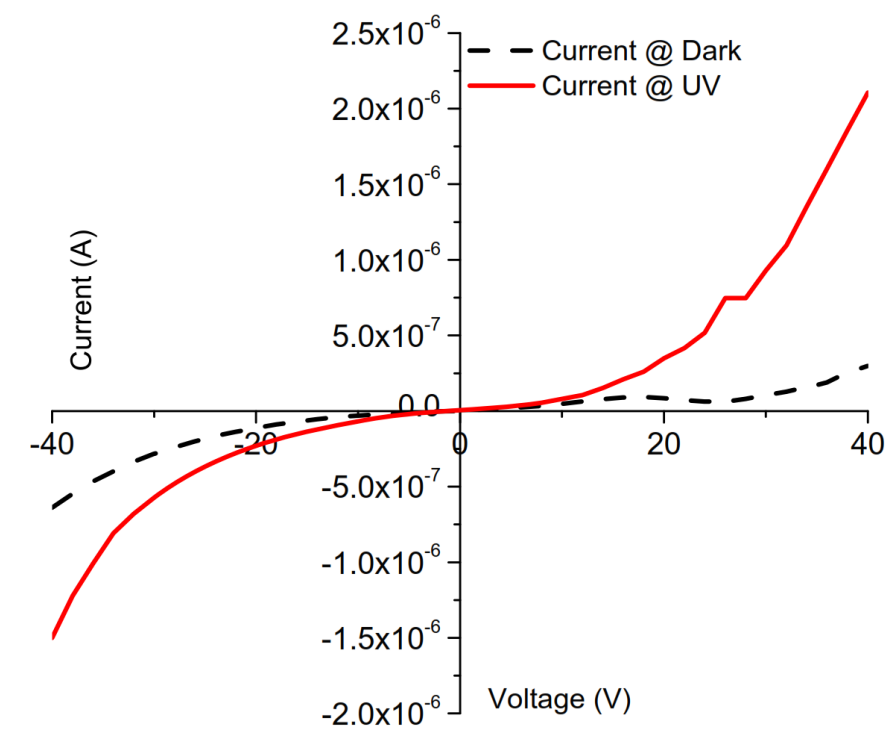

Figure 3.19. Current voltage characteristics of $\mathrm{ZnO}$ nanowalls measured at dark and under UV illumination.

The measurements were taken on nanowalls synthesized on $10 \mathrm{~nm}$ thick patterned 'Al' electrodes on a Si substrate with a separation distance of $\sim 50 \mu \mathrm{m}$ between the two tungsten probe tips. The grown $\mathrm{ZnO}$ nanowalls show a very low conductivity which was 
also observed and reported by Lee et al. who grew $\mathrm{ZnO}$ nanowalls using low pressure MOVPE.[32] The reason for low conductivity even in the presence of ultraviolet (UV) light can be attributed to the formation of $\mathrm{ZnAl}_{2} \mathrm{O}_{4}$ during the growth of the nanowalls. It has been reported that $\mathrm{ZnAl}_{2} \mathrm{O}_{4}$ is lower in electrical conductivity than $\mathrm{ZnO}$ and other oxide mixtures. [33] The clear UV photoresponse is typical of $\mathrm{ZnO}$ material. Although a 0.1 $\mathrm{W} / \mathrm{cm}^{2}$ intensity UV light was exposed to the nanowall sample, we observe only one magnitude difference in the conductivity. A high photoconductive gain is usually reported for $\mathrm{ZnO}$ material. [34] We do not observe this in case of $\mathrm{ZnO}$ nanowalls.

\subsubsection{ZnO Nanoflakes}

We have synthesized extremely thin $2 \mathrm{D} \mathrm{ZnO}$ nanoflakes on arbitrary substrates for the first time using sonochemical method. This method is a one step process which does not require a seed layer. This process was successfully tested on various substrates such as Si, PET and graphene. Growth of $\mathrm{ZnO}$ nanoflakes draws heavily upon the process used for nanorod growth. However no seed layer is required for this process and can be grown on most substrates available. The precursors used in this method are $0.2 \mathrm{M} \mathrm{ZNH}$ and $0.2 \mathrm{M}$ HMT. A solution of $0.2 \mathrm{M} \mathrm{ZNH}$ and $0.2 \mathrm{M}$ HMT was prepared at room temperature by stirring with a magnetic stirrer at $350 \mathrm{rpm}$ for 5 minutes to ensure a homogeneous solution. The substrates cleaned with acetone, isopropanol and finally with DI water were immersed in the as prepared solution and irradiated using the same ultra sound set up used for $\mathrm{ZnO}$ nanorod growth. However the amplitude of sonication is set at $70 \%$ which results in $\sim 30$

$\mathrm{W} \mathrm{cm}{ }^{-2}$ of energy. After the running a cycle for 15 minutes, the samples were cleaned with DI water and dried in air. For improving the density of growth, this process is repeated for 
further cycles. This process results in extremely thin hexagonal shaped nano crystals which eventually self-assemble in to parallelogram shaped $\mathrm{ZnO} \mathrm{NFs}$. It was observed that the thickness of the nanoflakes increase with the duration of each cycle with the thinnest flake measuring as thin at $12 \mathrm{~nm}$ and the thickest around $200 \mathrm{~nm}$.

The synthesis process of $\mathrm{ZnO}$ nanoflakes differs from nanorod growth only in terms of the concentration of the precursors primarily. The concentration of ZNH and HMT are increased 10- 20 times and the sonication amplitude to $70 \%$. The higher concentrations and the fast reaction rates achieved under intense cavitation causes HMT (was primarily used as shape inducing polymer in nanorod growth) to release a large amounts of $\mathrm{OH}^{-}$and $\mathrm{NH}_{4}{ }^{+}$ ions in a short period of time resulting in precipitation of $\mathrm{Zn}^{2+}$ ions at a phase much higher than the surface adhesion rate of HMT to the non- polar facets of $\mathrm{ZnO}$. $[35,36]$ This results in growth of nonpolar planes of $\mathrm{ZnO}$ along with the (0001) plane, forming parallelogram shaped 2D ZnO nanoflakes. To further understand the crystallization and growth process, time dependent study of SEM images along with TEM and HRTEM was studied. Figure $3.20(a-b)$ shows the SEM pictures of $\mathrm{ZnO}$ nanoflakes grown on Si substrate at 30 seconds and 60 seconds respectively. From the SEM images we can observe that the $2 \mathrm{D} \mathrm{ZnO}$ nanoflakes grows initially in the form of thin sheets and then self assembles in to hexagonal crystal structures which further stabilizes in to parallelogram like structures. To further study the growth dynamics, samples were imaged at different time intervals of growth from 1 minute to 60 minutes. Figure 3.20 (b-e) shows the time evolution of the growth process for $\mathrm{ZnO}$ nanoflakes on Si substrate at 1, 3, 15 and 30 minutes respectively. Further SAED and HRTEM were used to identify the crystal edges of the $\mathrm{ZnO}$ nanoflakes as shown in 
figure 3.21. On the basis of SEM, HRTEM and SAED data we infered that the anisotropic growth of $\mathrm{ZnO}$ paves way for the observed morphology. This is explained in detail using figure 3.22. Initially, $\mathrm{ZnO}$ sheets are self- assembled in to hexagonal single crystalline structures with (0001) plane in c-direction. The crystal continues to grow in (01-10) direction which results in the disappearance of (01-1) plane and the resulting crystal takes the shape of more stable parallelogram. The longest edge is in (10-10) plane. It was observed that beyond a growth time, the crystal growth in lateral direction saturates beyond which, not much change in dimensions can be observed. Instead, new flakes start nucleating on the top of the old flakes which increases the thickness of the $\mathrm{ZnO}$ layer.
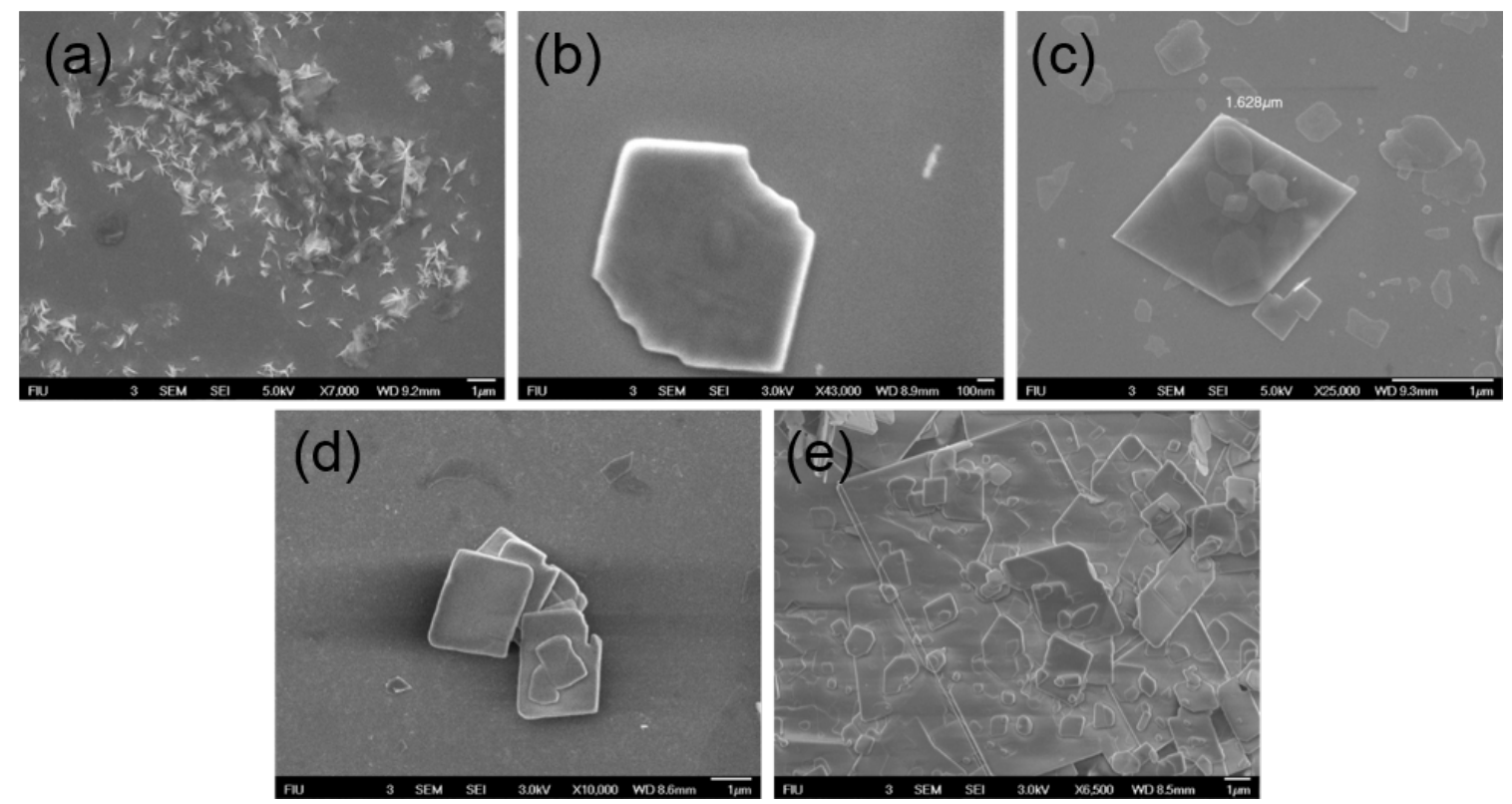

Figure 3.20 (a) $\mathrm{ZnO}$ nanoflakes grown over $\mathrm{Si}$ for 30 seconds (b) $\mathrm{ZnO}$ nanoflakes grown over Si for 60 seconds (c) $\mathrm{ZnO}$ nanoflakes grown over Si for 3 minutes (d) $\mathrm{ZnO}$ nanoflakes grown over $\mathrm{Si}$ for 15 minutes (e) $\mathrm{ZnO}$ nanoflakes grown over $\mathrm{Si}$ for 30 minutes 

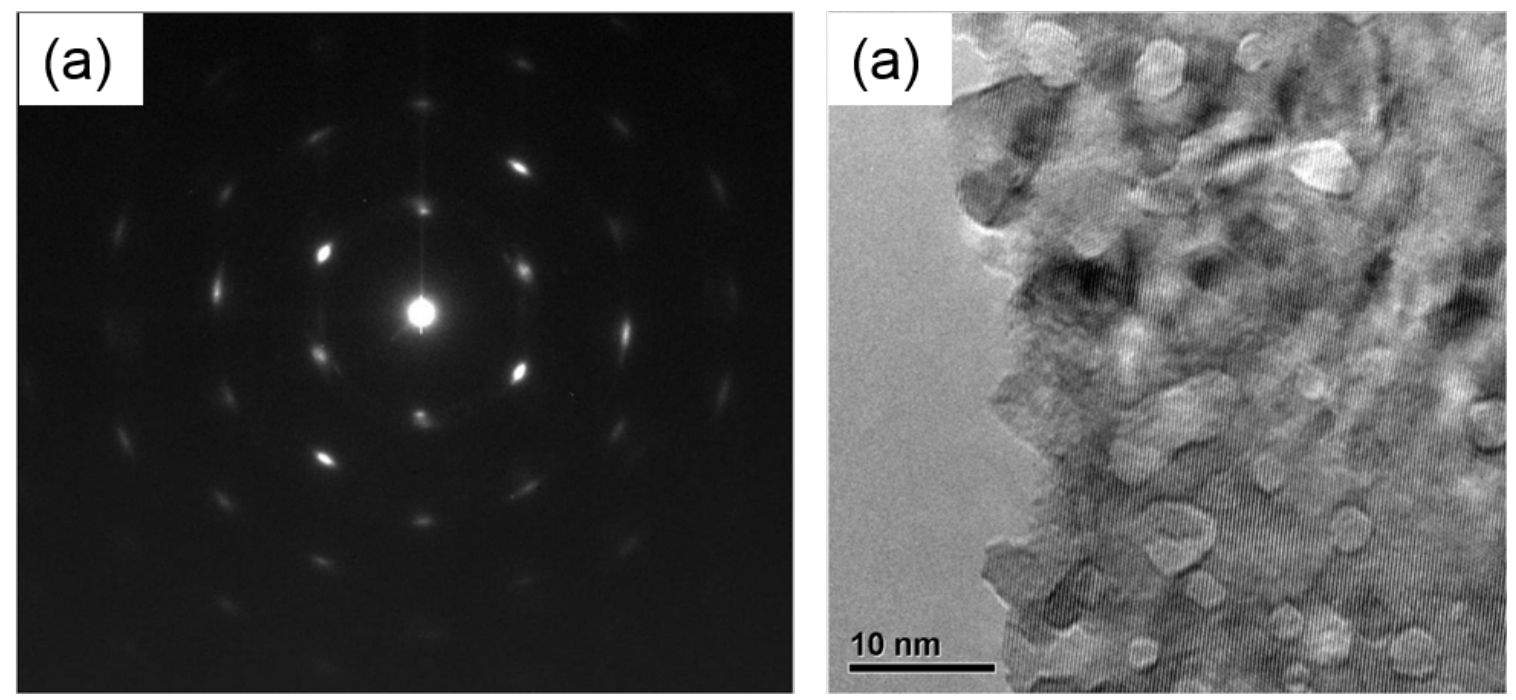

Figure 3.21 (a) SAED pattern showing a single crystalline wurtzite structure oriented in $<0001>$ direction and lateral growth direction perpendicular to (0110) (b) HRTEM at the edge of a flake with fringes almost parallel to the edge with a spacing of $2.74 \AA$, which is close to $2.82 \AA$ of (1010) plane

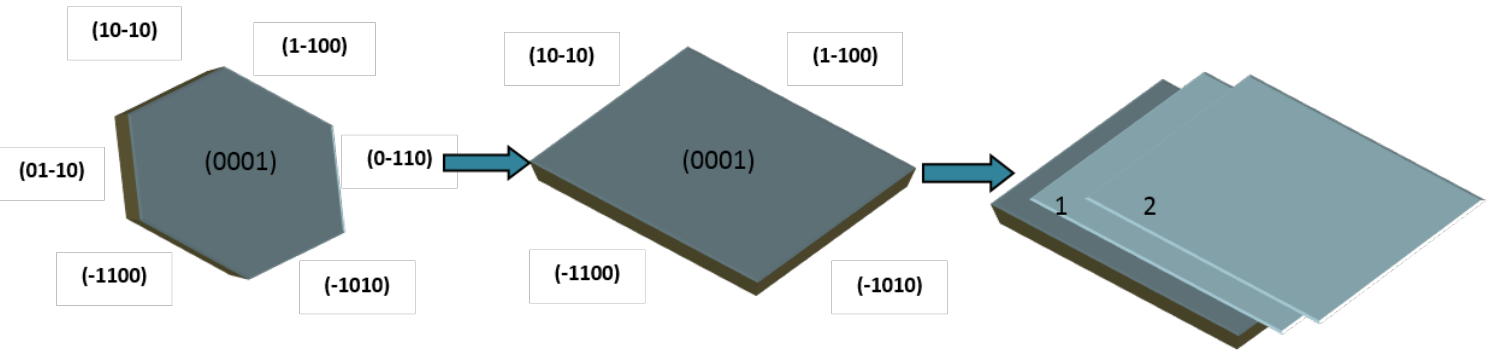

Figure 3.22 Schematic of the growth mechanism of $\mathrm{ZnO}$ nanoflakes showing the growth from hexagonal structure to parallelogram structure and further increase in thickness as new layers are formed

Figure 3.23 summarizes the change of lateral dimensions and the thickness of the flakes by growth period. The thickness measurements were carried out using AFM, while lateral dimensions were measured using SEM. Sizes of several flakes have been averaged to have 
statistically reliable data. The average thickness of the nanoflakes layer varies from $15 \mathrm{~nm}$ of single flake to $300 \mathrm{~nm}$ of a stack of several flakes for a growth time of 10 minutes and two cycles of 30 minutes each. However, the thickness of a single nanoflakes remains constant around 15-20 nm irrespective of the duration of each cycle. The lateral dimensions increases quickly form $0.76 \mu \mathrm{m}$ for growth time of 1 minute to $10 \mu \mathrm{m}$ at 15 minutes and remains the same as the time is increased. Therefore by controlling the time of each cycle and the number of cycles, the lateral dimensions, thickness and density of growth can be efficiently controlled using sonochemical method.

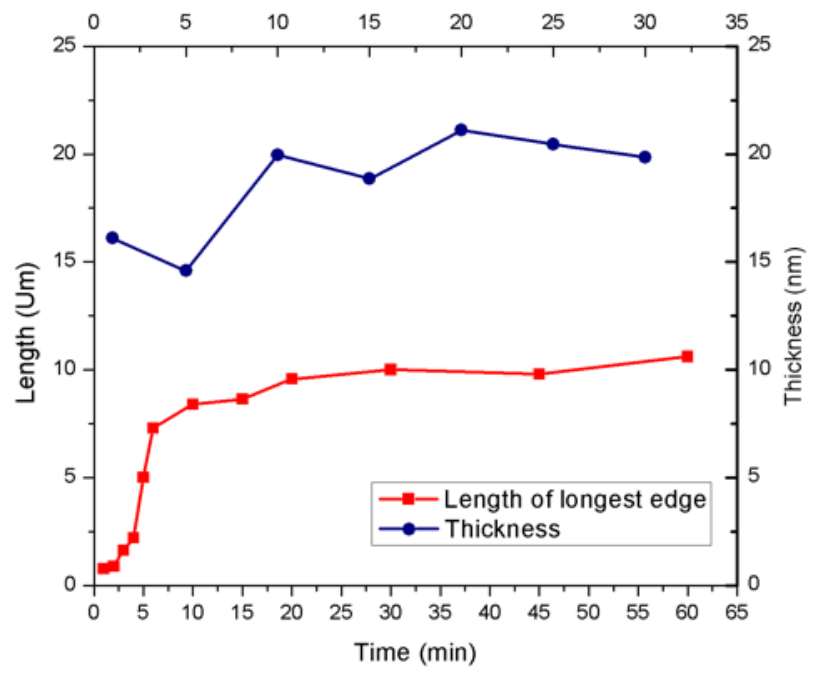

Figure 3.23 Evolution of length and thickness of the flakes by time showing that the lateral dimensions of the flakes increases rapidly to around $10 \mu \mathrm{m}$ at around $15 \mathrm{~min}$ and then stabilizes. The thickness of the single flakes remains constant around $20 \mathrm{~nm}$

\subsubsection{Properties of ZnO Nanoflakes}

SAED, HRTEM, EDS, PL and Raman studies were conducted to study the crystallographic properties of the as grown $\mathrm{ZnO}$ nanoflakes. SAED pattern and HRTEM image confirm the 
single- crystalline wurtzite structure of $2 \mathrm{D} \mathrm{ZnO}$ nanoflakes oriented in [0001] direction. The HRTEM images are taken at the major edge of the flake show that the fringes are almost parallel to the edge with a lattice spacing $2.74 \AA$. This lattice spacing is a representative of (10-10) plane which corresponds to the longest edge. The SAED measurements indicate that the nanoflakes exhibit hexagonal wurtzite structure with a= $3.25 \AA$ and $\mathrm{c}=5.21 \AA$, oriented along (0001) plane. The photoluminescence (PL) spectra is shown in figure 3.24 (a) shows an emission line at $376 \mathrm{~nm}$, which is characteristics of wurtzite $\mathrm{ZnO}$. The peak intensity is relatively low due to extremely thin nature of the nanoflakes. The $376 \mathrm{~nm}$ PL peak is attributed to the free- exciton annihilation in $\mathrm{ZnO}$. [37] The PL system used in this study upconverts the frequency from green light $(532 \mathrm{~nm})$ which causes the high- intensity stray green light, making it difficult to observe green PL emission. Raman spectra of $\mathrm{ZnO}$ nanoflakes is measured using $532 \mathrm{~nm}$ laser, is shown in figure 3.24 (b). Unlike in $1 \mathrm{D} \mathrm{ZnO}$ nanorods, the prominent peak in $2 \mathrm{D} \mathrm{ZnO}$ nanoflakes is not $\mathrm{E}_{2}$ (high) but the highest intensity is observed at second order longitudinal phonon vibration (2LO) at $1050 \mathrm{~cm}^{-1}$ which is due to the confinement in 'c' direction.
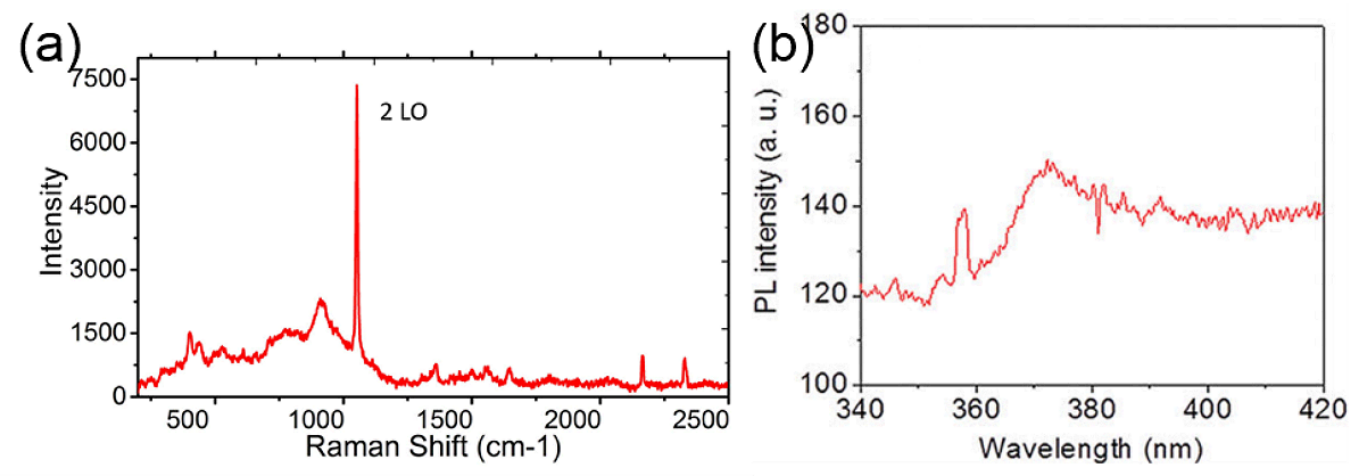

Figure 3.24 (a) Raman spectrum of $\mathrm{ZnO}$ on $\mathrm{Si}$, a strong second order longitudinal phonon vibration peak characteristic of confinement in c direction is observed at $1050 \mathrm{~cm}^{-1}$ (b) PL spectrum of the $\mathrm{ZnO}$ nanoflakes on graphene shows a peak at $376 \mathrm{~nm}$. 
In order to study the conductivity of the individual $\mathrm{ZnO}$ nanoflakes and the variation of conductance with the thickness, three samples Z-3, Z-5 and Z-15 were prepared by growing $\mathrm{ZnO}$ nanoflakes on $\mathrm{Si} / \mathrm{SiO}_{2}$ substrate with growth cycle of 3 minutes, 5 minutes and 15 minutes duration respectively. Electrical contacts were deposited using a focused ion beam (FIB) and I-V characteristics were measured using a probe station (The micromanipulator and results analyzed by semiconductor parameter analyzer, model no. Agilent $4156 \mathrm{~A}$ ) attached with micromanipulator tip (model 7A-M) as shown in figure 3.25 (a). It can be observed that the I-V curves show slightly super linear behavior and the conductance increases with the increase in thickness of $\mathrm{ZnO}$ nanoflakes. Super linear behavior is attributed to space-charge limited current (SCLC), which is commonly observed in nanostructures of various materials including $\mathrm{ZnO}$ nanowires. [38] When the number of carriers injected from contacts is greater than the free carriers in the semiconductors, the current is limited by the buildup of injected space charge. Since SCLC is sensitive to the density of trap states and their energy depth, it can be prominently observed in 2D structures with large surface to volume ratio. Photoconductivity was measured on sample 3Z-15. 3Z-15 is prepared by running 3 cycles of 15 minutes each. This ensured a continuous film growth on $\mathrm{Si} / \mathrm{SiO}_{2}$ substrate. Figure 3.16 (b) shows the current -voltage curves for the said sample in dark and in presence of UV light. A 10 fold increase in conductance in the presence of UV light is observed, a characteristic of $\mathrm{ZnO}$ nanostructures caused by the fast carrier thermal excitation and trapping at the surface of $\mathrm{ZnO}$ nanoflakes. In the presence of UV light the photon energy is larger than the band gap of $\mathrm{ZnO}$ which generates electron hole pairs. The photo generated electrons are left unpaired 
and therefore contribute to the rapid increase in photocurrent. This property of $\mathrm{ZnO}$ was observed in other nanostructures as well.
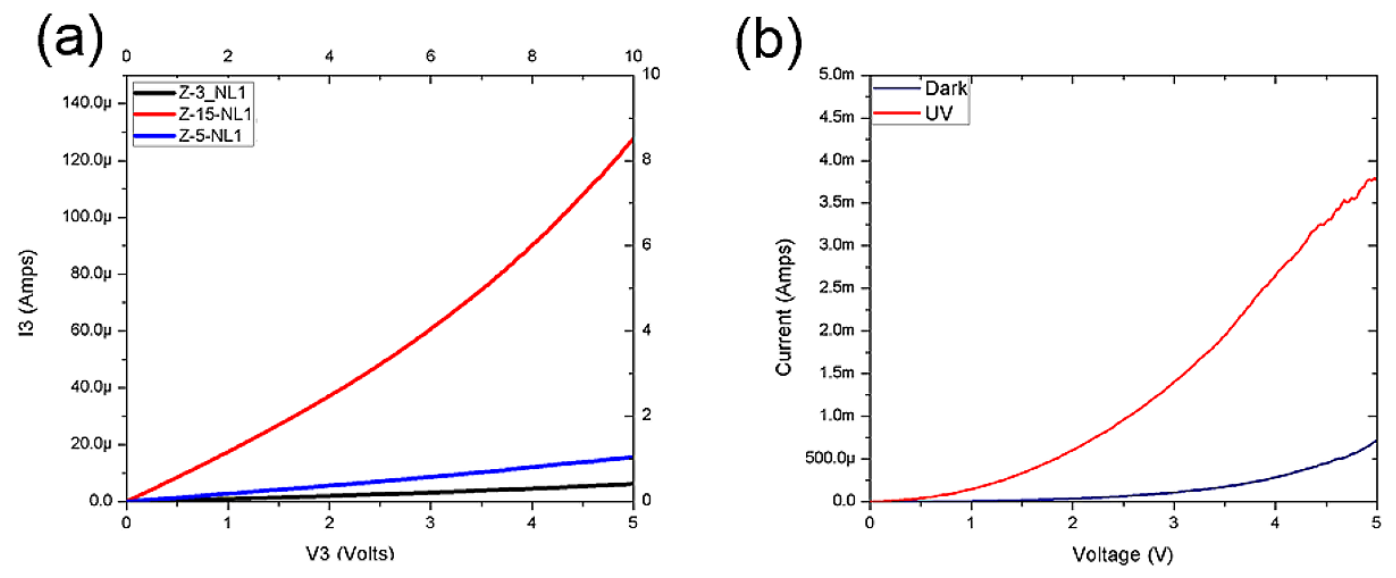

Figure 3.25 (a) Current-voltage ( $I-V$ ) for samples of growth time 3, 5, 15 min show that the conductance of the flakes increases with the time of synthesis as the thickness increases and new layers are added with time (b) $I-V$ for continuous fi $1 \mathrm{~m}$ of $\mathrm{ZnO}$ nanoflakes with growth time $15 \mathrm{~min}$ and three cycles show a 10-fold increase in conductivity in the presence of UV light

Graphene is a 2D carbon nanostructure, which has been studied extensively in recent years due to its remarkable mechanical, optical and electronic properties. Integrating graphene with other $2 \mathrm{D}$ materials so as to reap the benefits of both the materials has been the focus of many researches. Growing oxides over graphene can render additional functionality to graphene in electronic and optoelectronic applications as the hybrid material can have a band gap which is missing in graphene and at the same time exhibit high mobility. In this dissertation we used sonochemistry to grow ZnO NFs directly over graphene. For this purpose, a CVD grown monolayer graphene was transferred on to $\mathrm{Si} / \mathrm{SiO}_{2}$ substrate and was used as a substrate for $\mathrm{ZnO}$ nanoflakes growth. The resulting growth was compared with another sample prepared on $\mathrm{Si} / \mathrm{SiO}_{2}$ substrate under similar conditions. We observe 
an increased density of growth on graphene as shown in figure 3.26. This increased growth can be attributed to the similar hexagonal atomic configuration in the "c" plane of both materials, which act as good template for the growth of hexagonal $\mathrm{ZnO}$ nanostructures. [39] Also the high conductivity of the graphene might have accelerated the growth of $\mathrm{ZnO}$ nanoflakes. Figure 3.27 shows the TEM, SAED and HRTEM pictures of $\mathrm{ZnO}$ nanoflakes on graphene. HRTEM and SAED confirms the single crystalline wurtzite structure oriented in (0001) plane. From HRTEM we observe that at the boundary of ZnO NF and graphene the nanoflake loses it's crystalline nature and is more amorphous. This is thermodynamically stable structure in nanomaterials. [40]

(a)

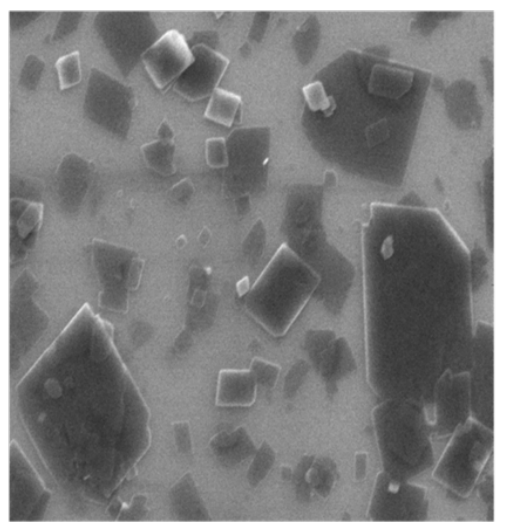

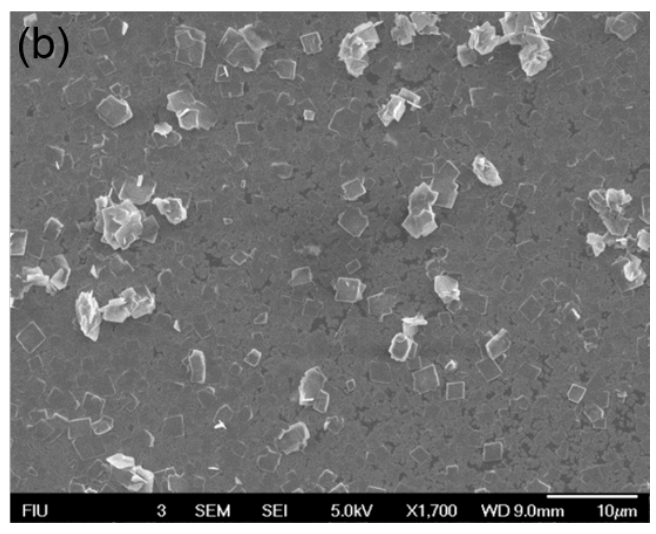

Figure 3.26 (a) $\mathrm{ZnO}$ nanoflakes on $\mathrm{SiO}_{2}$ Substrate (b) graphene showing aggressive growth on graphene making the growth process highly selective

$\mathrm{Ti} / \mathrm{Au}$ contacts were deposited on $\mathrm{ZnO} \mathrm{NF} /$ graphene sample to study the current-voltage characteristics in dark and under illumination. As shown in figure 3.28 (a) the conductance of $\mathrm{ZnO} \mathrm{NF} /$ graphene is 1000 times higher than that of $\mathrm{ZnO}$ nanoflakes grown under similar conditions. ZnO nanoflakes/Graphene can be used as transparent electrodes provided they show a good transmittance along with the high conductance they showed. As shown in 
figure 3.28 (b), the electrodes show a transmittance as high as $80 \%$ in the visible spectrum and a strong absorbance in UV spectrum.

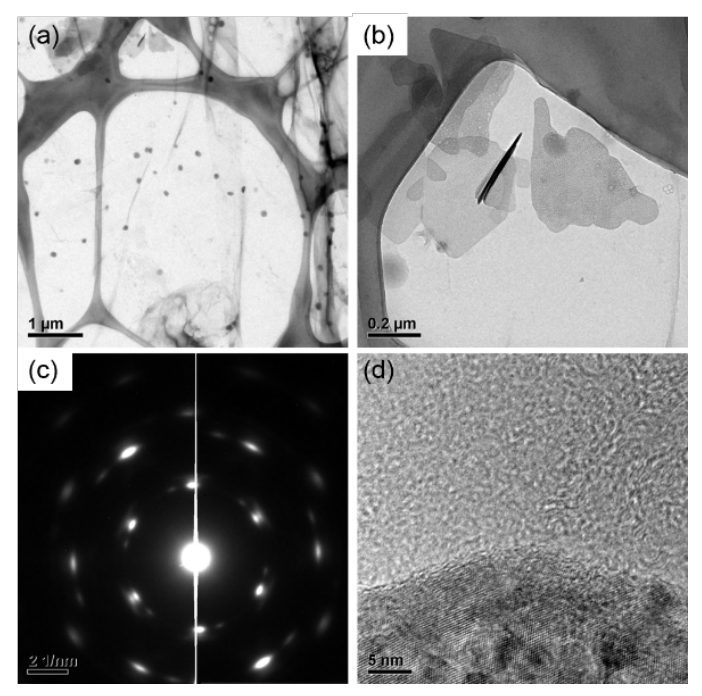

Figure 3.27 (a) ZnO nanoflakes/ graphene on a TEM grid (b) TEM image of Individual flakes on graphene (c) SAED image of $\mathrm{ZnO} \mathrm{NF} /$ graphene showing single crystal nature of $\mathrm{ZnO} \mathrm{NF}$ (d) HRTEM image at the $\mathrm{ZnO} \mathrm{NF}$ and graphene interface, $\mathrm{ZnO}$ nanoflake shows a single crystalline nature but at the interface where amorphous like behavior is observed.
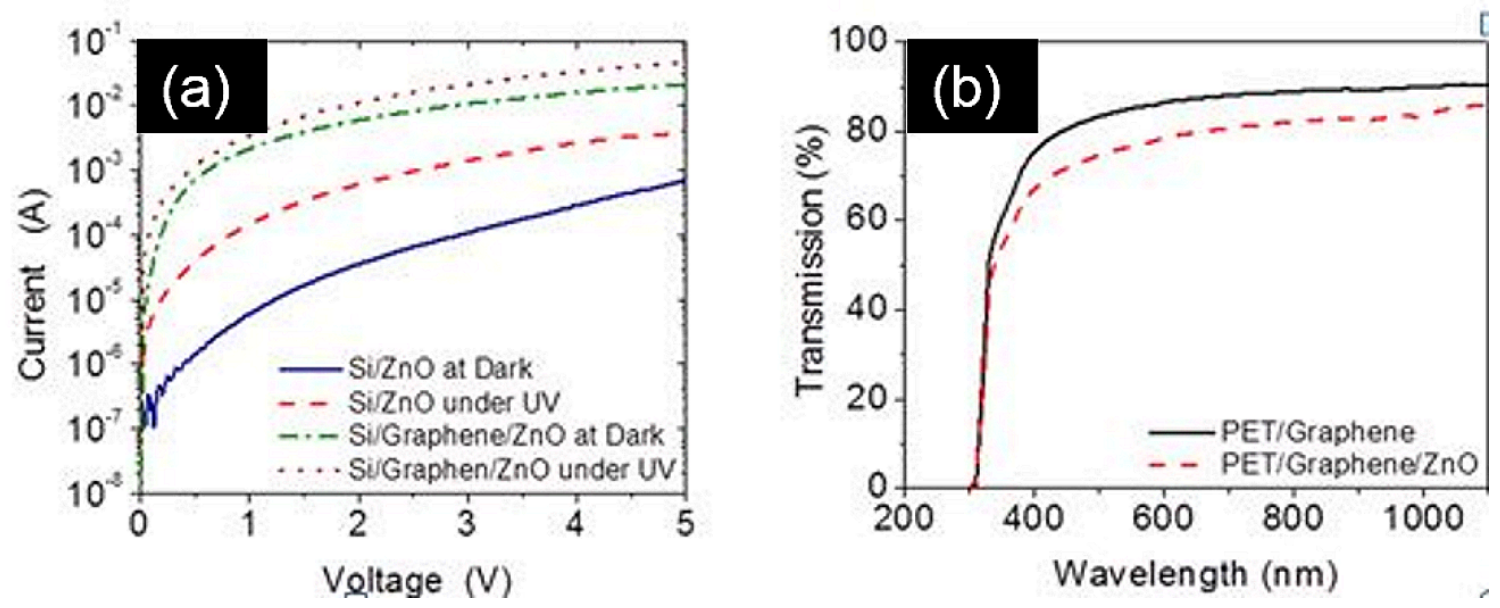

Figure 3.28 (a) Electrical conductivity comparison in the presence of graphene and without graphene shows that the conductivity increases for the hybrid structure $\mathrm{ZnO}$-graphene by more than 10 times when compared with just $\mathrm{ZnO}$. (b) Comparison of transmission for graphene and $\mathrm{ZnO}$-graphene hybrid structure 


\subsection{Conclusions}

In conclusion, we have successfully developed sonochemical synthesis technique to synthesize, high quality single crystalline $\mathrm{ZnO}$ nanostructures such as $1 \mathrm{D} \mathrm{ZnO}$ nanorods, $\mathrm{ZnO}-\mathrm{ZnO}$ core-shell nanorods, $\mathrm{ZnO}-\mathrm{ZnS}$ core-shell nanorods, 2D $\mathrm{ZnO}$ nanowalls and 2D $\mathrm{ZnO}$ nanoflakes on arbitrary substrates. The morphology and crystal structure of the nanostructures studied using SEM, TEM, XRD and Raman spectrum has shown that all the nanostructures were highly single crystalline in structure with very low levels of impurities. The electrical and optical properties measured indicate that the as grown nanostructures have applications in transparent electrodes and photodetectors.

\subsection{References}

1. Xu, H., Zeiger, B. W., \& Suslick, K. S. (2013). Sonochemical synthesis of nanomaterials. Chemical Society Reviews, 42 (7):2555-2567.

2. Gedanken, A. (2004). Using sonochemistry for the fabrication of nanomaterials. Ultrasonics sonochemistry, 11 (2):47-55.

3. Rayleigh, L. (1917). VIII. On the pressure developed in a liquid during the collapse of a spherical cavity. The London, Edinburgh, and Dublin Philosophical Magazine and Journal of Science, 34 (200):94-98.

4. Plesset, M. S. (1949). The dynamics of cavitation bubbles. Journal of applied mechanics, 16:277-282.

5. Jung, S. H., Oh, E., Lee, K. H., Yang, Y., Park, C. G., Park, W., \& Jeong, S. H. (2007). Sonochemical preparation of shape-selective $\mathrm{ZnO}$ nanostructures.Crystal growth and design, 8 (1):265-269.

6. Price, G. J., Ashokkumar, M., \& Grieser, F. (2004). Sonoluminescence quenching of organic compounds in aqueous solution: Frequency effects and implications for sonochemistry. Journal of the American Chemical Society, 126 (9):2755-2762. 
7. Ciawi, E., Rae, J., Ashokkumar, M., \& Grieser, F. (2006). Determination of temperatures within acoustically generated bubbles in aqueous solutions at different ultrasound frequencies. The Journal of Physical Chemistry B,110 (27):13656-13660.

8. Pokhrel, N., Vabbina, P. K., \& Pala, N. (2016). Sonochemistry: Science and Engineering. Ultrasonics Sonochemistry, 29:104-128.

9. Greene, L. E., Law, M., Tan, D. H., Montano, M., Goldberger, J., Somorjai, G., \& Yang, P. (2005). General route to vertical $\mathrm{ZnO}$ nanowire arrays using textured $\mathrm{ZnO}$ seeds. Nano Letters, 5 (7):1231-1236.

10. Breedon, M., Yu, J., Wlodarski, W., \& Kalantar-zadeh, K. (2008, February). ZnO nanostructured arrays grown from aqueous solutions on different substrates. In Nanoscience and Nanotechnology, 2008. ICONN 2008. International Conference on (pp. 9-12). IEEE.

11. Guo, W., Liu, T., Huang, L., Zhang, H., Zhou, Q., \& Zeng, W. (2011). HMT assisted hydrothermal synthesis of various $\mathrm{ZnO}$ nanostructures: Structure, growth and gas sensor properties. Physica E: Low-dimensional Systems and Nanostructures, 44 (3):680-685.

12. Xu, S., \& Wang, Z. L. (2011). One-dimensional ZnO nanostructures: solution growth and functional properties. Nano Research, 4 (11):1013-1098.

13. Fonoberov, V. A., Alim, K. A., Balandin, A. A., Xiu, F., \& Liu, J. (2006). Photoluminescence investigation of the carrier recombination processes in $\mathrm{ZnO}$ quantum dots and nanocrystals. Physical review B, 73 (16): 165317.

14. Wang, Z. L. (2004). Zinc oxide nanostructures: growth, properties and applications. Journal of Physics: Condensed Matter, 16 (25):R829.

15. Khan, A. (2010). Raman spectroscopic study of the $\mathrm{ZnO}$ nanostructures. J. Pak. Mater. Soc, 4:5-9.

16. Fan, Z., \& Lu, J. G. (2005). Zinc oxide nanostructures: synthesis and properties. Journal of nanoscience and nanotechnology, 5 (10):1561-1573.

17. Wang, L., Lou, Z., Fei, T., \& Zhang, T. (2011). Zinc oxide core-shell hollow microspheres with multi-shelled architecture for gas sensor applications.Journal of Materials Chemistry, 21 (48):19331-19336.

18. Sun, B., Hao, Y., Guo, F., Cao, Y., Zhang, Y., Li, Y., \& Xu, D. (2011). Fabrication of poly (3-hexylthiophene)/CdS/ZnO core-shell nanotube array for semiconductorsensitized solar cell. The Journal of Physical Chemistry C, 116 (1):1395-1400. 
19. Kong, X. Y., Ding, Y., \& Wang, Z. L. (2004). Metal-semiconductor Zn-ZnO core-shell nanobelts and nanotubes. The journal of physical chemistry B, 108 (2):570-574.

20. Greene, L. E., Law, M., Yuhas, B. D., \& Yang, P. (2007). ZnO-TiO2 core-shell nanorod/P3HT solar cells. The Journal of Physical Chemistry C, 111 (50):1845118456.

21. Guduru, R., Liang, P., Runowicz, C., Nair, M., Atluri, V., \& Khizroev, S. (2013). Magneto-electric nanoparticles to enable field-controlled high-specificity drug delivery to eradicate ovarian cancer cells. Scientific reports, 3.

22. Qi, J., Dang, X., Hammond, P. T., \& Belcher, A. M. (2011). Highly efficient plasmonenhanced dye-sensitized solar cells through metal@ oxide core-shell nanostructure. ACS nano, 5 (9):7108-7116.

23. Xia, X., Tu, J., Zhang, Y., Wang, X., Gu, C., Zhao, X. B., \& Fan, H. J. (2012). Highquality metal oxide core/shell nanowire arrays on conductive substrates for electrochemical energy storage. ACS nano, 6 (6):5531-5538.

24. Fang, X., Zhai, T., Gautam, U. K., Li, L., Wu, L., Bando, Y., \& Golberg, D. (2011). $\mathrm{ZnS}$ nanostructures: from synthesis to applications. Progress in Materials Science, 56 (2):175-287.

25. Li, J., Zhao, D., Meng, X., Zhang, Z., Zhang, J., Shen, D., \& Fan, X. (2006). Enhanced ultraviolet emission from $\mathrm{ZnS}$-coated $\mathrm{ZnO}$ nanowires fabricated by self-assembling method. The Journal of Physical Chemistry B, 110 (30):14685-14687.

26. Saha, S., Sarkar, S., Pal, S., \& Sarkar, P. (2013). Tuning the energy levels of ZnO/ZnS core/shell nanowires to design an efficient nanowire-based dye-sensitized solar cell. The Journal of Physical Chemistry C, 117 (31):15890-15900.

27. Greene, L. E., Law, M., Goldberger, J., Kim, F., Johnson, J. C., Zhang, Y., \& Yang, P. (2003). Low-temperature wafer-scale production of $\mathrm{ZnO}$ nanowire arrays. Angewandte Chemie, 115 (26):3139-3142.

28. Vanheusden, K., Warren, W. L., Seager, C. H., Tallant, D. R., Voigt, J. A., \& Gnade, B. E. (1996). Mechanisms behind green photoluminescence in $\mathrm{ZnO}$ phosphor powders. Journal of Applied Physics, 79 (10):7983-7990.

29. Mikho, V. V., \& Fedchuk, A. P. (1974). Special characteristics of the photoluminescence spectra of aluminum oxide arising from sorbed particles.Journal of Applied Spectroscopy, 21 (4):1331-1333.

30. Nagata, K., Sato, K., \& Goto, K. S. (1980). Kinetics of the solid state reaction between zinc oxide and aluminum oxide. Metallurgical Transactions B, 11 (3):455-461. 
31. Zawadzki, M., \& Wrzyszcz, J. (2000). Hydrothermal synthesis of nanoporous zinc aluminate with high surface area. Materials Research Bulletin, 35 (1):109-114.

32. Lee, C. H., Kim, Y. J., Lee, J., Hong, Y. J., Jeon, J. M., Kim, M., \& Yi, G. C. (2010). Scalable network electrical devices using $\mathrm{ZnO}$ nanowalls.Nanotechnology, 22 (5):055205.

33. Mousa, M. A., Diefallah, E. M., Fattah, A. A., \& Omran, Z. A. (1990). Physicochemical studies on $\mathrm{ZnO}-\mathrm{Al} 2 \mathrm{O} 3$ system. Journal of Materials Science, 25 (7):3067-3071.

34. Soci, C., Zhang, A., Xiang, B., Dayeh, S. A., Aplin, D. P. R., Park, J., ... \& Wang, D. (2007). $\mathrm{ZnO}$ nanowire UV photodetectors with high internal gain.Nano letters, 7 (4):1003-1009.

35. Xu, S., \& Wang, Z. L. (2011). One-dimensional ZnO nanostructures: solution growth and functional properties. Nano Research, 4 (11):1013-1098.

36. Jung, S. H., Oh, E., Lee, K. H., Yang, Y., Park, C. G., Park, W., \& Jeong, S. H. (2007). Sonochemical preparation of shape-selective $\mathrm{ZnO}$ nanostructures.Crystal growth and design, 8 (1):265-269.

37. Greene, L. E., Law, M., Goldberger, J., Kim, F., Johnson, J. C., Zhang, Y., \& Yang, P. (2003). Low-temperature wafer-scale production of $\mathrm{ZnO}$ nanowire arrays. Angewandte Chemie, 115 (26):3139-3142.

38. Nayak, A. P., Lin, T. C., Lam, D., Kaya, S., \& Islam, M. S. (2012). UV and oxygen sensing properties and space charge limited transport of sonochemically grown $\mathrm{ZnO}$ nanowires. Nanoscience and Nanotechnology Letters, 4 (10):977-982.

39. Kim, Y. J., Yoon, A., Kim, M., Yi, G. C., \& Liu, C. (2011). Hydrothermally grown $\mathrm{ZnO}$ nanostructures on few-layer graphene sheets. Nanotechnology, 22 (24):245603.

40. Sommer, F., Singh, R. N., \& Mittemeijer, E. J. (2009). Interface thermodynamics of nano-sized crystalline, amorphous and liquid metallic systems. Journal of Alloys and Compounds, 467 (1):142-153. 


\section{CHAPTER 4}

\section{Doping of Zinc Oxide}

\subsection{Al-doped ZnO}

Despite the many promising features of $\mathrm{ZnO}$ discussed earlier, a low intrinsic electron concentration in undoped $\mathrm{ZnO}$ nanorods limits its use in various optoelectronic applications. Group $2 \mathrm{~A}$ and $3 \mathrm{~A}$ elements were used to dope $\mathrm{ZnO}$ in order to increase the carrier concentration. Numerous reports were published over the years to show an improved performance of $\mathrm{ZnO}$ owing to doping by Ga, [1] In, [2] Al, [3-5] Mn, [6] Mg. [7] Fortuna et.al have doped $\mathrm{ZnO}$ using $\mathrm{Ga}$ to achieve carrier concentration of $1.3 \times 10^{21}$ $\mathrm{cm}^{-3}$, when $\mathrm{ZnO}$ nanobelts were doped with 'In' Jiansheng Jie et. al have observed that the carrier concentration increased to $7 \times 10^{19} \mathrm{~cm}^{-3}$.[8] Similarly Sasanka Deka and Vinod Kumar Etcheri have found an improved electrical response from $\mathrm{ZnO}$ nanparticles doped with $\mathrm{Mn}$ and $\mathrm{Mg}$ respectively. [9, 10] Similarly 'Al' was used to dope $\mathrm{ZnO}$ by various groups and found improved electrical properties without effecting its optical and crystalline properties to a greater degree which makes 'Al' a highly desirable dopant. [11] However, the high oxidation reactivity of 'Al' sources and the difference in vapor pressure between 'Al' and ' $\mathrm{Zn}$ ' present a huge challenge for researchers to attain successful doping using conventional methods such as thermal evaporation and vapor-liquid-solid method. Various studies have shown to overcome these obstacles and achieve successful 'Al' doping using thermal evaporation [12] and vapor-liquid-solid method [13] but these methods require extensive setup, sophisticated equipment and high temperatures. In contrast, solution methods which use chemical approaches requires very simple equipment and can be performed at very low temperatures which make them more effective method to synthesize 
$\mathrm{ZnO}$ nanostructures on a large scale. In this dissertation we have successfully doped $\mathrm{ZnO}$ nanorods using $\mathrm{Al}$ as dopant using sonochemical method, showing an increased electrical conductivity, 10 times increase in carrier concentration and a transmission as high as $70 \%$

\subsubsection{Synthesis of Al-ZnO Nanorods}

In order to grow $\mathrm{Al}: \mathrm{ZnO}$ nanorod arrays, first a seed layer was deposited on n-type Silicon wafer as described earlier in chapter 2. Following the seeding process $\mathrm{Al}: \mathrm{ZnO}$ nanorods were synthesized by sonicating a solution of $0.02 \mathrm{M} \mathrm{ZNH,} 0.02 \mathrm{M}$ HMT and Aluminum nitrate (AlN) at $50 \%$ amplitude $(\sim 20 \mathrm{~W} \mathrm{~cm}-2)$ for 30 minutes. A solution of Ammonium hydroxide $\left(\mathrm{NH}_{4} \mathrm{OH}\right)\left(28 \mathrm{wt} \% \mathrm{NH}_{3}\right.$ in water, $99.9 \%$, Aldrich) was added to maintain the $\mathrm{pH}$ of the solution around 6.2. Maintaining $\mathrm{pH}$ values around 6 is very crucial as sonochemical synthesis is highly sensitive to the changes in $\mathrm{pH}$ value of the solution. AlN has been used previously and proved to be a very effective 'Al' dopant in various hydrothermal methods. We have used two different concentrations of $0.0005 \mathrm{M}$ AIN and 0.001M AlN to dope $\mathrm{ZnO}$. An increase in concentration beyond $0.001 \mathrm{M}$ did not result in nanorod growth. The structure and morphologies of the $\mathrm{Al}$ doped $\mathrm{ZnO}$ nanorods were studied using, FESEM (JOEL 7000), EDS (JOEL 6330) and X-ray diffraction (XRD). The transmission properties were studied using IPEC measurement system (PV Measurements) and Hall mobility and current voltage characteristics were measured using HMS 3000 equipped with $0.55 \mathrm{~T}$ permanent magnet and four point probe station equipped with HP 4455 semiconductor parameter analyzer. 


\subsubsection{Structural and Electrical Characterization}

Figures $4.1(\mathrm{a}-\mathrm{c})$ shows the FESEM images of un-doped $\mathrm{ZnO}$ nanorods $(\mathrm{S} 10)$ and $\mathrm{Al}$ doped $\mathrm{ZnO}$ nanorods with AlN concentration $0.0005 \mathrm{M}$ (S11) and 0.001M (S12) respectively. It can be observed that vertically aligned $\mathrm{ZnO}$ nanorods were grown over $\mathrm{n}$ Si substrate, with uniform density. The density of nanorods is slightly reduced when AIN was added, however there is not much reduction in the density between $0.0005 \mathrm{M} \mathrm{AlN}$ (S11) and 0.001 M AlN (S12). The EDS analysis is shown in figure 4.1 (d-e) indicates the presence of 'Al' in a very small quantities in both samples with 0.42 weight percentage and 1.28 weight percentage.

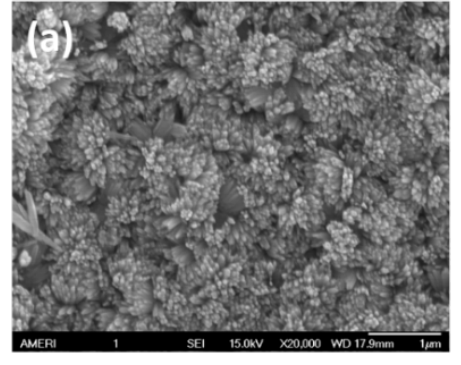

Full scale counts: $2000 \quad$ Al-ZnO(3)_pt1

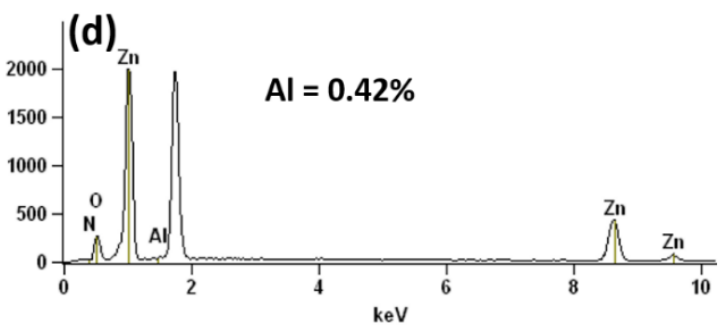

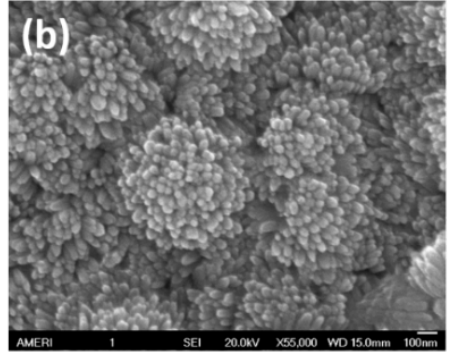

Full scale counts: 2000

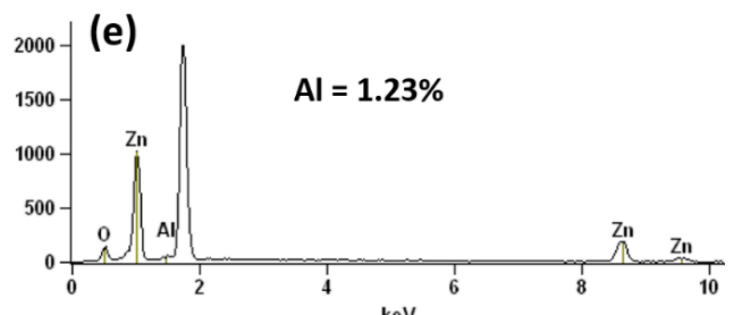

Figure 4.1 (a) SEM picture of undoped $\mathrm{ZnO}$ (S10) (b) $\mathrm{ZnO}$ nanorods doped with $0.5 \mathrm{mM}$ AlN (S11) (c) ZnO nanorods doped with $1 \mathrm{mM}$ AlN (S12) (d) EDS showing $0.42 \%$ weight percent of $\mathrm{Al}$ in $\mathrm{S} 11$ (e ) EDS showing $1.23 \%$ weight percent of $\mathrm{Al}$ in $\mathrm{S} 12$

Figure 4.2 (a) shows the XRD analysis for samples S10, S11 and S12. The spectra were dominated by (002) peak of wurtzite $\mathrm{ZnO}$, which implies that the preferred orientation is 
along (002) direction. We did not observe any $\mathrm{Al}_{2} \mathrm{O}_{3}$ peaks as shown by other studies, but instead we observe the formation of double oxide gahnite $\left(\mathrm{ZnO}^{-\mathrm{Al}_{2} \mathrm{O}_{3}}\right.$, JCPDS card No. 22-1034) similar to the one observed in $\mathrm{ZnO}$ nanowalls grown over 'Al' substrate. A similar peak was reported by Sining Yun et. al [14] and ascribed it to high aluminum concentrations. A broader (002) peak and peak shift towards higher angles of $\mathrm{Al}: \mathrm{ZnO}$ nanorods indicate the lattice distortion due to the introduction of Aluminum.
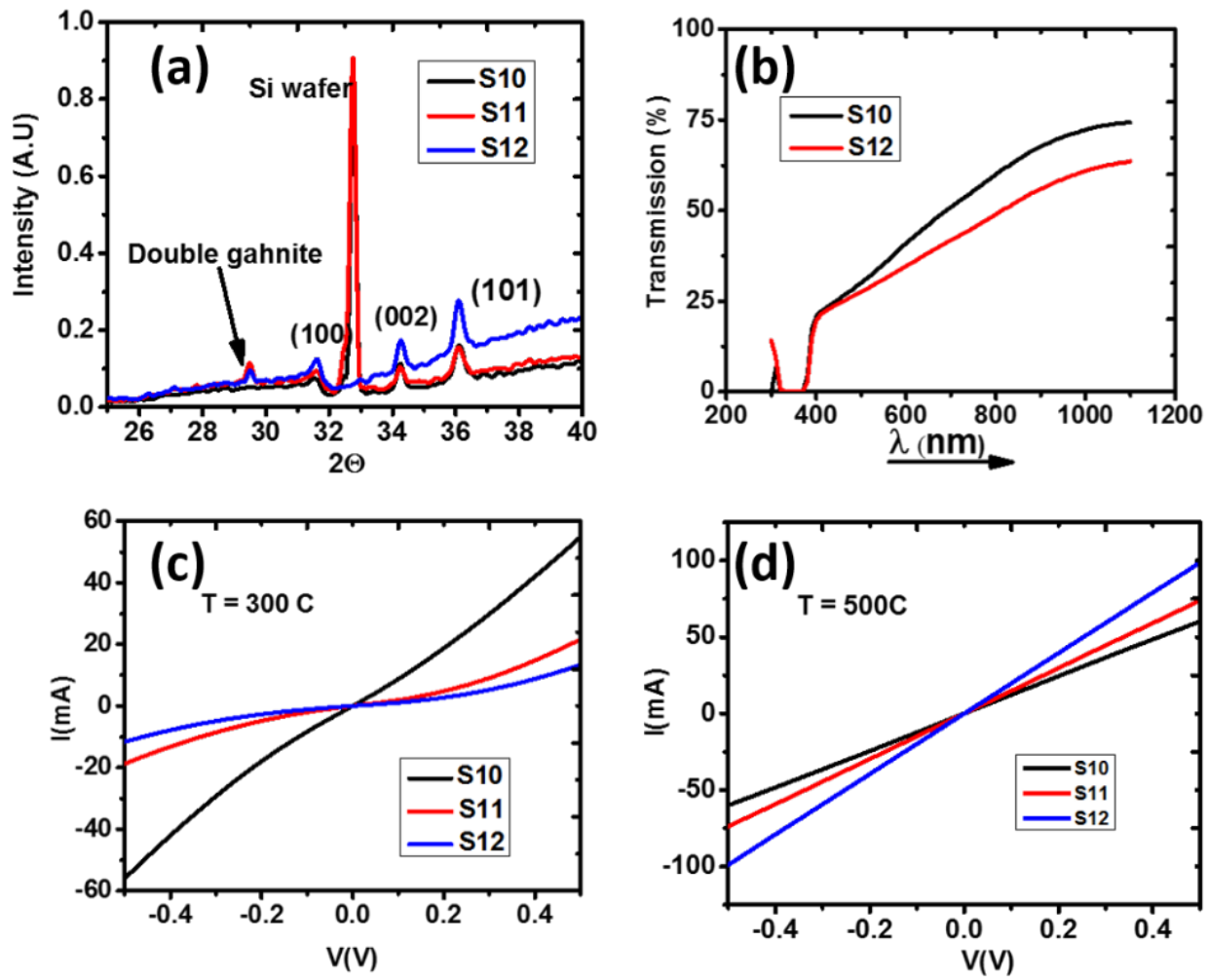

Figure 4.2 (a) XRD analysis of S10, S11 and S12 samples showing a double gahnite peak and a peak shift in Al doped samples (b) Transmission spectra of undoped and Al doped $\mathrm{ZnO}$ (c) Current- voltage characteristics of S10, S11 and S12 after annealing at $300 \mathrm{C}$ (d) Current- voltage characteristics of S10, S11 and S12 after annealing at $500 \mathrm{C}$ after dopants are activated. 
Figure 4.2 (b) shows the transmission spectra of S12 doped with $0.1 \mathrm{mM}$ AlN and $\mathrm{S} 10$ an undoped $\mathrm{ZnO}$ nanorods. There is drop in transmission due to higher absorption in $\mathrm{Al}: \mathrm{ZnO}$ however, albeit high transmission levels compared to other doped $\mathrm{ZnO}$ reported. Figure 4.2 (c-d) shows current-voltage characteristics of undoped and doped $\mathrm{ZnO}$ nanorods. It was observed that at $300{ }^{\circ} \mathrm{C}$ annealing temperature, the conductivity of undoped $\mathrm{ZnO}$ nanorods (S10) is high. This is expected as we have observed in $\mathrm{ZnO}$ nanowalls, the formation of double gahnite reduces the conductivity of $\mathrm{ZnO}$ nanorods. However, as the annealing temperature is increased to $500{ }^{\circ} \mathrm{C}$ the dopants are activated as such the conductivity of doped $\mathrm{ZnO}$ nanorods is higher than the undoped $\mathrm{ZnO}$ nanorods with $\mathrm{S} 12>\mathrm{S} 11>\mathrm{S} 10$. This behavior is collaborated by the Hall measurements which shows 10 times increase in carrier concentration when annealed at $500{ }^{\circ} \mathrm{C}$.

\subsection{P- Doping in $\mathrm{ZnO}$ Nanoshells}

The role of oxide based functional materials has rapidly increased over the past few decades as the focus of research widened beyond their use as mere dielectrics. Today metal oxides find applications in catalysts, transparent electrodes, magnetic materials, bio sensors, piezo electric materials, photonics and many more.[15, 16] Among these oxide materials, Zinc Oxide $(\mathrm{ZnO})$, a wide band gap $(3.37 \mathrm{eV})$ semiconductor material with a high exciton binding energy $(60 \mathrm{meV})$ at room temperature, has emerged as a promising material for fabrication of many optoelectronic devices such as light-emitting diodes (LEDs), laser diodes (LDs) and photodetectors (PDs).[17, 18] With a potential to replace other wide band gap materials such as $\mathrm{GaN}$ and $\mathrm{SiC}, \mathrm{ZnO}$ has received substantial attention owing to its 
diverse morphologies,[19, 20] low toxicity, bio-compatibility,[21, 22] radiation hardness and amenability to wet chemical etching, which makes it appealing to commercialization and industry applications. One dimensional $\mathrm{ZnO}$ nanostructures such as nanorods, nanowires, nanotubes have been extensively studied in fabrication of optoelectronic devices due to their single crystalline nature and high surface to volume ratio. However, despite its many advantages, the progress of $\mathrm{ZnO}$ in nano-scale optoelectronic devices is hindered by the lack of stable and reproducible p-type doping. The difficulty in attaining p-type doping in $\mathrm{ZnO}$ has been attributed to various factors such as the self-compensating effect of the inherent intrinsic donor defects, hydrogen impurities and low solubility of ptype dopants.[23, 24] Apart from the above bottlenecks, the tendency of acceptors in $\mathrm{ZnO}$ to form a deep impurity levels instead of shallow acceptor levels has made it challenging to achieve p-type doping in $\mathrm{ZnO}$.[25] This calls for development of a synthesis technique for successful and stable p-type doping in $\mathrm{ZnO}$ by introducing least amount of impurities without use of high processing temperatures and costs.

P-type doping in $\mathrm{ZnO}$ has been reported in recent times using techniques such as CVD, [26] ion implantation, [27] PLD, [28] MOCVD, [29] MBE, [30] which most commonly use nitrogen and phosphorous as dopant material. Aqueous solution methods have also been reported, which use both group I elements such as K, [31] and group II elements such as $\mathrm{N},[32,33]$ and $\mathrm{P},[34,35]$ but to the best of our knowledge there was no report on sonochemical method till date. In this research we for the first time synthesized p-type $\mathrm{ZnO}$ nanoshell ( $\mathrm{P}: \mathrm{ZnO}$ nanoshell) around $\mathrm{ZnO}$ nanorod $(\mathrm{ZnO} \mathrm{NR})$ by varying only the molar ratio of precursors and addition of ammonium dihydrogen phosphate (ADP) as 
source of phosphorous (P) using sonochemical method. In comparison to the more conventional approaches such as hydrothermal method, sonochemical method is 10 times faster due to the fast hydrolysis rate caused by cavitation. Apart from that, sonochemical method is inexpensive, environmentally benign, CMOS compatible and has been proved to induce minimum defects in $\mathrm{ZnO}$ crystal unlike hydrothermal method. [36] Since sonochemical synthesis is carried out at atmospheric conditions, wide range of substrates such as flexible and wearable substrates can be used, which makes it very attractive for synthesizing $\mathrm{ZnO}$ nanostructures for various applications. Theoretical studies have shown that nitrogen $(\mathrm{N})$ owing to its small atomic radii $(1.71 \AA)$ and low activation energy $(0.32$ $\mathrm{eV}$ ) is the most promising dopant.[37] However, experimental results have shown that phosphorous can be successfully used as a p-type dopant, with measured ionization energies $(0.18 \mathrm{eV})$ far less than theoretical calculations. The cause of this behavior is the formation of $\mathrm{P}_{\mathrm{zn}}-2 \mathrm{~V}_{\mathrm{zn}}$ complex defects, which act as shallow acceptors as studied by Woon- Jin Lee, Joongoo Kang and K. J. Chang and others. [38, 39] Ammonium dihydrogen phosphate (ADP), is the most suitable source of phosphorous for a solution based method as it readily dissolves in $\mathrm{H}_{2} \mathrm{O}$ to form $\mathrm{Zn}_{3}\left(\mathrm{PO}_{4}\right)_{2}$ following the reaction:

$$
\begin{aligned}
& {\left[\mathrm{H}_{2} \mathrm{PO}_{4}\right]^{-}+[\mathrm{OH}]^{-} \rightarrow \mathrm{H}_{2} \mathrm{O}+\left[\mathrm{PO}_{4}\right]^{3-}} \\
& 2\left[\mathrm{PO}_{4}\right]^{3-}+3 \mathrm{Zn}^{2+} \rightarrow \mathrm{Zn}_{3}\left(\mathrm{PO}_{4}\right)_{2}
\end{aligned}
$$


The $\mathrm{Zn}_{3}\left(\mathrm{PO}_{4}\right)_{2}$ contained in the $\mathrm{ZnO}$ nanorods decomposes at high annealing temperatures there by releasing $\mathrm{P}$ atoms, which would diffuse in to the $\mathrm{ZnO}$ crystal acting as acceptor dopants.[40]

Radial p-n homojunction offers wide range of advantages over conventional planar $\mathrm{p}-\mathrm{n}$ junctions. Foremost, the $\mathrm{p}-\mathrm{n}$ junction area is increased many fold in case of radial $\mathrm{p}-\mathrm{n}$ junction when compared to planar p-n junction, this increases the electron-hole collection efficiency. The distance that the electron-hole pairs need to travel before they are effectively collected is very small when compared to planar p-n junction, which reduces the recombination losses encountered in optoelectronic devices. The radial p-n homojunction configuration also increases the light absorption, which helps in improving the efficiency of the devices. We used X-ray diffraction (XRD), Raman spectrum and current-voltage (I-V) measurements, which show a rectification, characteristic of a p-n junction to verify the formation of p-n junction. The capacitance - voltage measurements $(\mathrm{C}-\mathrm{V})$ were used to extract the doping concentration.

\subsubsection{Growth of $\mathrm{ZnO}$ Nanorods}

The $\mathrm{ZnO}$ nanorods were synthesized using the sonochemical method described in detail in chapter 3.[41] Briefly, $200 \mathrm{~nm}$ thick $\mathrm{ZnO}$ seed layer was initially deposited over an n-Si substrate by sonicating in a $100 \mathrm{~mL}$ solution containing $0.005 \mathrm{M}$ Zinc acetate dehydrate (ZAD) in isopropyl alcohol (IPA) for four cycles of 15 minutes each. In the second step, high quality $\mathrm{ZnO}$ nanorods were grown by sonicating a $100 \mathrm{~mL}$ solution of $0.02 \mathrm{M}$ Zinc Nitrate Hexahydrate (ZNH) and 0.02M Hexamethylene tetramine (HMT) in deionized 
water (DI) for four cycles, each 30 minutes. The as grown $\mathrm{ZnO}$ nanorods are vertically oriented with an average diameter $50 \mathrm{~nm}$ and length $1 \mu \mathrm{m}$ long.

\subsubsection{Growth of P:ZnO Nanoshells}

$\mathrm{ZnO}$ nanoshells were grown around vertically oriented $\mathrm{ZnO}$ nanorods by varying the molar ratios of ZNH and HMT rather than using any other surfactants. HMT is known to play a crucial role in promoting directional growth along the 'c' axis as it binds to the non-polar facets of $\mathrm{ZnO}$, cutting off the supply of $\mathrm{Zn}^{2+}$ ions to these facets thereby promoting the growth in (0001) plane along 'c' direction.[42] Hence in this work, by changing the molar ratios of $\mathrm{ZNH}$ and HMT to 4:1 (1:1 is the preferred ratio for $\mathrm{ZnO}$ nanorod growth), we were able to promote the growth of $\mathrm{ZnO}$ along the non-polar facets of $\mathrm{ZnO}$ nanorods along with the growth in 'c' direction as described in chapter 3 . This resulted in growth of a nanoshell structure enclosing the whole nanorod including top basal plane with increased junction area when compared to conventional core- shell nanostructures where the shell is grown only around the non- polar facets of $\mathrm{ZnO}$ nanorod. This method is advantageous over the more common ones, which use surfactants such as citrate ions to achieve directional growth, as no impurities were added in this method while forming a more continuous and defect free junction as observed from the TEM picture. [43-45] A continuous and defect free junction is desired in designing optoelectronic devices in order to minimize the recombination losses at the junction. P-type doping in $\mathrm{ZnO}$ nanoshells was achieved by adding Ammonium dihydrogen phosphate (ADP) to the precursors. The concentrations of $\mathrm{ZNH}$ and HMT were adjusted to keep the $\mathrm{pH}$ around 6, which is the optimum condition for sonochemical growth. For this purpose, $1.2 \mathrm{gm}$ of ZNH, $0.14 \mathrm{gm}$ 
of HMT and $0.0184 \mathrm{gm}$ of ADP were dissolved in $100 \mathrm{~mL}$ of DI water and stirred for 5 minutes to form a homogeneous solution. The previously prepared sample with $\mathrm{ZnO}$ nanorods was dipped in to this solution and sonicated at 50\% amplitude for 20 minutes. The thickness of the nanoshell depends on the sonication time. The thickness increases with increasing sonication time. As prepared samples were then cleaned in DI water and allowed dry in ambient.

The step by step synthesis of p-doped $\mathrm{ZnO}$ nanoshells around $\mathrm{ZnO}$ nanorods to form a homogeneous radial $\mathrm{p}-\mathrm{n}$ junction is shown in figure 4.3. In step 1 , $\mathrm{ZnO}$ nanorods were grown on an n doped Silicon (n-Si) substrate using the process described earlier. As synthesized nanorods are $1 \mu \mathrm{m}$ long and $50 \mathrm{~nm}$ in diameter. In step 2, a $1 \mu \mathrm{m}$ thick PMMA was deposited by spin coating followed by a hard-bake at $180^{\circ} \mathrm{C}$ for 3 minutes. The PMMA is later carefully etched half way through, using reactive ion etching (RIE) in oxygen $\left(\mathrm{O}_{2}\right)$ plasma. This step exposes $600-800 \mathrm{~nm}$ of $\mathrm{ZnO}$ nanorods for further synthesis of $\mathrm{p}$-doped $\mathrm{ZnO}$ nanoshells, while the remaining PMMA shields the n-type $\mathrm{ZnO}$ nanorods at their base. This prevents the growth of $\mathrm{ZnO}$ nanoshell around the core at the base, which would then make contact with seed layer shorting the device. In step 4, a $7 \mu \mathrm{m}$ thick layer of AZ4620 photoresist was spin coated on the entire substrate and a $1 \mu \mathrm{m} \times 1 \mu \mathrm{m}$ window was opened for the growth of $\mathrm{ZnO}$ nanoshells. In step 5, $\mathrm{P}: \mathrm{ZnO}$ nanoshells were grown around the previously prepared $\mathrm{ZnO}$ nanorods by sonicating a solution of (ADP $+\mathrm{ZNH}+\mathrm{HMT})$ in deionized water (DI water) at 50\% amplitude for 20 minutes. The concentration of ADP was varied from $1 \mathrm{mM}$ to $2 \mathrm{mM}$ in steps of $0.2 \mathrm{mM}$. Subsequently, the photoresist was removed by dipping in acetone for 5 minutes and cleaning with DI water. SEM analysis 
presented in figure 4.4 (a) and (b) have shown that after the growth of nanoshell, the effective diameter of the nanorods increases from $50 \mathrm{~nm}$ to $100 \mathrm{~nm}$ which indicates towards successful growth of nanoshell. In step 6, another layer of PMMA was deposited over the synthesized core-shell structures and etched in RIE to expose the tips of the nanoshells for depositing metal contacts for electrical measurements. However, due to a slight angular growth of some nanorods, not all nanoshells were exposed equally during this process and some of the nanoshells remained covered by PMMA as seen in figure 4.4 (d). Further etching of PMMA was not performed in order to avoid the risk of exposing $\mathrm{ZnO}$ core, which would result in the top metal contact making direct connection with $\mathrm{n}-\mathrm{ZnO}$ core. In step 7, physical masks were used to deposit $\mathrm{Ti} / \mathrm{Au}$ contacts on $\mathrm{n}-\mathrm{ZnO}$ and $\mathrm{Ni} / \mathrm{Au}$ on the $\mathrm{P}: \mathrm{ZnO}$ nanoshells using e-beam evaporation. Current-voltage measurements at different annealing temperatures were taken, which show a successful p-type doping at $1.6 \mathrm{mM}$ ADP and $500{ }^{\circ} \mathrm{C}$ annealing temperature.

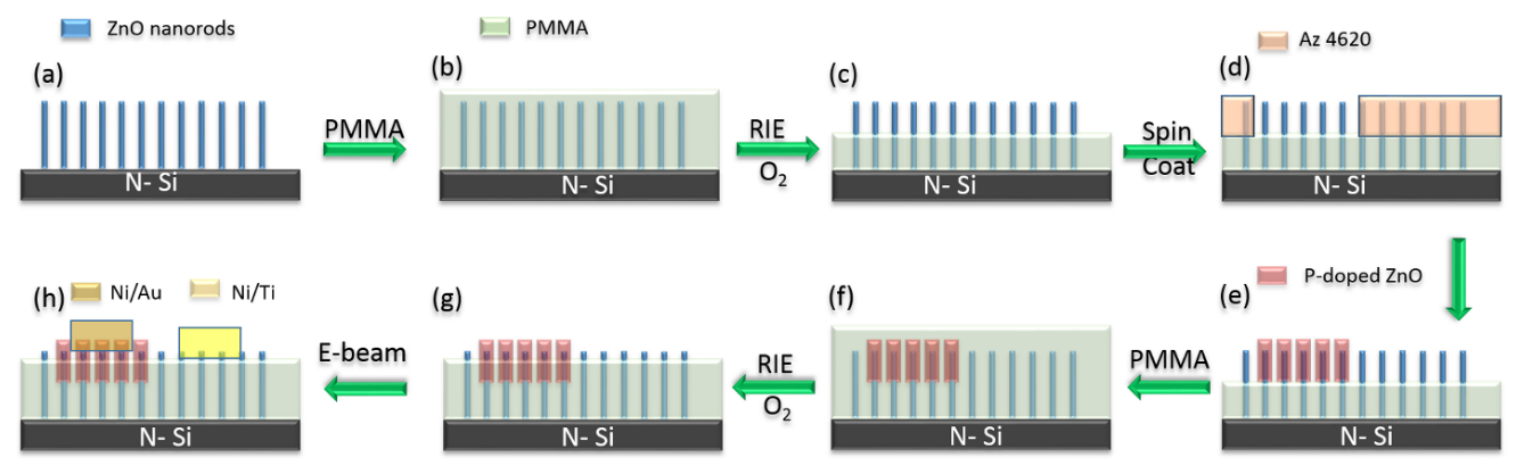

Figure 4.3. Synthesis of p-doped $\mathrm{ZnO}$ nanoshells around $\mathrm{ZnO}$ nanorods: (a) Vertically oriented $\mathrm{ZnO}$ nanorods grown on $\mathrm{n}-\mathrm{Si}$; (b) A thin layer of PMMA spin coated to cover the $\mathrm{ZnO}$ nanorods; (c) Partially etched $\mathrm{ZnO}$ nanorods; (d) Growth of $\mathrm{p}-\mathrm{ZnO}$ around partially exposed $\mathrm{ZnO}$ nanorods. 


\subsubsection{Deposition of Contacts}

Electrical contacts on the $\mathrm{ZnO}$ nanorods were deposited using e-beam evaporation. Initially a $1 \mu \mathrm{m}$ thick PMMA was spin- coated on to the sample and was hard baked at 180 ${ }^{\circ} \mathrm{C}$ for 3 minutes. RIE was used to etch the PMMA to expose 100-200 nm of ZnO nanorods and $\mathrm{P}: \mathrm{ZnO}$ nanoshells. Physical masks were prepared by using a laser engraver to cut windows with an area of $0.15 \mathrm{~cm}^{2}$ in to a PMMA sheet. These physical masks were carefully laid on top of the already prepared samples and loaded in to $\mathrm{CHA} 10 \mathrm{keV}$ four pocket e-beam deposition system and evacuated to $2 \times 10^{-6}$ Torr vacuum. $30 \mathrm{~nm} / 60 \mathrm{~nm}$ thick $\mathrm{Ti} / \mathrm{Au}$ and $\mathrm{Ni} / \mathrm{Au}$ contacts were deposited on the $\mathrm{ZnO}$ nanorods and $\mathrm{P}: \mathrm{ZnO}$ nanoshells respectively.

\subsubsection{Structural and Electrical Characterization}

Structural characterization was done by a 30 KV JEOL 7000 SEM and Philips CM-200 $200 \mathrm{kV}$ transmission electron microscope (TEM). Figure 4.4 shows the top view and crosssectional view of SEM images of $\mathrm{ZnO}$ core and $\mathrm{ZnO}$ core-shell nanorods. It is observed that the $\mathrm{ZnO}$ nanorods, which act as core are $50-60 \mathrm{~nm}$ in diameter and are vertically oriented with a needle like pointed tips, while the newly formed nanoshell around the core is hexagonal in structure with a thickness of $40-50 \mathrm{~nm}$ giving an overall diameter of $\approx 100$ nm. Figure 4.4 (c) shows the cross-sectional view of $\mathrm{P}: \mathrm{ZnO}$ nanoshell/n- $\mathrm{ZnO}$ NR with PMMA filling the voids between the rods isolating the $\mathrm{P}: \mathrm{ZnO}$ nanoshells from the 
nanorods. Figure 4.4 (d) shows the exposed tips of $\mathrm{P}: \mathrm{ZnO}$ nanoshell/n- $\mathrm{ZnO}$ NR for deposition of electrical contacts.
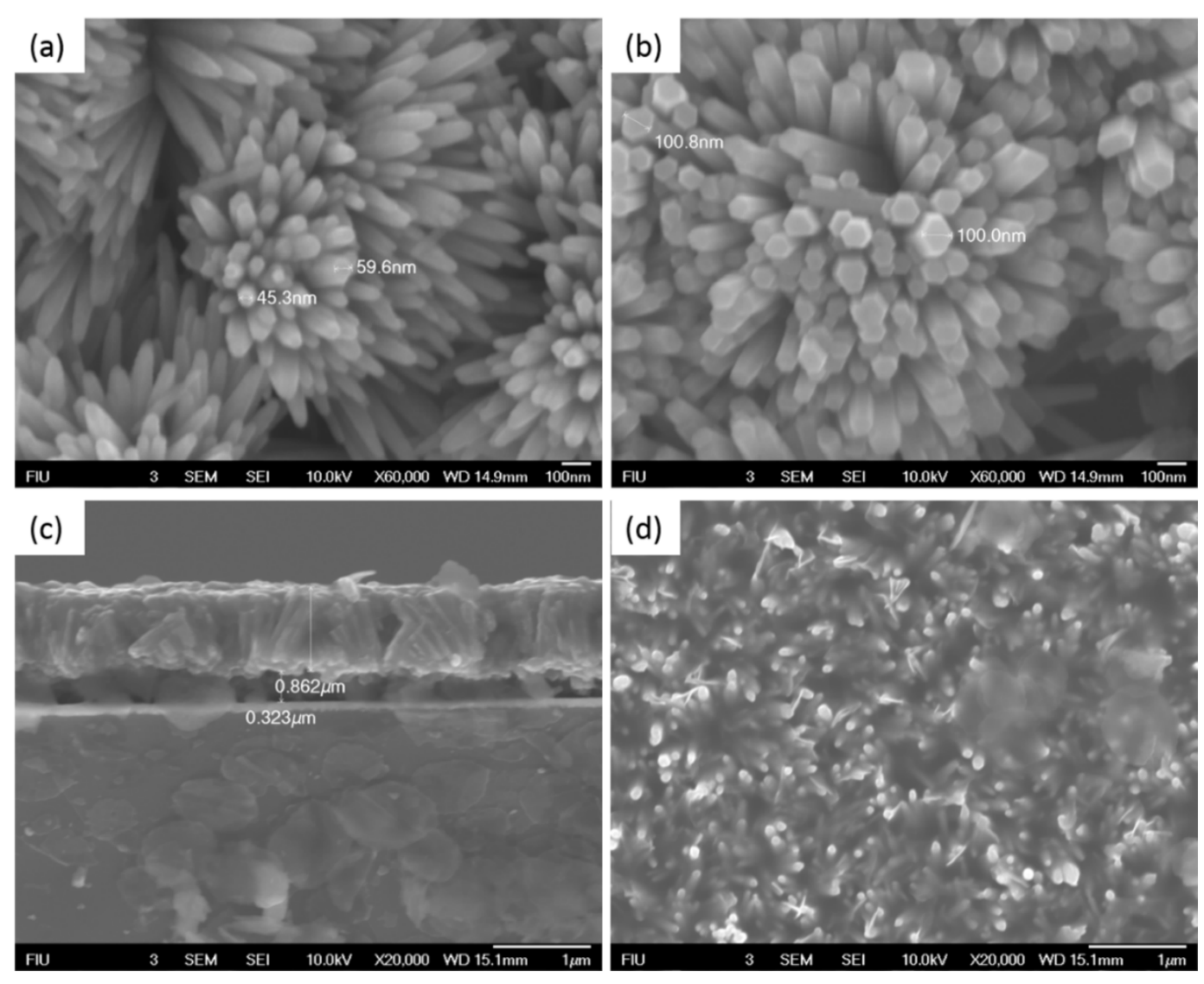

Figure 4.4. Structural characterization of $\mathrm{ZnO}$ core-shell by SEM: (a) $\mathrm{ZnO}$ nanorods with mean diameter of $50 \mathrm{~nm}$; (b) $\mathrm{ZnO}$ core-shell structure with mean diameter $100 \mathrm{~nm}$; (c) Cross-sectional view of P:ZnO nanoshell/ n- ZnO NR filled with PMMA; (d) partially etched PMMA and exposed tips of P:ZnO nanoshell for contact deposition.

Figure 4.5 (a-b) show the TEM image of a single core-shell nanorod and corresponding selected area electron diffraction pattern respectively. The $\mathrm{ZnO}$ core can be easily distinguished from the $\mathrm{P}: \mathrm{ZnO}$ nanoshell due to an obvious difference in contrast between core and shell regions. From the SAED pattern, it is obvious that both the $\mathrm{ZnO}$ core and $\mathrm{ZnO}$ nanoshell that encloses $\mathrm{ZnO}$ rod are single crystalline and forms a defect free junction. 
The result of the chemical composition analysis, which was performed using energy dispersive X-ray spectroscopy (EDS) is presented in Figure 4.5 (c), shows $0.96 \%$ weight of Phosphorous in the P:ZnO nanoshells. Figure 4.5 (d) shows the X-ray diffraction (XRD) measurements of both undoped $\mathrm{ZnO}$ nanorods and $\mathrm{p}$ doped $\mathrm{P}: \mathrm{ZnO}$ nanoshell/n- $\mathrm{ZnO} \mathrm{NR}$ structures after annealing. In $\mathrm{ZnO}$ nanorods, $\mathrm{ZnO}(002)$ diffraction peak is the dominant peak, which indicates that the samples have a preferred orientation along c-axis. We also observe $\mathrm{ZnO}$ (101) peak, which could be attributed to the tips of $\mathrm{ZnO}$ nanorods that sharpen like needles. In case of 'P' doped P:ZnO nanoshel1/n- ZnO NR the (002) peak is the only dominant peak which corresponds well with the SEM pictures showing smooth hexagonal edges on the nanoshells. We also observe that compared with the $\mathrm{ZnO} \mathrm{NR}$, the position of (002) diffraction peak in $\mathrm{P}: \mathrm{ZnO}$ nanoshell/ $\mathrm{n}$ - $\mathrm{ZnO}$ NR has shifted to the large-angle side by 1.2 degrees which provide a strong evidence that $\mathrm{ZnO}$ nanoshell has been successfully doped with phosphorous. Similar behavior was reported in earlier reports of 'P' doped ZnO. [40] In figure 4.5 (e) Raman spectra of the undoped $\mathrm{ZnO}$ nanorod and 'P' doped $\mathrm{P}: \mathrm{ZnO}$ nanoshell are presented. The non-polar $\mathrm{E}_{2}$ mode $\left(\mathrm{E}_{2}{ }^{\text {high }}\right)$, which was observed at 436 $\mathrm{cm}^{-1}$ in $\mathrm{ZnO}$ nanorods red shifts by $1.8 \mathrm{~cm}^{-1}$ (to $434.2 \mathrm{~cm}^{-1}$ ) and broadens in $\mathrm{P}: \mathrm{ZnO}$ nanoshell. Such shift in the non- polar $\mathrm{E}_{2}$ mode was reported earlier in Sb-doped and Ndoped $\mathrm{ZnO}$. This decrease in frequency can be ascribed to the local lattice softening due to the incorporation of ' $\mathrm{P}$ ' ions. Both XRD and Raman spectrum confirm the substitution of $\mathrm{Zn}$ sites by $\mathrm{P}$ ions in the crystal lattice and formation of $\mathrm{P}_{\mathrm{zn}}-2 \mathrm{~V}_{\mathrm{zn}}$ complex defects. [46, 47] 
Current-voltage (I-V) measurement is a useful tool to verify the formation of a p-n junction and to study the evolution of doping. Here, we studied the evolution of p-type doping by measuring the electrical current between the $\mathrm{P}: \mathrm{ZnO}$ nanoshell and $\mathrm{n}-\mathrm{ZnO} \mathrm{NR}$ for various concentrations of ADP. For this purpose, Ni/Au contact was deposited on the top of $\mathrm{P}: \mathrm{ZnO}$ nanoshells prepared with different concentrations of $\mathrm{ADP}$ and $\mathrm{Ti} / \mathrm{Au}$ contact deposited on $\mathrm{ZnO}$ nanorods acts as ohmic contact on the n-side.
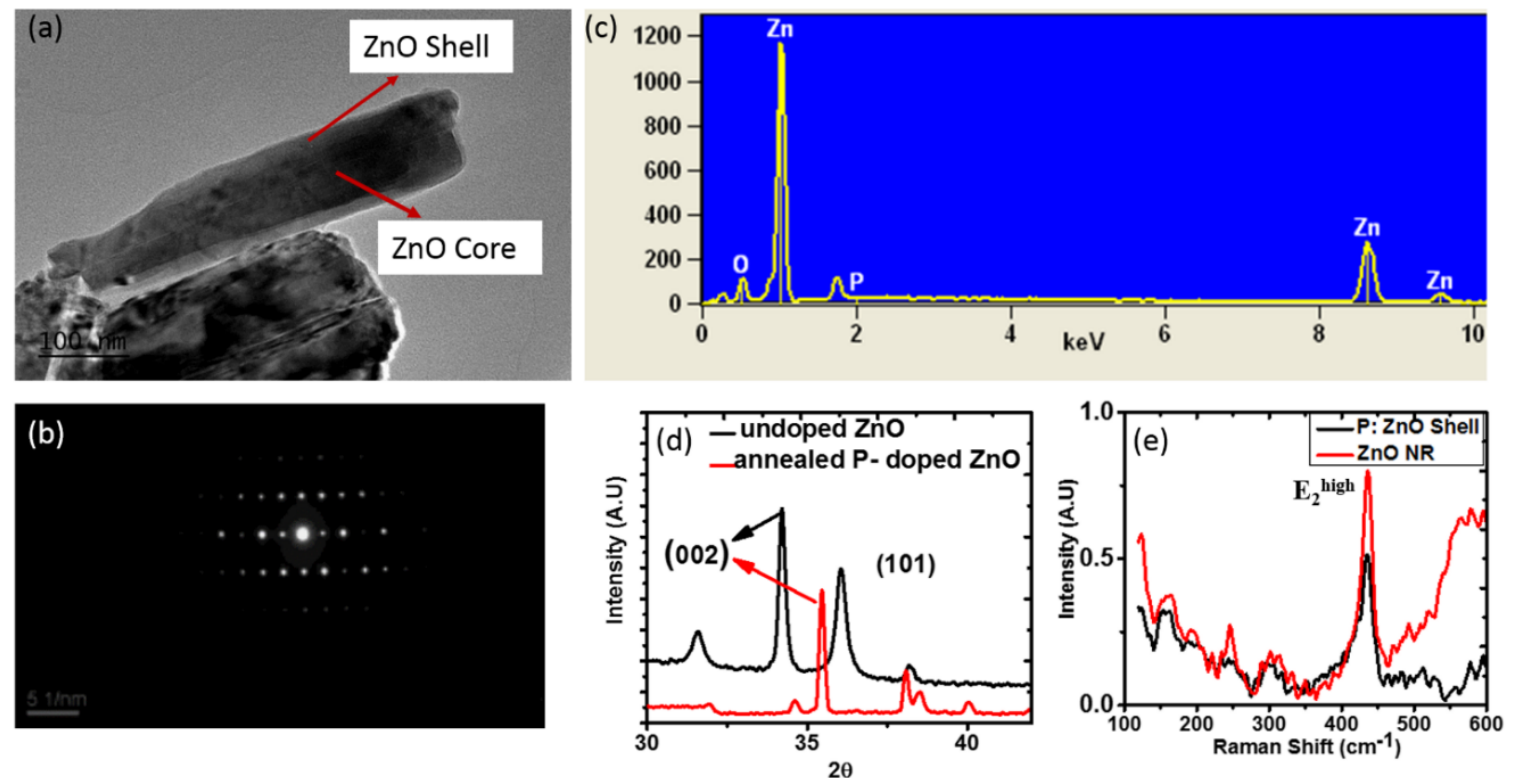

Figure 4.5. Growth orientation determination and chemical composition analysis by TEM, SAED, EDS, XRD and Raman: (a) TEM image of ZnO core-shell nanorod scratched from the substrate, shows a clear interface between nanoshell and core; (b) SAED pattern showing the nanorods are oriented along (002) plane; (c) EDS showing the presence of $\mathrm{ZnO}$ and $\mathrm{P}$; (d) XRD of $\mathrm{ZnO}$ nanorods showing the growth dominated along (002) plane; (e ) Raman spectrum of undoped and p-doped $\mathrm{ZnO}$ on ITO substrate where $\mathrm{E}_{2}^{\text {high }}$ peak is shifted by $1.8 \mathrm{~cm}^{-1}$ towards the lower frequency.

Figure 4.6 (a) shows the schematic of P:ZnO nanoshell/n-ZnO NR p-n junction. Figure 4.6 (b-d) and (h) show the evolution of p-doping in $\mathrm{ZnO}$ as the concentration of ADP is increased from $1 \mathrm{mM}$ to $1.6 \mathrm{mM}$. The rectification in current is observed when the 
concentration of ADP is $1.6 \mathrm{mM}$ shown in figure $4.6(\mathrm{~h})$, which proves successful p-type doping in $\mathrm{ZnO}$ nanoshells. The current - voltage measurement between two contacts placed on the same side have shown a linear behavior which confirms the formation of ohmic contacts and the rectification observed is entirely due to the junction between $\mathrm{P}: \mathrm{ZnO}$ nanoshell and $\mathrm{ZnO}$ nanorod. Beyond $1.6 \mathrm{mM}$ concentration of $\mathrm{ADP}$ the $\mathrm{pH}$ of the precursor solution becomes high making it untenable for growth using sonochemistry. It was also observed that temperature plays a crucial role in activating the dopants as can be seen from figure 4.6 (e-h), where I-V measurements of samples with same concentration of ADP and annealed at temperatures $25^{\circ} \mathrm{C}, 300{ }^{\circ} \mathrm{C}, 400{ }^{\circ} \mathrm{C}$ and $500{ }^{\circ} \mathrm{C}$ were presented. We found that the dopants are activated after annealing at $500{ }^{\circ} \mathrm{C}$ for 30 minutes. This annealing temperature is required for the $\mathrm{Zn}_{3}\left(\mathrm{PO}_{4}\right)_{2}$ induced in to the $\mathrm{ZnO}$ nanorods during cavitation to decompose and release ' $\mathrm{P}$ ' atoms, which would diffuse in to the $\mathrm{ZnO}$ crystal acting as acceptor dopants.[40] From figure 4.6 (h) we measured the junction properties. The turnon voltage is about $0.5 \mathrm{~V}$ and the reverse bias leakage current at $-2 \mathrm{~V}$ is $200 \mu \mathrm{A}$ which increases with increasing reverse bias voltage. This could be due to non-uniform doping in the P:ZnO nanoshell region. The ideality factor of the diode ' $n$ ' can be calculated from:

$$
n=\frac{q}{k T}\left(\frac{\partial \ln I}{\partial V}\right)^{-1}
$$

where $V$ is the applied voltage, $k$ is the Boltzmann constant and the whole value of $k T / q$ can be expressed as $0.0258 \mathrm{eV}$ at $\mathrm{T}=300 \mathrm{~K}$. In the voltage range of $0.5 \mathrm{~V}$ and $2 \mathrm{~V}$, the ideality factor ' $n$ ' was calculated to be 37 . Such high ideality factors in wide bandgap semiconductors have been reported earlier. [48] 

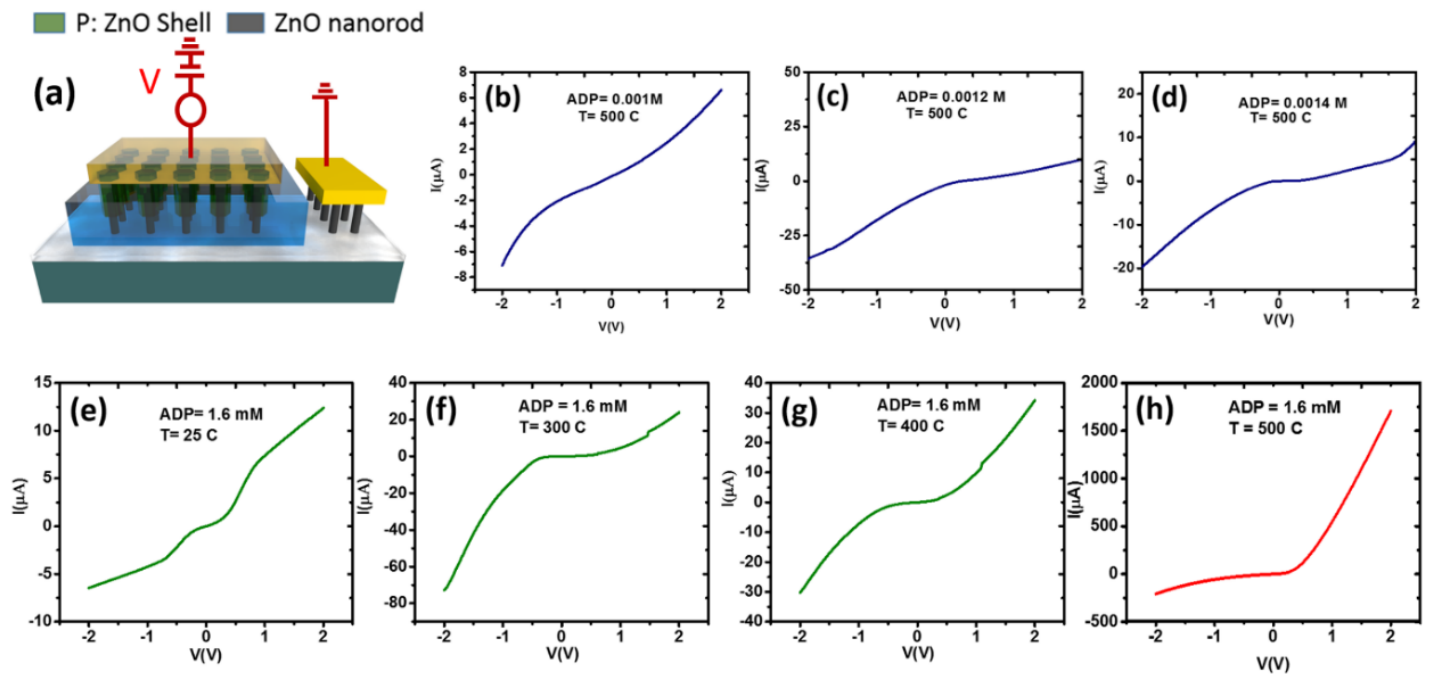

Figure 4.6. Verification of $p-n$ junction by I-V measurements: (a) Schematic of $P: Z n O$ nanoshell/ $\mathrm{n}$ - ZnO NR p-n junction; (b) I-V curve for $1 \mathrm{mM}$ ADP doped $\mathrm{ZnO}$ nanoshell; (c) I-V curve for $1.2 \mathrm{mM}$ ADP doped $\mathrm{ZnO}$ nanoshell; (d) I-V curve for $1.4 \mathrm{mM}$ ADP doped $\mathrm{ZnO}$ nanoshell; ( e) I-V curve for $1.6 \mathrm{mM}$ ADP doped $\mathrm{ZnO}$ nanoshell at room temperature; (f) I-V curve for $1.6 \mathrm{mM}$ ADP doped $\mathrm{ZnO}$ nanoshell at $300{ }^{\circ} \mathrm{C}$; (g) I-V curve for $1.6 \mathrm{mM}$ ADP doped $\mathrm{ZnO}$ nanoshell at $400{ }^{\circ} \mathrm{C}$; (h) I-V curve for $1.6 \mathrm{mM}$ ADP doped $\mathrm{ZnO}$ nanoshell at $500{ }^{\circ} \mathrm{C}$.

Capacitance voltage (C-V) measurements were measured using Keithley 4210- CVU to study the doping concentration of the as grown p-type $\mathrm{ZnO}$ nanoshells. When inverse of square of capacitance density was plotted against reverse bias voltage a linear plot is obtained. The slope of this plot is related to the doping density by:

$$
N_{A}=\frac{-2}{q \varepsilon_{0} \varepsilon_{r}} \frac{1}{\frac{d(A / C)^{2}}{d v}}
$$

where $\mathrm{q}=1.6 \times 10^{-19} \mathrm{C}$ is the charge of an electron, $\mathcal{E}_{0}=8.85 * 10^{-14}$ is the permittivity of the free space, $\varepsilon_{\mathrm{r}}=$ relative permittivity of the medium, 'A' is the area of the contact and ' $\mathrm{C}$ ' is the measured capacitance. Figure 4.7 (a, b) shows the capacitance vs voltage at 
different frequencies and $(\mathrm{A} / \mathrm{C})^{2}$ vs voltage of the $\mathrm{p}-\mathrm{n}$ junction at $10 \mathrm{kHz}$ frequency. The doping concentration $\mathrm{N}_{\mathrm{A}}$ at $10 \mathrm{~K} \mathrm{~Hz}$ frequency was calculated to be $6.7 \times 10^{17} \mathrm{~cm}^{-3}$ by measuring the slope of the C-V curve in the reverse bias presented in figure 4.7 (a).
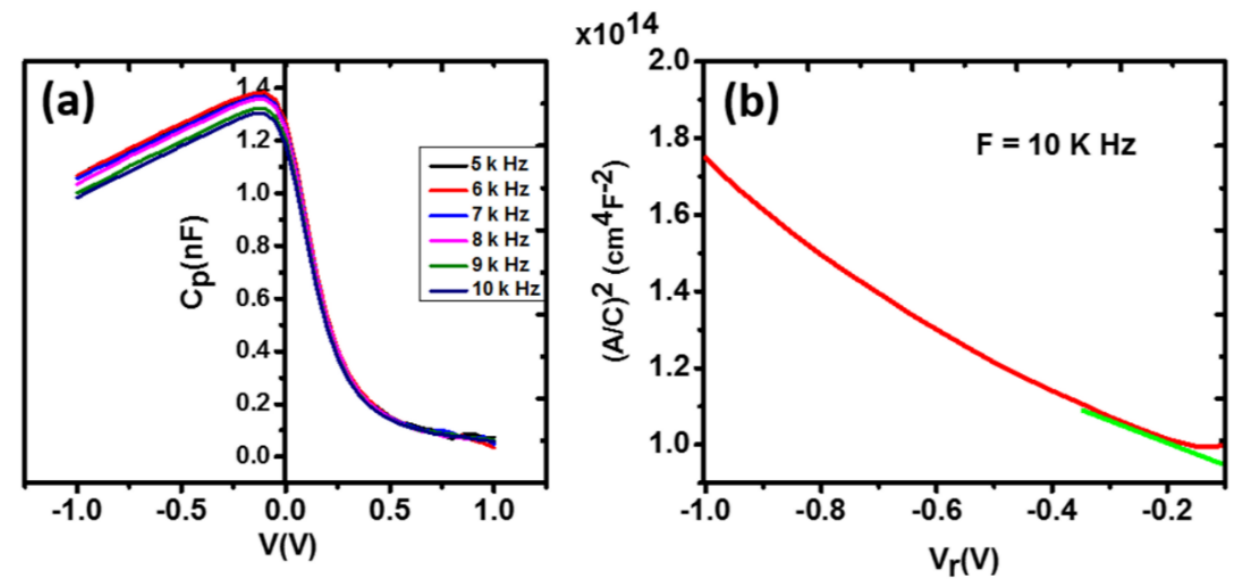

Figure 4.7. Study of doping concentration by $\mathrm{C}-\mathrm{V}$ measurements: (a) Capacitance vs Voltage measurements at frequencies between $5 \mathrm{k} \mathrm{Hz}$ to $10 \mathrm{k} \mathrm{Hz}$; (b) $1 /(\mathrm{C} / \mathrm{A})^{2}$ vs Reverse Voltage at $10 \mathrm{~K} \mathrm{~Hz}$ frequency.

\subsection{Conclusions}

We have developed and optimized a process to successfully dope $\mathrm{ZnO}$ both $\mathrm{n}$ - type and ptype by using 'Al' and ' $\mathrm{P}$ ' as respective dopants using sonochemistry for the first time. We have fabricated a radial p-n junction photo diode in a core-shell geometry. The core-shell structure was synthesized without using any external surfactants but rather used only different molar ratios of precursors. A doping concentration of $6.7 \times 10^{17} \mathrm{~cm}^{-3}$ was achieved for the $\mathrm{P}: \mathrm{ZnO}$ nanoshells. The as fabricated homogeneous $\mathrm{p}-\mathrm{n}$ junction shows a rectifying behavior with an ideality factor of 37 and a reverse saturation current of $200 \mu \mathrm{A}$ at $-2 \mathrm{~V}$. The developed method is fast, inexpensive and performed at ambient conditions while 
resulting very small amount of impurities. This facilitates the use of flexible substrates for $\mathrm{ZnO}$ nanostructures, opening the door for flexible and wearable electronic and photonic devices based on $\mathrm{ZnO}$.

\subsection{References}

1. Ko, H. J., Chen, Y. F., Hong, S. K., Wenisch, H., Yao, T., \& Look, D. C. (2000). Gadoped $\mathrm{ZnO}$ films grown on $\mathrm{GaN}$ templates by plasma-assisted molecular-beam epitaxy. Applied Physics Letters, 77 (23):3761-3763.

2. Major, S., \& Chopra, K. L. (1988). Indium-doped zinc oxide films as transparent electrodes for solar cells. Solar Energy Materials, 17 (5):319-327.

3. Agura, H., Suzuki, A., Matsushita, T., Aoki, T., \& Okuda, M. (2003). Low resistivity transparent conducting Al-doped $\mathrm{ZnO}$ films prepared by pulsed laser deposition. Thin solid films, 445 (2):263-267.

4. Kim, Y. S., \& Tai, W. P. (2007). Electrical and optical properties of Al-doped ZnO thin films by sol-gel process. Applied Surface Science, 253 (11):4911-4916.

5. Kuo, S. Y., Chen, W. C., Lai, F. I., Cheng, C. P., Kuo, H. C., Wang, S. C., \& Hsieh, W. F. (2006). Effects of doping concentration and annealing temperature on properties of highly-oriented Al-doped $\mathrm{ZnO}$ films. Journal of crystal growth, 287 (1):78-84.

6. Shinde, V. R., Gujar, T. P., Lokhande, C. D., Mane, R. S., \& Han, S. H. (2006). Mn doped and undoped $\mathrm{ZnO}$ films: A comparative structural, optical and electrical properties study. Materials Chemistry and Physics, 96 (2):326-330.

7. Kim, T. H., Park, J. J., Nam, S. H., Park, H. S., Cheong, N. R., Song, J. K., \& Park, S. M. (2009). Fabrication of Mg-doped $\mathrm{ZnO}$ thin films by laser ablation of $\mathrm{Zn}: \mathrm{Mg}$ target. Applied Surface Science, 255 (10):5264-5266.

8. Jie, J., Wang, G., Han, X., Yu, Q., Liao, Y., Li, G., \& Hou, J. G. (2004). Indium-doped zinc oxide nanobelts. Chemical Physics Letters, 387 (4):466-470.

9. Deka, S., \& Joy, P. A. (2007). Synthesis and magnetic properties of Mn doped ZnO nanowires. Solid State Communications, 142 (4):190-194. 
10. Etacheri, V., Roshan, R., \& Kumar, V. (2012). Mg-doped ZnO nanoparticles for efficient sunlight-driven photocatalysis. ACS applied materials \& interfaces, 4 (5):2717-2725.

11. Bai, S. N., Tsai, H. H., \& Tseng, T. Y. (2007). Structural and optical properties of Aldoped $\mathrm{ZnO}$ nanowires synthesized by hydrothermal method.Thin Solid Films, 516 (2):155-158.

12. Jin, M., Feng, J., De-Heng, Z., Hong-lei, M., \& Shu-Ying, L. (1999). Optical and electronic properties of transparent conducting $\mathrm{ZnO}$ and $\mathrm{ZnO}$ : $\mathrm{Al}$ films prepared by evaporating method. Thin solid films, 357 (2):98-101.

13. Kim, D., Yun, I., \& Kim, H. (2010). Fabrication of rough Al doped $\mathrm{ZnO}$ films deposited by low pressure chemical vapor deposition for high efficiency thin film solar cells. Current Applied Physics, 10 (3):S459-S462.

14. Yun, S., Lee, J., Yang, J., \& Lim, S. (2010). Hydrothermal synthesis of Al-doped ZnO nanorod arrays on Si substrate. Physica B: Condensed Matter, 405 (1):413-419.

15. Özgür, Ü. Alivov, Y. I., Liu, C., Teke, A., Reshchikov, M., Doğan, S., ... \& Morkoc, H. (2005). A comprehensive review of $\mathrm{ZnO}$ materials and devices. Journal of applied physics, 98 (4):041301.

16. Wang, Z. L. (2004). Zinc oxide nanostructures: growth, properties and applications. Journal of Physics: Condensed Matter, 16(25), R829.

17. Huang, M. H., Mao, S., Feick, H., Yan, H., Wu, Y., Kind, H.,\& Yang, P. (2001). Roomtemperature ultraviolet nanowire nanolasers. Science, 292 (5523):1897-1899.

18. Soci, C., Zhang, A., Xiang, B., Dayeh, S. A., Aplin, D. P. R., Park, J., ... \& Wang, D. (2007). ZnO nanowire UV photodetectors with high internal gain. Nano letters, 7 (4):1003-1009.

19. Wang, Z. L. (2004). Zinc oxide nanostructures: growth, properties and applications. Journal of Physics: Condensed Matter, 16 (25):R829.

20. Sun, X. H., Lam, S., Sham, T. K., Heigl, F., Jürgensen, A., \& Wong, N. B. (2005). Synthesis and synchrotron light-induced luminescence of $\mathrm{ZnO}$ nanostructures: nanowires, nanoneedles, nanoflowers, and tubular whiskers. The Journal of Physical Chemistry B, 109 (8):3120-3125.

21. Liu, Y., Zhong, M., Shan, G., Li, Y., Huang, B., \& Yang, G. (2008). Biocompatible $\mathrm{ZnO} / \mathrm{Au}$ nanocomposites for ultrasensitive DNA detection using resonance Raman scattering. The Journal of Physical Chemistry B, 112 (20):6484-6489. 
22. Arya, S. K., Saha, S., Ramirez-Vick, J. E., Gupta, V., Bhansali, S., \& Singh, S. P. (2012). Recent advances in $\mathrm{ZnO}$ nanostructures and thin films for biosensor applications: review. Analytica chimica acta: 737, 1-21.

23. Hsu, Y. F., Xi, Y. Y., Tam, K. H., Djurišić, A. B., Luo, J., Ling, C. C., ... \& Beling, C. D. (2008). Undoped p-Type $\mathrm{ZnO}$ Nanorods Synthesized by a Hydrothermal Method. Advanced Functional Materials, 18 (7):1020-1030.

24. Minami, T., Yamamoto, T., \& Miyata, T. (2000). Highly transparent and conductive rare earth-doped $\mathrm{ZnO}$ thin films prepared by magnetron sputtering. Thin Solid Films, 366 (1):63-68.

25. Park, C. H., Zhang, S. B., \& Wei, S. H. (2002). Origin of p-type doping difficulty in $\mathrm{ZnO}$ : The impurity perspective. Physical Review B, 66 (7):073202.

26. Wang, G., Chu, S., Zhan, N., Lin, Y., Chernyak, L., \& Liu, J. (2011). ZnO homojunction photodiodes based on Sb-doped p-type nanowire array and n-type film for ultraviolet detection. Applied Physics Letters, 98 (4):041107.

27. Lin, C. C., Chen, S. Y., Cheng, S. Y., \& Lee, H. Y. (2004). Properties of nitrogenimplanted p-type $\mathrm{ZnO}$ films grown on $\mathrm{Si} 3 \mathrm{~N} 4 / \mathrm{Si}$ by radio-frequency magnetron sputtering. Applied physics letters, 84 (24):5040-5042.

28. Vaithianathan, V., Lee, B. T., \& Kim, S. S. (2005). Pulsed-laser-deposited p-type ZnO films with phosphorus doping. Journal of applied physics, 98 (4):3519.

29. Chen, F., Ye, Z., Xu, W., Zhao, B., Zhu, L., \& Lv, J. (2005). Fabrication of p-type ZnO thin films via MOCVD method by using phosphorus as dopant source. Journal of crystal growth, 281 (2):458-462.

30. Look, D. C., Reynolds, D. C., Litton, C. W., Jones, R. L., Eason, D. B., \& Cantwell, G. (2002). Characterization of homoepitaxial p-type $\mathrm{ZnO}$ grown by molecular beam epitaxy. Applied physics letters, 81 (10):1830-1832.

31. Tay, C. B., Chua, S. J., \& Loh, K. P. (2010). Stable p-type doping of ZnO film in aqueous solution at low temperatures. The Journal of Physical Chemistry C, 114 (21):9981-9987.

32. Lin, C. C., Chen, H. P., \& Chen, S. Y. (2005). Synthesis and optoelectronic properties of arrayed p-type $\mathrm{ZnO}$ nanorods grown on $\mathrm{ZnO}$ film/Si wafer in aqueous solutions. Chemical physics letters, 404 (1):30-34.

33. Ashrafi, A. A., Suemune, I., Kumano, H., \& Tanaka, S. (2002). Nitrogen-doped p-type $\mathrm{ZnO}$ layers prepared with $\mathrm{H} 2 \mathrm{O}$ vapor-assisted metalorganic molecular-beam epitaxy. Japanese journal of applied physics, 41 (11B):L1281. 
34. Chen, M. T., Lu, M. P., Wu, Y. J., Song, J., Lee, C. Y., Lu, M. Y., \& Chen, L. J. (2010). Near UV LEDs made with in situ doped pn homojunction $\mathrm{ZnO}$ nanowire arrays. Nano letters, 10 (11):4387-4393.

35. Li, P. J., Liao, Z. M., Zhang, X. Z., Zhang, X. J., Zhu, H. C., Gao, J. Y., ... \& Yu, D. P. (2009). Electrical and photoresponse properties of an intramolecular pn homojunction in single phosphorus-doped $\mathrm{ZnO}$ nanowires. Nano letters, 9 (7):2513-2518.

36. Vabbina, P. K., Nayyar, P., Nayak, A. P., Katzenmeyer, A. M., Logeeswaran, V. J., Pala, N., ... \& Talin, A. A. (2011, September). Synthesis of crystalline ZnO nanostructures on arbitrary substrates at ambient conditions. In SPIE NanoScience+ Engineering (pp. 81060H-81060H). International Society for Optics and Photonics.

37. Avrutin, V., Silversmith, D. J., \& Morkoç, H. (2010). Doping asymmetry problem in $\mathrm{ZnO}$ : current status and outlook. Proceedings of the IEEE, 98 (7):1269-1280.

38. Jie, T. (2014). Doping and its effect on $\mathrm{ZnO}$ properties (Doctoral dissertation).

39. Lee, W. J., Kang, J., \& Chang, K. J. (2006). Defect properties and p-type doping efficiency in phosphorus-doped ZnO. Physical Review B, 73 (2):024117.

40. Fang, X., Li, J., Zhao, D., Shen, D., Li, B., \& Wang, X. (2009). Phosphorus-doped ptype $\mathrm{ZnO}$ nanorods and $\mathrm{ZnO}$ nanorod $\mathrm{p}-\mathrm{n}$ homojunction LED fabricated by hydrothermal method. The Journal of Physical Chemistry C,113 (50):21208-21212.

41. Vabbina, P. K., Kaushik, A., Pokhrel, N., Bhansali, S., \& Pala, N. (2015). Electrochemical cortisol immunosensors based on sonochemically synthesized zinc oxide 1D nanorods and 2D nanoflakes. Biosensors and Bioelectronics, 63:124-130.

42. Xu, S., \& Wang, Z. L. (2011). One-dimensional ZnO nanostructures: solution growth and functional properties. Nano Research, 4 (11):1013-1098.

43. Das, S., Dutta, K., \& Pramanik, A. (2013). Morphology control of ZnO with citrate: a time and concentration dependent mechanistic insight.CrystEngComm, 15 (32):63496358.

44. Tian, Z. R., Voigt, J. A., Liu, J., Mckenzie, B., Mcdermott, M. J., Rodriguez, M. A., ... $\& \mathrm{Xu}, \mathrm{H}$. (2003). Complex and oriented $\mathrm{ZnO}$ nanostructures. Nature materials, 2 (12):821-826.

45. Pradel, K. C., Ding, Y., Wu, W., Bando, Y., Fukata, N., \& Wang, Z. L. (2016). Optoelectronic Properties of Solution Grown $\mathrm{ZnO} n \mathrm{np}$ or pn Core-Shell Nanowire Arrays. ACS applied materials \& interfaces, 8 (7):4287-4291. 
46. Samanta, K., Bhattacharya, P., \& Katiyar, R. S. (2010). Raman scattering studies of ptype Sb-doped ZnO thin films. Journal of Applied Physics, 108 (11):3501.

47. Du, G., Ma, Y., Zhang, Y., \& Yang, T. (2005). Preparation of intrinsic and N-doped ptype $\mathrm{ZnO}$ thin films by metalorganic vapor phase epitaxy. Applied Physics Letters, 87 (21).

48. Nguyen, X. S., Tay, C. B., Fitzgerald, E. A., \& Chua, S. J. (2012). ZnO Coaxial Nanorod Homojunction UV Light-Emitting Diodes Prepared by Aqueous Solution Method. Small, 8 (8):1204-1208. 


\section{CHAPTER 5}

\section{Zinc Oxide Based Biosensing}

Zinc oxide nanostructures have been extensively used in fabrication of biosensors over the past few decades. The interest in $\mathrm{ZnO}$ nanostructures originates from their high biocompatibility, low toxicity and high isoelectric point. Zinc Oxide nanostructures due to high anisotropy can be grown in various morphologies and as such a myriad of nanostructures were studied for sensing various biological materials such as glucose, galactose cholesterol etc. During the course of this research we fabricated electrochemical immunosensors for detection of cortisol using $\mathrm{ZnO}$ NRs and ZnO NFs as immobilizing matrix and compared their performance and rate of electron transport.

\subsection{Electrochemical Cortisol Immunosensor Based on Sonochemically Synthesized 1D ZnO Nanorods and 2D ZnO Nanoflakes}

Electrochemical immunosensors demonstrate improved performance over other sensing methods with increased detection range, rapid selective detection, and higher sensitivity which make them the preferred sensing method of targeted biomolecules for health quality monitoring. In order to achieve low detection limits and high sensitivity the immobilizing matrix used in immunosensors should have high surface functionality, high biomolecule loading and small resistance to electron transport resulting in high electron transfer rate. $[1,2]$ This encourages researchers to explore the utilization of inorganic semiconductor nanostructures (NSs) as potential immobilizing matrix for immunosensor development to detect desired target analyte. [2] $\mathrm{ZnO}$, a semiconducting material with high catalytic 
efficiency, biocompatibility, chemical stability in physiological environments, low toxicity and a high isoelectric point (IEP) of about 9.5, has all the qualities for biosensing applications.[3,4] Literature shows the use of $\mathrm{ZnO}-\mathrm{NSs}$ with different morphologies such as nanorods (NRs), nanowalls (NWs), nanobelts and quantum dots as immobilizing matrix in fabrication of biosensors for the detection of physiologically relevant biomarkers such as cholesterol, galactose, glucose.[5-8] These sensors have demonstrated high stability, better sensitivity, fast response time and excellent selectivity. 1D ZnO-NRs which boast high surface-to-volume ratio, and high electron mobility [9] provides a direct, stable pathway for rapid electron transport and have emerged as a very promising material for immobilization of biomolecules without electron mediator for use in immunosensor. [1012] However, despite high surface area in $1 \mathrm{D} \mathrm{ZnO}-\mathrm{NRs}$ most of the area is enclosed by non-polar(10-10) facets, which have less catalytic activity compared to (0001) plane. This results in reduced sensitivities due to diminished signal strength and weak adsorption of antibody. Apart from small signal strength, incompatibility with CMOS process, difficulty in making electrical contacts and conventional nanostructure synthesis processes that generally require high temperature hinder the integration of $1 \mathrm{D}$ ZnO-NSs in immunosensors.[14] 2D ZnO-NFs synthesized by sonochemical method have greater active surface area in (0001) plane. [19] This provides more binding sites for antibody in (0001) plane which has high surface charge density, higher catalytic activity, smaller charge transfer resistance and higher signal strength. Fabrication of electrical contacts on 2D nanostructures is much easier than 1D structures which allows for easier integration in to CMOS devices. Sonochemical process is a simple one-step process in which high quality single crystalline $\mathrm{ZnO}-\mathrm{NS}$ 's are grown at ambient conditions on a variety of substrates. 
The method is rapid, inexpensive, low-temperature, catalyst-free, CMOS compatible, and environmentally benign. [14,15]

In this part of the research, a simple low-cost and label free immunosensors were fabricated using $1 \mathrm{D} \mathrm{ZnO}-\mathrm{NRs}$ and 2D ZnO-NFs as immobilizing matrix to detect cortisol. In brief, Cortisol is a steroid hormone known as a potential biomarker for psychological stress estimation. Abnormality in cortisol levels is an indicative of many other disorders such as Cushing's disease, inflammation and Addison's disease. [16, 17] Cortisol is an important molecule in regulating blood pressure, glucose levels, and carbohydrate metabolism. The conventional laboratory cortisol detection techniques such as chromatography, spectroscopy, immune-assays and ELISA are only limited to laboratory as they involve time taking measurement, complex sample preparation and expensive diagnosis. [16] This deemed the necessity of electrochemical immunosensing protocol for rapid and selective cortisol detection.

For selective cortisol estimation, Anti-cortisol antibody (Anti- $\mathrm{C}_{\mathrm{ab}}$ ) obtained from the BIO-MEMS \& MICROSYSTEMS lab at FIU was immobilized on ZnO-NSs matrix via electrostatic interaction. The electron transfer phenomena for both $\mathrm{ZnO}-\mathrm{NSs}$ during fabrication of immunosensor was studied using electrochemical impedance spectroscopy (EIS). The results of cyclic voltammetry (CV) studies related to electrochemical sensing showed a high sensitivity of $11.86 \mu \mathrm{A} / \mathrm{M}$ for sensor fabricated with $\mathrm{ZnO} \mathrm{NRs}$ as immobilizing matrix and a low detection concentration of $1 \mathrm{pM}$. For real applications, the developed immunosensor were tested on human salivary cortisol and results were validated using ELISA technique. 


\subsubsection{Synthesis of ZnO Nanostructures}

Two different morphologies, 1D ZnO-NRs which are oriented perpendicular to the substrate and 2D ZnO-NFs were synthesized via sonochemical method described in previous chapter 3 and reported elsewhere. [18, 19]

For $\mathrm{ZnO}-\mathrm{NRs}$, 150nm gold was initially deposited on ' $\mathrm{Si}$ ' substrate by e-beam evaporation followed by growth of $\mathrm{ZnO}$ seed layer and $\mathrm{ZnO}$ NRs. The seeding process was performed by immersing the substrate in a solution of isopropyl alcohol and $5 \mathrm{mM}$ ZAD. The solution was then irradiated using a commercially available high-intensity ultrasound setup (750 W ultrasonic processor, Sonics and Systems), for 1-15 min cycles at an amplitude of $75 \%$ of the maximum amplitude $\left(\approx 32.14 \mathrm{~W} \mathrm{~cm}^{-2}\right)$ and frequency of $20 \mathrm{kHz}$. After the seed layer, nanorods were grown by immersing the substrate in an aqueous solution of $0.02 \mathrm{M} \mathrm{ZNH}$ and $0.02 \mathrm{M}$ HMT and irradiating the solution at $50 \%$ of the maximum amplitude of the ultrasonic probe for 20 minutes providing the solution with an intensity of $21 \mathrm{~W} . \mathrm{cm}^{-2}$. The substrate was rinsed with DI water then dried with $\mathrm{N}_{2}$ after each cycle. For, $\mathrm{ZnO}-\mathrm{NFs}$, 150nm gold was initially deposited on 'Si' substrate by e-beam evaporation, followed by growth of ZnO-NFs. A solution of $20 \mathrm{mM}$ ZNH and $20 \mathrm{mM}$ HMT prepared at room temperature by stirring with a magnetic stir bar at $350 \mathrm{rpm}$ for $5 \mathrm{~min}$ to ensure a mixed solution was used as the only solution for the growth of $2 \mathrm{D} \mathrm{ZnO}-\mathrm{NFs}$. The solution with the immersed substrate was then irradiated at $70 \%$ of the maximum amplitude $\left(\approx 30 \mathrm{~W} \mathrm{~cm}^{-2}\right)$ and $20 \mathrm{kHz}$ frequency for 15 minutes. This process was repeated four times to ensure a uniform growth. The temperature of the aqueous solutions did not exceed $\approx 70^{\circ} \mathrm{C}$. 


\subsubsection{Fabrication of ZnO-NSs Based Immunosensors}

For the preparation of $\mathrm{ZnO}-\mathrm{NSs}$ based immunosensor, $10 \mu \mathrm{L}$ of Anti- $\mathrm{C}_{\mathrm{ab}}$ was covalently immobilized via electrostatic interaction. A huge difference in IEPs of $\mathrm{ZnO}$ (9.5) and antibody (4.5) ensures high binding strength using physical adsorption. Phosphate buffer saline (PBS, pH 7.4, $10 \mathrm{mM}$ ) solution was prepared by dissolving $1 \mathrm{PBS}$ tablet in $200 \mathrm{~mL}$ of de-ionized water and was used to wash the $\mathrm{ZnO}-\mathrm{NSs} / \mathrm{Au}$ electrodes after they were incubated with Anti- $\mathrm{C}_{\mathrm{ab}}$ for $2 \mathrm{hrs}$ to remove any unbound molecules. The non-binding sites of Anti- $\mathrm{C}_{\mathrm{ab}} / \mathrm{ZnO}-\mathrm{NSs} / \mathrm{Au}$ bio electrode were blocked by immobilizing $10 \mu \mathrm{L}$ of bovine serum albumin (BSA) for 1 hour followed by washing in PBS solution and drying at room temperature. The fabricated $\mathrm{BSA} / \mathrm{Anti}-\mathrm{C}_{\mathrm{ab}} / \mathrm{ZnO}-\mathrm{NSs} / \mathrm{Au}$ immunoelectrodes were stored in refrigerator at $4{ }^{\circ} \mathrm{C}$ when not in use.

\subsubsection{Structural and Morphological Characterization}

Scanning Electron Microscopy (SEM, JOEL 7000 FSEM) was used to image the surface during various stages of electrode fabrication. Figure $5.1(\mathrm{a}, \mathrm{b})$ show scanning electron microscopy (SEM) images of vertically oriented and uniformly grown $\mathrm{ZnO}-\mathrm{NRs}$ and 2D $\mathrm{ZnO}-\mathrm{NFs}$ over $\mathrm{Au} / \mathrm{Si}$ substrate. The average diameter of $\mathrm{ZnO}-\mathrm{NRs}$ is $20 \mathrm{~nm}$ and the average length is $3 \mu \mathrm{m}$. $\mathrm{ZnO}-\mathrm{NFs}$ are $20 \mathrm{~nm}$ thick and have the average lateral dimensions of $5 \mu \mathrm{m} \times 5 \mu \mathrm{m}$. Figure. 5.1 (a-b) shows the FESEM image of $\mathrm{ZnO}-\mathrm{NR} / \mathrm{Au}$ and $\mathrm{ZnO}-\mathrm{NF} / \mathrm{Au}$ electrodes before Anti- $\mathrm{C}_{\mathrm{ab}}$ antibody was immobilized. Both anodes show a uniform and dense growth of $\mathrm{ZnO}$ nanorods and $\mathrm{ZnO}$ nanoflakes over gold coated silicon substrates. 

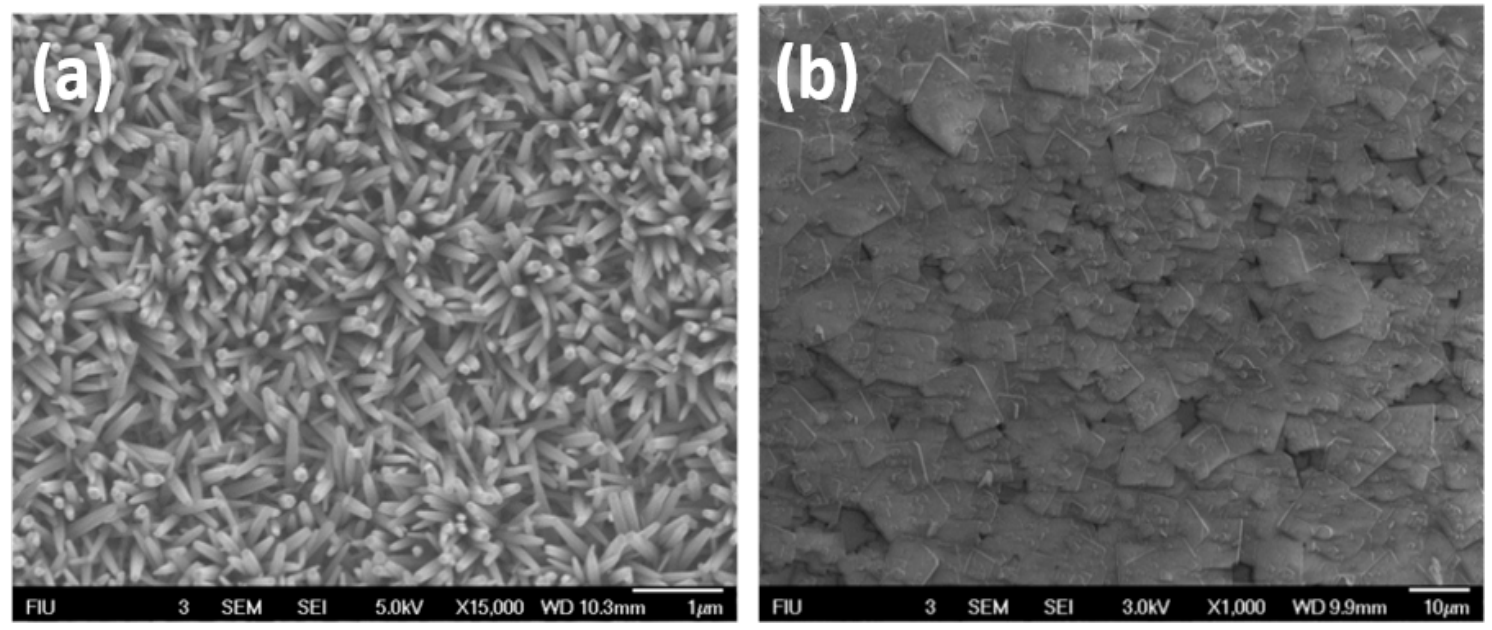

Figure 5.1 (a) $\mathrm{ZnO}$ nanorods on $\mathrm{Au} / \mathrm{Si}$ substrate (b) $\mathrm{ZnO}$ nanoflakes grown in $\mathrm{Au} / \mathrm{Si}$ substrate.

Atomic force microscopy (AFM) is a powerful tool used to study the surface roughness variations at nanoscale. This helps us to understand and quantify the adsorption of antibody over the $\mathrm{ZnO}$ nanostructures after introduction of Anti- $\mathrm{C}_{\mathrm{ab}}$. The surface roughness of the electrodes prior to the introduction of antibody was measured at INSYST using atomic force microscope from Nanonics which is operated in resonance frequency mode using a 'Cr' tip with a resonant frequency of $34.95 \mathrm{kHz}$ and tip diameter $20 \mathrm{~nm}$. This roughness will be later compared with the one calculated after immobilization of antibody to study the amount of antibody that was immobilized. High Resolution Transmission Electron Microscopy (HRTEM), Tecnai transmission electron microscope with $300 \mathrm{keV}$ electron beam was used to obtain, HRTEM and SAED data. The data confirms that both ZnO-NRs and $\mathrm{ZnO}-\mathrm{NFs}$ are single crystalline and oriented in [0001] direction with wurtzite structure. Raman Spectroscopy was studied using Nomadic Raman microscope by BaySpec (532 nm laser). 


\subsubsection{Electrochemical Characterization}
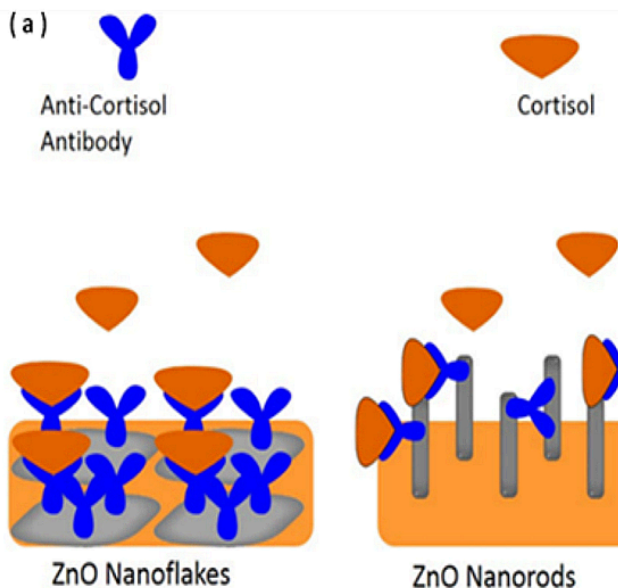

(b)

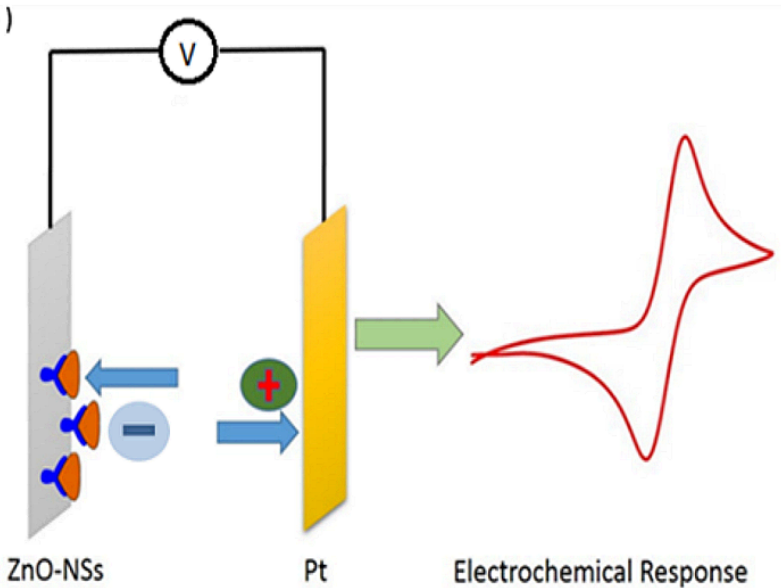

Figure 5.2 (a) Illustration of $\mathrm{ZnO}-\mathrm{NRs}$ and $\mathrm{ZnO}-\mathrm{NFs}$, prepared using sonochemical method along with immobilization of monoclonal anti-cortisol antibody onto $\mathrm{ZnO}$-NSs to fabricate electrochemical cortisol immunosensor. (b) Electrochemical response at the fabricated electrodes.

In an electrochemical immunosensor, oxidation occurs at the biomolecule immobilized electrode-electrolyte interface, where the biomolecule is oxidized as it loses electrons which are collected by the $\mathrm{ZnO}$ nanostructures (Figure 5.2). The generated electrons are rapidly transferred through the electrode material to the external circuit. However, most biomolecules are insulating in nature which increases the charge transfer resistance inhibiting the charge carriers. This change in resistance is used in sensing the biomolecule otherwise called antigen as, clear and distinct oxidation peaks are detected for varying concentrations of biomolecule during $\mathrm{CV}$ measurements. Therefore, in fabricating electrodes for an effective biosensor, factors such as high antibody binding and electron transfer rate play a major role. 1D $\mathrm{ZnO}-\mathrm{NRs}$ with high IEP $(\sim 9.5)$ has positive surface charge at $\mathrm{pH}$ value less than 9.5. All the experiments in this report were at a $\mathrm{pH}$ of 7.4 
which was the recommended $\mathrm{pH}$ to presume higher biological activity. At this $\mathrm{pH}$ value 1D ZnO-NRs provides binding sites for antibody $\left(\right.$ Anti- $\mathrm{C}_{\mathrm{ab}}$ ) whose isoelectric point is 4.2 and thereby is negatively charged under the experimental conditions. The high surface area in 1D nanostructures when compared to bulk materials will provide much more binding sites thereby increasing the antibody loading. At the same time 2D ZnO-NFs also result in high antibody binding due to large area in (0001) plane which has higher catalytic activity and low charge transfer resistance.

EIS and CV studies were performed to compare the electro active behavior of the electrodes. The electro activity of $\mathrm{ZnO}-\mathrm{NRs} / \mathrm{Au}, \mathrm{ZnO}-\mathrm{NFs} / \mathrm{Au}, \mathrm{Anti}-\mathrm{C}_{\mathrm{ab}} / \mathrm{ZnO}-\mathrm{NRs} / \mathrm{Au}$ and Anti- $\mathrm{C}_{\mathrm{ab}} / \mathrm{ZnO}-\mathrm{NF}$ s/Au electrodes was studied using a three electrode system with $3 \mathrm{~mL}$ PBS (pH 7.4) containing $5 \mathrm{mM} \mathrm{Fe}(\mathrm{CN})_{6}^{3-/ 4-}$ acting as an electrolyte. VMP3 electrochemical workstation from BioLogic Science Instrument, France was purchased to perform the electrochemical analysis. All CV measurements were performed at $30 \mathrm{mV} / \mathrm{s}$ scan rate which ensured maximum and repeatable current values. The $\mathrm{CV}$ measurements were made between $-0.6 \mathrm{~V}$ to $0.6 \mathrm{~V}$ multiple times in order to test the repeatability. The obtained results show that the $\mathrm{ZnO}-\mathrm{NSS}$ are stable over a period of time. All the electrochemical measurements were made in triplet set and an average is used for analysis.

\subsubsection{Electrochemical Sensing of Cortisol}

Saliva samples were derived from a biologically-relevant sample of two female agricultural workers of reproductive age who engage in shift-work. Much evidence indicates that cortisol levels vary significantly among female shift workers, and that stress associated with agricultural work is associated with cortisol level variation, as is exposure to cortisol. 
Farmworkers were 24 and 39 years of age, and were recruited based on the following criteria: be at least 18 years of age, work in agricultural fieldwork, work early morning shifts, and have exposure to pesticides. These samples were drawn from another study measuring the effects of a behavioral study to assess pesticide exposures and stress response. Recruitment, analyses and other procedures for this study were approved by the Human Subjects Boards at the Penn State University and the Florida International University.

Samples were collected five times: at awakening, before their first work break, at their lunch break (before eating), upon arrival from work and before bedtime. Samples were stored by participants at freezing temperature $\left(-20^{\circ} \mathrm{C}\right)$ until they were transferred and stored at -80 by the project team in the field lab. The standard protocol requires saliva samples to be stored at $-20{ }^{\circ} \mathrm{C}$ or lower for preservation of natural and biological properties over extended periods and while transportation. Each farmworker were given written and oral instruction on how to collect saliva using a Salivette (Sarstedt Inc., Rommelsdorf, Germany) that consisted of a small cotton roll inside a centrifuge tube. Participants collected a saliva sample by chewing on the cotton roll for 60 seconds.

The collected saliva samples were stored at $-20{ }^{\circ} \mathrm{C}$ to maintain its biological characteristics. Before sensing, the saliva samples were de-freezed to room temperature and centrifuged at $3500 \mathrm{rpm}$ for 15 minutes to extract saliva from salivettes. The separated saliva was then pipette out and kept at $-20{ }^{\circ} \mathrm{C}$ when not in use. These samples were further used to detect cortisol using electrochemical immunosensors and ELISA for comparison.

The fabricated BSA/Anti- $\mathrm{C}_{\mathrm{ab}} / \mathrm{ZnO}-\mathrm{NP} / \mathrm{Au}$ immunoelectrodes were used to detect various concentration of cortisol using $\mathrm{CV}$ techniques in $30 \mu \mathrm{L}$ PBS $(\mathrm{pH} 7.4)$ containing 5 
$\mathrm{mM}\left[\mathrm{Fe}(\mathrm{CN})_{6}\right]^{3-/ 4-}$ as redox moieties. The fabricated immunoelectrodes were used to detect cortisol in saliva samples of two specimens collected at different time intervals. $10 \mu \mathrm{l}$ of saliva sample was placed on the electrochemical immunosensor and was allowed to incubate for 30 minutes to ensure proper binding. Immunoelectrodes were then washed using PBS $\sim 10 \mathrm{~mL}$ to remove unbound saliva. Cortisol Enzyme Immunoassay Kit was procured from Arbor Assays, MI and a standard protocol was adopted to detect saliva cortisol. In Brief, $50 \mu 1$ of $4 \mathrm{X}$ diluted saliva was used for the detection of cortisol.

Figure 5.3 (a-b) shows SEM images of Anti-C $\mathrm{C}_{\mathrm{ab}} / \mathrm{ZnO}-\mathrm{NRs} / \mathrm{Au}$ and Anti- $\mathrm{C}_{\mathrm{ab}} / \mathrm{ZnO}$ $\mathrm{NFs} / \mathrm{Au}$ electrodes, the change in morphology when compared to the SEM images acquired before introduction of antibody as shown in figure $5.1(\mathrm{a}-\mathrm{b})$ confirms the binding of antibody to nanostructure matrix. Figure 5.3 (c-d) shows the AFM images of the electrodes after introduction of the antibody. The average roughness of Anti- $\mathrm{C}_{\mathrm{ab}} / \mathrm{ZnO}-\mathrm{NRs} / \mathrm{Au}$ (Figure $5.3 \mathrm{c}$ ) over an area of $20 \mu \mathrm{m} \times 20 \mu \mathrm{m}$ was measured to be $124 \mathrm{~nm}$ while for the $\mathrm{ZnO}-\mathrm{NRs} / \mathrm{Au}$ electrode it was $171 \mathrm{~nm}$. In figure 5.3 (d) the measured average surface roughness of Anti- $\mathrm{C}_{\mathrm{ab}} / \mathrm{ZnO}-\mathrm{NFs} / \mathrm{Au}$ was $158 \mathrm{~nm}$, while $\mathrm{ZnO}-\mathrm{NF} / \mathrm{Au}$ electrode shows a higher average roughness of $214 \mathrm{~nm}$. The drop in roughness value is due to immobilization of Anti- $\mathrm{C}_{\mathrm{ab}}$ which fills the porous surface of the electrode. AFM measurements suggests that the ZnO-NFs structures offers higher surface area for successful a binding. The larger drop in surface roughness value in $\mathrm{ZnO} \mathrm{NFs} \mathrm{after} \mathrm{the} \mathrm{introduction} \mathrm{of} \mathrm{Anti-} \mathrm{C}_{\mathrm{ab}}$ suggests greater antibody binding than was observed on $\mathrm{ZnO}$ NRs. This proves our initial assumption that higher surface area in (0001) plane observed in ZnO NFs can enhance the antibody absorption when compared to $\mathrm{ZnO}$ NRs whose directional growth results in smaller area in (0001) plane. 

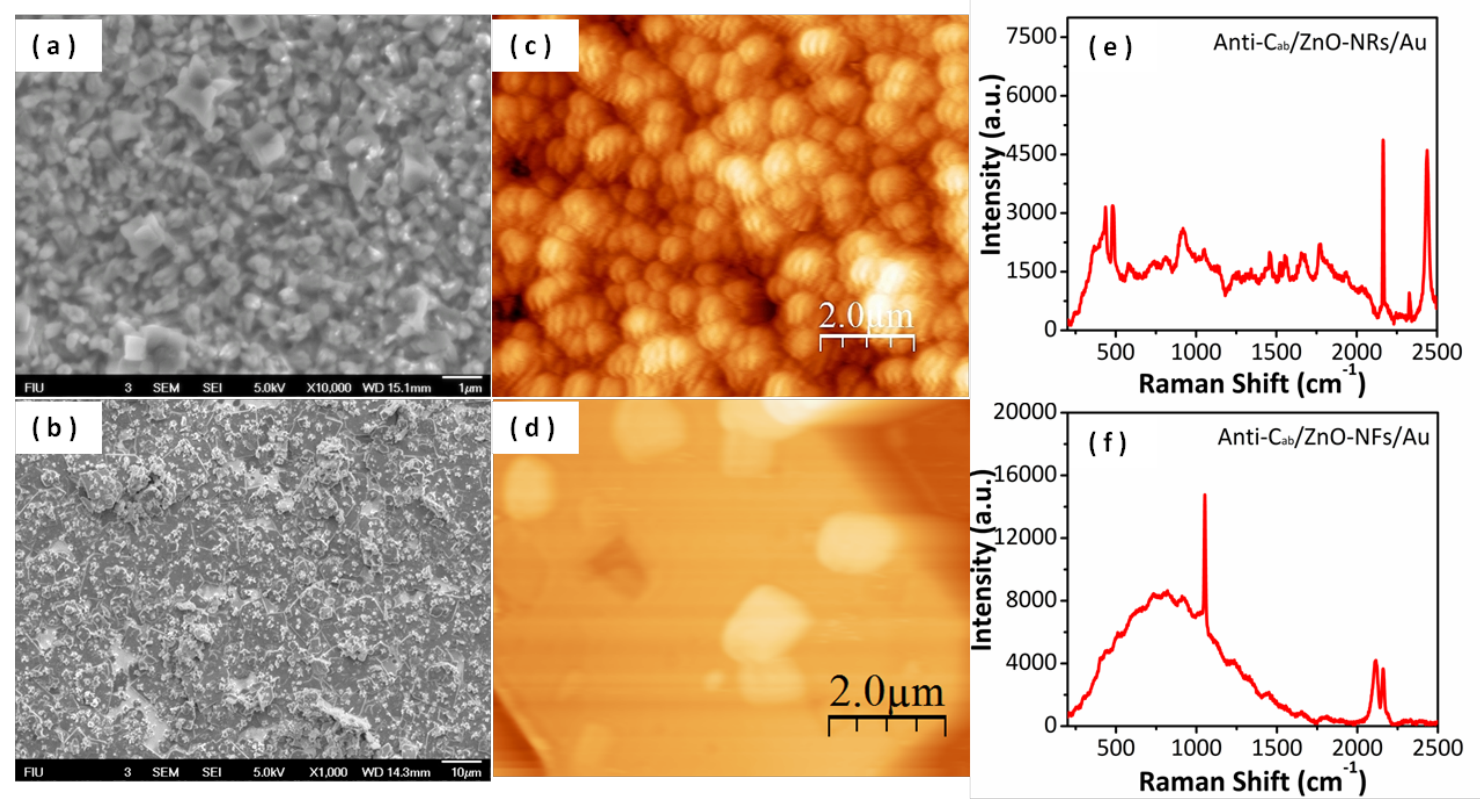

Figure5.3 (a) FSEM image of Anti-Cab/ZnO-NRs/Au immunoelectrode, (b) FSEM image of Anti-C/ZnO-NFs/Au immunoelectrode showing change in morphology after antibody introduced, (c) AFM image of Anti- $\mathrm{C}_{\mathrm{ab}} / \mathrm{ZnO}-\mathrm{NRs} / \mathrm{Au}$ with a measured roughness of 124 $\mathrm{nm}$, (d) AFM image of Anti-C $\mathrm{ab} / \mathrm{ZnO}-\mathrm{NFs} / \mathrm{Au}$ immunoelectrode with a measured roughness of $158 \mathrm{~nm}$, (e) Raman shift of $A n t i-\mathrm{C}_{\mathrm{ab}} / \mathrm{ZnO}-\mathrm{NRs} / \mathrm{Au}$ immunoelectrode and (f) Raman shift for Anti- $\mathrm{C}_{\mathrm{ab}} / \mathrm{ZnO}-\mathrm{NFs} / \mathrm{Au}$ immunoelectrode.

Raman spectroscopy of Anti-C $\mathrm{C}_{\mathrm{ab}} / \mathrm{ZnO}-\mathrm{NRs} / \mathrm{Au}$ and $\mathrm{Anti}_{\mathrm{ab}} / \mathrm{ZnO}-\mathrm{NFs} / \mathrm{Au}$ electrodes (Figure 5.3 e-f) shows many more peaks other than that characteristic of wurtzite $\mathrm{ZnO}$ NSs, which suggests a successful binding of Anti- $\mathrm{C}_{\mathrm{ab}}$ over ZnO-NSs surface. Further electro chemical impedance spectroscopy (EIS) is employed to study the electron transfer characteristics and association constant for binding interactions at the electrode surface. To improve the selectivity by locking the signal from unbounded sites on nanoparticles, $10 \mu 1$ of bovine saline albumin (BSA) solution is applied.

Figure 5.4 (a) shows the Nyquist plots of the EIS spectra for bare $\mathrm{Au}, \mathrm{ZnO}-\mathrm{NRs} / \mathrm{Au}$, Anti- $\mathrm{C}_{\mathrm{ab}} / \mathrm{ZnO}-\mathrm{NRs} / \mathrm{Au}, \mathrm{BSA} / \mathrm{Anti}-\mathrm{C}_{\mathrm{ab}} / \mathrm{ZnO}-\mathrm{NRs} / \mathrm{Au}$ electrodes and the equivalent Randles circuit (inset). The diameter of the semicircle represents the charge transfer resistance $\left(\mathrm{R}_{\mathrm{ct}}\right)$ 
on the electrode surface. The value of $R_{c t}$ changes from $108.8 \Omega$ for bare Au electrode to $2.677 \mathrm{k} \Omega$ for $\mathrm{ZnO}-\mathrm{NRs} / \mathrm{Au}$ electrode, which further increases to $3.552 \mathrm{k} \Omega$ with the introduction of antibody. Upon introduction of BSA, an insulating material, it isolates the non-bounded sites and further increases $\mathrm{R}_{\mathrm{ct}}$ value for $\mathrm{BSA} / \mathrm{Anti}-\mathrm{C}_{\mathrm{ab}} / \mathrm{ZnO}-\mathrm{NRs} / \mathrm{Au}$ electrode to $7.768 \mathrm{k} \Omega$. The electron transfer from the electrolyte $\left(5 \mathrm{mM}\left[\mathrm{Fe}(\mathrm{CN})_{6}\right]^{3-4-}\right.$ in phosphate buffer solution (PBS)) to the electrode is hindered with the addition of antibody which further decreases after addition of BSA, resulting in increase in $\mathrm{R}_{\mathrm{ct}}$. The same characteristics can be observed in $\mathrm{BSA} / \mathrm{Anti}-\mathrm{C}_{\mathrm{ab}} / \mathrm{ZnO}-\mathrm{NFs} / \mathrm{Au}$ electrodes as shown in figure 5.4 (b). Here the $\mathrm{R}_{\mathrm{ct}}$ values for bare gold electrode is $120.3 \Omega$, for $\mathrm{ZnO}-\mathrm{NFs} / \mathrm{Au}$ is $1.462 \mathrm{k} \Omega$ which increases to $1.643 \mathrm{k} \Omega$ upon application of antibody for Anti$\mathrm{C}_{\mathrm{ab}} / \mathrm{ZnONFs} / \mathrm{Au}$ and finally to $5.962 \mathrm{k} \Omega$ upon introduction of BSA for BSA/Anti$\mathrm{C}_{\mathrm{ab}} / \mathrm{ZnONFs} / \mathrm{Au}$ electrode. As can be seen, the introduction of BSA, an insulating material greatly increases the charge transfer resistance which decreases the redox current. However BSA is essential in order to limit the binding of Cortisol at unwanted sites. We also observe that the charge transfer resistance of $\mathrm{ZnO}-\mathrm{NRs}$ is higher than the electrodes with $\mathrm{ZnO}-\mathrm{NFs}$, which results in higher oxidation current at $\mathrm{BSA} / \mathrm{Anti}-\mathrm{C}_{\mathrm{ab}} / \mathrm{ZnO}-\mathrm{NFs} / \mathrm{Au}$ electrode interface as more charge carriers are absorbed, when compared to BSA/Anti- $\mathrm{C}_{\mathrm{ab}} / \mathrm{ZnO}-\mathrm{NRs} / \mathrm{Au}$ interface. This can be due to the high single crystalline nature of ZnO NFs when compared to the seed layer used in the growth of ZnO NRs. The thickness of ZnO NFs $(\approx 200 \mathrm{~nm})$ which is smaller than the seed layer $(\approx 500 \mathrm{~nm})$ used in $\mathrm{ZnO}$ nanorod growth can also play a major role in boosting the electron transfer from electrolyte to the electrode. 

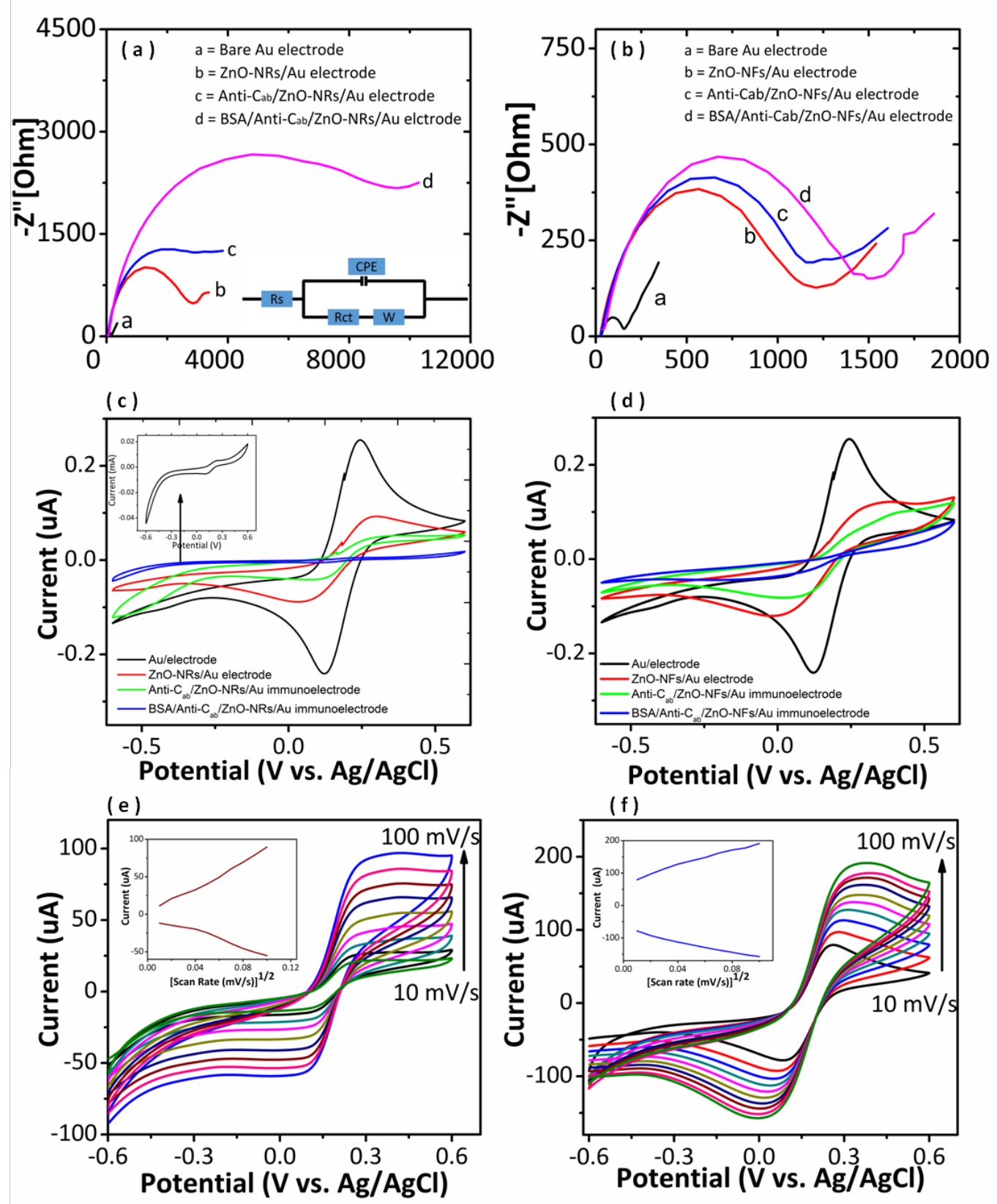

Figure. 5.4. Stepwise characterization related to the fabrication of $\mathrm{ZnO}-\mathrm{NSs}$ based electrochemical immunosensor using electrochemical impedance spectroscopy and cyclic voltammetry ( $A$ and $B$ ). (a) An increase in $\mathrm{R}_{\mathrm{ct}}$ from bare $\mathrm{Au}$ electrode to BSA/Anti- $\mathrm{C}_{\mathrm{ab}} / \mathrm{ZnO}$ $\mathrm{NRs} / \mathrm{Au}$. (b) Rise of $\mathrm{R}_{\mathrm{ct}}$ from bare $\mathrm{Au}$ electrode to $\mathrm{BSA} / \mathrm{Anti}-\mathrm{C}_{\mathrm{ab}} / \mathrm{ZnO}-\mathrm{NF} \mathrm{s} / \mathrm{Au}$ immunoelectrode. (c) Fall in the magnitude of oxidation response current from $\mathrm{Au}$ electrode to BSA/Anti- $\mathrm{C} a \mathrm{a} / \mathrm{ZnO}$ $\mathrm{NRs} / \mathrm{Au}$ immunoelectrode. (d) Fall in the magnitude of oxidation response current from $\mathrm{Au}$ electrode to $\mathrm{BSA} / \mathrm{Anti}-\mathrm{C}_{\mathrm{ab}} / \mathrm{ZnO}-\mathrm{NFs} / \mathrm{Au}$ immunoelectrode. (e) An increment in the magnitude of oxidation response current of $A n t i-\mathrm{C}_{\mathrm{ab}} / \mathrm{ZnO}-\mathrm{NRs} / \mathrm{Au}$ immunoelectrode with increase in scan rate from $10 \mathrm{mV} / \mathrm{s}$ to $100 \mathrm{mV} / \mathrm{s}$. (f) An increment in the magnitude of oxidation response current of Anti- $\mathrm{C}_{\mathrm{ab}} / \mathrm{ZnO}-\mathrm{NFs} / \mathrm{Au}$ with increase in scan rate from $10 \mathrm{mV} / \mathrm{s}$ to $100 \mathrm{mV} / \mathrm{s}$. 
The electron transfer rate $\left(\mathrm{K}_{\mathrm{et}}\right)$ at the electrode interface can be estimated by using the EIS and equation (1) [21]

$$
K_{e t}=\frac{1}{2\left(R_{c t}\right)(C P E)}
$$

Where ' $\mathrm{CPE}$ ' is constant phase element and $\mathrm{R}_{\mathrm{ct}}$ is the charge transfer resistance. The binding constant $\mathrm{K}_{\mathrm{ac}}$ which is an indicative of the stable binding between the nanoparticles and antibody can be estimated by using equation (2) [22]

$$
K_{a c}=\frac{\Delta \mathrm{R}_{c t}}{\mathrm{R}_{c t}\left(C_{o}\right)}
$$

Where $\Delta \mathrm{R}_{c t}$ is the difference in charge transfer resistance due to the introduction of antibody and $\mathrm{R}_{\mathrm{ct}}\left(\mathrm{c}_{\mathrm{o}}\right)$ is charge transfer resistance without antibody. The results of the EIS at various stages of electrode fabrication are given in Table 5.1. Anti- $\mathrm{C}_{\mathrm{ab}} / \mathrm{ZnO}-\mathrm{NFs} / \mathrm{Au}$ electrodes exhibited higher charge transfer rate when compared to Anti- $\mathrm{C}_{\mathrm{ab}} / \mathrm{ZnO}-\mathrm{NRs} / \mathrm{Au}$ which explains the higher oxidation current observed in $\mathrm{CV}$ measurements. As shown in figure 5.4 (c) and 5.4 (d), the magnitude of oxidation current reduces from bare $\mathrm{Au}$ electrode to BSA/Anti- $\mathrm{C}_{\mathrm{ab}} / \mathrm{ZnO}-\mathrm{NRs} / \mathrm{Au}$ and $\mathrm{BSA} / \mathrm{Anti}-\mathrm{C}_{\mathrm{ab}} / \mathrm{ZnO}-\mathrm{NFs} / \mathrm{Au}$ electrodes as the charge transfer resistance increases with every step. As indicated by the higher $\mathrm{K}_{\mathrm{ac}}$ value in $\mathrm{ZnO}-\mathrm{NRs}$, the Anti- $\mathrm{C}_{\mathrm{ab}} / \mathrm{ZnO}-\mathrm{NRs} / \mathrm{Au}$ exhibit stable binding between $\mathrm{Anti}-\mathrm{C}_{\mathrm{ab}}$ and the NRs when compared to $\mathrm{ZnO}-\mathrm{NFs}$.

CV method was used to investigate the electro-active behavior of electrodes and determine the sensitivity of the fabricated electrodes over a range of Cortisol concentrations. Initially Anti- $\mathrm{C}_{\mathrm{ab}} / \mathrm{ZnO}-\mathrm{NRs} / \mathrm{Au}$ and $\mathrm{Anti}-\mathrm{C}_{\mathrm{ab}} / \mathrm{ZnO}-\mathrm{NFs} / \mathrm{Au}$ electrodes were studied by varying the scan rate from $10 \mathrm{mV} / \mathrm{s}$ to $100 \mathrm{mV} / \mathrm{s}$ (Figure $5.4 \mathrm{e}-\mathrm{f}$ ). 
Table 5.1. Summary of the impedimetric parameters obtained in stepwise fabrication of immunosensor

\begin{tabular}{|c|c|c|c|c|}
\hline Electrode & $\mathbf{R}_{\mathrm{ct}}(\mathbf{\Omega})$ & $\operatorname{CPE} 1(\mu \mathrm{F} / \mathrm{s})$ & $\mathbf{K}_{\mathrm{et}}$ & $\mathbf{K}_{\mathrm{ac}}$ \\
\hline $\mathbf{A u}$ & 108.8 & 02.74 & 1677.22 & \\
\hline ZnO-NRs/Au & 2672 & 09.80 & 19 & \\
\hline $\begin{array}{l}\text { Anti-C }_{a b} / \mathrm{ZnO}- \\
\text { NRs/Au }\end{array}$ & 3552 & 14.70 & 9.57 & 0.3268 \\
\hline $\begin{array}{l}\text { BSA/Anti-C }{ }_{a b} / \mathrm{ZnO}- \\
\text { NRs/Au }\end{array}$ & 7768 & 10.45 & 6.159 & \\
\hline Au & 120.3 & 10.11 & 411 & \\
\hline ZnO-NFs/Au & 1459 & 20.83 & 16.45 & \\
\hline $\begin{array}{l}\text { Anti-C }_{a b} / \mathrm{ZnO}- \\
\text { NFs/Au }\end{array}$ & 1643 & 21.18 & 14.3 & 0.126 \\
\hline $\begin{array}{l}\text { BSA/Anti-C }{ }_{a b} / \mathrm{ZnO}- \\
\text { NFs/Au }\end{array}$ & 7768 & 10.45 & 6.16 & \\
\hline
\end{tabular}

The change in current response with scan rate plotted in the inset of Fig. 4(e-f) shows that the oxidation current increases linearly with scan rate and follows the relation: (a) I ( $\mu \mathrm{A})$ $=2.6+0.835 v\left(\mathrm{mVs}^{-1}\right)$ in case of Anti-C $\mathrm{ab} / \mathrm{ZnO}-\mathrm{NRs} / \mathrm{Au}$ electrode and $(\mathrm{b}) \mathrm{I}(\mu \mathrm{A})=74.6+$ $1.2 v\left(\mathrm{mV} \mathrm{s}^{-1}\right)$ in case of Anti- $\mathrm{C}_{\mathrm{ab}} / \mathrm{ZnO}-\mathrm{NFs} / \mathrm{Au}$ electrode, which indicates a surface controlled process. $10 \mu \mathrm{l}$ of PBS $(10 \mathrm{mM}, \mathrm{pH} 7.0,0.9 \% \mathrm{NaCl})$ solution containing specific concentration of Cortisol was introduced to BSA/ Anti- $\mathrm{C}_{\mathrm{ab}} / \mathrm{ZnO}-\mathrm{NRs} / \mathrm{Au}$ and BSA/Anti$\mathrm{C}_{\mathrm{ab}} / \mathrm{ZnO}-\mathrm{NFs} / \mathrm{Au}$ electrodes by incubating for 30 mins. The prepared electrodes were cleaned using DI water before introducing Cortisol. During incubation, antigen (Cortisol) binds with the specific antibody $\left(\right.$ Anti- $\mathrm{C}_{\mathrm{ab}}$ ) forming an insulating immuno-complex between Anti- $\mathrm{C}_{\mathrm{ab}}$ and cortisol which inhibits the electron transport from electrolyte to the 
electrode and further increases the charge transfer resistance $\left(\mathrm{R}_{\mathrm{ct}}\right)$. Electrodes prepared from the same batch were incubated in solutions with different concentrations of Cortisol. The CV measurements indicate a fall in maximum oxidation current with the addition of cortisol to the electrode, confirming the increase in $\mathrm{R}_{\mathrm{ct}}$. This fall in value increases with the increase in concentration of Cortisol incubated in the range of $1 \mathrm{pM}$ to $100 \mathrm{nM}$. The current difference directly correlates to the cortisol concentration being sensed. Sharp and distinct oxidation peaks were obtained for ZnO-NFs. For a concentration of 100pm, peak current of $100 \mu \mathrm{A}$ was observed for $\mathrm{ZnO}-\mathrm{NF}$ s while for the same concentration the peak current was $50 \mu \mathrm{A}$ for $\mathrm{ZnO}-\mathrm{NRs}$. High current values and well separated oxidation peaks were obtained for both Anti- $\mathrm{C}_{\mathrm{ab}} / \mathrm{ZnO}-\mathrm{NRs} / \mathrm{Au}$ and Anti- $\mathrm{C}_{\mathrm{ab}} / \mathrm{ZnO}-\mathrm{NFs} / \mathrm{Au}$ electrodes as shown in Figure 5.5 (a) and 5.5 (b). The graph showing change in current with the log of concentration is almost linear following the equation: (a) $\Delta \mathrm{I}(\mu \mathrm{A})=7.74 \log$ (Cortisol conc. $(\mathrm{M}))+94.18$ for $\mathrm{BSA} / \mathrm{Anti}-\mathrm{C}_{\mathrm{ab}} / \mathrm{ZnO}-\mathrm{NFs} / \mathrm{Au}$ giving a sensitivity of $7.74 \mu \mathrm{A} / \mathrm{M}$ and (b) $\Delta \mathrm{I}(\mu \mathrm{A})=11.86 \log ($ Cortisol Conc. $(\mathrm{M}))+121.69$ for BSA/Anti-C $\mathrm{C}_{\mathrm{ab}} / \mathrm{ZnO}-\mathrm{NRs} / \mathrm{Au}$ electrode at a sensitivity of $11.86 \mu \mathrm{A} / \mathrm{M}$. A very clear separation of oxidation current is obtained, which shows that the electrodes are stable and can be re-used. EIS (Fig 5c \& 5d) for both electrodes at different cortisol concentrations shows that the values of $\mathrm{R}_{\mathrm{ct}}$ increases almost linearly with increase in cortisol concentration (shown in inset). CV based cortisol immunosensor were used to detect human salivary cortisol and obtained results were validated using commercially available ELISA sensing technique. The protocol adopted to detect saliva cortisol using electrochemical immunosensor and ELISA is reported in our previous work. [23]. Both ZnO-NSs based cortisol immunosensor are used for cortisol detection in human saliva collected at different time. The cortisol concentration of same 
saliva samples is detected using ELISA and compared with the values measured using the fabricated immunosensor. It was observed that a factor of 2.6 was applied to all the $\mathrm{CV}$ calculations in comparison to ELISA.

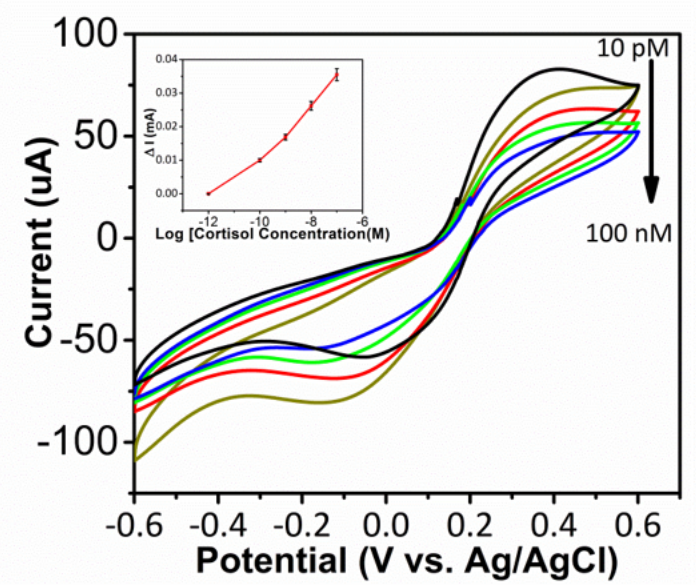

(c)

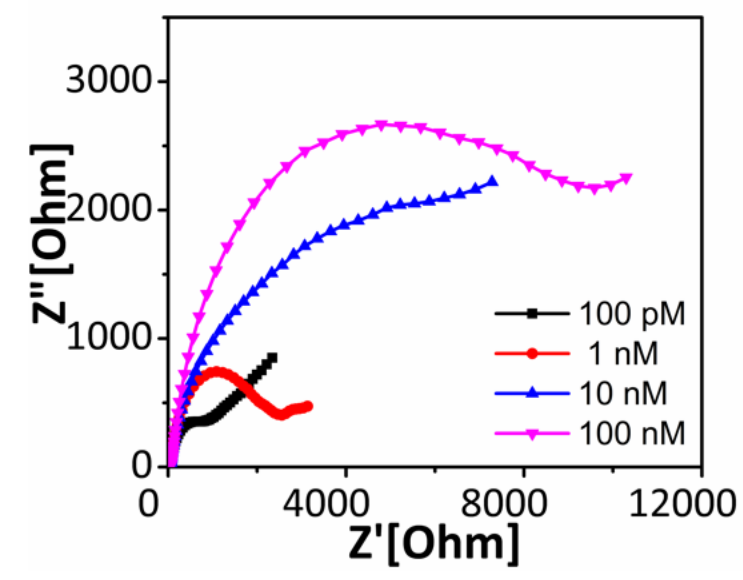

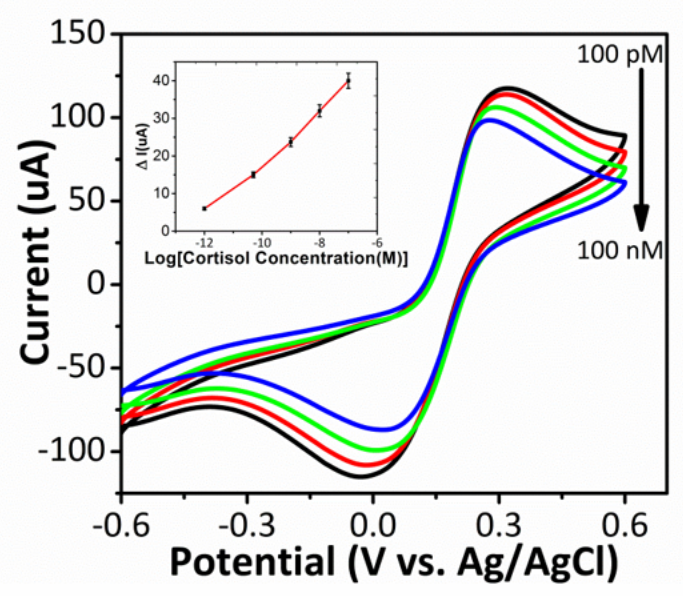

(d)

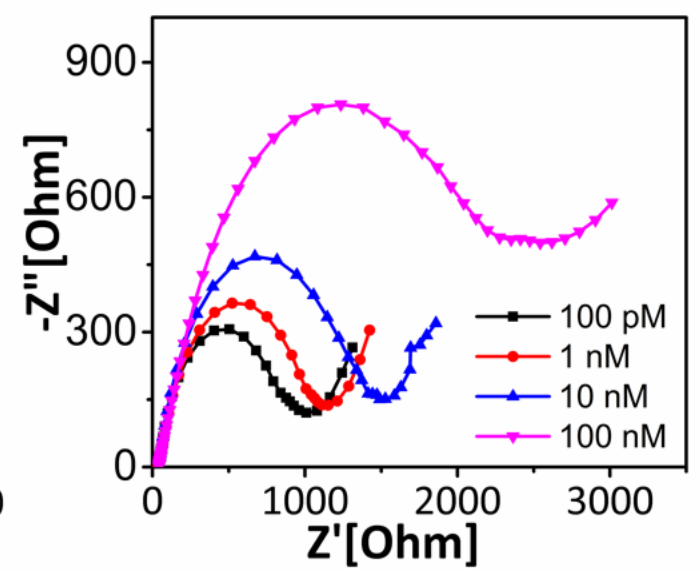

Figure 5.5 (a) $\mathrm{CV}$ studies of immunosensors as function of cortisol concentration varying from $100 \mathrm{pM}$ to $100 \mathrm{nM}$ for $\mathrm{BSA} / \mathrm{Anti}-\mathrm{C}_{\mathrm{ab}} / \mathrm{ZnO}-\mathrm{NFs} / \mathrm{Au}$ electrode, inset: a calibration plotted between the obtained change in response current with respect to cortisol concentration (b) CV curves with cortisol concentration varying from $100 \mathrm{pM}$ to $100 \mathrm{nM}$ for BSA/Anti-C $\mathrm{Cab}_{\mathrm{ab}} / \mathrm{ZnO}-\mathrm{NRs} / \mathrm{Au}$ immunoelectrode, inset: a calibration plotted between the obtained change in response current with respect to cortisol concentration (c) Change in EIS of $\mathrm{BSA} / \mathrm{Anti}-\mathrm{C}_{\mathrm{ab}} / \mathrm{ZnO}-\mathrm{NFs} / \mathrm{Au}$ immunoelectrode with respect to cortisol concentrations (d) Change in EIS of BSA/Anti- $\mathrm{C}_{\mathrm{ab}} / \mathrm{ZnO}-\mathrm{NRs} / \mathrm{Au}$ immunoelectrode with respect to cortisol concentrations 
Table 5.2. Comparison of saliva cortisol estimated using ELISA and ZnO-NSs based cortisol immunosensor.

\begin{tabular}{|c|c|c|}
\hline $\begin{array}{c}\text { Salivary Cortisol } \\
\text { (ELISA)(ng/dL) }\end{array}$ & $\begin{array}{c}\text { Salivary Cortisol } \\
\text { BSA/Anti-C } \mathrm{C}_{\mathrm{ab}} / \mathrm{ZnO} \mathrm{ONFs} / \mathrm{Au} \\
(\mathrm{ng} / \mathrm{dL})\end{array}$ & $\begin{array}{c}\text { Salivary Cortisol } \\
\text { BSA/Anti-C } \mathbf{C}_{\mathrm{ab}} / \mathrm{ZnO} \text {-NRs/Au } \\
(\mathbf{n g} / \mathbf{d L})\end{array}$ \\
\hline 155 & 146 & 143 \\
\hline 144 & 139 & 138 \\
\hline 237 & 228 & 231 \\
\hline 72 & 65 & 62 \\
\hline 240 & 230 & 233 \\
\hline 153 & 142 & 141 \\
\hline
\end{tabular}

\subsection{Conclusions}

We have fabricated vertically standing $1 \mathrm{D} \mathrm{ZnO}-\mathrm{NRs}$ and lateral 2D ZnO-NFs on Au coated $\mathrm{Si}$, using sonochemical technique to prepare label free, highly sensitive and selective electrochemical cortisol immunosensors. Both 1D ZnO-NRs and 2D ZnO-NFs exhibit selective electrochemical cortisol detection at $1 \mathrm{pM} 100$ times better than ELISA. ZnONFs with sharp and distinct oxidation peaks indicate a much better surface controlled process when compared to ZnO-NRs. The sensitivity of $\mathrm{ZnO}-\mathrm{NFs}$ is $7.74 \mu \mathrm{A} / \mathrm{M}$ which is comparable to $11.86 \mu \mathrm{A} / \mathrm{M}$ of $\mathrm{ZnO}-\mathrm{NRs}$ coupled with ease of fabrication in case of $2 \mathrm{D}$ materials, we have successfully demonstrated the use of 2D $\mathrm{ZnO}$ nanoflakes as an alternate material for use as immobilizing matrix in electrochemical biosensors. It is demonstrated in this work that ZnO-NSs based immunosensors are capable of detecting cortisol in human saliva sample and well-validated using ELISA values. This work suggest ZnO-NSs with high surface-to-volume ratio (NRs) and larger surface area (NFs) as viable materials for cortisol sensing in human saliva. 


\subsection{References}

1. Luppa, P. B., Sokoll, L. J., \& Chan, D. W. (2001). Immunosensors-principles and applications to clinical chemistry. Clinica Chimica Acta, 314 (1):1-26.

2. Arya, S. K., Dey, A., \& Bhansali, S. (2011). Polyaniline protected gold nanoparticles based mediator and label free electrochemical cortisol biosensor. Biosensors and Bioelectronics, 28 (1):166-173.

3. Arya, S. K., Saha, S., Ramirez-Vick, J. E., Gupta, V., Bhansali, S., \& Singh, S. P. (2012). Recent advances in $\mathrm{ZnO}$ nanostructures and thin films for biosensor applications: review. Analytica chimica acta, 737, 1-21.

4. Zhang, F., Wang, X., Ai, S., Sun, Z., Wan, Q., Zhu, Z., \& Yamamoto, K. (2004). Immobilization of uricase on $\mathrm{ZnO}$ nanorods for a reagentless uric acid biosensor. Analytica Chimica Acta, 519 (2):155-160.

5. Nozaki, S., Sarangi, S. N., Uchida, K., \& Sahu, S. N. (2013). Hydrothermal growth of zinc oxide nanorods and glucose-sensor application. Soft Nanoscience Letters, 2013.

6. Chey, C. O., Ibupoto, Z. H., Khun, K., Nur, O., \& Willander, M. (2012). Indirect determination of mercury ion by inhibition of a glucose biosensor based on $\mathrm{ZnO}$ nanorods. Sensors, 12 (11):15063-15077.

7. Psychoyios, V. N., Nikoleli, G. P., Tzamtzis, N., Nikolelis, D. P., Psaroudakis, N., Danielsson, B., \& Willander, M. (2013). Potentiometric cholesterol biosensor based on $\mathrm{ZnO}$ nanowalls and stabilized polymerized lipid film. Electroanalysis, 25 (2):367-372.

8. Xu, C., Yang, C., Gu, B., \& Fang, S. (2013). Nanostructured $\mathrm{ZnO}$ for biosensing applications. Chinese Science Bulletin, 58 (21):2563-2566.

9. Chang, P. C., Fan, Z., Wang, D., Tseng, W. Y., Chiou, W. A., Hong, J., \& Lu, J. G. (2004). $\mathrm{ZnO}$ nanowires synthesized by vapor trapping CVD method.Chemistry of materials, $16(24): 5133-5137$.

10. Zhou, J., Xu, N. S., \& Wang, Z. L. (2006). Dissolving behavior and stability of ZnO wires in biofluids: a study on biodegradability and biocompatibility of $\mathrm{ZnO}$ nanostructures. Advanced Materials, 18 (18):2432-2435.

11. Li, Z., Yang, R., Yu, M., Bai, F., Li, C., \& Wang, Z. L. (2008). Cellular level biocompatibility and biosafety of $\mathrm{ZnO}$ nanowires. The Journal of Physical Chemistry C, 112 (51):20114-20117.

12. Israr, M. Q., Sadaf, J. R., Asif, M. H., Nur, O., Willander, M., \& Danielsson, B. (2010). Potentiometric cholesterol biosensor based on $\mathrm{ZnO}$ nanorods chemically grown on $\mathrm{Ag}$ wire. Thin Solid Films, 519 (3):1106-1109. 
13. Xu, S., \& Wang, Z. L. (2011). One-dimensional ZnO nanostructures: solution growth and functional properties. Nano Research, 4 (11):1013-1098.

14. Xu, H., Zeiger, B. W., \& Suslick, K. S. (2013). Sonochemical synthesis of nanomaterials. Chemical Society Reviews, 42 (7):2555-2567.

15. Palumbo, M., Henley, S. J., Lutz, T., Stolojan, V., \& Silva, S. R. P. (2008). A fast sonochemical approach for the synthesis of solution processable $\mathrm{ZnO}$ rods. Journal of Applied Physics, 104 (7):074906.

16. Kaushik, A., Vasudev, A., Arya, S. K., Pasha, S. K., \& Bhansali, S. (2014). Recent advances in cortisol sensing technologies for point-of-care application. Biosensors and Bioelectronics, 53:499-512.

17. Holsboer, F., \& Ising, M. (2010). Stress hormone regulation: biological role and translation into therapy. Annual review of psychology, 61:81-109.

18. Vabbina, P. K., Nayyar, P., Nayak, A. P., Katzenmeyer, A. M., Logeeswaran, V. J., Pala, N., ... \& Talin, A. A. (2011, September). Synthesis of crystalline ZnO nanostructures on arbitrary substrates at ambient conditions. In SPIE NanoScience+ Engineering (pp. 81060H-81060H). International Society for Optics and Photonics.

19. Vabbina, P. K., Karabiyik, M., Al-Amin, C., Pala, N., Das, S., Choi, W., \& Shur, M. (2014). Controlled synthesis of single-crystalline $\mathrm{ZnO}$ nanoflakes on arbitrary substrates at ambient conditions. Particle \& Particle Systems Characterization, 31 (2):190-194.

20. Calzolari, A., \& Nardelli, M. B. (2013). Dielectric properties and Raman spectra of $\mathrm{ZnO}$ from a first principles finite-differences/finite-fields approach.Scientific reports, 3 .

21. Nkosi, D., Pillay, J., Ozoemena, K. I., Nouneh, K., \& Oyama, M. (2010). Heterogeneous electron transfer kinetics and electrocatalytic behaviour of mixed selfassembled ferrocenes and SWCNT layers. Physical Chemistry Chemical Physics, 12 (3):604-613.

22. Arya, S. K., Kongsuphol, P., Wong, C. C., Polla, L. J., \& Park, M. K. (2014). Label free biosensor for sensitive human influenza virus hemagglutinin specific antibody detection using coiled-coil peptide modified microelectrode array based platform. Sensors and Actuators B: Chemical, 194:127-133.

23. Pasha, S. K., Kaushik, A., Vasudev, A., Snipes, S. A., \& Bhansali, S. (2014). Electrochemical immunosensing of saliva cortisol. Journal of the Electrochemical Society, 161 (2):B3077-B3082. 


\section{CHAPTER 6}

\section{ZnO Nanostructures for Photovoltaic Devices}

\subsection{Dye Sensitized Solar Cells}

In the $21^{\text {st }}$ century, the world's demand for energy has reached unprecedented levels putting severe stress on world fossil fuel reserves. Fossil fuels have also been the main cause increased global carbon levels which has left us no choice but to develop renewable-energy technologies that can rival that of fossil fuels. Significant progress has been made in developing several technologies such as solar cells, fuel cells and bio fuels. Solar cells in particular have seen rapid rise in the past few years as can be seen in figure 6.1[1]

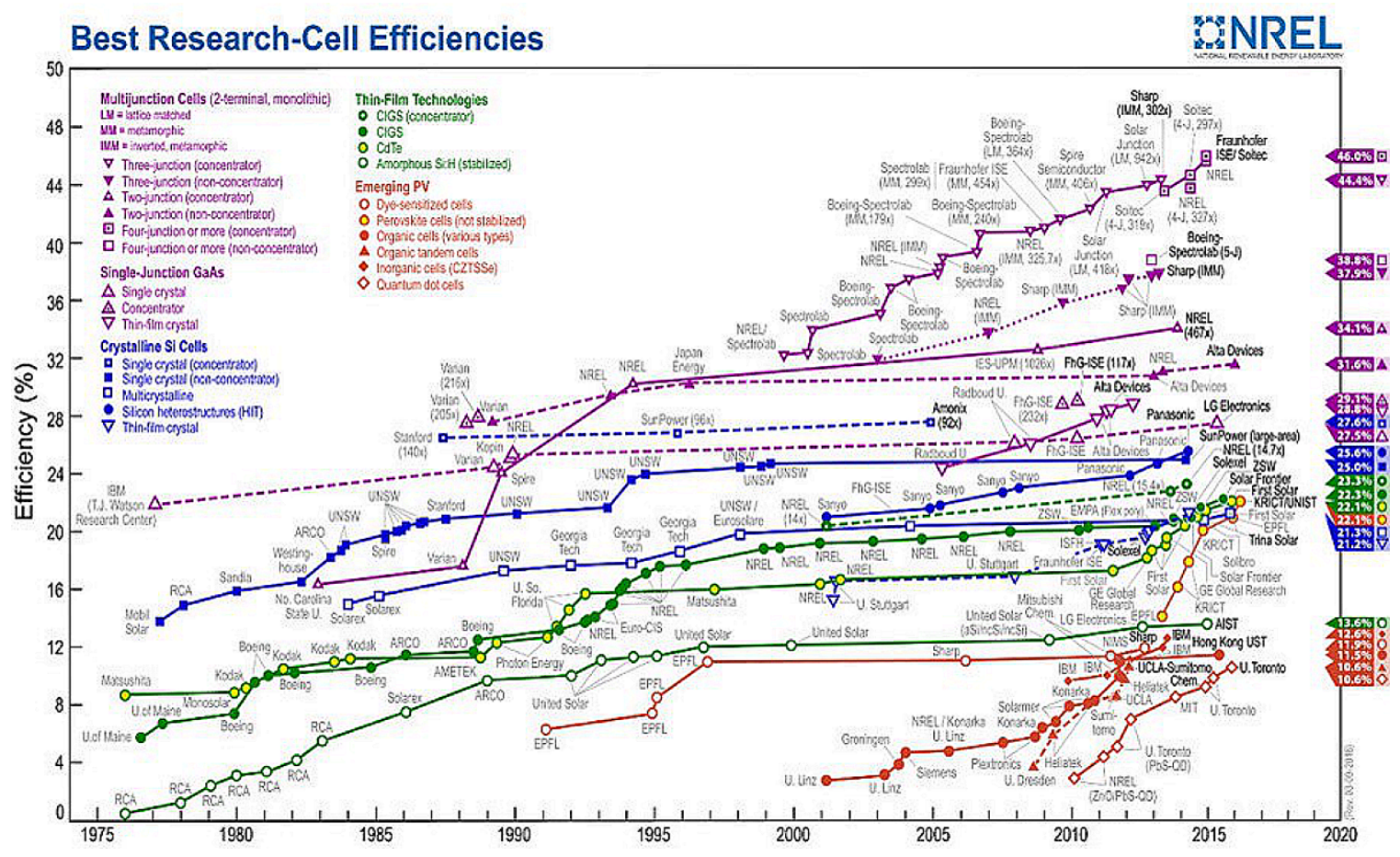

Figure 6.1. The rise of solar cell technologies over past 40 years 
Conversion of solar energy in to electrical energy in solar cells is based on photovoltaic effect where solar energy is absorbed by photosensitive material to produce charge carriers which are collected by the electrical circuit. Several devices that make use of this technology have been developed over the past five decades as seen in figure 6.1 above. However, their use in daily life has been limited by (1) conversion efficiency and (2) cost per $\mathrm{kW} / \mathrm{h}$. The cost per $\mathrm{kW} / \mathrm{h}$ has to reach well below US\$ $0.40 \mathrm{~kW} / \mathrm{h}$ [2] before they can be commercially viable. Single crystalline Silicon solar cell, which was invented 50 years ago makes for $95 \%$ of the market share, [3] they operate on the principle of $p-n$ junction formed at the interface of a p-type semiconductor and n-type semiconductor. In the presence of light, electrons and holes are photogenerated in the junction which are driven in opposite direction due to the internal electric field along the junction. These electron-hole pairs are collected by an external electrical circuit. Silicon ( $\mathrm{Si}$ ) solar cells can attain $92 \%$ of the theoretical energy conversion with maximum conversion efficiency reaching to $22 \%$ by Sun power. However, due to high material costs and low effective efficiencies 'Si' solar cells face difficulties in achieving wide spread usage. Several other technologies such as amorphous Silicon (a-Si), [4] polycrystalline solar cells [5] and compound semiconductor solar cells which use direct band gap semiconductors such as GaAs, CdTe, CIGS to achieve higher efficiencies [6-8] have been developed with the goal to achieve low cost per $\mathrm{kW} / \mathrm{h}$ values. However, they still fail to replace the 'Si' solar cells as they have failed to achieve higher efficiencies and were plagued by low stability especially in a-Si solar cells, while compound semiconductors have high manufacturing costs. 
The quest for new solar cell technologies that would realize the goal of attaining low cost per $\mathrm{kW} / \mathrm{h}$ has received a significant boost during the past decade with the introduction of organic solar cells. Namely, two technologies (1) Dye sensitized solar cells (DSSC) and (2) Perovskite solar cells have shown a significant potential to reduce the operating and manufacturing costs while producing higher efficiencies. DSSC is a photoelectrochemical system in which dye molecules absorbed on the surface of porous metal-oxide film act as photo anode. A liquid electrolyte with $\mathrm{I}^{-} / \mathrm{I}_{3}{ }^{-}$act as the medium between anode and platinum (Pt) coated fluorine doped tin oxide (FTO) glass which acts as cathode. When light is incident on DSSC the photons are absorbed by the dye monolayer creating excitons which are split at the dye and nanocrystalline metal oxide film interface. The electrons are fast absorbed in to the oxide film while the holes are released by the electrolyte and are collected by the cathode. The working mechanism is shown in figure $6.2(b)$

(a)

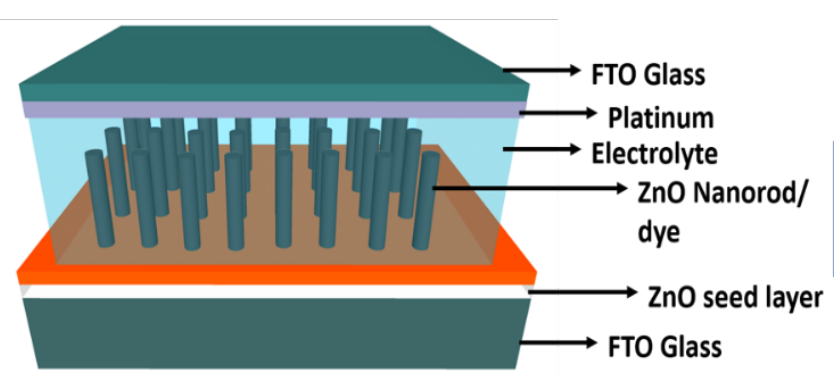

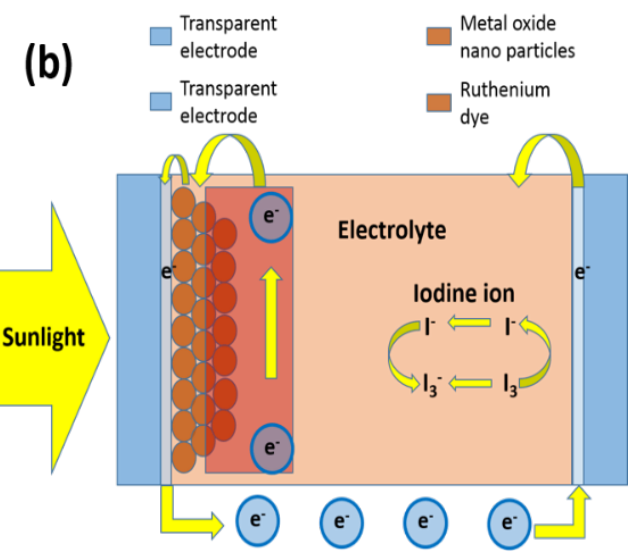

Figure 6.2 (a) ZnO nanorod based DSSC (b) Working mechanism of DSSC.

Compared to conventional silicon solar cells, the DSSCs offer an advantage in terms of manufacturing cost. As efficiencies reaching $10.4 \%$ in $\mathrm{TiO}_{2}$ - Ruthenium dyes [9] have been 
achieved the scope of DSSCs replacing or being used in tandem with 'Si' solar cells has increased. This led to further investigation in to use of $\mathrm{ZnO}$ nanostructures in place of $\mathrm{TiO}_{2}$. $\mathrm{ZnO}$ nanostructures provide significant advantage over $\mathrm{TiO}_{2}$ due to their comparative high electron mobility and diverse morphologies which gives higher surface area than traditional $\mathrm{TiO}_{2}$ nanoporous film. Table 6.1 shows the summary of DSSCs based on $\mathrm{ZnO}$ nanostructures reported in literature.

Table 6.1. Summary of DSSCs Base Don ZnO Nanostructures [10]

\begin{tabular}{|c|c|c|}
\hline Structure & Photosensitizer & Efficiency (Max, Avg) \\
\hline Nanoparticles & N719 & $2.1 \%, 1.5 \%$ \\
& N3 & $3.4 \%, 2 \%$ \\
\hline Nanoporous films & N3 & $5.08 \%$ \\
& N719 & $4.1 \%$, \\
& D149 & $4.27 \%$ \\
\hline Nanowires & N3 & $4.7 \%, 2.4 \%$ \\
& N719 & $1.54 \%, 1 \%$ \\
\hline Nanotubes & N719 & $2.3 \%, 1.5 \%$ \\
\hline Nanobelts & N719 & $2.6 \%$ \\
\hline Core-shell nanowires & N719 & $2.25 \%$ \\
(ZnO- TiO $\left.{ }_{2}\right)$ & & $5.4,4 \%$ \\
\hline Aggregates & N3 & \\
\hline
\end{tabular}

In this dissertation, we have fabricated DSSCs using ZnO nanorods Sonochemically grown over FTO and dipped in ruthenium dye (N3) as photo anode. The photovoltaic behavior of the fabricated DSSC was studied using Sol 2A solar simulator from Oriel. An efficiency of $2.74 \%$, open circuit voltage of $\mathrm{V}_{\mathrm{oc}}=0.843 \mathrm{~V}$, short circuit current $\left(\mathrm{I}_{\mathrm{sc}}\right)$ of $6.46 \mathrm{~mA}$ and high fill factor of 50.3 were measured. These values are in the range of best efficiencies achieved using $\mathrm{ZnO}$ nanorods as shown in Table 6.1 


\subsubsection{Fabrication of Dye Sensitized Solar Cells}

The fabrication of $\mathrm{ZnO}$ DSSC starts with the synthesis of $\mathrm{ZnO}$ nanorods on FTO. This is done by the process discussed in chapter 3. As synthesized $\mathrm{ZnO}$ anodes are shown in figure

\section{$6.3(\mathrm{a})$}
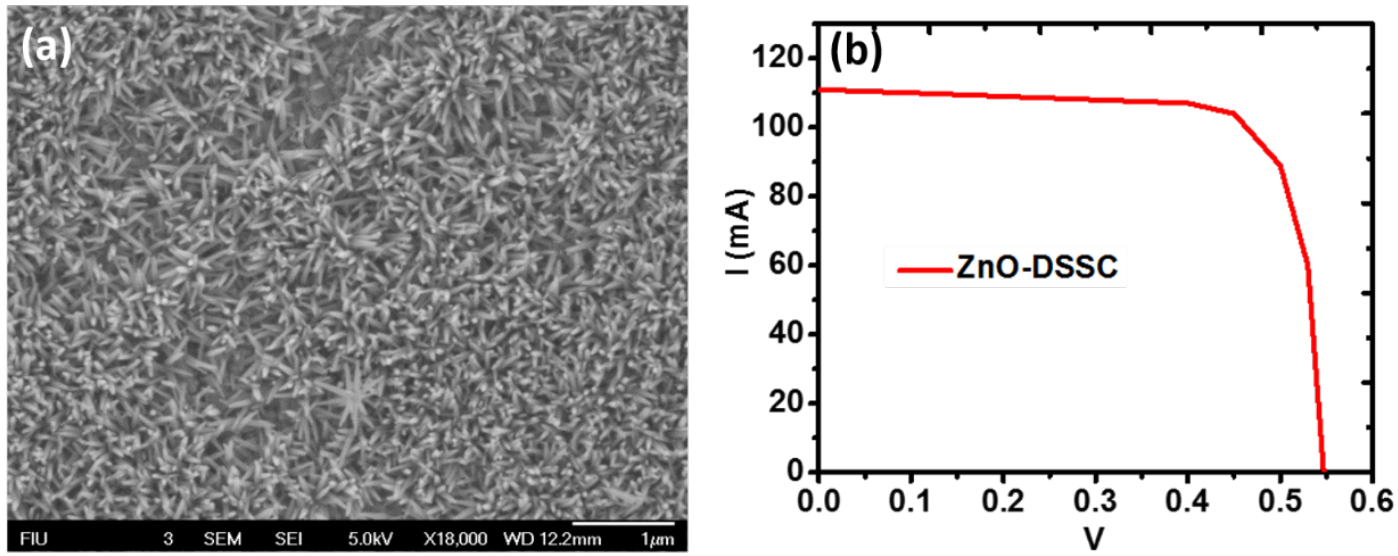

Figure 6.3 (a) ZnO nanorods grown over FTO (b) Photovoltaic behavior

The dye which acts as photo absorber was prepared by dissolving $17.8 \mathrm{mg}$ of N3 dye in 50 $\mathrm{ml}$ of ethanol to make $0.3 \mathrm{mM}$ solution. The immersion time was optimized by immersing $\mathrm{ZnO} / \mathrm{FTO}$ samples in dye solution for various times. It was found that 3 hours immersion time produces the best results. Beyond 6 hours of immersion, the dye molecules begin to agglomerate around the $\mathrm{ZnO}$ nanorods which decrease the charge transfer efficiency of $\mathrm{ZnO}$ nanorods. After immersing the $\mathrm{ZnO} / \mathrm{FTO}$ samples in dye for 3 hours, the anodes were removed and washed in ethanol to remove any excess dye. Cathodes were prepared by spin coating a solution 'Pt' nanoparticles (platisol obtained from Solaronix) and sintered at 400 ${ }^{\circ} \mathrm{C}$ for 30 minutes. The cathode and anode were brought together and sealed using Meltonix hot melt sealing film from Solaronix. Iodolyte HI-30 a $30 \mathrm{mM}$ Iodine/tri-iodide electrolyte 
procured from Solaronix was introduced through the holes drilled on the back surface of the cathode which were then sealed using epoxy from Solaronix (Amisol).

\subsubsection{Optical \& Electrical Characterization}

The fabricated DSSCs were characterized using Oriel Sol 2A solar simulator under 1 Sun shown in figure 6.4 (a). The resulting photovoltaic behavior is shown in figure 6.3 (b). The DSSCs presented an efficiency of efficiency of $2.74 \%$ which is in accordance with the average efficiencies obtained using $\mathrm{ZnO}$ nanowires as shown in table 6.1. However the fabricated DSSCs suffered from well-known limitations that have plagued $\mathrm{ZnO}$ based DSSCs as, the efficiencies fell rapidly due to rapid degradation of $\mathrm{ZnO}$ nanorods in acidic N3 dye and the gradual leakage of liquid iodide electrolyte. Apart from the above limitations we have also observed that the thick seed layer used in sonochemical synthesis of $\mathrm{ZnO}$ nanostructures has led to high recombination losses resulting in low short circuit current $\left(\mathrm{J}_{\mathrm{sc}}\right)$. This led us to consider improved and stable organic solar cells that have inspired research in photovoltaics recently namely, Perovskite Solar cells.
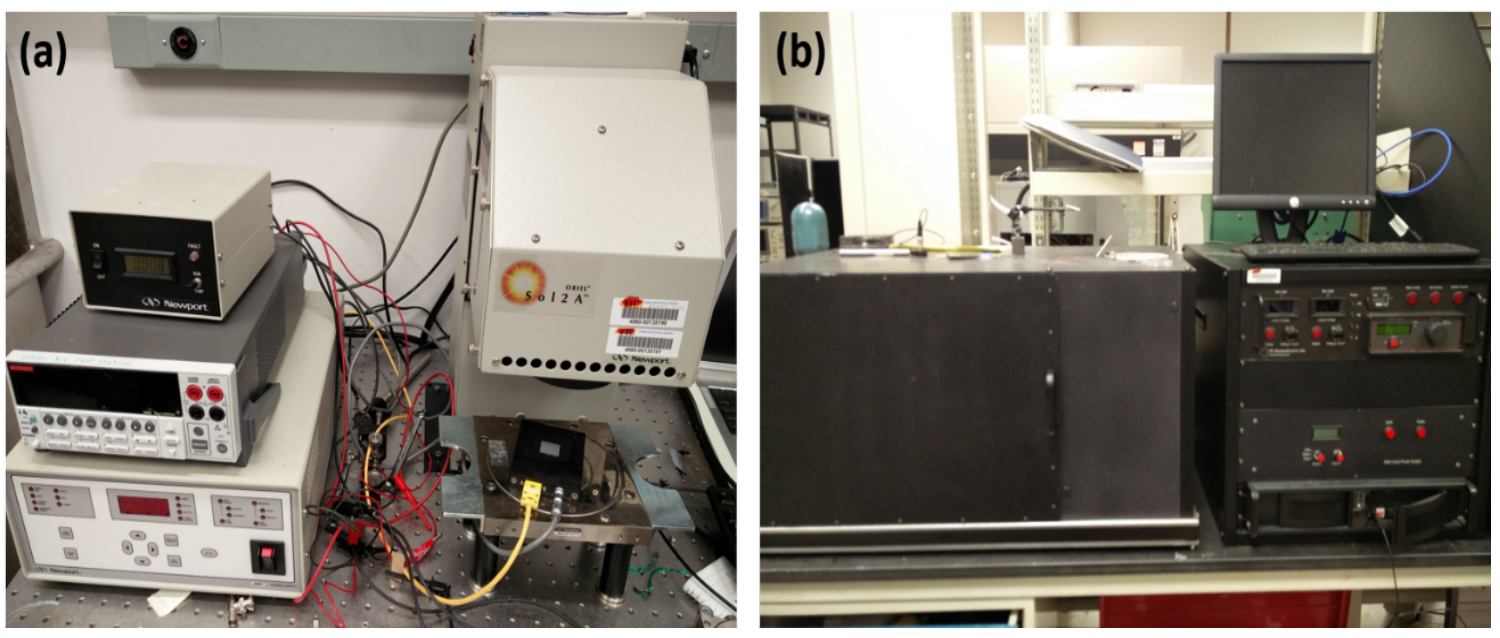

Figure 6.4 (a) Solar Simulator ORIEL Sol 2A (b) Spectral Response Measurement System 


\subsection{Perovskite Solar Cells}

The difficulties in fabricating stable DSSCs has inspired investigators to explore photon absorbing materials other than ruthenium dyes. In year 2006, Miyasaka and co-workers reported the use of $\mathrm{CH}_{3} \mathrm{NH}_{3} \mathrm{PbBr}_{3}$, a perovskite material as a sensitizer in photoelectrochemical cell and reported an efficiency of $2.2 \%$. [11] One year later they reported an improved efficiency by replacing Bromine with Iodine $\mathrm{CH}_{3} \mathrm{NH}_{3} \mathrm{PbI}_{3}$. [12] However, these cells suffered from the same issues that plagued DSSCs as the perovskite easily dissolves in the liquid electrolyte. This problem was later overcome by replacing the electrolyte with solid hole-transportation layers. This led to higher efficiencies and increased stability. [13] There were even reports where no hole-transportation layer was used and instead, the perovskite layer acts as both photo sensitizer and hole conduction layer. $[14,15]$ Recent efforts have resulted in efficiencies greater than $15 \%$ [16] with high open-circuit voltage $\mathrm{V}_{\mathrm{oc}}$ and high short circuit currents $\left(\mathrm{J}_{\mathrm{sc}}\right)$ owing to high diffusion lengths in perovskite. PCE of $20 \%$ is predicted from perovskite solar cells.[17] This indicates that organometal halide perovskite is a very promising material for future solar cells.

There are two configurations in which perovskite solar cells are being developed. One is based on electron injection in to an oxide layer such as $\mathrm{TiO}_{2}$ and $\mathrm{ZnO}$. The other is based on scaffold layer or p-n junction type planar structure. One dimensional $\mathrm{ZnO}$ nanostructures are attractive alternative to $\mathrm{TiO}_{2}$ as they provide faster electron mobilities, however the photovoltaic performances of $\mathrm{ZnO}$ nanorod based perovskite solar cells has been poor when compared with $\mathrm{TiO}_{2}$. This has changed when Dae-Yong and his colleagues reported $11 \%$ efficiency in $\mathrm{ZnO}$ nanorod based perovskite solar cells. [18] This has inspired us to fabricate $\mathrm{ZnO}$ nanorod based perovskite solar cells. 
For fabrication of perovskites owing to the lack of stability of $\mathrm{CH}_{3} \mathrm{NH}_{3} \mathrm{PbI}_{3}$ in conditions where humidity is higher than $37 \%$ and also keeping in mind the toxicity of $\mathrm{Pb}$, it is imperative to have working glove box for fabrication of perovskite solar cells. As such we have installed mbraun's labstar glove box with nitrogen as working gas shown in figure 6.5. A compact spinner and a hotplate were placed inside for fabrication of perovskite. A small desiccator with a hand pump for creating vacuum was used for sample transportation. The humidity and oxygen content in this glove box is maintained at $0.1 \mathrm{ppm}$. The fabrication of the cell was based on the findings of Dae-Yong son and colleagues.

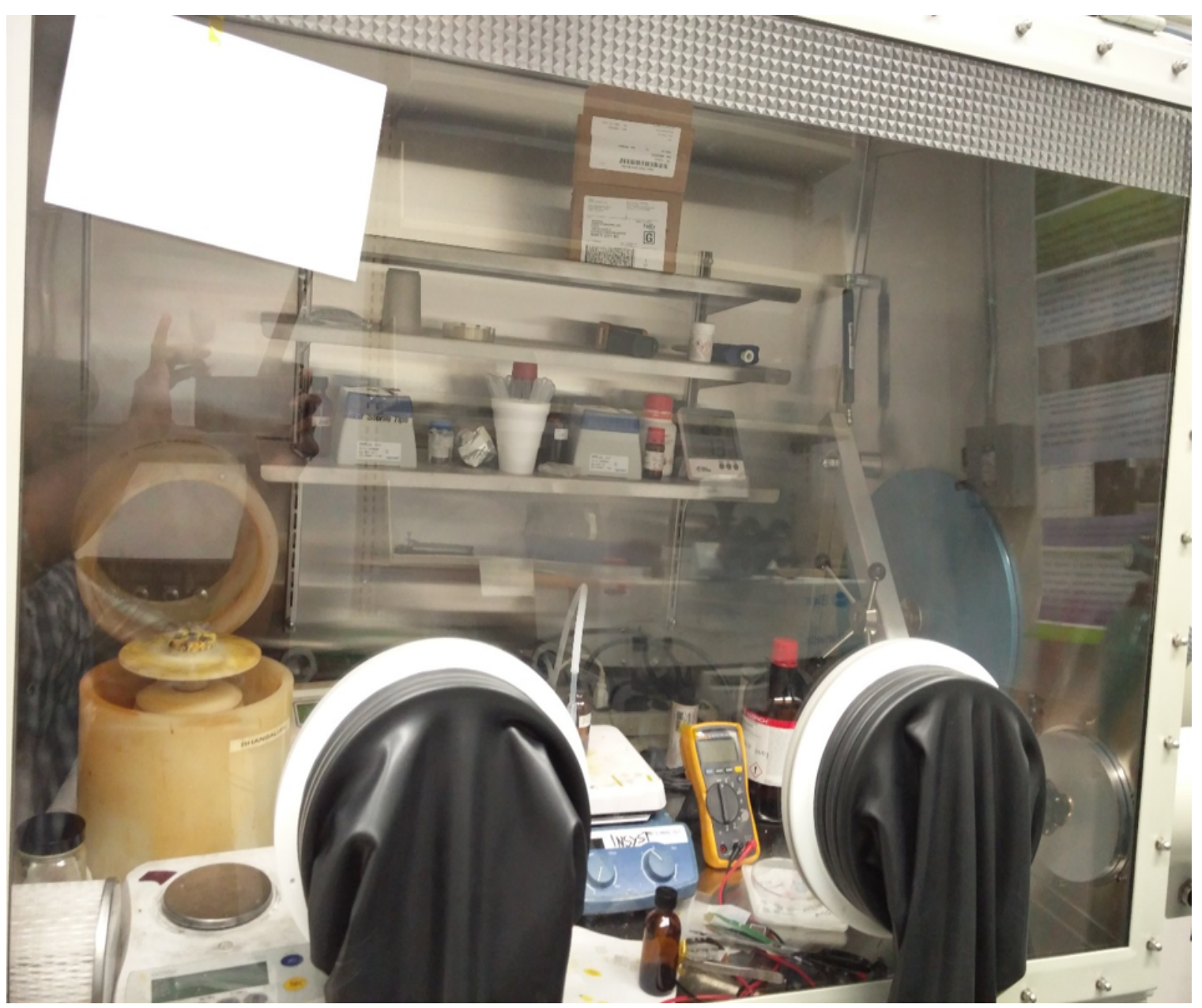

Figure 6.5 MBRAUN glove box filled with nitrogen with $\mathrm{O}_{2}$ and $\mathrm{H}_{2} \mathrm{O}$ maintained less than 1 part per million 


\subsubsection{Fabrication of Perovskite:}

FTO glass substrates were cleaned with acetone, isopropyl alcohol followed by DI water several times. The cleaned substrates were used as substrates for growth of $1 \mu \mathrm{m}$ long $\mathrm{ZnO}$ nanorods by sonochemical method as described in chapter 3 of this dissertation. Figure 6.6 (b-c) shows both the top view and cross-sectional view of $\mathrm{ZnO}$ nanorods grown over FTO.

(a)
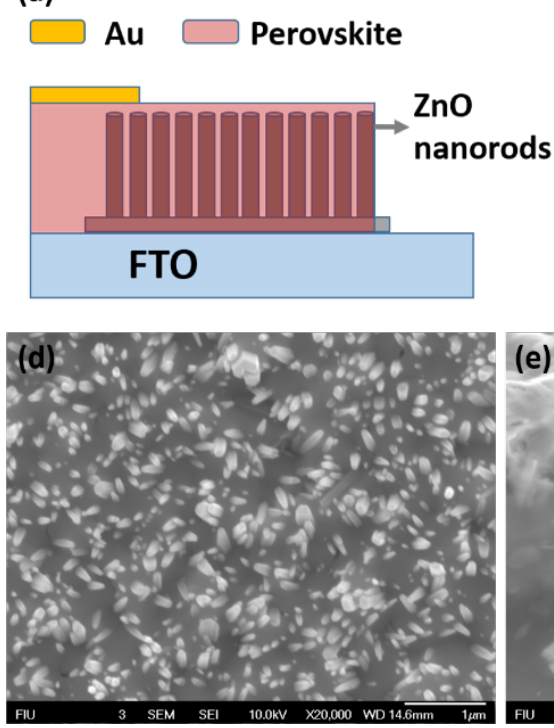

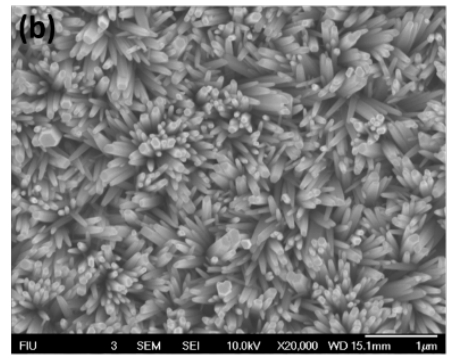

(e)

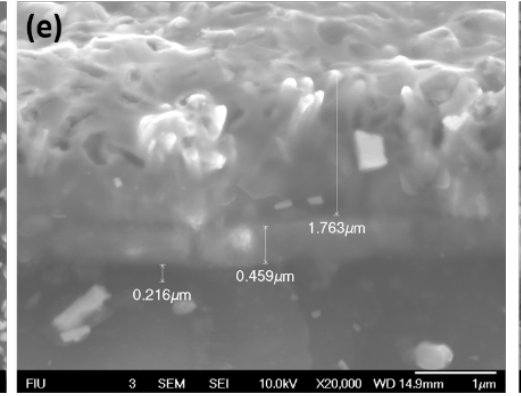

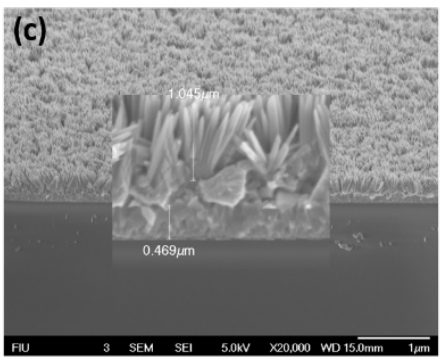

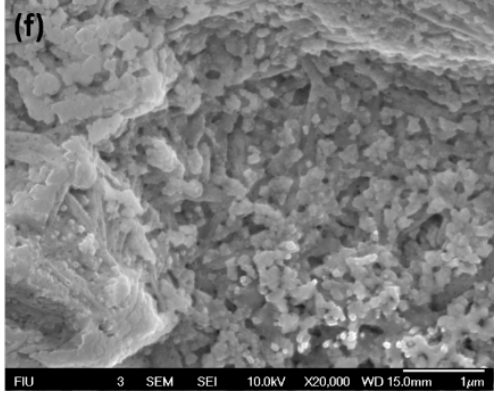

Figure 6.6 (a) Schematic of fabricated Perovskite solar cell (b) Top view of ZnO nanorods on FTO (c) Cross-sectional view of $\mathrm{ZnO}$ nanorods on FTO (d) Perovskite filling on $\mathrm{ZnO}$ nanorods/FTO (e ) Cross-sectional view of perovskite/ZnO nanorods/FTO (f) Perovskite filling on $\mathrm{ZnO}$ nanorods/FTO at low spin speed

A two-step method was used to deposit perovskite on $\mathrm{ZnO}$ nanorods. [19] A $1 \mathrm{M} \mathrm{PbI}_{2}$ solution was prepared by dissolving $4.6 \mathrm{~g}$ of $\mathrm{PbI}_{2}$ in $10 \mathrm{ml}$ of $\mathrm{N}, \mathrm{N}$ - dimethylformamide $(\mathrm{DMF})$ and stirred on spin coater while temperature is maintained at $70{ }^{\circ} \mathrm{C}$. This solution is allowed to stir at the set temperature for 2 hours. $100 \mu 1$ of this solution was dropped on ZnO NR/FTO substrate and spun immediately at $3000 \mathrm{rpm}$ for 20 seconds and immediately dried at $100{ }^{\circ} \mathrm{C}$ for 10 minutes. After the substrate is cooled, a $200 \mu \mathrm{lof} \mathrm{CH}_{3} \mathrm{NH}_{3} \mathrm{I}$ was 
dropped and allowed to rest for 20 seconds, before it was spun at $2000 \mathrm{rpm}$ for 20 seconds. The sample was placed on hot plate at $100{ }^{\circ} \mathrm{C}$ and dried for 10 minutes. As the sample dries, the layer on the $\mathrm{ZnO}$ nanorods turns brown in color from yellow, indicating the formation of perovskite. After the samples were cooled, a physical mask was placed on the samples and transferred in to a compact desiccator for transferring in to e-beam deposition chamber for gold contact deposition. An extra sample was prepared for SEM and XRD analysis. Photo- current vs voltage characteristics were measured using Oriel SOL 2A solar simulator.

\subsubsection{Structural \& Electrical Properties}

SEM analysis was done using JEOL 7000 FESEM to study the deposition of perovskite on $\mathrm{ZnO}$ nanorods. As can be seen in figure 6.6 (c-d) the perovskite failed to cover the whole $\mathrm{ZnO}$ nanorods as tips of nanorods are clearly visible protruding from the perovskite layer. This resulted in shorting the gold contacts to FTO as we observed no photovoltaic activity. In second phase, the thickness of the perovskite was increased so as to cover the as synthesized $\mathrm{ZnO}$ nanorods by reducing the spin speed of $\mathrm{PbI}_{2}$ to $1000 \mathrm{rpm}$ from $3000 \mathrm{rpm}$. Figure 6.6 (e) shows SEM picture of Perovskite/ ZnO nanorods/FTO when perovskite was deposited at lower spin speeds. It can be observed that at lower speeds the perovskite film is non uniform however no $\mathrm{ZnO}$ nanorods are visible. Figure 6.7 (a-c) shows the $\mathrm{XRD}$ analysis which shows the formation of perovskite on $\mathrm{ZnO}$ nanorods. Figure 6.7 (a) shows the transition from lead iodide to methyl ammonium lead iodide in samples $\mathrm{S} 1$ as $\mathrm{PbI}_{2}$ peaks disappear and perovskite peaks appear. The perovskite peaks indicate towards formation of tetragonal crystal structure in perovskite. 

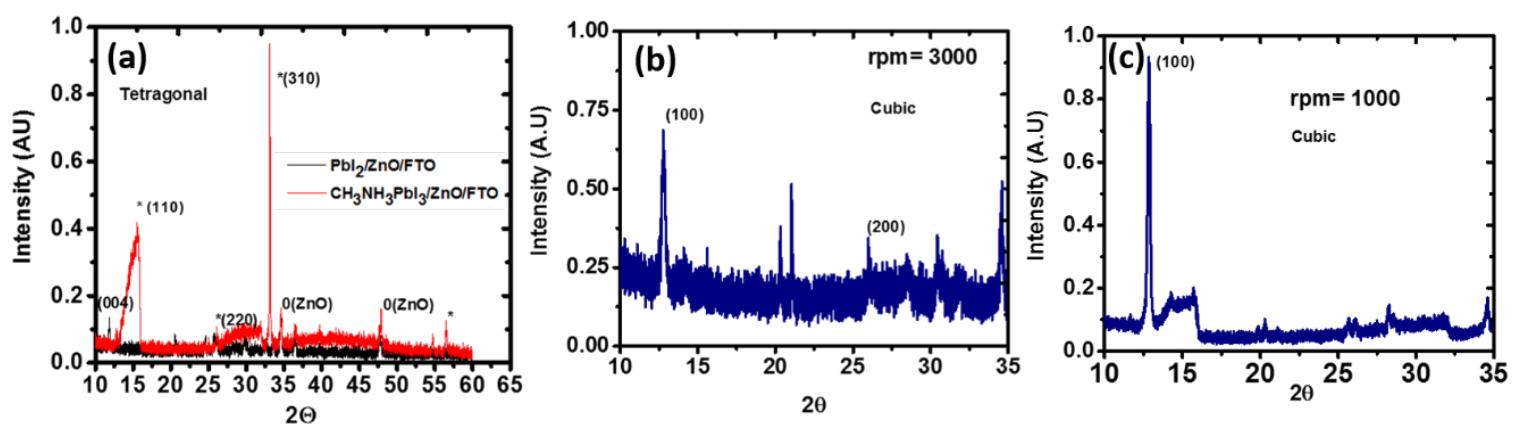

Figure 6.7 (a) $\mathrm{XRD}$ showing the change in peaks as $\mathrm{PbI}_{2}$ is changed to perovskite after introduction of $\mathrm{CH}_{3} \mathrm{NH}_{3} \mathrm{I}$ and heating. (b) Perovskite formed in cubic lattice at $3000 \mathrm{rpm}$ spin speed (c) perovskite formation in cubic lattice at $1000 \mathrm{rpm}$ spin speed and showing less peaks of $\mathrm{ZnO}$ due to higher coverage.

Figure 6.7 (b) shows the XRD analysis of sample S2 in which the spin speed was maintained at $3000 \mathrm{rpm}$ resulting in incomplete coverage of $\mathrm{ZnO}$ nanorods. The dominant (100) clearly indicates towards the formation of cubic lattice. The difference in crystal structure when compared to sample $\mathrm{S} 1$ could be due to experimental conditions as sample $\mathrm{S} 1$ was prepared in clean room for experimental convenience which could have resulted in tetragonal crystal structure due higher humidity present. Figure 6.7 (c) shows the XRD analysis on Sample $\mathrm{S} 3$ on which $\mathrm{PbI}_{2}$ was deposited by spin coating at $1000 \mathrm{rpm}$ speed which led to complete coverage of $\mathrm{ZnO}$ nanorods albeit the non-uniformity. We observe a clear dominant (100) peak indicating a cubic lattice structure. The lack of intermediate peaks corresponding $\mathrm{ZnO}$ unlike the previous samples also indicate towards complete coverage of perovskite. However the sample S3 when characterized under solar simulator again showed very small short circuit currents $\mathrm{J}_{\mathrm{sc}}$ of $54 \mu \mathrm{A}$ which leads to very low efficiencies. The extremely low values of short circuit currents indicate towards very high recombination losses which can attributed to the thickness of $\mathrm{ZnO}$ seed layer which is very high. However from our previous experiments we realize that a thick seed layer $\approx 400 \mathrm{~nm}$ 
is essential for uniform and vertically oriented $\mathrm{ZnO}$ nanorods. This calls for alternative methods to grow $\mathrm{ZnO}$ nanorods.

In this work, we used $\mathrm{ZnO}$ nanoflakes/ graphene as a seed layer for $\mathrm{ZnO}$ nanorod growth. As shown in chapter 3 , the $\mathrm{ZnO}$ nanoflakes are extremely thin with maximum thickness reaching $200 \mathrm{~nm}$. ZnO nanoflakes which are oriented in (001) plane are single crystalline in nature and form a thin continuous layer on graphene. In figure 6.8 (a) we show the modified architecture of $\mathrm{ZnO}$ nanorod based perovskite using flexible PET as substrate. Use of $\mathrm{ZnO}$ nanoflakes not only reduces the recombination losses but also enhances the electron transport as was shown in earlier studies (cortisol sensor). Figure 6.8 (b) shows the successfully grown $\mathrm{ZnO}$ nanorods using $\mathrm{ZnO}$ nanoflakes grown over graphene/PET as seed layer. Further growth cycles are needed to achieve a uniform vertically oriented $\mathrm{ZnO}$ nanorods. Another architecture we use is $\mathrm{ZnO}$ Nanowalls grown on 'Al' coated PET substrate as scaffold layer in fabricating planar perovskite solar cells as shown in figure 6.8 (c). $\mathrm{ZnO}$ Nanowalls are $10-15 \mathrm{~nm}$ thick and highly porous which is a required feature for successful fabrication of perovskite solar cells.

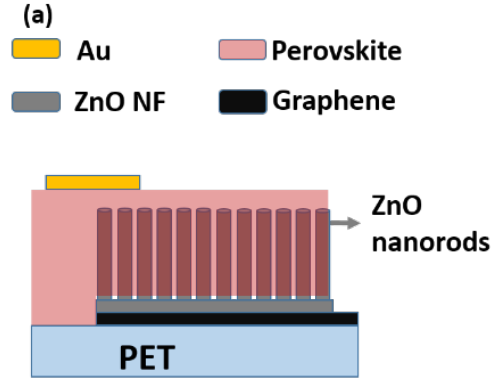

(b)

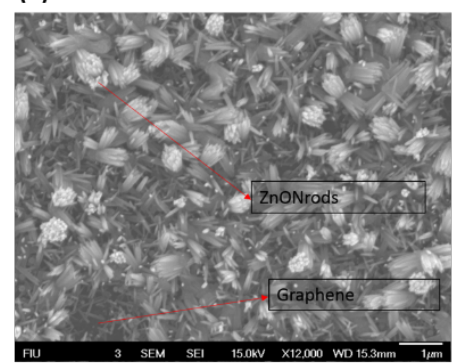

(c)

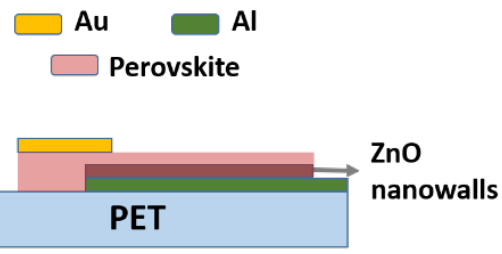

Figure 6.8 (a) $\mathrm{ZnO}$ nanorods grown over $\mathrm{ZnO}$ nanoflakes/graphene/PET as electron transport layer (b) Partially grown $\mathrm{ZnO}$ nanorods on $\mathrm{ZnO}$ nanoflakes/PET showing both $\mathrm{ZnO}$ nanorods and graphene (c) $\mathrm{ZnO}$ Nanowalls grown over Al/PET as scaffolding layer planar perovskite solar cell. 


\subsection{Conclusions}

In conclusion, we have fabricated DSSC's using $\mathrm{ZnO}$ nanorods as electron transport material. The as fabricated DSSC' showed an external quantum efficiency of $2.74 \%$ which is in accordance with the values reported in literature. We also observed that $\mathrm{ZnO}$ is not stable in acidic dyes which prompted us to fabricate perovskite solar cells. We have fabricated perovskite solar cells using $\mathrm{ZnO}$ nanorods grown on FTO as electron transport layer and found that the thick seed layer used in sonochemistry results in heavy recombination losses. To overcome this we have come with a new method of synthesizing $\mathrm{ZnO}$ nanorods, where $\mathrm{ZnO}$ nanoflakes grown over graphene/PET are used as electron transport layer in fabrication of flexible perovskite solar cells.

\subsection{References}

1. http://www.nrel.gov/ncpv/images/efficiency_chart.jpg

2. Qian, J., Liu, P., Xiao, Y., Jiang, Y., Cao, Y., Ai, X., \& Yang, H. (2009). TiO2-coated multilayered $\mathrm{SnO} 2$ hollow microspheres for dye-sensitized solar cells. Advanced Materials, 21 (36):3663-3667.

3. Chapin, D. M., Fuller, C. S., \& Pearson, G. L. (1954). A new silicon p-n junction photocell for converting solar radiation into electrical power. Journal of Applied Physics, 25 (5):676-677.

4. Yang, J., Banerjee, A., \& Guha, S. (2003). Amorphous silicon based photovoltaicsfrom earth to the "final frontier". Solar energy materials and solar cells, 78 (1):597612.

5. Narasimha, S., \& Rohatgi, A. (1998). Fabrication and characterization of $18.6 \%$ efficient multicrystalline silicon solar cells. Electron Devices, IEEE Transactions on, 45 (8):1776-1783.

6. Ward, J. S., Ramanathan, K., Hasoon, F. S., Coutts, T. J., Keane, J., Contreras, M. A., Moriarty, T., \& Noufi, R. (2002). A 21.5\% efficient Cu (In, Ga) Se2 thin-film 
concentrator solar cell. Progress in Photovoltaics: Research and Applications, 10 (1):41-46.

7. Afzaal, M., \& O'Brien, P. (2006). Recent developments in II-VI and III-VI semiconductors and their applications in solar cells. Journal of Materials Chemistry, 16 (17):1597-1602.

8. Schock, H. W. (1996). Thin film photovoltaics. Applied surface science, 92:606-616.

9. Grätzel, M. (2001). Photoelectrochemical cells. Nature, 414 (6861):338-344.

10. Zhang, Q., Dandeneau, C. S., Zhou, X., \& Cao, G. (2009). ZnO Nanostructures for Dye-Sensitized Solar Cells. Advanced Materials, 21 (41):4087-4108.

11. Kojima, A., Teshima, K., Miyasaka, T. \& Shirai, Y., (June, 2006). Novel photoelectrochemical cell with mesoscopic electrodes sensitized by lead-halide compounds (2). Paper presented at the meeting of the 210th ECS, San Diego, CA.

12. Kojima, A., Teshima, K., Shirai, Y., \& Miyasaka, T. (2009). Organometal halide perovskites as visible-light sensitizers for photovoltaic cells. Journal of the American Chemical Society, 131 (17):6050-6051.

13. Lee, M. M., Teuscher, J., Miyasaka, T., Murakami, T. N., \& Snaith, H. J. (2012). Efficient hybrid solar cells based on meso-superstructured organometal halide perovskites. Science, 338 (6107):643-647.

14. Yan, K., Wei, Z., Li, J., Chen, H., Yi, Y., Zheng, X., Long, X., Wang, Z., Wang, J., $\mathrm{Xu}$, J., \& Yang, S. (2015). High-Performance Graphene-Based Hole Conductor-Free Perovskite Solar Cells: Schottky Junction Enhanced Hole Extraction and Electron Blocking. Small, 11 (19):2269-2274.

15. Laban, W. A., \& Etgar, L. (2013). Depleted hole conductor-free lead halide iodide heterojunction solar cells. Energy \& Environmental Science, 6 (11):3249-3253.

16. Burschka, J., et al (2013). Sequential deposition as a route to high-performance perovskite-sensitized solar cells. Nature, 499:316-319.

17. Park, N. G. (2013). Organometal perovskite light absorbers toward a $20 \%$ efficiency low-cost solid-state mesoscopic solar cell. The Journal of Physical Chemistry Letters, 4 (15):2423-2429.

18. Son, D. Y., Im, J. H., Kim, H. S., \& Park, N. G. (2014). 11\% efficient perovskite solar cell based on $\mathrm{ZnO}$ nanorods: an effective charge collection system. The Journal of Physical Chemistry C, 118 (30):16567-16573. 
19. Burschka, J., Pellet, N., Moon, S. J., Humphry-Baker, R., Gao, P., Nazeeruddin, M. K., \& Grätzel, M. (2013). Sequential deposition as a route to high-performance perovskitesensitized solar cells. Nature, 499 (7458):316-319.

20. Zhang, Q., Dandeneau, C. S., Zhou, X., \& Cao, G. (2009). ZnO Nanostructures for Dye-Sensitized Solar Cells. Advanced Materials, 21 (41):4087-4108. 


\section{CHAPTER 7}

\section{Photodetectors}

\subsection{P:ZnO-ZnO Core-Shell Photodetectors}

Zinc oxide due to its wide bandgap and superior stability under harsh environments has been widely used for UV photodetection.[1] In a $\mathrm{ZnO}$ p-n junction, an increase in reverse current is observed under UV illumination as electron-hole pairs are generated in depletion region by band to band excitation in semiconductor when $h v>E_{g}$. These electron-hole pairs are quickly swept away towards the electrodes due to the internal electric field. This increased reverse saturation current due to the incident light is also called the photo current $\left(\mathrm{I}_{\mathrm{ph}}\right)$.[2] We have fabricated a UV p-n junction photodetector by growing a $\mathrm{P}: \mathrm{ZnO}$ nanoshell/ n- ZnO NR p-n junction on $\mathrm{Au} / \mathrm{Ti} / \mathrm{Si}$ substrate which acts as ohmic contact to the $\mathrm{ZnO}$ nanorods while a physical mask with a window size of $0.15 \mathrm{~cm}^{2}$ was used to deposit $100 \mathrm{~nm}$ thick ITO by RF sputtering to form contact on the P:ZnO nanoshells to allow maximum transmission of incident light. The RF sputtering was performed at room temperature with pressure maintained steady at 11 mTorr. The RF power and time were 70 $\mathrm{W}$ and 100 minutes respectively to produce a deposition rate of $1 \mathrm{~nm} / \mathrm{s}$. The schematic of as prepared p-n junction is shown in figure 7.1 (a). $\mathrm{ZnO}$ with wide bandgap $(3.37 \mathrm{eV})$ is known to generate electron-hole pairs when exposed to UV illumination where wavelength corresponds to the band edge excitation. The diode was tested under a commercially available UV compact fluorescent lamp with a broad band emission (365 nm - $385 \mathrm{~nm})$. The output of the lamp measured by OAI $306 \mathrm{UV}$ power meter was $4.6 \mathrm{~mW} / \mathrm{cm}^{2}$. The photoresponse under UV illumination is measured and plotted in figure 7.1 (b), which 
shows a 100 fold increase in reverse bias current at $4 \mathrm{~V}$ reverse bias, which gives a photo current ( $\mathrm{I}_{\mathrm{ph}}$ ) of $371.88 \mu \mathrm{A}$. The photo responsivity $R_{p h}$ measures the input-output gain of the photo detector given by:

$$
R_{p h}=J_{p h} / P_{o}
$$

Where $\mathrm{J}_{\text {ph }}$ is the photo current density, and $\mathrm{P}_{0}$ is the input optical power density. We have estimated the number of $\mathrm{P}: \mathrm{ZnO}$ nanoshell/n- $\mathrm{ZnO}$ NR structures that actually make contact with our deposited ITO contact and calculated the area under the contacts from which $\mathrm{J}_{\mathrm{ph}}$ and $R_{p h}$ were calculated to be $0.02 \mathrm{~A} / \mathrm{cm}^{2}$ and $60 \mathrm{~A} / \mathrm{W}$ respectively.
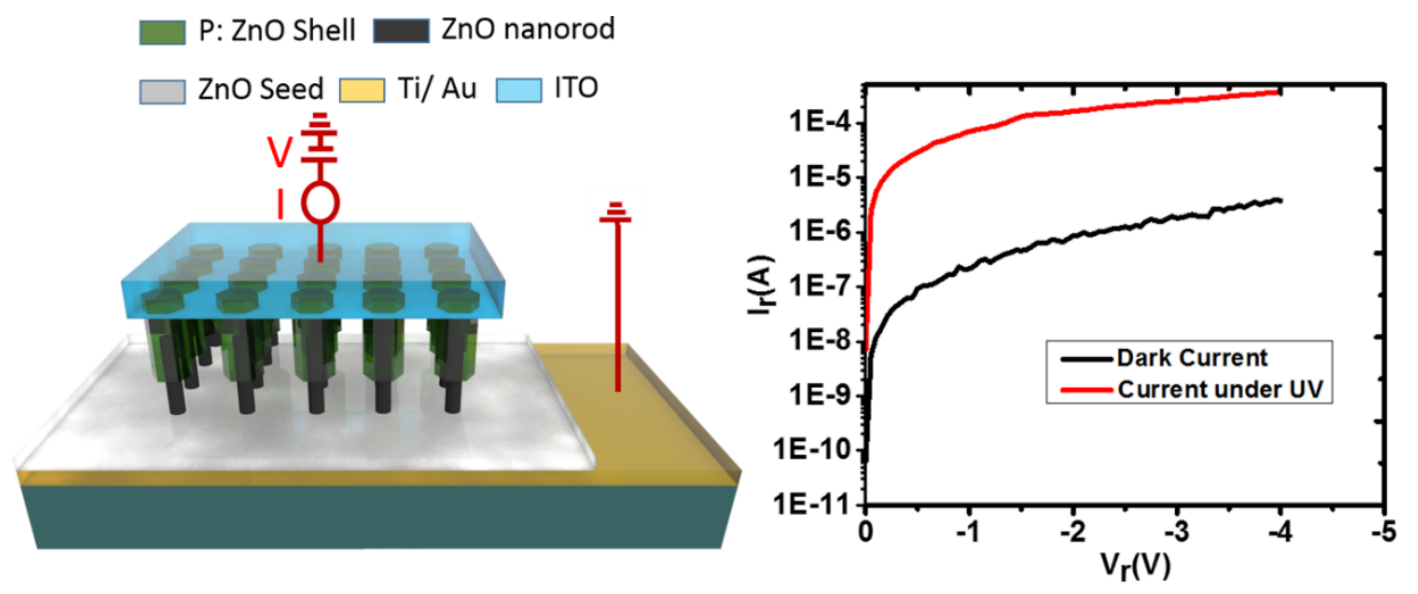

Figure 7.1. Characterization of the fabricated UV radial p-n junction photo detector: (a) Schematic of $\mathrm{p}-\mathrm{ZnO} / \mathrm{n}-\mathrm{ZnO}$ core-shell homojunction; (b) Photoresponse in presence of UV light.

Another important feature of photodetectors is their noise equivalent power (NEP), which represents the lowest input power that gives a unit signal to noise ratio. Conventionally, in p-n junction photodiodes the contribution of shot noise towards over all noise is negligible. 
However, considering the $200 \mu \mathrm{A}$ reverse saturation current in our diode, we have considered both shot noise and Johnson noise for noise calculations. Johnson noise current $i_{j}$ is due to thermal noise associated with the resistance and is given by $i_{j}=\sqrt{\frac{4 k B T}{R_{e q}}}$, where $\mathrm{k}$ is the Boltzmann constant, $\mathrm{T}$ is the absolute temperature and $R_{e q}$ is the equivalent resistance. The $R_{e q}$ is obtained from the slope of $\mathrm{I}-\mathrm{V}$ of $\mathrm{P}: \mathrm{ZnO}$ nanoshell/ $\mathrm{ZnO}$ at $-2 \mathrm{~V}$ measured in dark. For $R_{e q}$ of $4.45 \mathrm{k} \Omega$ and for normalized bandwidth (B) at room temperature the Johnson noise $i_{j}$ is $19.2 \mu \mathrm{A}$. The shot noise is given by $i_{s}=\sqrt{2 q\left(I_{p h}+I_{d}\right) B}$ , where $I_{p h}$ is photo current and $I_{d}$ is dark current. The measured shot noise current at $-2 \mathrm{~V}$ is $7.28 \mathrm{pA}$. The total noise current $i_{n} \approx i_{j}=19.2 \mu \mathrm{A}$ and the NEP which is the ratio of $i_{n}$ and the responsivity is calculated.[3, 4] We obtain a minimum NEP of $324 \mathrm{nW} / \sqrt{ } \mathrm{Hz}$. Table 7.1 compares the performance of as fabricated $\mathrm{P}: \mathrm{ZnO}$ nanoshell- $\mathrm{ZnO}$ p-n junction photo diode with other UV photo detectors reported in literature.

Table 7.1. Performance comparison of the fabricated UV photo detector with the recently reported ones

\begin{tabular}{|c|c|c|c|c|}
\hline $\begin{array}{l}\text { Material/ } \\
\text { Structure }\end{array}$ & Device & Method & Responsivity & $\begin{array}{l}\text { Turn On } \\
\text { Voltage }\end{array}$ \\
\hline $\mathrm{P}-\mathrm{NiO} / \mathrm{n}-\mathrm{ZnO}$ & $\begin{array}{c}\text { Planar p-n } \\
\text { junction diode }\end{array}$ & RF Sputtering & $0.09 \mathrm{~A} / \mathrm{W}$ & $0.9 \mathrm{~V},[5]$ \\
\hline $\begin{array}{l}\text { Graphene/ n- } \\
\mathrm{ZnO}\end{array}$ & $\begin{array}{c}\text { Schottky } \\
\text { junction diode }\end{array}$ & & $113 \mathrm{~A} / \mathrm{W}$ & $0.5 \mathrm{~V}[6]$ \\
\hline $\mathrm{P}-\mathrm{GaN} / \mathrm{n}-\mathrm{ZnO}$ & $\begin{array}{c}\text { Planar p-n } \\
\text { junction diode }\end{array}$ & MBE & $0.68 \mathrm{~mA} / \mathrm{W}$ & $3.7 \mathrm{~V}[7]$ \\
\hline $\begin{array}{c}\mathrm{P}(\mathrm{Al}-\mathrm{N}) \mathrm{ZnO} / \mathrm{n}- \\
\mathrm{ZnO}\end{array}$ & $\begin{array}{c}\text { Planar p-n } \\
\text { junction diode }\end{array}$ & Sol- Gel & $4 \mathrm{~A} / \mathrm{W}$ & $1.4 \mathrm{~V},[8]$ \\
\hline $\begin{array}{c}\mathrm{P}(\mathrm{Sb}) \mathrm{ZnO} / \mathrm{n}- \\
\mathrm{ZnO}\end{array}$ & $\begin{array}{c}\text { Radial p-n } \\
\text { junction diode }\end{array}$ & $\begin{array}{c}\text { Hydrothermal } \\
\text { method }\end{array}$ & $0.425 \mathrm{~A} / \mathrm{W}$ & $2.5 \mathrm{~V},[4-26]$ \\
\hline $\mathrm{P}-\mathrm{ZnO} / \mathrm{n}-\mathrm{ZnO}$ & $\begin{array}{c}\text { Radial p-n } \\
\text { junction diode }\end{array}$ & $\begin{array}{l}\text { Sonochemical } \\
\text { Method }\end{array}$ & $60 \mathrm{~A} / \mathrm{W}$ & $\begin{array}{c}0.5 \mathrm{~V} \text { [presen } \\
\text { work] }\end{array}$ \\
\hline
\end{tabular}




\subsection{Highly Sensitive Wide Bandwidth Photodetector Based on Internal Photoemission in CVD Grown P-Type $\mathrm{MoS}_{2} /$ Graphene Schottky Junction}

Graphene, a semi-metallic, two-dimensional (2D) material with a single atomic thickness has been the most widely researched material owing to its superior electrical, mechanical and optical properties such as high carrier mobility $\left(\approx 200,000 \mathrm{~cm}^{2} \mathrm{~V}^{-1} \mathrm{~s}^{-1}\right)$, high mechanical strength, flexibility, transparency, and high absorption rate $(2.30 \%$ of incident light per each layer) among many other properties.[10,11] Further, gapless nature of graphene enables charge carrier generation over a wide energy spectrum from ultra violet (UV) to terahertz $(\mathrm{THz})$ making it a unique material for photonics and optoelectronics during the recent past.[12] Making use of the unique capabilities of graphene, many studies have been performed over the past decade to demonstrate highly efficient graphene photodetectors (GPDs) from visible to infrared (IR) range.[13-15] Despite the many favorable properties, factors such as low absorption due to single layer nature of graphene limited the responsivity of conventional GPDs to few tens of $\mathrm{mAW}^{-1}$.[12] Alternative methods such as colloidal quantum dots, microcavities or plasmonic nanostructures have been used to improve the responsivity of the GPDs but these devices were found to respond to very limited wavelengths of light.[16] On the other hand, 2D semiconductor transition metal dichalcogenides (sTMDs) materials have also been widely used for photodetector applications.[17] Atomically thin sTMDs provide a wide range of advantages in optoelectronics when compared to their bulk counterparts owing to their high transparency, flexibility and tunable bandgap. In particular, $\mathrm{MoS}_{2}$ is a unique semiconductor material whose bulk counterpart has an indirect-gap of $1.20 \mathrm{eV}$ but when reduced to a monolayer, it changes into direct bandgap material with a bandgap of $1.80 \mathrm{eV}$ due to quantum 
confinement. This results in higher absorption coefficient and efficient electron-hole pair generation under photo excitation in monolayer $\mathrm{MoS}_{2}$. A $10^{4}$ fold enhancement of luminescence quantum yield for monolayer $\mathrm{MoS}_{2}$ compared with bulk $\mathrm{MoS}_{2}$ has been observed. [18] There are several reports on the fabrication of $\mathrm{MoS}_{2}$ based photodetectors. The first phototransistor based on monolayer $\mathrm{MoS}_{2}$ showed a relatively poor photo responsivity of $7.50 \mathrm{mAW}^{-1}$.[19] Woong Choi et al. used multilayer $\mathrm{MoS}_{2}$ to achieve 100 $\mathrm{mAW}^{-1}$ photo responsivity,[20] showing an improvement over the first phototransistor but still low compared to GPDs. Since then, much progress has been made and more recently, phototransistors with responsivities ranging from few hundreds of $\mathrm{mAW}^{-1}$ to hundreds of $\mathrm{AW}^{-1}$ were reported. [21, 22] However, the reported $\mathrm{MoS}_{2}$ based photodetectors are limited by narrow wavelength range and long response times.

To further improve the properties of graphene and $\mathrm{MoS}_{2}$-based photodetectors, it is imperative to design new device structures like composites, heterostructures or functionally graded thin films. Numerous efforts have been made to combine the properties of TMDs and graphene by assembling graphene with other 2D crystals to create multifunctional high-performance hybrid devices. [23- 29] One of the hybrid structures includes the combination of graphene and $\mathrm{MoS}_{2}$ in the form of thin film heterostructures. Coupling graphene with $\mathrm{MoS}_{2}$ can produce a hybrid material that can utilize the high photon absorption capability in $\mathrm{MoS}_{2}$ and high electron mobility in graphene to realize a highly efficient photodetector as shown by Wenjing Zhang et al who have achieved a high responsivity of $1.2 \times 10^{7} \mathrm{~A} / \mathrm{W}$ by applying a gate voltage of $-10 \mathrm{~V}$ at $690 \mathrm{~nm}$ laser illumination by simply stacking n-type monolayer $\mathrm{MoS}_{2}$ over graphene.[30] In this research, we have assembled few layers of graphene with few layers of $p$-type $\mathrm{MoS}_{2}$ to 
form a simple $\mathrm{MoS}_{2} /$ graphene Schottky junction photodiode. We found that $p$-type $\mathrm{MoS}_{2}$ provides a much lower Schottky barrier height with graphene with a broad spectral range of detection.

\subsubsection{Fabrication of $\mathrm{MoS}_{2} /$ Graphene Photodetector}

Fabrication of $\mathrm{MoS}_{2} /$ graphene junction devices starts with the growth of atomically thin $\mathrm{MoS}_{2}$ film on $\mathrm{Si} / \mathrm{SiO}_{2}$ substrates followed by the transfer of graphene. The growth of both $\mathrm{MoS}_{2}$ and graphene was done by "Nanomaterials and Device Laboratory" at University of North Texas. For $\mathrm{MoS}_{2}$ deposition, the first step involves the sputtering of Mo thin films on (100) oriented $n$-type (As doped, resistivity $<0.005 \Omega . \mathrm{cm}$ ) silicon substrates coated with $300 \mathrm{~nm}$ thick $\mathrm{SiO}_{2}$ layer. High purity (99.99\%) Mo metal target of $50 \mathrm{~mm}$ diameter was used for sputtering Mo thin films. In second step, magnetron sputtered $\mathrm{Mo} / \mathrm{SiO}_{2} / \mathrm{Si}$ films were subsequently placed in a low-pressure chemical vapor deposition (LPCVD) system (Graphene Square CVD) and sulfurization was proceeded at $600{ }^{\circ} \mathrm{C}$ for $30 \mathrm{~min}$. [31] Polycrystalline copper foils (Nimrod Hall, $99.9 \%$ purity, $25 \mu \mathrm{m}$ thick) was used as the substrates for graphene growth. The ' $\mathrm{Cu}$ ' foil was electro-polished using a home-built electrochemistry cell followed by rinsing in methanol and deionized water solution (1:1), and then gently blown with compressed nitrogen for drying. The cleaned ' $\mathrm{Cu}$ ' foil was loaded into the low-pressure thermal CVD system. The reaction chamber was evacuated to $\sim 0.1$ mTorr and refilled with $2.5 \mathrm{sccm}$ of pure $\mathrm{H}_{2}$. The temperature was increased to 1000 ${ }^{0} \mathrm{C}$ within $40 \mathrm{~min}$ and then annealed for $1 \mathrm{~h}$. After annealing, $20 \mathrm{sccm}$ of $\mathrm{CH}_{4}$ and $2.5 \mathrm{sccm}$

of $\mathrm{H}_{2}$ were introduced into the chamber for graphene growth at $1000{ }^{\circ} \mathrm{C}$ under the pressure of 5 Torr for a certain growth time. After the growth, the $\mathrm{CH}_{4}$ flow was turned off and the 
chamber was cooled down under $\mathrm{H}_{2}$ environment. [32] The graphene transfer method used was as follows: (1) PMMA (MicroChem Corp. 495 PMMA A2) solution was spin-coated onto the graphene/ $\mathrm{Cu}$ foil at $5000 \mathrm{rpm}$ for $1 \mathrm{~min}$, followed by drying the sample in the air; (2) the $\mathrm{Cu}$ foil was etched with metal etchant (type I, Transene company, INC.), resulting in the PMMA/graphene film floating to the top of the etchant solution; (3) the PMMA/graphene film was washed in a beaker containing deionized water, and floated on $10 \% \mathrm{HCl}$ solution for $10 \mathrm{~min}$, and transferred to a beaker with deionized water for another wash (done $3 \times$ ); (4)the film was transferred to a beaker with deionized water for another wash and this process was repeated three times; (5) the film was then finally scooped onto a Si/SiO2/MoS 2 substrate with the PMMA side up and dried in the air; (6) the PMMA layer was removed by immersing the sample in a large volume of acetone; (7) the sample was dried with compressed nitrogen. Figure 7.2 (a) shows the schematic of the $\mathrm{MoS}_{2} /$ graphene photodetector device structure simply formed by a manual stacking of a graphene onto $\mathrm{MoS}_{2} .50 \mathrm{~nm}$ thick $\mathrm{Au} / \mathrm{Ti}$ metal contacts were deposited by electron beam evaporation after using a shadow mask. The shadow masks were carefully prepared using a laser writer so as to maintain the contact area and position accurately. The deposited contacts were later annealed at $350{ }^{\circ} \mathrm{C}$ for 30 minutes.

\subsubsection{Structural Properties of $\mathrm{MoS}_{2} /$ Graphene}

Figure 7.2 (a) shows the schematic of the studied photodiode. Figure 7.2 (b) shows the optical microscope image of $\mathrm{MoS}_{2} /$ graphene junction which clearly shows a color contrast over the four different regions; (1) $\mathrm{SiO}_{2}$ (2) $\mathrm{MoS}_{2}$ (3) Graphene and (4) $\mathrm{MoS}_{2} /$ graphene junction (MGJ). Atomic force microscopy (AFM) was used to study the thickness and the 
interface of $\mathrm{MoS}_{2}$ and graphene. Figures 7.2 (c) and 7.2 (e) show the thickness measured using AFM. We observed that the average thickness of $\mathrm{MoS}_{2}$ layer is $2 \mathrm{~nm}$ and that of graphene is $5 \mathrm{~nm}$, which suggests that as grown $\mathrm{MoS}_{2}$ was about 3-4 layers thick. Raman spectroscopy which is a widely used method to determine the number of layers, quality and defects present in these 2D materials [33] was used to complement the AFM findings and to study the quality of $\mathrm{MoS}_{2}$ and graphene films.

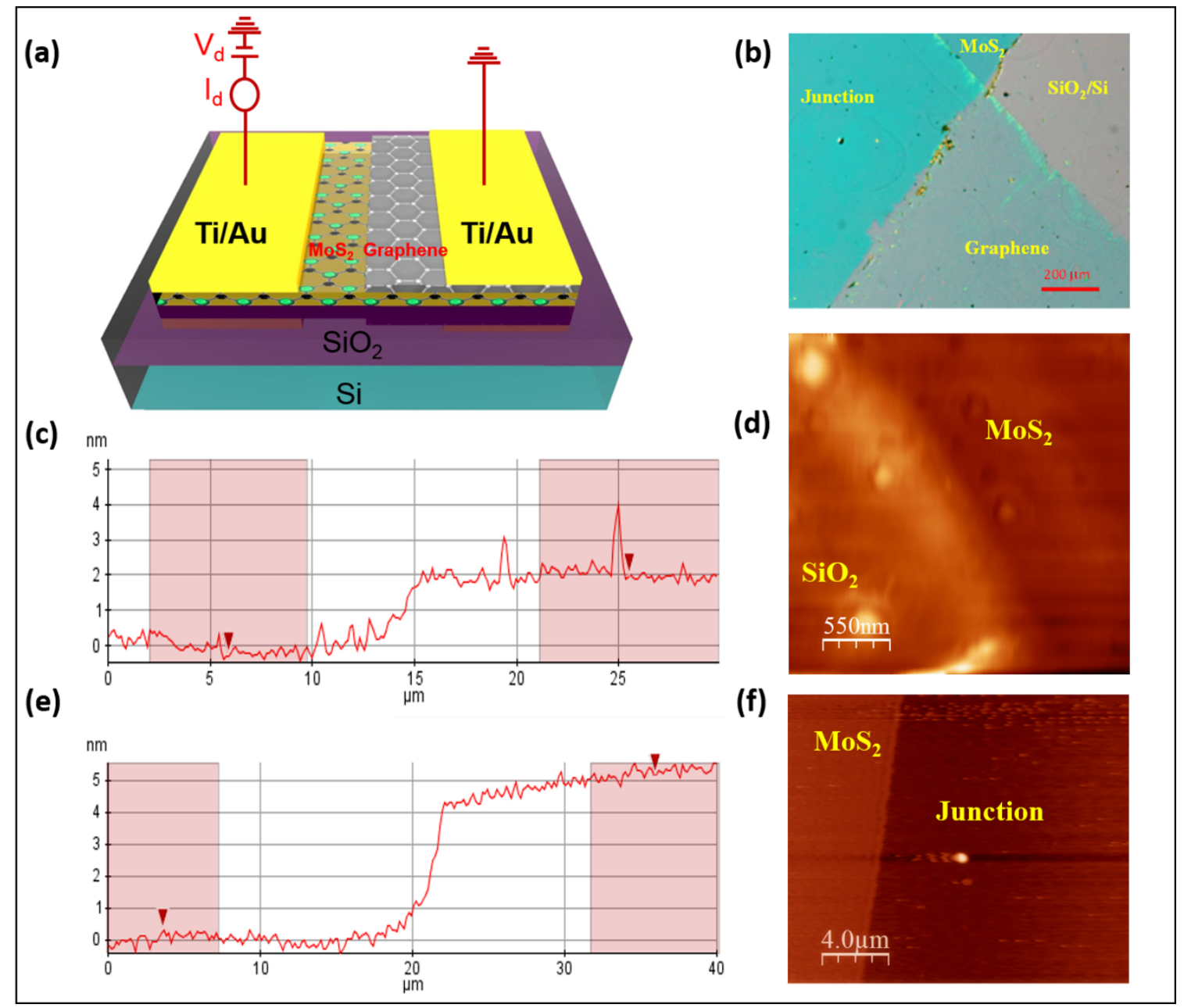

Figure 7.2. (a) Schematic of p-type $\mathrm{MoS}_{2} /$ graphene junction device (b) Optical image of $\mathrm{MoS}_{2}$ /graphene junction with individual areas clearly visible (c) AFM height profile showing height of $\mathrm{MoS}_{2}$ (d) AFM image of $\mathrm{MoS}_{2}-\mathrm{SiO}_{2}$ interface (e) Thickness of graphene at $\mathrm{MoS}_{2} /$ graphene junction (f) AFM image of $\mathrm{MoS}_{2} /$ graphene junction 
Figure 7.3 (a) shows the Raman spectra of $\mathrm{MoS}_{2}$ and graphene, measured over $\mathrm{SiO}_{2}$ and junction regions using a $532 \mathrm{~nm}$ excitation laser line.

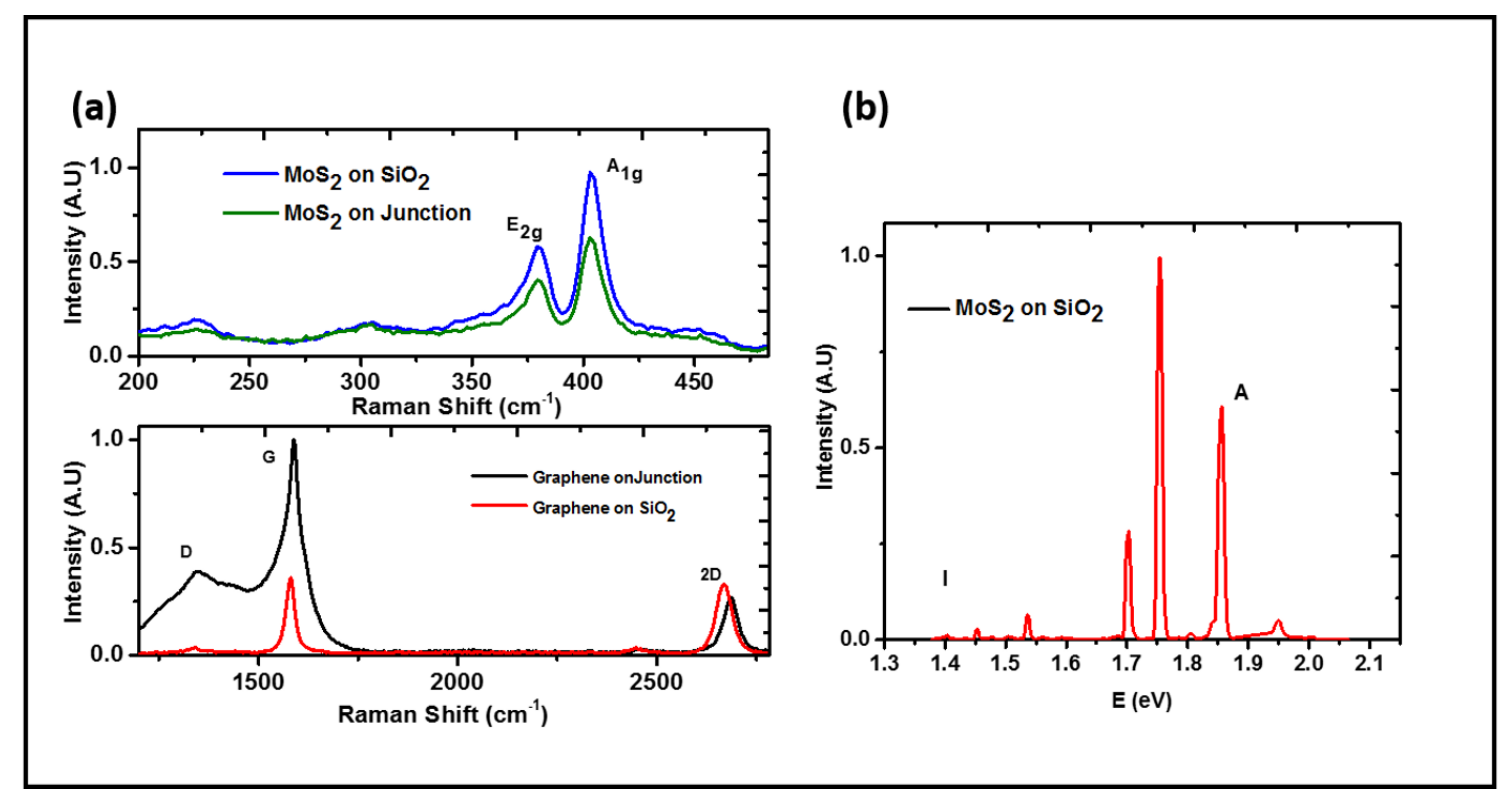

Figure 7.3. (a) Raman spectrum of $\mathrm{MoS}_{2}$ and Graphene on $\mathrm{SiO}_{2}$ and junction (b) Photoluminescence of $\mathrm{MoS}_{2}$ on $\mathrm{SiO}_{2}$ showing sharp peaks at 1.7, 1.75 and $1.85 \mathrm{eV}$, and smaller ones at 1.4 and $1.55 \mathrm{eV}$.

We observed strong peaks at $379.77 \mathrm{~cm}^{-1}$ and $403.52 \mathrm{~cm}^{-1}$ corresponding to the in plane $\mathrm{E}^{1}{ }_{2 \mathrm{~g}}$ mode and out-of-plane $\mathrm{A}_{1 \mathrm{~g}}$ mode of $\mathrm{MoS}_{2}$, respectively. The peak frequency difference of $23.75 \mathrm{~cm}^{-1}$ between the two modes indicates that as grown $\mathrm{MoS}_{2}$ is 4-5 layers thick, which is in agreement with the previously reported results [34] and also with our results obtained by AFM height analysis. Raman spectra of graphene on $\mathrm{SiO}_{2}$ shows the formation of '2D' and ' $G$ ' characteristics peaks at $2666.83 \mathrm{~cm}^{-1}$ and $1580.16 \mathrm{~cm}^{-1}$, respectively, which is consistent with the previous reports on few layer graphene.[35] However, a red peak shift of $\approx 18.8 \mathrm{~cm}^{-1}$ was observed in the '2D' peak of graphene when Raman spectra was taken at the junction. The observed peak shift could be attributed to an increase in hole concentration at the $\mathrm{MoS}_{2}$ /graphene junction. [36] This is a common phenomenon for $p$ - 
type semiconductor-metal Schottky junction where holes travel from the $p$-type semiconductor to metal as their Fermi levels are aligned. Figure 7.3 (b) shows photoluminescence (PL) spectrum measured at room temperature.

Peak ' $A$ ' associated with excitonic transitions at the ' $\mathrm{K}$ ' point of Brillouin zone is observed at $1.85 \mathrm{eV}$ while peak 'I' at $1.40 \mathrm{eV}$ corresponding to indirect gap which is prominent in bulk $\mathrm{MoS}_{2}$ is almost negligible confirming that the fabricated device is formed by few layers of $\mathrm{MoS}_{2}$. [37, 38] We also observe a strong emission at $1.75 \mathrm{eV}$ which has been attributed to radiative recombination of neutral excitons bound to defects $\left(\mathrm{X}^{0}\right)$ caused by Sulfur (S) vacancies. [39, 40]

\subsubsection{Electrical Properties of $\mathrm{MoS}_{2} /$ Graphene}

The conduction behavior of $\mathrm{MoS}_{2}$ films deposited on $\mathrm{Si} / \mathrm{SiO}_{2}$ substrates was determined by fabricating field effect transistor (FET) devices with $50 \mathrm{~nm}$ thick Au as source and drain electrodes, $300 \mathrm{~nm}$ thick $\mathrm{SiO}_{2}$ served as the dielectric layer, while doped silicon was used as the back gate. The output and transfer characteristics of our $\mathrm{MoS}_{2}$ FET showed a $p$-type conduction behavior with a field effect mobility of $\approx 12.24 \mathrm{~cm}^{2} \mathrm{~V}^{-1} \mathrm{~s}^{-1}$ which is higher than mechanically exfoliated and CVD grown $\mathrm{MoS}_{2}$ FETs on $\mathrm{Si} / \mathrm{SiO}_{2}$ substrates $[41,42]$ and $\mathrm{I}_{\mathrm{on} / \mathrm{off}}$ ratio of $\approx 10^{6}$.[31] The origin of p-type conduction in $\mathrm{MoS}_{2} / \mathrm{SiO}_{2}$ system is not explored in this research. However, Douli et al. in their studies showed that a p-type conduction in $\mathrm{MoS}_{2}$ films on $\mathrm{SiO}_{2}$ substrates could be due to the presence of localized trap states arising from impurities or defects within the oxide substrate or at the interface with the conducting channel, can redefine the effective Fermi level of the hybrid system to make it either n-type or p-type.[43] The trap states might have originated from the immobile 
ionic charges, $\mathrm{SiO}_{2}$ surface oxygen dangling bonds or foreign impurities presented at the $\mathrm{SiO}_{2} / \mathrm{MoS}_{2}$ interface during $\mathrm{MoS}_{2}$ synthesis. The defects present at the $\mathrm{SiO}_{2}$ and $\mathrm{MoS}_{2}$ interface could also be due to the 'Mo' diffusion into $\mathrm{SiO}_{2}$ when it was sulfurized in the CVD furnace at the high temperature of $600{ }^{\circ} \mathrm{C}$. $[44,45]$. When a semi-metallic graphene is assembled over semiconducting $\mathrm{MoS}_{2}$ a Schottky junction like behavior is expected. The schematic of carrier transport at $\mathrm{MoS}_{2} /$ graphene junction under forward and reverse bias is shown in Figure 7.4 (a).

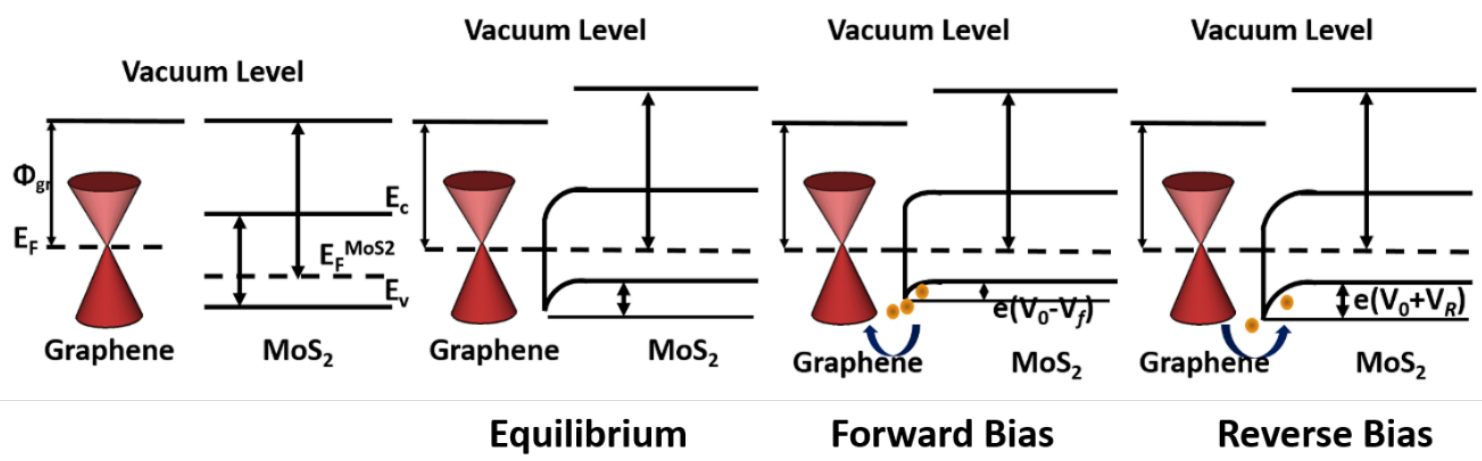

Figure 7.4 (a) Energy level alignment for $\mathrm{MoS}_{2} /$ graphene structure, band diagram at junction in equilibrium, forward bias and reverse bias with carrier flow

Figure 7.5 (a) shows the current-voltage (J-V) characteristics measured at $\mathrm{MoS}_{2} /$ graphene. As can be seen from the J-V plot and the $|\log (\mathrm{J})|$ vs. $\mathrm{V}$ plot shown in the inset, the junction shows a clear rectification as exponentially increasing current passes in the forward bias while there is strong resistance in the reverse bias which prevents flow of holes from graphene to $\mathrm{MoS}_{2}$. From the current-voltage and the Raman measurement results which shows an influx of holes in to graphene from $\mathrm{MoS}_{2}$ at the junction, it can be concluded that a Schottky barrier junction (SBJ) similar to a metal-semiconductor junction is formed between graphene and $\mathrm{MoS}_{2}$. However, we observe that the current never reaches a 
complete saturation in reverse bias unlike an ideal metal-semiconductor Schottky junction. This is due to the bias dependent Fermi level observed in graphene which results in a variable Schottky barrier height (SBH) at different bias voltages.

(a)

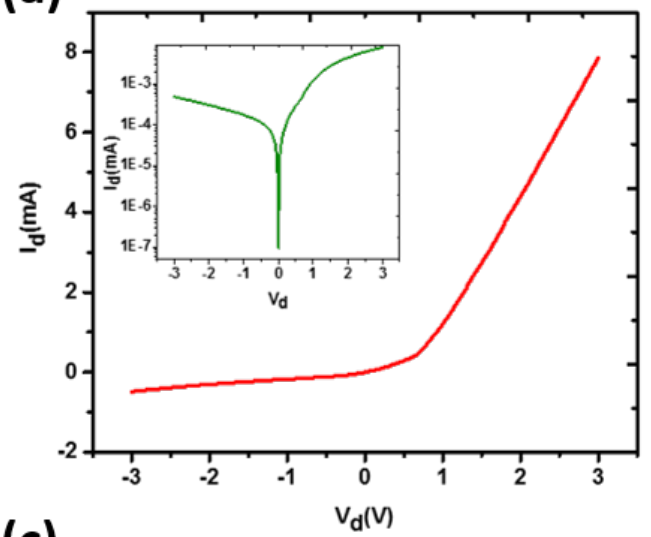

(c)

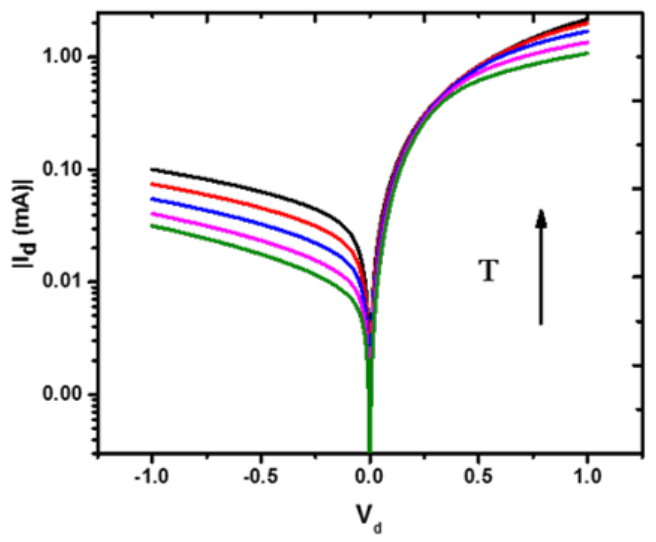

(b)

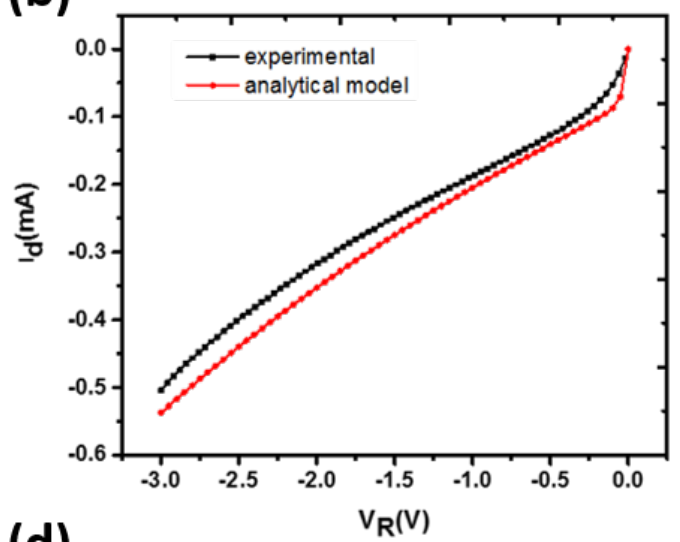

(d)

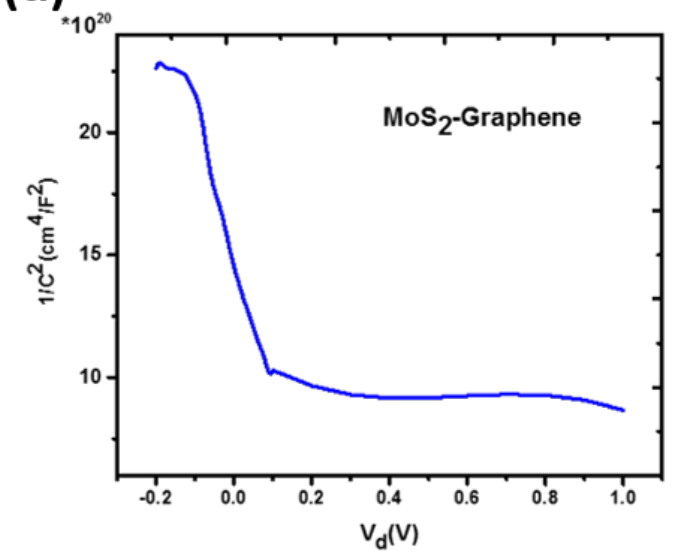

Figure 7.5 (a) J-V curve showing rectification under reverse bias and exponentially increasing current in forward bias (inset: Absolute value of $\mathrm{J}-\mathrm{V}$ plotted in logarithmic scale) (b) J-V at different temperatures showing an increase in $\mathrm{J}$ with increase in temperature (c) $1 / \mathrm{C}^{2}$ plotted against voltage (d) Reverse current from experimental and analytical model

We have used the model developed by Tongay et al. for the current observed in graphene - semiconductor junctions taking into account the change in graphene Fermi level with applied bias. [46] The current in the Schottky diode is given by 


$$
J(V)=A^{*} T^{2} \exp \left(-\frac{e \Phi_{S B H}^{0}+e \Delta \Phi_{S B H}(V)}{k_{B} T}\right)\left[\exp \left(\frac{e V}{k_{B} T}\right)-1\right]
$$

Where $A^{*}$ is Richardson's constant, $\Phi_{S B H}^{0}$ is Schottky barrier height (SBH) at zero bias and $e \Delta \Phi_{S B H}(V)$ is the difference in Schottky barrier height due to change in the Fermi level of Graphene with applied bias and is given by

$$
e \Delta \Phi_{S B H}(V)=-\left(\Delta E_{F}^{G}(V)\right)=V_{F}\left[\sqrt{\pi\left(n_{0}-n_{\text {induced }}\right)}-\sqrt{\pi n_{0}}\right]=-\frac{1}{2} \quad v_{F} \sqrt{\frac{\pi \varepsilon_{s} \varepsilon_{0} N_{A}\left(V_{0}+V_{R}\right)}{2 e n_{0}}}
$$

where $N_{A}$ is acceptor concentration in the semiconductor, $V_{0}$ is the built-in voltage, $V_{R}$ reverse bias voltage and $n_{0}$ the carrier density in graphene. The modified saturation current is

$$
J_{s}(V)=A^{*} T^{2} \exp \left(-\frac{e \Phi_{S B H}^{0}+e \Delta \Phi_{S B H}(V)}{k_{B} T}\right)
$$

Zero bias Schottky barrier height $\left(\Phi_{S B H}^{0}\right)$ was measured from the temperature dependent $\mathrm{J}-\mathrm{V}$ measurements carried at four different temperatures and capacitance- voltage $(\mathrm{C}-\mathrm{V}$ measurements were used to measure acceptor concentration $N_{A}$ and built in voltage $V_{0}$. The change in current $(|\mathrm{J}|)$ with temperature is shown in Figure $7.5 \mathrm{c}$ which shows that the current increases with temperature in both bias directions. The value of $\Phi_{S B H}^{0}$ can be obtained from the slope of Richardson's plot given by [47, 48]

$$
\Phi_{S B H}^{0}=\frac{V_{1}}{n}-\frac{k}{q} \frac{\partial\left[\ln \left(I / T^{2}\right)\right]}{\partial(1 / T)}
$$

We measured the $\Phi^{0}{ }_{S B H}$ of MGJ at $\mathrm{V}_{1}=0.3 \mathrm{~V}$ to be $139.20 \mathrm{meV}$ where the ideality factor ' $n$ ' is obtained from intercept of the linear region of the $J-V$ plot and measured to be 1.86 
while Richardson's constant $\mathrm{A}^{*}$ is $0.70 \times 10^{-6} \mathrm{~A} \mathrm{~cm}^{-2} \mathrm{~K}^{-2}$. The greater than unity value of the ideality factor can be attributed to enhanced image-force lowering across the MGJ and Schottky-barrier inhomogeneity.[46] Capacitance-Voltage measurements are used to obtain built - in voltage $\left(V_{0}\right)$ and doping density values, from Schottky-Mott relationship. When square of inverse of capacitance $\left(1 / \mathrm{C}^{2}\left(\mathrm{~cm}^{4} \mathrm{~F}^{-2}\right)\right)$ plotted against applied voltage in reverse bias, $\left(1 / \mathrm{C}^{2}\right)$ varies linearly with applied bias before saturating this can be extrapolated to intersect the abscissa to obtain built-in potential $V_{0}=\left(\Phi_{\mathrm{MoS}_{2}}-\Phi_{G r}\right)$ and the slope of the linear region gives the doping density $\left(N_{A}\right)$ of $\mathrm{MoS}_{2}$. From Figure $7.5 \mathrm{~d}$ we can see that the measured values hold the linearity in reverse bias. We measured $V_{0}$ and $N_{A}$

values to be $280 \mathrm{mV}$ and $6.64 \times 10^{21} \mathrm{~cm}^{-3}\left(3.32 \times 10^{15} \mathrm{~cm}^{-2}\right)$ respectively. By considering the work function of graphene from literature to be $4.50 \mathrm{eV}$, the work function of $p$-type $\mathrm{MoS}_{2}$ is found to be $4.78 \mathrm{eV}$.[49] Experimental and theoretical values of reverse current obtained from the analytical model developed shown in figure $7.5 \mathrm{~b}$ closely match each other.

\subsection{4 $\mathrm{MoS}_{2} /$ Graphene Photodetector}

One of the most interesting application of Schottky diodes is their use as photodetectors. $\mathrm{MoS}_{2} /$ graphene hybrid structure would be an excellent material for photo-detection as both materials show high photosensitivity. Graphene being a gapless material exhibits sensitivity to light over a wide range of wavelengths from visible light to mid and far infrared. High electron mobility and high absorption would also contribute towards high responsivity in graphene. On the other hand, atomically thin $\mathrm{MoS}_{2}$ has shown some interesting optical phenomenon such as $10^{4}$ fold increase in photoluminescence when 
compared to bulk $\mathrm{MoS}_{2}$ and significant responsivity in visible light.[38] By Stacking both $\mathrm{MoS}_{2}$ and graphene together to form Schottky junction, we would be able to harness these features of both materials to build high performing photodetectors. In general Schottky photodiodes operates in two modes: (1) Energy gap excitation where electron-hole pairs are generated by band to band excitation in the semiconductor when energy of photon is greater than the band gap of semiconductor $h v>E_{g}$ and (2) Internal photoemission which is observed when the incident light energy is greater than the Schottky barrier energy and smaller than the bandgap of semiconductor $\left(\Phi_{S B H}<h v<E_{g}\right)$ resulting in photo emission of carriers from metal surface close to the junction which are then driven towards the semiconductor over the Schottky barrier due to the electric field in the junction. This leads to a wide spectral range of detection based on the SBH values obtained. [50] Both schemes are explained in figure 7.6 (b). A Schottky barrier photodiode is conventionally operated in reverse bias where the increase in barrier results in very small reverse current and hence any increase in current by the photocurrent can be detected with a high sensitivity. This makes it easy to exactly measure the photocurrent generated. The expression for diode current is given by

$$
J(V)=A^{*} T^{2}\left[\exp \left(\frac{e V}{k_{B} T}\right)-1\right]-J_{o p}
$$

where $J_{o p}$ is the photon induced current equal to $R^{*} P_{o p}$ where $R$ be the responsivity of the photodiode and $P_{o p}$ is the power of incident light, the first part of the equation is the current equation in ideal Schottky diode. By replacing the diode current term with the 
modified Schottky diode current presented in equation (1), we can write the diode current equation as

$$
J(V)=A^{*} T^{2} \exp \left(-\frac{e \Phi_{S B H}^{0}+e \Delta \Phi_{S B H}(V)}{k_{B} T}\right)\left[\exp \left(\frac{e V}{k_{B} T}\right)-1\right]-J_{o p}
$$

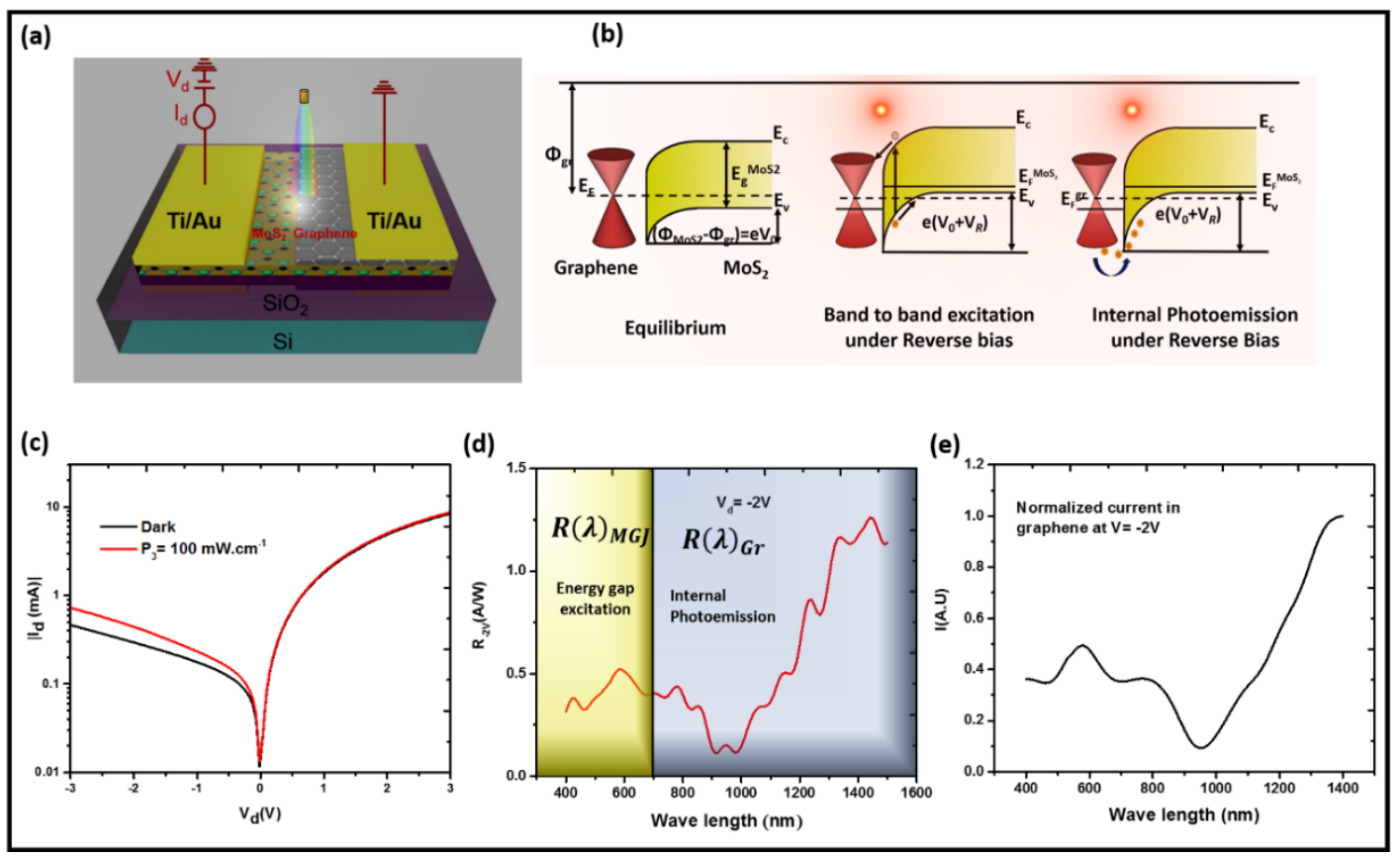

Figure 7.6. (a) MGPD under illumination (b) Illustration of photocurrent generation in a Schottky diode under illumination (c) J-V at dark and under $100 \mathrm{~mW} / \mathrm{cm}^{2}$ illumination (d) Photo responsivity of MGPD at different wavelengths (Spectral Response) Photoconductivity of graphene.

In order to study the operation of the photodiode in both modes we have studied the performance of the device in a wide spectral range from $400 \mathrm{~nm}$ to $1500 \mathrm{~nm}$. The spectral response ' $R$ ' of the device measured at $2 \mathrm{~V}$ reverse bias is shown in figure $4 \mathrm{~d}$. When the diode is operated in energy gap excitation mode where $h v>E_{g}^{M o S_{2}}$ a maximum photo responsivity of $R_{\max }=0.52 \mathrm{AW}^{-1}$ is observed at $590 \mathrm{~nm}$. Beyond $670.00 \mathrm{~nm}$, where the incident photon energy is smaller than $E_{g}{ }^{M o S}{ }_{2}$ the photo current is due to internal photo 
emission in Graphene where photo generated holes move towards $\mathrm{MoS}_{2}$. We find that the responsivity actually increases from $980 \mathrm{~nm}$ reaching a maximum value of $1.26 \mathrm{AW}^{-1}$ at $1440 \mathrm{~nm}$ before starting to fall. The obtained responsivity is not the highest but higher than many state of the art devices. This increase in responsivity follows the increase in photoconductivity observed in graphene which is shown in figure 7.6 (e). This kind of increased optical conductivity in graphene has been observed in intra band conductivity in earlier studies. [51]

One of the most important detector characteristics is the noise equivalent power (NEP) which represents the lowest input power giving a unit signal/noise ratio. In a Schottky junction photodetector, both Johnson noise which is due to thermal noise associated with the resistance and shot noise which is associated with the overall current contribute towards the overall noise. The Johnson noise current $i_{j}$ is given by $i_{j}=\sqrt{\frac{4 k B T}{R_{e q}}}$ where $\mathrm{k}$ is the Boltzmann constant, $\mathrm{T}$ is the absolute temperature and $R_{e q}$ is the equivalent resistance. The $R_{e q}$ is obtained from the slope of I-V of MGPD at $-2 \mathrm{~V}$ measured in dark. For $R_{e q}$ of $5.83 \mathrm{M} \Omega$ and for normalized bandwidth (B) at room temperature the Johnson noise $i_{j}$ is $1.68 \mathrm{pA}$. The shot noise is given by $i_{s}=\sqrt{2 q\left(I_{p h}+I_{d}\right) B}$ where $I_{p h}$ is photo current and $I_{d}$ is dark current. The measured shot noise current at $-2 \mathrm{~V}$ is $11.2 \mathrm{pA}$ at $1400 \mathrm{~nm}$. The total noise current $i_{n}$ is $11.3 \mathrm{pA}$ and the NEP which is the ratio of $i_{n}$ and the responsivity is calculated.[52, 53] We obtain a minimum NEP of $7.8 \times 10^{-12} \mathrm{~W} / \sqrt{\mathrm{Hz}}$ and corresponding detectivity of $4.2 \times 10^{10} \mathrm{~cm} \cdot \sqrt{ } \mathrm{Hz} / \mathrm{W}$ at $1400 \mathrm{~nm}$. The measured NEP of MGPD is less than typical Si photodetectors. 


\subsection{Conclusions}

We have fabricated $\mathrm{P}: \mathrm{ZnO}$ core-shell/n- $\mathrm{ZnO}$ radial $\mathrm{p}-\mathrm{n}$ junction based photodetector which showed a record photoresponsivity of $60 \mathrm{~A} / \mathrm{W}$ under UV illumination. High junction area characteristic of core-shell structures and low recombination losses owing to both the design and method of synthesis contributes to the high responsivity observed. We also stacked few layers of $p$-type $\mathrm{MoS}_{2}$ over few layers of graphene to form a Schottky junction photodiode with wide bandwidth. Stable optical properties of $\mathrm{MoS}_{2}$ and high carrier mobility in graphene contribute to efficient charge separation at the junction. Apart from the impressive charge carrier properties, graphene also exhibits a wide bandwidth absorption which allows for the photodiode to operate in both energy gap excitation mode and internal photo emission mode, there by extending the detection range to higher wavelengths which is not reported in earlier $\mathrm{MoS}_{2}$ /graphene Schottky junctions. From the spectral response, we find that the fabricated device performs well over a wide range of wavelengths from visible region to mid infrared region with internal photo emission in graphene playing a major role in extending the range of the device. We have studied the junction characteristics and presented the underlying phenomenon of charge transfer in 2D $\mathrm{MoS}_{2}$ /graphene Schottky junction. CVD process is used in growing large area $\mathrm{MoS}_{2}$ and graphene which along with the simplicity of fabrication can be easily integrated with metal oxide semiconductor (CMOS) technology. 


\subsection{References}

1. Gedamu, D., Paulowicz, I., Kaps, S., Lupan, O., Wille, S., Haidarschin, G., Mishra, Y. K., Adelung, R. (2014). Rapid Fabrication Technique for Interpenetrated ZnO Nanotetrapod Networks for Fast UV Sensors. Advanced Materials, 26 (10):1541-1550.

2. Bhattacharya, P. (1994). Photodetectors. In Semiconductor Optoelectronic Devices. Prentice-Hall, Inc., New Jersey, pp 342-357.

3. Casalino, M., Sirleto, L., Moretti, L., Rendina, I. (2008). A silicon compatible resonant cavity enhanced photodetector working at $1.55 \mu \mathrm{m}$. Semiconductor Science and Technology, 23 (7):075001.

4. Rumyantsev, S., Pala, N., Shur, M., Gaska, R., Levinshtein, M., Adivarahan, V., Yang, J., Simin, G., Khan, M. A. (2001). Low-frequency noise in Al0.4Ga0.6N-based Schottky barrier photodetectors. Applied Physics Letters, 79 (6):866-868.

5. Zhang, X. L., Hui, K. S., Hui, K. N. (2013). High photo-responsivity ZnO UV detectors fabricated by RF reactive sputtering. Materials Research Bulletin, 48 (2):305-309.

6. Nie, B., Hu, J.-G., Luo, L.-B., Xie, C., Zeng, L.-H., Lv, P., Li, F.-Z., Jie, J.-S., Feng, M., Wu, C.-Y., Yu, Y.-Q., Yu, S.-H. (2013). Monolayer Graphene Film on ZnO Nanorod Array for High-Performance Schottky Junction Ultraviolet Photodetectors. Small, 9 (17):2872-2879.

7. Su, L.; Zhang, Q., Wu, T., Chen, M., Su, Y., Zhu, Y., Xiang, R., Gui, X., Tang, Z. (2014). High-performance zero-bias ultraviolet photodetector based on $\mathrm{p}-\mathrm{GaN} / \mathrm{n}-\mathrm{ZnO}$ heterojunction. Applied Physics Letters, 105 (7):072106.

8. Leung, Y. H., He, Z. B., Luo, L. B., Tsang, C. H. A., Wong, N. B., Zhang, W. J., Lee, S. T. (2010). ZnO nanowires array pn homojunction and its application as a visibleblind ultraviolet photodetector. Applied Physics Letters, 96 (5):053102.

9. Pradel, K. C., Ding, Y., Wu, W., Bando, Y., Fukata, N., \& Wang, Z. L. (2016). Optoelectronic Properties of Solution Grown $\mathrm{ZnO} \mathrm{np}$ or pn Core-Shell Nanowire Arrays. ACS applied materials \& interfaces, 8 (7):4287-4291.

10. Xia, F., Mueller, T., Lin, Y. M., Valdes-Garcia, A., \& Avouris, P. (2009). Ultrafast graphene photodetector. Nature nanotechnology, 4 (12):839-843.

11. Kang, C. G., Lee, S. K., Yoo, T. J., Park, W., Jung, U., Ahn, J., \& Lee, B. H. (2014). Highly sensitive wide bandwidth photodetectors using chemical vapor deposited graphene. Applied Physics Letters, 104 (16):161902. 
12. Kang, C. G., Lee, S. K., Yoo, T. J., Park, W., Jung, U., Ahn, J., \& Lee, B. H. (2014). Highly sensitive wide bandwidth photodetectors using chemical vapor deposited graphene. Applied Physics Letters, 104 (16):161902.

13. Lemme, M. C., Koppens, F. H., Falk, A. L., Rudner, M. S., Park, H., Levitov, L. S., \& Marcus, C. M. (2011). Gate-activated photoresponse in a graphene $\mathrm{p}-\mathrm{n}$ junction. Nano letters, 11 (10):4134-4137.

14. Pospischil, A., Humer, M., Furchi, M. M., Bachmann, D., Guider, R., Fromherz, T., \& Mueller, T. (2013). CMOS-compatible graphene photodetector covering all optical communication bands. Nature Photonics, 7 (11):892-896.

15. Liu, C. H., Chang, Y. C., Norris, T. B., \& Zhong, Z. (2014). Graphene photodetectors with ultra-broadband and high responsivity at room temperature. Nature nanotechnology, 9 (4):273-278.

16. Withers, F., Bointon, T. H., Craciun, M. F., \& Russo, S. (2013). All-graphene photodetectors. ACS nano, 7 (6):5052-5057.

17. Koppens, F. H. L., Mueller, T., Avouris, P., Ferrari, A. C., Vitiello, M. S., \& Polini, M. (2014). Photodetectors based on graphene, other two-dimensional materials and hybrid systems. Nature nanotechnology, 9 (10):780-793.

18. Mak, K. F., Lee, C., Hone, J., Shan, J., \& Heinz, T. F. (2010). Atomically thin $\mathrm{MoS}_{2}$ : a new direct-gap semiconductor. Physical Review Letters, 105 (13):136805.

19. Yin, Z., Li, H., Li, H., Jiang, L., Shi, Y., Sun, Y., Lu, G., Zhang, Q., Chen, X., Zhang, H. (2011). Single-layer $\mathrm{MoS}_{2}$ phototransistors. ACS nano, 6 (1):74-80.

20. Choi, W., Cho, M. Y., Konar, A., Lee, J. H., Cha, G., Hong, S. C., Kim, S., Kim, J., Jena, D., Joo, J. (2012). High-detectivity multilayer MoS2 phototransistors with spectral response from ultraviolet to infrared. Advanced materials, 24 (43):5832-5836.

21. Tsai, D., Liu, K., Lien, D., Tsai, M., Kang, C., Lin, C., Li, L., He, J. (2013). Few-layer $\mathrm{MoS}_{2}$ with high broadband photogain and fast optical switching for use in harsh environments. ACS Nano, 7 (5):3905-3911.

22. Lopez-Sanchez, O., Lembke, D., Kayci, M., Radenovic, A., \& Kis, A. (2013). Ultrasensitive photodetectors based on monolayer $\mathrm{MoS}_{2}$. Nature nanotechnology, 8 (7):497-501.

23. Wang, H., Taychatanapat, T., Hsu, A., Watanabe, K., Taniguchi, T., Jarillo-Herrero, P., \& Palacios, T. (2011). BN/Graphene/BN Transistors for RF Applications. IEEE Electron Device Letters, 32:1209-1211. 
24. Jena, D. (2013). Tunneling transistors based on graphene and 2-D crystals. Proceedings of the IEEE, 101 (7):1585-1602.

25. Yang, J., Voiry, D., Ahn, S. J., Kang, D., Kim, A. Y., Chhowalla, M., \& Shin, H. S. (2013). Two-Dimensional Hybrid Nanosheets of Tungsten Disulfide and Reduced Graphene Oxide as Catalysts for Enhanced Hydrogen Evolution. Angewandte Chemie International Edition, 52 (51):13751-13754.

26. Georgiou, T., Jalil, R., Belle, B. D., Britnell, L., Gorbachev, R. V., Morozov, S. V., Kim, Y., Gholinia, A., Haigh, S. J., Makarovsky, O. (2013). Vertical field-effect transistor based on graphene-WS2 heterostructures for flexible and transparent electronics. Nature nanotechnology, 8 (2):100-103.

27. Roy, K., Padmanabhan, M., Goswami, S., Sai, T. P., Ramalingam, G., Raghavan, S., \& Ghosh, A. (2013). Graphene- $\mathrm{MoS}_{2}$ hybrid structures for multifunctional photoresponsive memory devices. Nature nanotechnology, 8 (11):826-830.

28. Zhang, W., Chuu, C., Huang, J., Chen, C., Tsai, M., Chang, Y., Liang, C., Chen, Y., Chueh, Y., He, J. (2014). Ultrahigh-gain photodetectors based on atomically thin graphene-MoS2 heterostructures. Scientific reports, 4:3826.

29. Bertolazzi, S., Krasnozhon, D., \& Kis, A. (2013). Nonvolatile memory cells based on $\mathrm{MoS}_{2} /$ graphene heterostructures. ACS Nano, 7 (4):3246-3252.

30. Yoon, J., Park, W., Bae, G., Kim, Y., Jang, H. S., Hyun, Y., Lim, S. K.; Kahng, Y. H., Hong, W., Lee, B. H., \& Ko, H. C. (2013). Highly flexible and transparent multilayer MoS2 transistors with graphene electrodes. Small, 9 (19):3295-3300.

31. Choudhary, N., Park, J., Hwang, J. Y., \& Choi, W. (2014). Growth of Large-Scale and Thickness-Modulated $\mathrm{MoS}_{2}$ Nanosheets. ACS applied materials \& interfaces, 6 (23):21215-21222.

32. Das, S., Sudhagar, P., Verma, V., Song, D., Ito, E., Lee, S. Y., Kang, Y. S., Choi, W. (2011). Amplifying Charge-Transfer Characteristics of Graphene for Triiodide Reduction in Dye-Sensitized Solar Cells. Advanced Functional Materials, 21 (19):3729-3736.

33. Pimenta, M. A., del Corro, E., Carvalho, B. R., Fantini, C., \& Malard, L. M. (2014). Comparative study of Raman spectroscopy in graphene and MoS2-type transition metal dichalcogenides. Accounts of chemical research, 48 (1):41-47.

34. Li, H., Zhang, Q., Yap, C. C. R., Tay, B. K., Edwin, T. H. T., Olivier, A., \& Baillargeat, D. (2012). From bulk to monolayer $\mathrm{MoS}_{2}$ : evolution of Raman scattering. Advanced Functional Materials, 22 (7):1385-1390. 
35. Ferrari, A. C., \& Basko, D. M. (2013). Raman spectroscopy as a versatile tool for studying the properties of graphene. Nature nanotechnology, 8 (4):235-246.

36. Malard, L. M., Pimenta, M. A., Dresselhaus, G., \& Dresselhaus, M. S. (2009). Raman spectroscopy in graphene. Physics Reports, 473 (5): 51-87.

37. Sundaram, R. S., Engel, M., Lombardo, A., Krupke, R., Ferrari, A. C., Avouris, P., \& Steiner, M. (2013). Electroluminescence in single layer MoS2. Nano letters, 13 (4):1416-1421.

38. Splendiani, A., Sun, L., Zhang, Y., Li, T., Kim, J., Chim, C., Galli, G., \& Wang, F. (2010). Emerging photoluminescence in monolayer MoS2. Nano letters, 10 (4):12711275.

39. Tongay, S., Suh, J., Ataca, C., Fan, W., Luce, A., Kang, J. S., Liu, J., Ko, C., Raghunathanan, R., \& Zhou, J. (2013). Defects Activated Photoluminescence in TwoDimensional Semiconductors: Interplay between Bound, Charged, and Free Excitons. Scientific reports, 3:2657.

40. Ye, Y., Ye, Z., Gharghi, M., Yin, X., Zhu, H., Zhao, M., \& Zhang, X., (June, 2014). Exciton-related electroluminescence from monolayer MoS2. Paper presented at the meeting of CLEO: Science and Innovations, San Jose, California, United States.

41. Zhang, W., Huang, J. K., Chen, C. H., Chang, Y. H., Cheng, Y. J., \& Li, L. J. (2013). High-Gain Phototransistors Based on a CVD MoS2 Monolayer. Advanced Materials, 25 (25):3456-3461.

42. Wu, W., De, D., Chang, S. C., Wang, Y., Peng, H., Bao, J., \& Pei, S. S. (2013). High mobility and high on/off ratio field-effect transistors based on chemical vapor deposited single-crystal $\mathrm{MoS}_{2}$ grains. Applied Physics Letters, 102 (14):142106.

43. Dolui, K., Rungger, I., \& Sanvito, S. (2013). Origin of the n-type and p-type conductivity of $\mathrm{MoS}_{2}$ monolayers on a $\mathrm{SiO}_{2}$ substrate. Physical review $\mathrm{B}, 87$ (16):165402.

44. Zeng, Z., Yin, Z., Huang, X., Li, H., He, Q., Lu, G., Boey, F., \& Zhang, H. (2011). Single-Layer Semiconducting Nanosheets: High-yield preparation and device fabrication. Angewandte Chemie International Edition, 50 (47):11093-11097.

45. Zhan, Y., Liu, Z., Najmaei, S., Ajayan, P. M., \& Lou, J. (2012). Large-area vapor-phase growth and characterization of $\mathrm{MoS} 2$ atomic layers on a $\mathrm{SiO}_{2}$ substrate. Small, 8 (7):966-971. 
46. Tongay, S., Lemaitre, M., Miao, X., Gila, B., Appleton, B. R., \& Hebard, A. F. (2012). Rectification at graphene-semiconductor interfaces: zero-gap semiconductor-based diodes. Physical Review X, 2 (1):011002.

47. Schroder, D. K. (2006). Semiconductor material and device characterization. John Wiley \& Sons INC.: New York, NY, US.

48. Cheung, S. K., \& Cheung, N. W. (1986). Extraction of Schottky diode parameters from forward current-voltage characteristics. Applied Physics Letters, 49 (2):85-87.

49. Chuang, S., Battaglia, C., Azcatl, A., McDonnell, S., Kang, J. S., Yin, X., Tosun, M., Kapadia, R., Fang, H., Wallace, R. M., \& Javey, A. (2014). $\mathrm{MoS}_{2}$ P-type Transistors and Diodes Enabled by High Work Function $\mathrm{MoO}_{\mathrm{x}}$ Contacts. Nano letters, 14 (3):13371342.

50. Ng, Kwok. K. (2015). Complete Guide to Semiconductor Devices. J. Wiley \& Sons, New York, N.Y, US.

51. Dawlaty, J. M., Shivaraman, S., Strait, J., George, P., Chandrashekhar, M., Rana, F., Spencer, M. G., Veksler, D., \& Chen, Y. (2008). Measurement of the optical absorption spectra of epitaxial graphene from terahertz to visible. Applied Physics Letters, 93 (13): 131905 .

52. Casalino, M., Sirleto, L., Moretti, L., \& Rendina, I. (2008). A silicon compatible resonant cavity enhanced photodetector working at $1.55 \mu \mathrm{m}$. Semiconductor Science and Technology, 23 (7):075001.

53. Rumyantsev, S., Pala, N., Shur, M., Gaska, R., Levinshtein, M., Adivarahan, V., Yang, J., Simin, G., \& Khan, M. A. (2001). Low-frequency noise in A10. 4Ga0. 6N-based Schottky barrier photodetectors. Applied Physics Letters, 79 (6):866-868. 


\section{CHAPTER 8}

\section{Summary and Future Direction}

\subsection{Summary}

In summary, this dissertation has detailed the development of Sonochemical method to synthesize $\mathrm{ZnO}$ nanorods, $\mathrm{ZnO}-\mathrm{ZnO}$ core-shell nanorods, $\mathrm{ZnO}-\mathrm{ZnS}$ core-shell nanorods, 2D $\mathrm{ZnO}$ nanowalls, 2D $\mathrm{ZnO}$ nanoflakes and their applications in sensing and energy harvesting. The developed method is 10 times faster than other chemical methods and synthesizes high quality single crystalline nanostructures at ambient conditions. For the first time, both n- type and p-type doping in $\mathrm{ZnO}$ via. Sonochemical method was reported using ' $\mathrm{Al}$ ' and ' $\mathrm{P}$ ' as dopants respectively. We have for the first time fabricated a radial p$\mathrm{n}$ junction photo diode in a core-shell geometry. The core-shell structure was synthesized without using any external surfactants but rather used only different molar ratios of precursors. A doping concentration of $6.7 \times 10^{17} \mathrm{~cm}^{-3}$ was achieved for the $\mathrm{P}: \mathrm{ZnO}$ nanoshells. The as fabricated homogeneous $\mathrm{p}-\mathrm{n}$ junction shows a rectifying behavior with an ideality factor of 37 and a reverse saturation current of $200 \mu \mathrm{A}$ at $-2 \mathrm{~V}$. The developed method is fast, inexpensive and performed at ambient conditions while resulting very small amount of impurities. This facilitates the use of flexible substrates for $\mathrm{ZnO}$ nanostructures, opening the door for flexible and wearable electronic and photonic devices based on $\mathrm{ZnO}$. The photoresponse of the device was studied under UV illumination and the device recorded $60 \mathrm{~A} / \mathrm{W}$ photoresponsivity which is the highest in $\mathrm{ZnO}$ p-n junction UV detectors. The high responsivity values are attributed to the increased junction area in core- shell geometry and reduced recombination losses at the interface. 
We have also explored future 2D materials such as $\mathrm{MoS}_{2}$ and graphene and succeeded in fabricating a high bandwidth photodetectors by stacking few layers of $p$-type $\mathrm{MoS}_{2}$ over few layers of graphene to form Schottky junction photodiode. Stable optical properties of $\mathrm{MoS}_{2}$ and high carrier mobility in graphene contribute to efficient charge separation at the junction. Apart from the impressive charge carrier properties, graphene also exhibits a wide bandwidth absorption which allows for the photodiode to operate in both energy gap excitation mode and internal photo emission mode, there by extending the detection range to higher wavelengths which is not reported in earlier $\mathrm{MoS}_{2} /$ graphene Schottky junctions. From the spectral response, we find that the fabricated device performs well over a wide range of wavelengths from visible region to mid infrared region with internal photo emission in graphene playing a major role in extending the range of the device. We have studied the junction characteristics and presented the underlying phenomenon of charge transfer in 2D MoS$/$ graphene Schottky junction. CVD process is used in growing large area $\mathrm{MoS}_{2}$ and graphene which along with the simplicity of fabrication can be easily integrated with metal oxide semiconductor (CMOS) technology.

Further we have fabricated vertically standing $1 \mathrm{D} \mathrm{ZnO}-\mathrm{NRs}$ and lateral 2D ZnONFs on $\mathrm{Au}$ coated $\mathrm{Si}$, using sonochemical technique to prepare label free, highly sensitive and selective electrochemical cortisol immunosensors. Both 1D ZnO-NRs and 2D ZnONFs exhibit selective electrochemical cortisol detection at 1pM 100 times better than ELISA. ZnO-NFs with sharp and distinct oxidation peaks indicate a much better surface controlled process when compared to ZnO-NRs. The sensitivity of ZnO-NFs is $7.74 \mu \mathrm{A} / \mathrm{M}$ which is comparable to $11.86 \mu \mathrm{A} / \mathrm{M}$ of $\mathrm{ZnO}-\mathrm{NRs}$ coupled with ease of fabrication in case of $2 \mathrm{D}$ materials, we present $\mathrm{ZnO}$ nanoflakes as an alternate material for use as 
immobilizing matrix in electrochemical biosensors. It is demonstrated in this work that ZnO-NSs based immunosensors are capable of detecting cortisol in human saliva sample and well-validated using ELISA values. The results of presented work suggest ZnO-NSs with high surface-to-volume ratio (NRs) and larger surface area (NFs) as viable materials for cortisol sensing in human saliva.

The role of $\mathrm{ZnO}$ nanorods as anode in organic photovoltaic cells was also explored. We have used $\mathrm{ZnO}$ nanorods grown on FTO as anodes in fabricating DSSCs. As fabricated device has shown an efficiency of $2.74 \%$, and high fill factors. However the devices suffered from low short circuit currents due to high recombination losses and low stability as $\mathrm{ZnO}$ degraded rapidly in the acidic dye. The leakage of electrolyte has also been detrimental factor. From the gained experience of fabricating DSSCs we have setup a perovskite solar cell fabrication setup, in an environment isolated from the ambience and used $\mathrm{ZnO}$ nanorods grown on FTO as anodes. The perovskite formation and filling at different spin speeds was studied using SEM and XRD. The as fabricated devices suffered from high recombination losses due to thick seed layer, which led us to alternative geometry where $\mathrm{ZnO}$ nanoflakes grown over graphene/ PET was used as seed layer for $\mathrm{ZnO}$ nanorod growth. The as synthesized seed layer is less than $200 \mathrm{~nm}$ thick and single crystalline in nature which enhances the electron transport.

\subsection{Future Direction}

From the knowledge and experience gained over the course of this dissertation we propose two applications for Sonochemically synthesized $\mathrm{ZnO}$ nanostructure 


\subsubsection{Flexible and Transparent P:ZnO Nanoshell-/n-ZnO Nanorod Core- Shell LED}

Ultra violet light emitting diodes have attracted tremendous attention in wide range of applications. $\mathrm{ZnO}$ with wide bandgap of $3.37 \mathrm{eV}$ and high exciton binding energy of 60 $\mathrm{meV}$ is one of the most promising materials for fabricating UV LEDs. Encouraged by the successful p-type doping and high photoresponsivity of $\mathrm{P}: \mathrm{ZnO}$ nanoshell/ $\mathrm{n}-\mathrm{ZnO}$ nanorod core- shell structures under UV illumination we propose to further characterize and optimize the P:ZnO shell thickness and length for optimum electroluminescence. The proposed device is shown in figure 8.1. Where the $\mathrm{P}: \mathrm{ZnO}$ nanoshell- $\mathrm{n}-\mathrm{ZnO}$ nanorod coreshell structures are grown on graphene coated flexible substrate (PET)

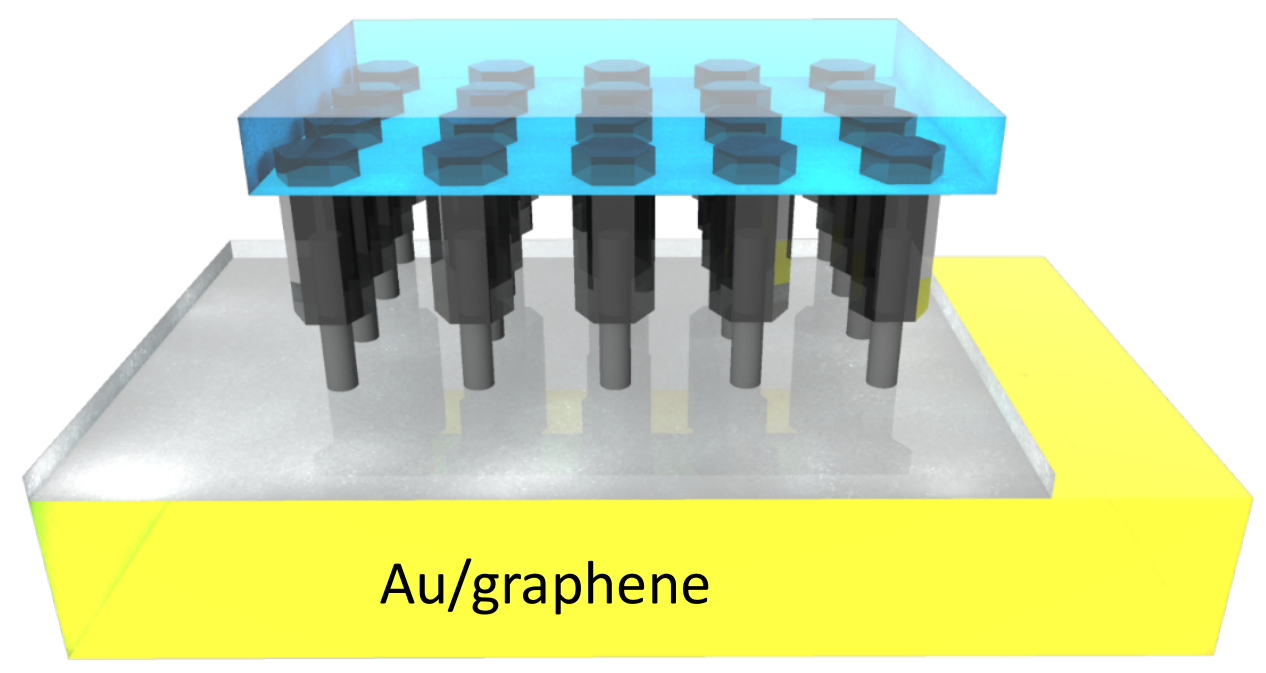

Figure 8.1 P:ZnO nanoshell- n-ZnO nanorod core- shell structure grown on Au/graphene

\subsubsection{Flexible Perovskite Solar Cells}

With the insight obtained from our study of $\mathrm{ZnO}$ nanorod based perovskite solar cells, we propose fabricating of flexible highly efficient perovskite solar cells by growing $\mathrm{ZnO}-\mathrm{ZnS}$ 
core shell nanorods on $\mathrm{ZnO}$ nanoflake/ graphene/PET substrate. $\mathrm{ZnO}-\mathrm{ZnS}$ core shell nanostructures have been successfully used in DSSCs solar cells by various groups to decrease the recombination losses as $\mathrm{ZnS}$ with larger band gap than $\mathrm{ZnO}$ isolated the injected electrons from being recombined with the holes. The proposed device is shown in figure 8.2

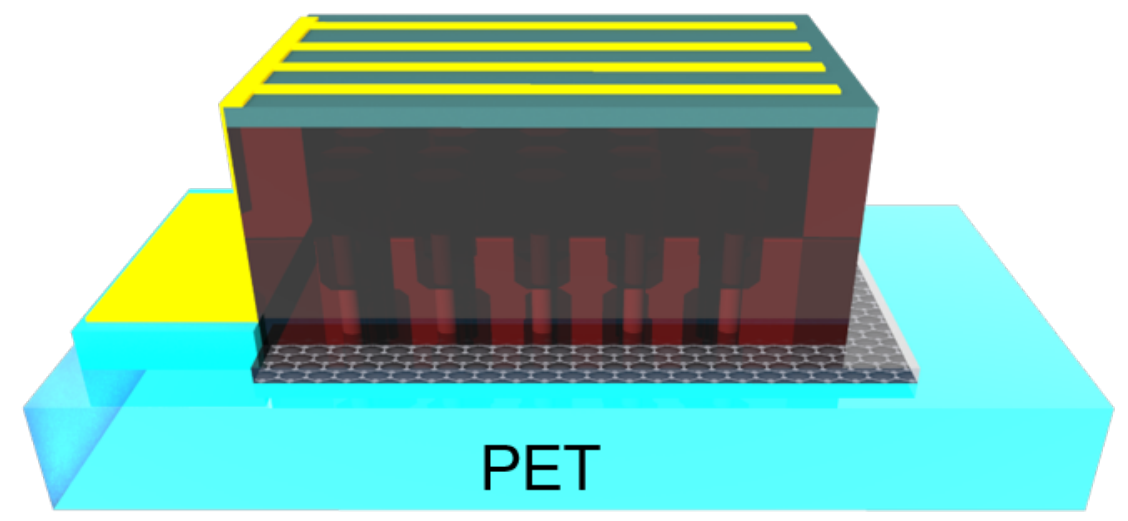

Figure 8.2 Perovskite solar cells based on $\mathrm{ZnO}-\mathrm{ZnS}$ core-shell nanorods synthesized on $\mathrm{ZnO}$ nanoflakes/graphene/ PET as electron transport layer 
VITA

\section{PHANI KIRAN VABBINA}

Born, Visakhapatnam, Andhra Pradesh, India

2001- 2005

B. Tech., Electrical engineering

Jawaharlal Nehru technological University

Hyderabad, India

2005- 2007

Lecturer, electrical Engineering

Sridevi women's Engineering College

Hyderabad, India

2007-2009

M.S., Electrical and Computer Engineering

University of Nebraska - Lincoln

Lincoln, Nebraska

$2009-2016$

Doctoral Candidate

Florida International University

Miami, Florida

\section{PUBLICATIONS AND PRESENTATIONS}

1. Vabbina. P., Sinha. R., Ahmadivand. A., Karabiyik. M., Gerislioglu. B., Awadallah. O., Pala. N., Sonochemical Synthesis of Zinc Oxide Core-Shell Nanorod Radial P-N Homojunction Ultraviolet Photodetector "Under Review" ACS applied materials \& interfaces June 2016

2. Vabbina, P., Choudhary, N., Chowdhury, A. A., Sinha, R., Karabiyik, M., Das, S., \& Pala, N. (2015). Highly Sensitive Wide Bandwidth Photodetector Based on Internal Photoemission in CVD Grown p-Type MoS2/Graphene Schottky Junction. ACS applied materials \& interfaces, 7(28), 15206-15213.

3. Vabbina, P. K., Kaushik, A., Pokhrel, N., Bhansali, S., \& Pala, N. (2015). Electrochemical cortisol immunosensors based on sonochemically synthesized zinc oxide 1D nanorods and 2D nanoflakes. Biosensors and Bioelectronics, 63, 124-130.

4. Vabbina, P. K., Karabiyik, M., Al-Amin, C., Pala, N., Das, S., Choi, W., \& Shur, M. (2014). Controlled synthesis of single-crystalline $\mathrm{ZnO}$ nanoflakes on arbitrary substrates at ambient conditions. Particle \& Particle Systems Characterization, 31(2), 190-194. 
5. Pokhrel, N., Vabbina, P. K., \& Pala, N. (2016). Sonochemistry: Science and Engineering. Ultrasonics Sonochemistry, 29, 104-128.

6. Sinha, R., Karabiyik, M., Al-Amin, C., Vabbina, P. K., Güney, D. Ö. \& Pala, N. (2015). Tunable room temperature $\mathrm{THz}$ sources based on nonlinear mixing in a hybrid optical and $\mathrm{THz}$ micro-ring resonator. Scientific reports, 5 .

7. Al-Amin, C., Vabbina, P. K., Karabiyik, M., Sinha, R., Wang, C., \& Pala, N. Bandgap engineering of single layer graphene by randomly distributed nanoparticles. Journal of Materials Science: Materials in Electronics, 1-6.

8. Al-Amin, C., Vabbina, P. K., Karabiyik, M., Sinha, R., Pala, N., \& Choi, W. (2013). Improving High-Frequency Characteristics of Graphene FETs by Field-Controlling Electrodes. Electron Device Letters, IEEE, 34(9), 1193-1195.

9. Al-Amin, C., Karabiyik, M., Vabbina, P. K., Sinha, R., \& Pala, N. (2014). Field controlled RF Graphene FETs with improved high frequency performance. Solid-State Electronics, 95, 36-41.

10. Imafidon, O., Georgakopoulos, S., Vabbina, P. K., \& Pala, N. (2010, April). Multifunctional nanodevices for energy harvesting in unconventional spectral ranges. In SPIE Defense, Security, and Sensing (pp. 76792L-76792L). International Society for Optics and Photonics.

11. Vabbina, P. K., Nayyar, P., Nayak, A. P., Katzenmeyer, A. M., Logeeswaran, V. J., Pala, N.,\& Talin, A. A. (2011, September). Synthesis of crystalline ZnO nanostructures on arbitrary substrates at ambient conditions. In SPIE NanoScience+ Engineering (pp. $81060 \mathrm{H}-81060 \mathrm{H})$. International Society for Optics and Photonics.

12. Vabbina, P. K., Kaushik, A., Tracy, K., Bhansali, S., \& Pala, N. (2014, May). Zinc oxide nanostructures for electrochemical cortisol biosensing. In SPIE Sensing Technology+ Applications (pp. 91070U-91070U). International Society for Optics and Photonics.

13. Vabbina, P. K., Das, S., Pala, N., \& Choi, W. (2012). Synthesis of crystalline ZnO nanosheets on graphene and other substrates at ambient conditions. InMRS Proceedings (Vol. 1449, pp. mrss12-1449). Cambridge University Press.

14. Al-Amin, C. G., Vabbina, P. K., Karabiyik, M., Sinha, R., \& Pala, N. (2016, May). Bandgap engineering of graphene decorated with randomly distributed $\mathrm{ZnO}$ nano-seed. In SPIE Defense+ Security (pp. 98362V-98362V). International Society for Optics and Photonics. 